\title{
INFLUENCE OF CRACKS ON CHLORIDE INGRESS INTO CONCRETE
}

by

Olga Garces Rodriguez

A thesis submitted in conformity with the requirements for the degree of Master of Applied Science Graduate Department of Civil Engineering

University of Toronto

(C) Copyright by Olga Garces Rodriguez, 2001 
The author has granted a nonexclusive licence allowing the National Library of Canada to reproduce, loan, distribute or sell copies of this thesis in microform, paper or electronic formats.

The author retains ownership of the copyright in this thesis. Neither the thesis nor substantial extracts from it may be printed or otherwise reproduced without the author's permission.
L'auteur a accordé une licence non exclusive permettant à la Bibliothèque nationale du Canada de reproduire, prêter, distribuer ou vendre des copies de cette thèse sous la forme de microfiche/film, de reproduction sur papier ou sur format électronique.

L'auteur conserve la propriété du droit d'auteur qui protège cette thèse. $\mathrm{Ni}$ la thèse ni des extraits substantiels de celle-ci ne doivent être imprimés ou autrement reproduits sans son autorisation. 
Influence of Cracks on Chloride Ingress into Concrete

Olga Garces Rodriguez, Master of Applied Science, 200l

Department of Civil Engineering, University of Toronto

\begin{abstract}
Exposure of concrete to chloride ions is considered to be the main cause of premature corrosion of steel reinforcement. Cracking is an inevitable characteristic of reinforced concrete structures. Although, it is generally recognized that cracks promote the ingress of chlorides in concrete, a lack of sufficient knowledge on this subject does not yet allow reliable quantification of their effects. In the current study, the influence of artificially created, parallel-wall cracks with widths ranging from 0.06 to $0.74 \mathrm{~mm}$ on chloride ingress was examined. The effect of crack wall surface roughness was also evaluated. Based on the results of the chloride bulk diffusion test and SEM/EDX analysis, it was concluded that chloride diffusion in concrete was independent of either crack width or the crack wall roughness for the ranges studied. The transecting, parallel-wall cracks were found to behave like a free concrete surface, resulting in a case of two-dimensional diffusion and greatly promoting chloride ingress. A 2D simulation approach was proposed for predicting the chloride concentration profile in this case. It was also found that coarse aggregate contributes to chloride transport, likely due to percolating interfacial transition zones. A relationship between the depth of chloride penetration and time for both cracked and uncracked concrete was studied, as well.
\end{abstract}




\section{ACKNOWLEDGMENTS}

I would like to express my deepest gratitude to Prof. R.D. Hooton for his guidance, support, and valued help throughout this project. It was a great privilege to work and study under his supervision. I also thank Prof. M.D.A. Thomas for agreeing to act as second reader to this work.

The financial assistance provided by Materials and Manufacturing Ontario, the Natural Science and Engineering Research Council of Canada, American Concrete Institute (V. Mohan Malhotra Fellowship), Govemment of Ontario (Paul\&Suzana Price Graduate Scholarship in Science and Technology), and the Department of Civil Engineering at the University of Toronto is gratefully acknowledged.

Among my colleagues and friends from the Concrete Materials Group, Michelle Nokken deserves special recognition. Her advice, experience, and friendship are greatly appreciated. I also thank Urszula Nytko, Kyle Stanish, Medhat Shehata, Hassan Zibara, Roland Bleszynski, Terry Ramlochan, and Amanda Smith for their help throughout the different stages of my work.

I am grateful to my friends and family for their love and support, especially to my mother. Finally, I would like to thank my husband for his love, dedication, and understanding. His encouragement and support gave me the strength to pursue my aspirations. 


\section{TABLE OF CONTENTS}

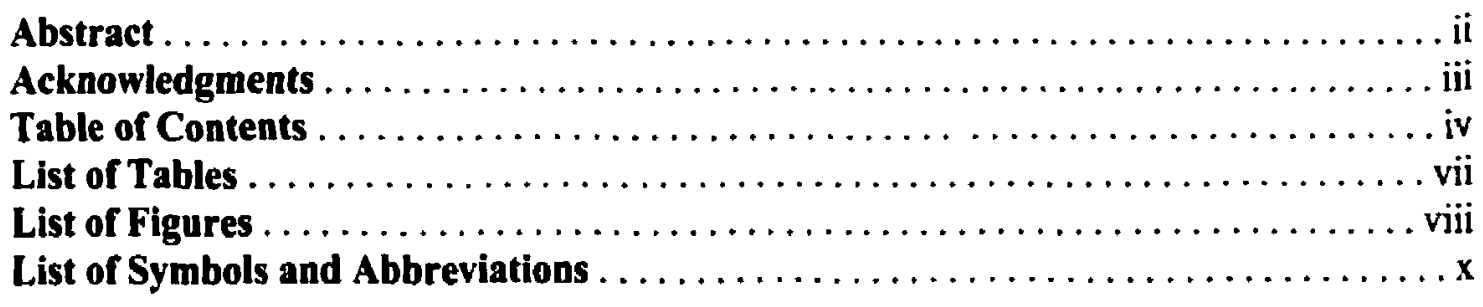

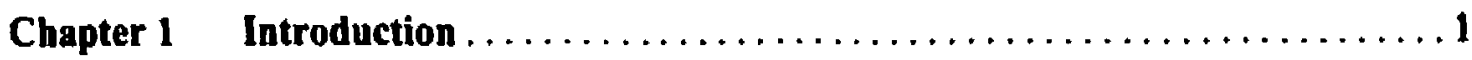

Chapter $2 \quad$ Literature Review $\ldots \ldots \ldots \ldots \ldots \ldots \ldots \ldots \ldots \ldots \ldots \ldots \ldots \ldots \ldots \ldots \ldots$

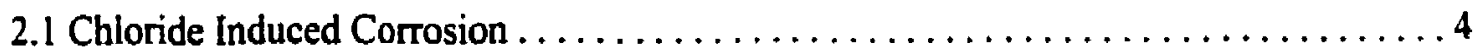

2.1.1 Depassivation of Steel by Chloride Ions . . . . . . . . . . . . . . . . 4

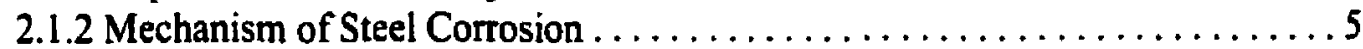

2.1.3 Corrosion in Cracked Concrete . . . . . . . . . . . . . . . . . . 6

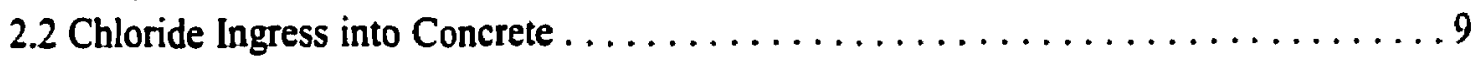

2.2.1 Mechanisms of Chloride Ingress . . . . . . . . . . . . . . . . 9

2.2.2 Transport Properties due to Cracked Concrete ................ Il

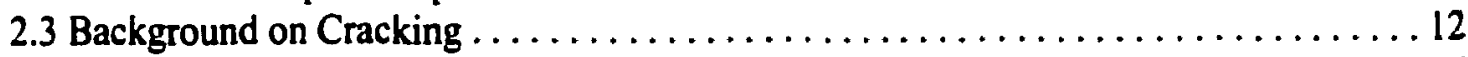

2.3.1 Classification of Cracks According to Their Causes ........... 12

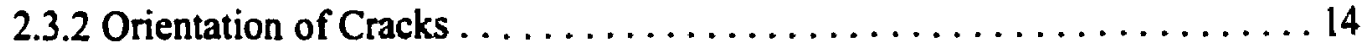

2.3 .3 Crack Healing . . . . . . . . . . . . . . . . . . . . . . 16

2.3.4 Permissible Crack Width ........................ 17

2.4 Effect of Cracks on Chloride Ingress into Concrete $\ldots \ldots \ldots \ldots \ldots \ldots \ldots$

2.4.1 Flexural Loading . . . . . . . . . . . . . . . . . . . . . . 19

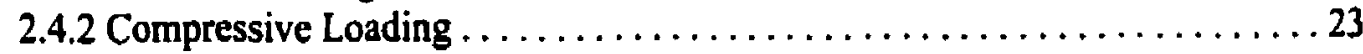

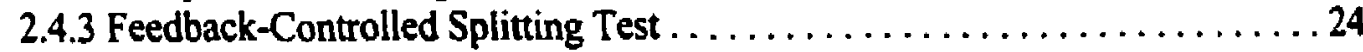

2.4.4 Numerical Simulations . . . . . . . . . . . . . . . . . . . . . . . 25

2.4 .5 Other Methods . . . . . . . . . . . . . . . . . . . . . . . 27

2.5 Test Methods Used to Evaluate the Chloride Resistance of Concrete . . . . . . . 32

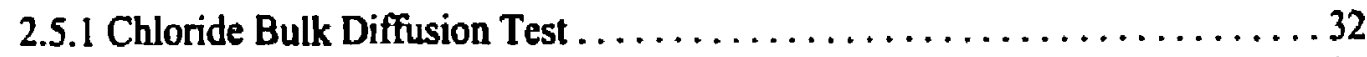

2.5.2 Chloride Diffusion Cell . . . . . . . . . . . . . . . . . . . . . 34

2.5.3 Scanning Electron Microscopy Combined with

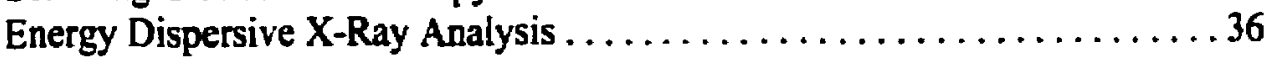

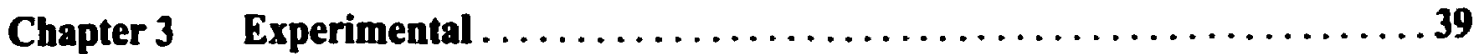


3.1 Overview ................................................... 39

3.2 Sample Preparation .......................................... 39

3.2.1 Materials, Mix Design and Casting ........................ 39

3.2.2 Creation of Artificial Cracks ............................ 43

3.2.2.1 Smooth Crack Samples .......................... 43

3.2.2.2 Rough Crack Samples ........................ 45

3.2.3 Measurement of Crack Width . . . . . . . . . . . . . . . . . . . . 46

3.2.4 Sample Identification ................................ 46

3.2.5 Outline of Experimental Program ........................ 47

3.3 Chloride Bulk Diffusion Test ................................ 49

3.3.1 Sample Preparation and Exposure $\ldots \ldots \ldots \ldots \ldots \ldots \ldots \ldots \ldots \ldots . \ldots \ldots$

3.3.2 Experimental Details ............................... 50

3.3.3 Obtaining the Chloride Concentration Profile $\ldots \ldots \ldots \ldots \ldots \ldots \ldots \ldots . \ldots \ldots 2$

3.3.4 Calculation of the Diffusion Coefficient ...................... 54

3.4 SEM/EDX Chloride Profiling . . . . . . . . . . . . . . . . . . . . . . . . . . 56

3.5 Chloride Diffusion Cell ..................................... 59

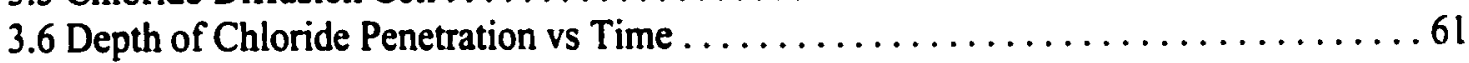

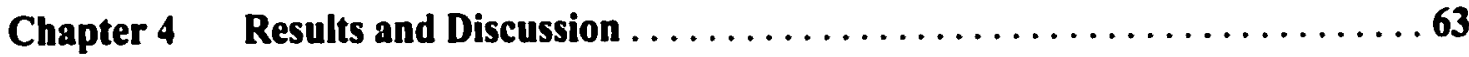

4.1 Measurement of Crack Width . . . . . . . . . . . . . . . . . . . . . . . . . . . 63

4.2 Chloride Bulk Diffusion Test ..................................6 65

4.2.1 The Chloride Penetration Depth...........................65

4.2.2 The Chloride Diffusion Coefficient ..........................68

4.2.3 2D Simulations ................................. 78

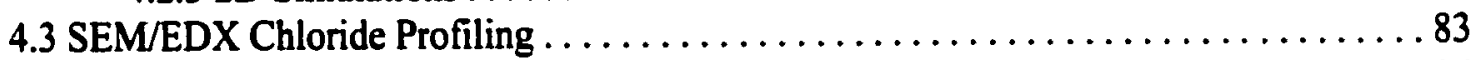

4.4 Chioride Diffusion Cell .................................... 86

4.5 Depth of Chloride Penetration vs Time .......................... 89

Chapter 5 Conclusions and Recommendations.................. 100

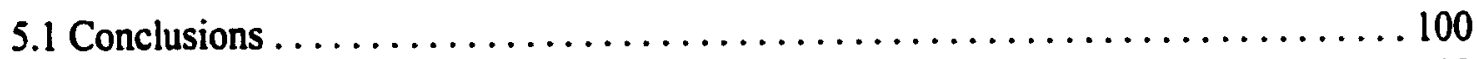

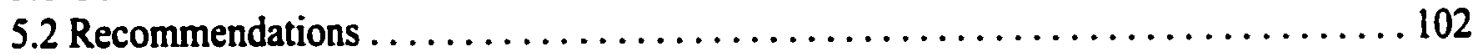

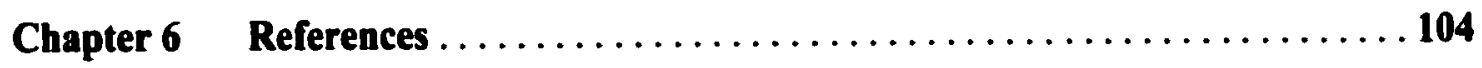

\section{APPENDICES}

Appendix A Crack Width Measurement

Appendix B Chloride Bulk Diffusion Test/Table Curve

Appendix C Chloride Bulk Diffusion Test/ConFlux 
Appendix D Chloride Bulk Diffusion Test/2D Simulations

Appendix E Chloride Diffusion in Rough Surface Samples

Appendix F SEM/EDX Chloride Profiling

Appendix G Chloride Diffusion Cell

Appendix H Depth of Chloride Penetration vs Time/Including Aggregate

Appendix I Depth of Chloride Penetration vs Time/Excluding Aggregate

Appendix J Depth of Chloride Penetration vs Time/Results 


\section{LIST OF TABLES}

Table $2.1 \quad$ Causes and Properties of Cracks ......................... 13

Table 2.2 Tolerable Crack Widths for Different Exposure Conditions ............ 18

Table 3.1 Physical and Chemical Properties of Cementitious Materials .......... 40

Table $3.2 \quad$ Raw Materials .................................... 41

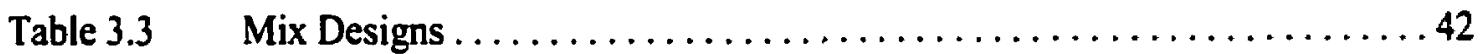

Table $3.4 \quad$ Experimental Program $\ldots \ldots \ldots \ldots \ldots \ldots \ldots \ldots \ldots \ldots \ldots \ldots \ldots$

Table 4.1 Chloride Bulk Diffusion Test, Depth of Chloride Penetration ........... 66

Table 4.2 40 Day Chloride Bulk Diffusion Test Results for $100 \%$ OPC Concrete, Table Curve .................................. 71

Table 4.3 40 Day Chloride Bulk Diffusion Test Results for $25 \%$ Slag Concrete, Table Curve ................................. 72

Table 4.4 Chloride Diffusion Cell, Comparison of Crack Widths ............. 88

Table 4.5 Depth of Chloride Penetration vs Time, $100 \%$ OPC Concrete .......... 91

Table 4.6 Depth of Chloride Penetration vs Time, $25 \%$ Slag Concrete . ......... 92 


\section{LIST OF FIGURES}

Figure 2.1 Schematic Representation of Two Types of Corrosion Process in the Region of Cracks .............................. 7

Figure 2.2 Cracking and Corrosion for (a) Coincident Cracks and (b) Intersecting Cracks .........................................15

Figure 2.3 Chloride Diffusion Cell . ............................ 35

Figure 3.1 Concrete Samples Containing One and Two Smooth Cracks ...........45

Figure 3.2 Arrangement for the Concrete Cylinder Splitting ................ 46

Figure 3.3 Chloride Bulk Diffusion Test - Experimental Details ............... 50

Figure 4.1 Measurement of Crack Width Under the Optical Microscope (4x):

(a) - Sample PSIDI, Sawcut Smooth Crack, $C w=0.12 \mathrm{~mm}$;

(b) - Sample SR3P2, Fracture Rough Crack, $\mathrm{CW}=0.32 \mathrm{~mm} \ldots \ldots \ldots \ldots 6$

Figure 4.2 Chloride Bulk Diffusion Test, Depth of Chloride Penetration; $100 \%$ OPC Concrete, Single Smooth Cracks ...................67 67

Figure 4.3 Typical Chloride Bulk Diffusion Test Curves, Table Curve:

Figure 4.4 Chloride Bulk Diffusion Test Results, Table Curve:

(a) $-100 \%$ OPC Concrete; (b) $-25 \%$ Slag Concrete .............. 73

Figure 4.5 Typical Chloride Bulk Diffusion Test Curves, ConFlux:

(a) - ID Diffuison; (b) - 2D Diffusion ..................... 76

Figure 4.6 Chloride Bulk Diffusion Test Results, ConFlux:

(a) - $100 \%$ OPC Concrete; (b) - $25 \%$ Slag Concrete ............. 77

Figure 4.7 Lines of Equal Concentration for One- and

Two-Dimensional Diffusion .......................... 79

Figure 4.8 Model for Calculating the Average Chloride Concentration at

Any Given Depth for the Case of 2D Diffusion ................. 80

Figure 4.9 Chloride Bulk Diffusion Test, Table Curve vs 2D Simulation .........81

Figure 4.10 X-Ray Map of the Free Edge, Sample SR31 (40x) $\ldots \ldots \ldots \ldots \ldots \ldots 84$

Figure 4.11 Micrograph of the X-Ray Map Area, Sample SR31 (40x) . . . . . . . . 84

Figure 4.12 Chloride Profiling: SEM/EDX vs Chemical Method ............... 85

Figure 4.13 Chloride Diffusion Cell, Mass of Chlorides Diffused vs Time .......... 88

Figure 4.14 Measurement of the Chloride Penetration Depth, Sample PSIP8, $100 \%$ OPC, 16 Day Exposure: (a) - Including Aggregate,

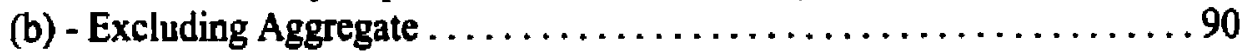

Figure 4.15 Typical Plot of Vertical Chloride Penetration Depth vs

Square Root of Time ............................. 94

Figure 4.16 Typical Plot of Lateral Chloride Penetration Depth vs

Square Root of Time ............................. 94

Influence of Cracks on Chloride Ingress into Concrete 
Figure 4.17 Lateral Depth of Chloride Penetration Excluding Absorption Effect vs Square Root of Time ........................... 97

Figure 4.18 Saturation of Samples Containing Single Smooth Crack and No Crack ..... 98 


\section{LiST OF SYMBOLS AND ABBREVIATIONS}

\section{Symbols}

$C_{(x, 1)}$

$\mathrm{C}_{0}$

erf

$\mathrm{D}_{\mathrm{a}}$

$\mathrm{J}$

$D_{e}$

$\mathrm{x}$

$C_{\text {u }}$

$C_{d}$

D

A

B

$r^{2}$

$P$

$\mathrm{m}_{\mathrm{ssd}}$

$m_{d}$

$\mathbf{m}_{\text {susp }}$

$\mathrm{C}_{\mathrm{Cl}}$

$\mathrm{n}_{\mathrm{CI}}$

$\mathrm{m}_{\mathrm{Cl}}$

$\mathbf{n}_{\mathbf{i}}$

$m_{i}$

$\mathrm{Cw}$

$\mathrm{V}$

L

$\mathrm{C}_{\mathrm{b}}$

Dsm.lat.

Dsm.vert.

Drh.lat.

Drh.vert.
Concentration of chlorides at distance $\mathrm{x}$ and time $\mathrm{t}, \%$ mass of concrete

Chloride surface concentration, $\%$ mass of concrete

Error function

Apparent chloride diffusion coefficient, $\mathrm{m}^{2} / \mathrm{s}$

Flow of chloride ions, mole/s* $\mathrm{m}^{2}$

Effective chloride diffusion coefficient, $\mathrm{m}^{2} / \mathrm{s}$

Thickness of the specimen, $m$

Chloride concentration in the upstream compartment of the chloride diffusion cell, mole $/ \mathrm{m}^{3}$

Chloride concentration in the downstream compartment of the chloride diffusion cell, mole $/ \mathrm{m}^{3}$

Sample diameter, $\mathrm{m}$

Vertical chloride concentration profile

Lateral chloride concentration profile

Correlation coefficient

Water porosity of concrete, $\%$

Mass of water saturated surface dry concrete, $g$

Mass of concrete dried at $100^{\circ} \mathrm{C}, \mathrm{g}$

Mass of concrete suspended in water, $g$

Chlorine concentration by mass of the SEM/EDX tested area, \%

Atomic percentage of chlorine, $\%$

Atomic mass of chlorine

Atomic percentage of i-element, $\%$

Atomic mass of i-element

Crack width, mm

Vertical depth of chloride penetration, mm

Lateral depth of chloride penetration, $\mathrm{mm}$

Background chloride concentration, \% mass of concrete

Apparent chloride diffusion coefficient obtained from grinding a smooth surface sample in the lateral direction, $\mathrm{m}^{2} / \mathrm{s}$

Apparent chloride diffusion coefficient obtained from grinding a smooth surface sample in the vertical direction, $\mathrm{m}^{2} / \mathrm{s}$

Apparent chloride diffusion coefficient obtained from grinding a rough surface sample in the lateral direction, $\mathrm{m}^{2} / \mathrm{s}$

Apparent chloride diffusion coefficient obtained from grinding a rough 
surface sample in the vertical direction, $\mathrm{m}^{2} / \mathrm{s}$

$\Delta \quad$ Constant, expressing the distance from the axis to the line of equal concentration away from the coordinate system origin, $\mathrm{mm}$

d Diameter of the milling machine core bit, $\mathrm{mm}$

$D_{2, \text { uncr }}$

$\mathrm{Ve}$

Le

A Apparent chloride diffusion coefficient of uncracked concrete, $\mathrm{m}^{2} / \mathrm{s}$ Vertical depth of chloride penetration excluding the aggregate, $\mathrm{mm}$

j Lateral depth of chloride penetration excluding the aggregate, $\mathrm{mm}$

$\mathrm{j}$ Ground layer number

$\mathrm{C}_{\mathrm{j}}$

Chloride concentration of $j$-ground layer, $\%$ mass concrete

Chloride concentration of $\mathrm{j}$-layer of equal chloride content, \% mass concrete

$m_{j} \quad$ Mass of $j$-ground concrete layer, $g$

$\mathrm{m}_{j} \quad$ Mass of $\mathrm{j}$-ground layer portion that corresponds to the preceding layer of equal concentration, $m_{j}-m_{j-1}, g$

$\mathrm{D}_{\mathrm{Cl}^{-}} \quad$ Chloride diffusion coefficient in water, $\mathrm{m}^{2} / \mathrm{s}$

$\mathrm{S} \quad$ Slope of steady state diffusion from regression analysis, mole/s

$A_{c r} \quad$ Surface Area of Crack, $m^{2}$

\section{Abbreviations}

$\begin{array}{ll}\text { ACI } & \text { American Concrete Institute } \\ \text { ASTM } & \text { American Society for Testing and Materials } \\ \text { BSE } & \text { Back Scattered Electron } \\ \text { CSA } & \text { Canadian Standards Association } \\ \text { EDX } & \text { Energy Dispersive X-Ray } \\ \text { OPC } & \text { Ordinary Porland Cement } \\ \text { RCPT } & \text { Rapid Chloride Permeability Test } \\ \text { RILEM } & \text { (French Acronym) International Association for Building Materials and } \\ & \text { Structures } \\ \text { SE } & \text { Secondary Electron } \\ \text { SEM } & \text { Scanning Electron Microscopy } \\ \text { SL } & \text { Slag } \\ \text { ID } & \text { One-Dimensional } \\ \text { 2D } & \text { Two-Dimensional }\end{array}$




\section{ChaPTER 1 INTRODUCTION}

Reinforced concrete is probably the most widely used construction material in the world due iv its considerable strength and variability in properties. Properly designed, built, and maintained, reinforced concrete structures remain in service for many decades. There are many factors that influence performance and durability of concrete structures during their service life. Different physicochemical processes take place in reinforced concrete structures that may result in their deterioration and distress.

Corrosion of reinforcing steel is one of the major deterioration mechanisms of reinforced concrete, and it may seriously compromise safety and serviceability of the structure. Costs related to repair of structures damaged by reinforcement corrosion have been estimated in the billions of dollars in the United States alone (Lorentz and French, 1995).

Contamination of concrete with chloride ions is considered to be the main cause of premature corrosion of steel reinforcement. Chlorides disrupt the natural high-alkali environment which protects steel within the concrete. Chloride induced corrosion is a common problem for reinforced concrete structures exposed to seawater or deicing salts.

The development of reliable methods for predicting chloride ingress into concrete is important to prevent deterioration of new structures and to assess the condition of existing ones. Extensive research has been conducted over the past decades to study transport properties of concrete and numerous service life prediction models have been introduced. While these models correlate with laboratory investigations, they usually fail to accurately predict service life of real 
structures. Their common disadvantage is that all predictions are carried out considering a 'perfect' and uncracked concrete (De Schutter, 2000). The fact that most reinforced concrete structures have cracks is often ignored (Pettersson and Sandberg, 1997).

Cracking is usually a result of various physical and chemical interactions between concrete and environment, and it may develop at different stages throughout the life of the structure. Once initiated, cracks create perfect pathways for gas and liquid transportation, thus, facilitating the ingress of deleterious species, such as chlorides, into concrete.

A detailed review of the literature has revealed at least two main reasons as to why the influence of cracking is often omitted from service life predictions of concrete structures. One of them is lack of sufficient knowledge on the effect of cracks. Although a general consensus exists about the fact that cracks can significantly modify the transfer properties of concrete, the limited research in this area has not yet allowed any accurate quantification of such effect (De Schutter, 1999; Gerard and Marchand, 2000).

The second reason is that the introduction of cracks into the models greatly complicates the analysis. There are a number of factors that have to be taken into account when modeling transport properties of cracked concrete. Some of them are the geometry of the cracks, their distribution, which is usually non-uniform, connectivity of cracks, scatter in crack sizes, and crack healing (Breysse and Gerard, 1997). The complexity of modeling transport in cracked concrete, as well as the pressing need for reliable methods of evaluation and prediction of concrete durability, poses a new challenge in the field of concrete research.

The main objective of this thesis is to examine the influence of cracks on chloride ingress into concrete and to produce some laboratory results that would facilitate quantification of this 
effect. For this purpose two types of concrete with a range of different crack widths were exposed to steady and non-steady state chloride diffusion tests, which are commonly used to assess the chloride resistance of concrete. To uncover the effect of surface roughness of the cracks on chloride ingress, two types of cracks were produced, 'smooth' artificial surface and 'rough' fracture surface cracks. In addition, the lateral movement of chlorides from the side of the crack into the concrete was studied. Chloride diffusion laterally from the crack at different depths within the sample was evaluated using scanning electron microscopy (SEM) combined with energy dispersive X-ray analysis (EDX). Finally, the relationship between the depth of chloride penetration and time was compared for uncracked concrete and concrete containing one and two cracks. 


\section{Chapter 2 Literature Review}

\subsection{Chloride Induced Corrosion}

Chloride induced corrosion is considered to be the predominant type of premature corrosion of steel reinforcement (ACI 222R-96). The problem of chloride attack usually arises when chloride ions ingress from outside. Sometimes, chloride ions are present in the original concrete constituents, however, it is external chloride ions introduced during the service exposure of the structure that cause an increase in their concentration up to and above the threshold level - a critical concentration of chlorides that marks the onset of corrosion. Marine structures, bridge decks, road slabs, and parking structures are the types of concrete structures that are mostly susceptible to corrosion induced by chlorides.

\subsubsection{Depassivation of Steel by Chloride Ions}

Some metals, including steel, can react with oxygen to form very thin layers of insoluble metal oxide on their surface. If this film remains stable in contact with the aqueous solution, the metal can be considered electrochemically passive. As long as a passivating film stays effective, the corrosion rates are so negligible that the metal can be considered as non-corroding (Bentur et al., 1997).

Concrete naturally provides very favorable conditions for steel. Its high alkaline environment ensures the stability of the passivating film, and, thus, protects the reinforcement from corrosion. Chloride ions can react with insoluble metal oxide forming a soluble complex 
which dissolves in the surrounding solution and does not protect steel anymore.

\subsubsection{Mechanism of Steel Corrosion}

Once the protective layer on the steel surface is destroyed, a difference in electrical potential develops along the reinforcement in concrete. An electrochemical cell is formed with anodic and cathodic regions, connected by the electrolyte in the form of pore water in the hardened cement paste. The corrosion process involves a progressive removal of atoms of iron from the anodic steel surface. The removed iron atoms dissolve in the surrounding water solution and appear as positively charged ferrous ions $\mathrm{Fe}^{2+}$. This process takes place at the anode and causes steel to lose mass, i.e. its cross-section becomes smaller.

At the same time, hydroxyl ions $\mathrm{OH}^{-}$are formed at the cathode with the consumption of water and oxygen. Hydroxyl ions, in turn, react with ferrous ions to form ferrous hydroxide, which is converted to rust by oxidation (Neville, 1995).

The corrosion products swell or expand causing concrete to crack and spall over the reinforcing steel. If left untreated, continued corrosion of embedded reinforcement may result in further spalling, cracking, delamination, and more extensive deterioration of the structure.

From the brief description of the corrosion mechanism presented above, it is evident that oxygen and water are needed for corrosion to occur. This implies that high rates of corrosion takes place neither in dry concrete nor in concrete fully immersed in water. The optimum relative humidity for corrosion lies between 70 and $80 \%$ (Neville, 1995). 


\subsubsection{Corrosion in Cracked Concrete}

Formation of cracks in concrete promotes the ingress of chloride ions and reduces the corrosion initiation time, provided other conditions required for corrosion are fulfilled. In cracked concrete, corrosion first starts either in the crack zone or in the areas immediately adjacent to the crack.

There are two different corrosion mechanisms that are theoretically possible in the region of cracks (Figure 2.1):

- In mechanism 1 both the anodic and cathodic processes take place in the zone of the crack. Anodic and cathodic areas are very small and located closely to each other (microcell corrosion). The oxygen required for the cathodic reaction is supplied through the crack.

- In mechanism 2 the reinforcement in the crack zone acts as an anode, and the passive steel surface between the cracks forms the cathode. In this instance, oxygen penetrates mainly through the uncracked area of the concrete (macrocell corrosion). The steel surface involved in this corrosion process is larger than in the first mechanism, hence, higher corrosion rates can be expected (Schiessl and Raupach, 1997).

The extent of corrosion in the presence of cracks depends on the following factors:

- Concrete properties, such as permeability and conductivity.

- Environment conditions: moisture and oxygen availability, depassivation, etc.

- Geometry factors: thickness of the concrete cover, crack frequency, crack width and orientation.

Since depassivating agents, water, and oxygen control the corrosion, and since their access to steel is facilitated in cracked concrete, environment plays a more important role for 
WZI cathodically acting steel surface

DN anodically acting steel surface
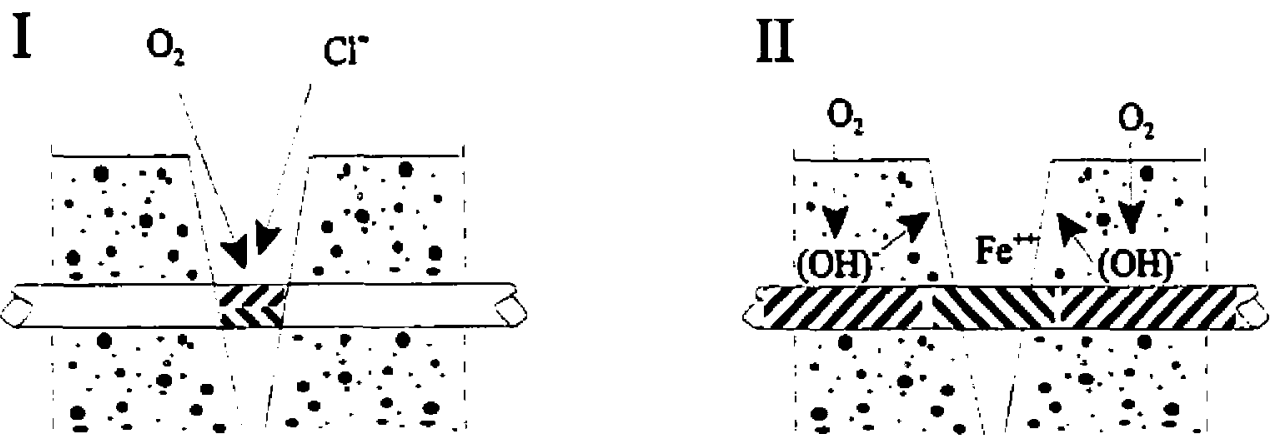

Figure 2.1 Schematic Representation of Two Types of Corrosion Process in the Region of Cracks (Schiessl and Raupach, 1997).

corrosion in cracked than in uncracked concrete (Jacobsen et al., 1998).

It is agreed to by many authors that corrosion in cracked concrete may develop as a direct result of cracking and that corrosion initiation time in such concrete is reduced as compared to uncracked concrete subjected to similar conditions (Suzuki et al., 1989; Suzuki et al., 1990; Borgard et al.,1991; Bentur et al., 1997; Thuresson et al., 1997). Corrosion rates are also expected to be higher in cracked concrete (Otsuki et al., 2000).

What sets the grounds for the ongoing debate is the influence of crack width on corrosion. While there is some indication that increasing crack width decreases the time to corrosion (Suzuki et al., 1990; Bentur et al., 1997), the relationship between crack width and 
corrosion rates is not clear. It appears that orientation of the cracks, as well as the exposure conditions, greatly affects this relationship (Campbell-Allen and Roper, 1992; Pettersson, 1996), but mainly during the early stages of corrosion (Beeby, 1978; Suzuki et al., 1989; Schiesssl and Raupach, 1997). 


\subsection{Chloride Ingress into Concrete}

Chloride ions can be transported from different sources depending on the service environment of the structure: action of de-icing salts, sea water, airborne droplets of sea water, and so on. Chloride intrusion into concrete is a complex time-dependent process which is mainly controlled by the properties of the concrete cover, such as water to cement ratio, concrete chemistry, and the presence of faults, as well as by exposure conditions - weather cycles, changes in chloride concentration at the concrete surface, and so on (Suryavanshi et al., 1998). Different transport mechanisms can contribute to the penetration of chlorides, and, frequently, more than one mechanism governs chloride ingress into concrete structures. The predominant mechanism depends upon the moisture condition of concrete or degree of saturation.

\subsubsection{Mechanisms of Chloride Ingress}

In the literature, it is quite common to distinguish the various mass transport mechanisms by the driving force acting on the transported matter (Marchand and Gerard, 1995). Diffusion is one of the most common transport mechanisms and it can be defined as the transfer of matter due to a concentration gradient. It involves the motion of the individual molecules or ions from highly concentrated regions towards less concentrated ones. In concrete, diffusion takes place when it is completely saturated and at least one of its surfaces is exposed to chloride solution (Hooton and McGrath, 1995). Diffusion acts as a predominant mechanism for concrete structures fully submerged in sea water or salt-contaminated soil. In combination with other mechanisms, diffusion contributes to chloride transport in concrete under most exposure 
conditions.

Despite the fact that diffusion is not the only process that governs intrusion of chloride ions, theories relating to diffusion are generally used when calculating chloride ingress into concrete (Konin et al., 1998). The important role of diffusion in relation to concrete durability made it the focus of this project.

Another very common mechanism of mass transport is permeation. The driving force for permeation is a pressure gradient. When the concrete structure is subjected to hydraulic pressure (e.g.: fluid retaining structures), the penetration of chlorides is determined by the convection of fluid through the concrete. Permeation plays an important role for tunnel liners, pavements, bridge decks, off-shore structures, basements, and swimming pools.

In the cases where concrete structures are not completely saturated, action of capillary forces due to surface tension can draw the chloride solution into the concrete surface. This defines the mechanism of absorption. The governing parameters for absorption are degree of material saturation, viscosity of the penetrating fluid, and surface tension (Gerard et al., 1997). Absorption leads to a deeper chloride penetration than diffusion over a given period of time (Thaulow and Grelk, 1993). However, it only affects the initial few centimeters of the concrete cover, and its rate drops as the concrete becomes more and more saturated with depth (Hong, 1998).

As chlorides diffuse throughout the concrete matrix, not all ions are drifting at the same speed - some move faster and others move slower than the average diffusion rate. This effect is called dispersion and can be attributed to inhomogeneities in concrete (Hooton and McGrath, 1995). Dispersion can microscopically be observed as non-uniform distributions of chiorides in 
concrete (Volkwein, 1995).

Chlorides can aiso penetrate concrete by wicking. Wick action is the transport of water through a concrete structure from a face in contact with water to a drying face, which results in a build-up of chlorides inside the concrete. Examples of wick action can be found in basements, parking structures, and tunnel liners (Buenfeld et al., 1995).

Penetration of chloride ions into concrete is accompanied by its interaction with the cement paste, namely by binding of chlorides to cement paste hydrates. It is important to discern between bound and unbound or free chlorides, as only the latter are available to attack the reinforcement causing subsequent corrosion.

\subsubsection{Transport Properties due to Cracked Concrete}

The presence of cracks can significantly modify transport properties of concrete. Since the kinetics of different transport processes varies, changes resulting from cracking greatly depend on which mechanism is predominant. For instance, an increase in permeability as a direct result of cracking can be of several orders of magnitude, while diffusivity is much less affected by cracks (Breysse et al., 1994; Breysse and Gerard, 1995 and 1997; Gerard et al., 1997).

Regardless of the transport mechanism, properties of cracks become more important in cracked concrete than the properties of concrete itself. Parameters, such as crack width and shape, crack density and degree of connectivity, as well as crack origin, govern mass transport in cracked concrete. A review of the literature on chloride ingress in cracked concrete is presented further in this chapter.

Influence of Cracks on Chloride Ingress into Concrete 


\subsection{Background on Cracking}

Given the importance of crack properties as related to the ingress of chloride ions or any other species in cracked concrete, some fundamental concepts on cracking need to be reviewed. In the RILEM draft recommendation for damage classification of concrete structures (1994) cracks are defined as "spaces in an original monolithic mass of concrete or masonry resulting from a complete or incomplete separation of the mass into two (single crack) or more parts (multiple cracks)". In other words, cracks are discontinuities or open flaws in concrete (Gerard et al., 1998).

Cracks are the most common signs of deterioration of the concrete structure. They do not only increase penetrability of concrete, but also reduce concrete strength, impair the appearance of the structure, and, in extreme cases, indicate major structural problems. The extent to which cracks affect the concrete structure largely depends on the nature of cracking.

\subsubsection{Classification of Cracks According to Their Causes}

Table 2.1 presents the most common causes of cracking with the approximate time of crack appearance, ranges of expected crack widths, and an indication as to whether cracks tend to be active or dormant. This table is a brief summary of the types of cracking mechanisms in concrete drawn from several literature sources (Campbell-Allen and Roper, 1992; Mailvaganam, 1992; Mays, 1992; Arya, 1995).

The use of steel in concrete allows achievement of ductility in reinforced concrete structures, since concrete on its own has a low tensile strength. At the same time, in order to 
Table 2.l Causes and Properties of Cracks.

\begin{tabular}{|c|c|c|c|c|}
\hline \multicolumn{2}{|c|}{ Causes of Cracks } & Time of & Size & Active or \\
\hline \multirow{6}{*}{ 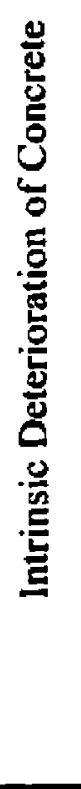 } & $\begin{array}{c}\text { Tensile Structural } \\
\text { Loads }\end{array}$ & time of loading & $\begin{array}{c}<0.4 \mathrm{~mm}-\text { if } \\
\text { designed to } \\
\text { crack }\end{array}$ & $\begin{array}{c}\text { active; dormant } \\
\text { for temporal } \\
\text { overloading }\end{array}$ \\
\hline & $\begin{array}{c}\text { Early Plastic } \\
\text { Shrinkage }\end{array}$ & $\begin{array}{l}\text { first few hours } \\
\text { after casting }\end{array}$ & up to $>1 \mathrm{~mm}$ & dormant \\
\hline & Plastic Settlement & $\begin{array}{l}\text { first few hours } \\
\text { after casting }\end{array}$ & up to $2-4 \mathrm{~mm}$ & dormant \\
\hline & $\begin{array}{c}\text { Early Thermal } \\
\text { Stresses }\end{array}$ & first few days & up to $0.4 \mathrm{~mm}$ & dormant \\
\hline & $\begin{array}{l}\text { Long-Term Drying } \\
\text { Shrinkage }\end{array}$ & $\begin{array}{c}\text { several weeks or } \\
\text { months }\end{array}$ & up to $>1 \mathrm{~mm}$ & active \\
\hline & $\begin{array}{c}\text { Alkalí-Aggregate } \\
\text { Reaction }\end{array}$ & $\begin{array}{c}\text { more than a few } \\
\text { years }\end{array}$ & $>1 \mathrm{~mm}$ & active \\
\hline \multirow{2}{*}{ 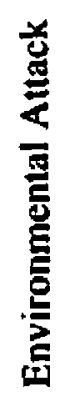 } & $\begin{array}{l}\text { Reinforcement } \\
\text { Corrosion }\end{array}$ & $\begin{array}{c}\text { more than two } \\
\text { years }\end{array}$ & $\begin{array}{c}\text { initially }<0.2 \mathrm{~mm} \\
\text { increase with } \\
\text { time }\end{array}$ & active \\
\hline & $\begin{array}{l}\text { Cycles of Freezing } \\
\text { and Thawing }\end{array}$ & $\begin{array}{l}\text { after one or } \\
\text { more cycles }\end{array}$ & $\begin{array}{l}\text { increase with } \\
\text { number of } \\
\text { cycles up to } \\
>\text { Imm }\end{array}$ & active \\
\hline
\end{tabular}

ensure that reinforcement works efficiently, the maximum tensile strain concrete can tolerate without cracking must usually be exceeded. This implies that tensile load-induced cracking is an inevitable characteristic of reinforced concrete structures. However, it is possible to predict and control the properties of such cracks with proper design (Bentur et al., 1997). 
Cracking associated with weathering and alkali-aggregate reaction is much harder to control. This normally requires appropriate choices of materials and mix designs. Early plastic and thermal stresses can also be minimized with proper mix design and good concrete practices on site.

To characterize the size of cracks, crack width at the concrete surface is usually referred to. Hence, cracks can be categorized according to their widths. Micro cracks have a width of less than $0.01 \mathrm{~mm}$ and are considered to be natural to concrete. They are generally associated with self-desiccation and hydration processes. Cracks in the range between 0.01 and $0.1 \mathrm{~mm}$ are regarded as fine cracks. Large cracks have a width of greater than $0.1 \mathrm{~mm}$ and can be divided into more subcategories, however, this classification varies from author to author (Mailvaganam, 1992; Frederiksen et al., i997). The effect of micro cracks on concrete properties should be accounted for when concrete is designed. It is the effect of fine and large cracks that needs to be quantified.

The mechanism of cracking can be of either short or long-term nature, producing dormant or active cracks. The crack will be considered dormant, if its width does not increase with time, in other words, if the cause of cracking is not expected to occur again and no other processes act on it. Dormant cracks are less detrimental to concrete, as they have a greater tendency to self-heal.

\subsubsection{Orientation of Cracks}

Orientation of cracks with respect to reinforcement is an important factor influencing crack-induced corrosion. According to their orientation, cracks can be divided into coincident 
(a)
$\mathrm{O}_{2}+\mathrm{H}_{2} \mathrm{O}$ able to penetrate
$\mathrm{Cl}$ able to to cathodic area penetrate anodic area

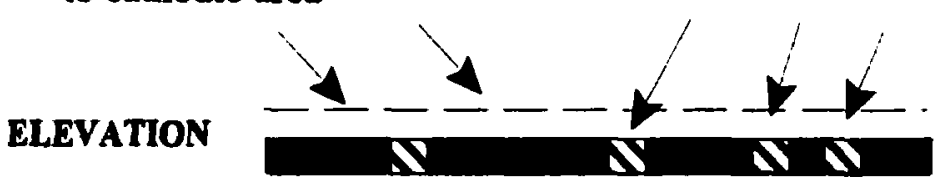

$\mathbf{X}$ Anodic areas

(b)
$\mathrm{O}_{2}+\mathrm{H}_{2} \mathrm{O}$ prevented from
$\mathrm{Cl}$ able to penetrating to cathodic area $\mathrm{Cl}$ penetrate anodic area
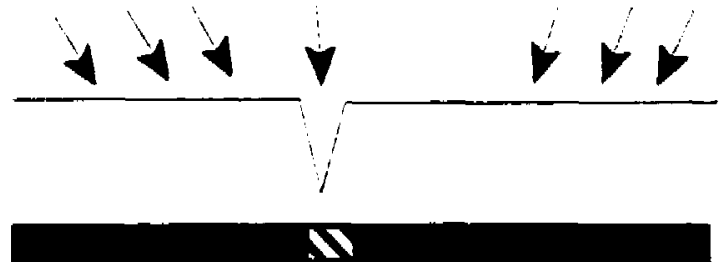

Anodic areas

Figure 2.2 Cracking and Corrosion for (a) Coincident Cracks and (b) Intersecting Cracks (Arya, 1995).

and intersecting.

Cracks along the line of the reinforcement are called coincident or longitudinal. They can be induced by various mechanisms including plastic settlement, plastic shrinkage, early bond contraction, and bond failure. With regards to corrosion, this type of cracking is extremely dangerous, since chlorides, moisture, and oxygen can easily penetrate to the embedded steel and engage quite large areas of steel in the corrosion process (Figure 2.2-a). 
Cracks across the reinforcement are termed intersecting or transverse. In this case, the cathodic areas of reinforcement mostly occur in the crack-free regions (Figure 2.2-b), therefore, moisture and oxygen that enter trough the cracks do not significantly affect the rate of corrosion (Arya, 1995).

Longitudinal cracking has been found to be more likely to cause corrosion with consequent higher corrosion rates than intersecting cracks (Beeby, 1978; Wilkins and Stiliwell, 1986; Arya, 1995; Arya and Ofori-Darko, 1996; Bentur et al., 1997).

\subsubsection{Crack Healing}

Under favorable conditions, cracks in concrete can exhibit the effect of self-healing. As stated by Jacobsen et al. (1998), "the term healing ... can be defined as recovery of certain properties of reinforced concrete structures (strength, porosity, permeability, ... etc.) after reduction or increase due to exposure of various kinds."

Three main categories of self-healing in concrete can be deduced (Jacobsen et al., 1998):

- Physico-chemical healing involves reaction of magnesium ions from sea water with concrete constituents, forming dense products (Eriksen et al., 1996; Pettersson, 1996), and continued hydration of cement or cement hydrates.

- Mechanical healing is characterized by blocking of cracks with corrosion products, loose particles from the crack walls and exterior particles, as well as by precipitation of calcite from water flowing trough the cracks (Edvardsen, 1996 and 1999; Eriksen et al., 1996; Bentur et al., 1997; Gerard et al., 1997).

- Use of "smart" materials, such as sealant bearing fibres, that can release self-repairing 
agents.

The critical parameters for crack healing are exposure conditions, access to moisture, crack size, and whether crack is dormant or active. The composition of concrete seems to be a secondary factor (Edvardsen, 1999). The self-healing of cracks can reduce the penetrability of cracked concrete, and, thus, slow down the ingress of deleterious species.

\subsubsection{Permissible Crack Width}

As corrosion protection measures, most existing specifications set recommended values for parameters, such as maximum chloride content in the concrete mix, thickness and composition of the concrete cover, as well as the maximum tolerable crack width. It has been recognized that exposure conditions of the concrete structure greatly determine the corrosion risk. Therefore, permissible crack widths are often limited depending on the severity of the environment. Table 2.2 is a general guide for tolerable crack widths at the tensile face of reinforced concrete structures as specified by the ACI Manual of Concrete Practice (ACI 224R90).

These guidelines should not be regarded as a unique source for design that ensures adequate protection against corrosion. Properties of the concrete cover are equally important. Another essential consideration is the type of structure. For example, the permissible crack width for prestressed concrete could be lower than for normal concrete (Mailvaganam, 1992). The projected service life of the structure is also a key component for the design, since there is really no permissible crack width that can ensure permanent corrosion protection. It is just a question of the duration and intensity of the chloride exposure before the permissible crack width 
Table 2.2. Tolerable Crack Widths for Different Exposure Conditions (ACI 224R-90).

\begin{tabular}{|l|c|c|}
\hline \multirow{2}{*}{ Exposure Conditions } & \multicolumn{2}{|c|}{ Tolerable Crack Width } \\
\cline { 2 - 3 } & (in.) & (mm) \\
\hline Dry air, protective membrane & 0.016 & 0.41 \\
\hline Humidity, moist air, soil & 0.012 & 0.3 \\
\hline De-icing chemicals & 0.007 & 0.18 \\
\hline $\begin{array}{l}\text { Seawater and seawater spray; } \\
\text { wetting and drying }\end{array}$ & 0.006 & 0.15 \\
\hline Water-retaining structures & & \\
\hline
\end{tabular}

becomes zero (Hartl and Lukas, 1987).

The autogenous healing of cracks should also be taken into account when specifying tolerable crack widths. Based on experimental results, Edvardsen (1999) proposed permissible crack widths which can be expected to reach aimost total self-healing after a short water pressure exposure. They range from 0.1 to $0.25 \mathrm{~mm}$ depending on the hydraulic gradient acting on the concrete structure.

It appears that there is no single answer to the question on permissible crack widths. Complex interrelations among properties of the concrete cover, exposure conditions, and designed service life of the structure determine the crack widths that can be tolerated without significant corrosion. 


\subsection{Effect of Cracks on Chloride Ingress into Concrete}

The background on chloride ingress and cracking in concrete was covered in previous sections. A review of the existing literature on the influence of cracks on chloride ingress into concrete shall follow next.

When studying cracked concrete, the first question that has to be addressed is how cracks are to be produced. Several experimental set-ups are possible depending on the method used to induce cracking in concrete.

\subsubsection{Flexural Loading}

To produce natural cracks that are a perfect simulation of cracking in real concrete structures, various loading mechanisms are often used. Flexure induced cracking is covered extensively in the literature due to the inherent nature of this type of cracking in reinforced concrete structures.

Mangat and Gurusamy (1987) studied the influence of flexural cracks on chloride diffusion into steel fibre reinforced concrete. Cracks of widths ranging between 0.07 and 1.08 $\mathrm{mm}$ were produced on prism specimens prior to 1450 cycles of splash and tidal zone marine exposure. It was found that chloride concentration in the vicinity of cracks rises as the width of the cracks increases. The effect was more pronounced for crack widths larger than $0.5 \mathrm{~mm}$. Smaller cracks with widths less than $0.2 \mathrm{~mm}$ appeared to have an insignificant influence on chloride intrusion.

The relationship between concrete deterioration and steel corrosion was examined by 
Raharinaivo et al. (1986). As part of this research, the effect of crack width on chloride diffusivity was studied on concrete samples immersed in salt solution. Comparison of diffusion coefficients for cracked and uncracked concrete shows an increase in the diffusion coefficient for cracked concrete by one or two orders of magnitude, with wider cracks resulting in higher values. Contrary to Mangat's and Gurusamy's observations, the effect of even small cracks (about $0.1 \mathrm{~mm}$ ) was regarded as important. This is somewhat surprising, since the tidal zone marine cycles offer a more aggressive environment than the complete salt water submersion used in the experiments by Raharinaivo et al. These contradictory conclusions on the effect of smaller cracks can, perhaps, be attributed to differences in concrete type.

An apparent drawback of the tests discussed above is that samples were unloaded prior to salt exposure, which does not correspond to actual service conditions. Francois and Maso (1988) initiated a long-term study on reinforced concrete beams loaded in three-point flexure and, in this condition, stored in a confined salt fog. Two different stress levels were maintained throughout the exposure period. The generated crack widths were between 0.05 and $0.5 \mathrm{~mm}$. The aim of the study was to determine the effect of both cracking and microcracking on the service life of the structure. The authors have concluded that an increase in penetration of chlorides in the tensile zone is triggered by damage at the paste-aggregate interface. It was also noted that chlorides penetrate rapidly through cracks, diffuse into the concrete mass from crack walls, and quickly progress along reinforcement. No comments were made concerning the relationship between crack width and chloride ingress.

Following up on the same study, Francois and Arliguie (1999) reported some additional findings twelve years into the experimental program. They pointed out that the load applied to 
a reinforced concrete beam greatly affects the penetration of chlorides. Furthermore, the apparent chloride diffusion coefficient was related to the load level through the tensile stress in the reinforcing bar. They also suggested that this relationship could be used as a guideline for evaluation of chloride ingress into concrete subjected to a tensile stress.

Konin et al. (1998) performed more research on penetration of chloride ions in relation to microcracking resulting from flexural load, Normal, high, and very high strength concretes were subjected to cycles of wetting and drying in a saline humid atmosphere. The state of concrete microcracking was characterized using scanning electron microscopy and replica technique. The results indicated that chloride penetration rate increases with increasing density of microcracks. Moreover, a linear relationship between the chloride apparent diffusion coefficient and the applied tensile load was established, which is in agreement witi research by Francois and Arliguie (1999). It was noted that chloride diffusion coefficients and concrete strengths are also linearly related.

Sakai and Sasaki (1994) conducted a ten year exposure test on precracked concrete slabs in a coastal marine environment. Initially, slabs were cracked up to $0.2 \mathrm{~mm}$ wide and fixed at both ends with bolts. Strong wind from the sea transported the chlorides. Although, it was clear that chloride contents in the cracked portion of the slabs were much greater than in sound concrete, the effect of crack width seemed to be counter intuitive. It was actually found that smaller cracks (up to $0.1 \mathrm{~mm}$ ) resulted in higher chloride concentrations than larger cracks (with crack widths bigger than $0.3 \mathrm{~mm}$ ). The explanation presented by the authors was associated with the washing out action of rain that more easily affects larger cracks. While rain wash-out may be a part of the problem, reinforcement corrosion activity could have contributed to it, as well. 
Since the initial cracking was induced only to the maximum target width of $0.2 \mathrm{~mm}$, the increase in crack widths was caused by steel corrosion. It is then reasonable to assume that corrosion products have blocked the wide cracks, preventing more chlorides from entering the crack.

Chloride diffusivity of concrete cracked in flexure was also studied by Gowripalan et al. (2000). Concrete prisms were cracked in three-point loading and tightened by bolts to keep the cracks open up to $0.3 \mathrm{~mm}$. Prisms were ponded in salt solution for 300 days. The experiment showed that the apparent chloride diffusion coefficient is larger in the tensile than in the compressive zone. The damage in the tensile zone was associated with the aggregate-paste interface. These conclusions are consistent with previous research (Francois and Maso, 1988). In addition, it was recommended in this work that the crack width to cover ratio should be used as a performance parameter for cracked concrete. This seems to be more appropriate than reliance on the crack width alone, since crack width at the concrete surface is not representative of the crack width at steel (Beeby, 1978). The bigger the concrete cover, the larger the difference between these two crack widths.

Edvardsen (1995) investigated the influence of crack width on water permeability. Since chloride ions are transported with water, concrete subjected to a hydrostatic pressure will suffer chloride intrusion by permeation. A special device was designed to produce realistic tensile cracks and subject specimens to water pressure. It was concluded that water flow through cracks is mainly proportional to the crack width cubed. Furthermore, healing of cracks can significantly reduce water flow, thus, decreasing chloride transport in cracked concrete. 


\subsubsection{Compressive Loading}

Loading concrete samples in compression to a preselected fraction of the ultimate strength results in the creation of a microcracking network. Therefore, compressive loading is often used to examine the effect of microcracks on concrete properties.

Locoge et al. (1992) studied diffusion of three different species through concrete including chloride ions. Discs cut from concrete cylinders damaged in triaxial compression were analyzed using a surface replica technique that allowed calculation of the specific microcracking surface. Diffusion cells were used to measure the flow of chlorides through the concrete. The results indicated that there is a correlation between the chloride flow rate and the specific microcracking surface which is related to the applied load. Another observation that has been made is that the interactions between chloride ions and the cement paste is lower for damaged than for sound concrete. This was attributed to the reduction in the specific area caused by the appearance of microcracks.

Samaha and Hover (1992) performed rapid chloride permeability tests (RCPT) on concrete samples damaged in compression. The resulting microcracking was characterized by neutron radiography. No influence of the microcracks on the electrical charge passed through the sample (an output of the test indicating resistance of the concrete to the migration of chlorides) was detected at load levels below 0.75 of the ultimate. Beyond this point, a slight increase (15-20\%) in the total charge was noticed. Although, the microcracking steadily increased with the applied load, no relationship between the degree of microcracking and the average charge passed could be found.

Saito and Ishimori (1995) have confirmed that static compressive loading up to $90 \%$ of 
the maximum capacity of concrete has little effect on chloride permeability (as characterized by RCPT). Repeated compressive loading at the maximum stress levels of 60 to $80 \%$ appeared to trigger a significant increase in chloride permeability of concrete. However, no assessment of the microcracking was conducted.

Continuing the same line of research, Lim et al. (2000) suggested that the chloride permeability of concrete is influenced by the occurrence of a certain stress level, named the critical stress. Until this critical stress is exceeded, there is no significant increase in chloride permeability. In this study, the critical stress was found to range between 0.8 and 0.95 of the ultimate stress. Thus, there is a fairly good agreement on the influence of static compressive loading on chloride conductivity of concrete measured by RCPT.

\subsubsection{Feedback-Controlled Splitting Test}

Feedback-controlled splitting test is used on cylindrical concrete samples to produce a single crack of a chosen width. Crack opening is monitored using linear variable displacement transducers throughout the loading. The advantages of this splitting test as a method to induce cracks are full control of the crack width and good crack width reproducibility. The drawback is that only a single crack can be generated.

Aldea et al. (1999-2) carried out an investigation on the influence of cracks from 50 to $400 \mu \mathrm{m}$ on chloride permeability of normal and high strength concretes by RCPT. Chloride conductivity was sensitive to cracking only for high strength concrete with low water to cement ratio of 0.25 as follows: cracks less than $200 \mu \mathrm{m}$ had no effect, while cracks between 200 and $400 \mu \mathrm{m}$ resulted in higher chloride conduction. 
As discussed earlier, water permeability is an important property of concrete in relation to its durability and, particularly, to chloride intrusion. Aldea et al. (1999-1) found that the relationships between water permeability and material type differ for cracked and sound material. In fact, for uncracked material permeability decreases with increasing material "quality" - from paste, mortar, normal to high strength concrete, whereas for cracked material normal strength concrete exhibited the highest water permeability. Besides, a strong influence of crack width on permeability was observed, especially, for crack widths larger than $100 \mu \mathrm{m}$.

Wang et al. (1998) also reported a great dependency of water permeability on crack width. Cracks ranging between 50 and $200 \mu \mathrm{m}$ caused the most rapid increase in permeability.

\subsubsection{Numerical Simulations}

Numerical simulations are powerful tools in studying transport properties of concrete. Bringing existing theoretical knowledge and experimental evidence together, numerical models offer a great flexibility and precision. They allow examination of the relationships among different parameters and, thereby, prediction of general trends in the material properties. The predictive ability and the accuracy of these models depend on the choice of the theoretical approach, relevant material parameters, assumptions made, and scale of modeling.

When modeling transport properties of cracked concrete, consideration has to be given to the type of transfer mechanism, properties of cracks, such as size of cracks (micro- or macrocracks) and form of cracks (single, pattern, or map cracking), as well as to the theories that can relate these phenomena.

Breysse and Gerard (1995) presented a review on the most important problems 
associated with the prediction of transfer properties of cementitious materials, namely permeability. Both uncracked and cracked materials were considered. They pointed out that concrete response to permeation cannot be deduced from that of cement paste or mortar due to a greater degree of concrete inhomogeneity. It has also been shown that the main parameters for describing flow in damaged and sound material are different - in uncracked concrete permeability is related to its porosity, while in cracked concrete it is related to crack properties. Therefore, no predictions on the behavior of cracked concrete can be made based on the data for uncracked concrete. From different models and test results reviewed, the increase in permeability of cracked concrete was estimated to be of several orders of magnitude. In addition, the importance of the relevant choice of scale for the experimental data introduction was illustrated.

A theoretical study was conducted by Frederiksen et al. (1997) on the effect of transverse cracks on chloride penetration into the concrete cover. A 2D simulation software was used to model chloride diffusion. Calculations were performed for various depths and crack densities, assuming unlimited chloride supply. The results were evaluated in terms of an "equivalent cover thickness" when the cover contained cracks. The results indicated that a single crack does not considerably reduce the equivalent cover thickness until the depth of the crack reaches over 50 $\%$ of the actual cover. However, the higher the crack density, the smaller the equivalent cover thickness. The drawbacks of these simulations lie in the oversimplification of the exposure conditions and in excluding the crack's self-healing effect.

Gerard and Marchand (2000) carried out a theoretical investigation on the influence of transverse continuous cracking on steady-state diffusion (no interaction between diffusing 
species and concrete constituents) in concrete. The following simplifying assumptions were made: all cracks had the same size and were evenly distributed on a one- or two- dimensional grid. The parameters chosen to characterize cracking were the mean aperture of the cracks and the mean crack spacing. Diffusion coefficients drawn from the theoretical simulations were compared with the experimental results obtained on concrete samples damaged by cycles of freezing and thawing. A reasonable correlation between the analytical model and laboratory resuits was achieved. Diffusivity of cracked concrete was found to increase by a factor of 2 to 10. This corresponds to the range of increase in diffusion coefficient obtained by Thaulow and Grelk (1993) from in-situ testing of marine structures.

Analytical simulations performed by Gerard and Marchand (2000) have also indicated that the effect of cracking could be more pronounced for denser material. For concrete structures, this would basically imply that high performance concretes are influenced by cracking to a higher degree. Some other experimental evidence supports this observation (Aldea et al.,1999-2).

\subsubsection{Other Methods}

Other methods of inducing cracks for experimental purposes may include imitation of various cracking mechanisms, different from loading, that concrete structures encounter under actual service conditions, as well as the creation of artificial cracks.

Hartl and Lukas (1987) examined the relationship between the chloride penetration into concrete and cycles of freezing and thawing. Concrete slabs, while exposed on one face to a salt solution, were subjected to various numbers of freeze/thaw cycles, and then chloride contents 
at different depths in the concrete were analyzed. The depth of chloride penetration was found to increase with the number of freeze/thaw cycles. Moreover, it appeared to be linked to the duration of testing by a square root of time relationship, i.e. depth of chloride penetration was linearly proportional to the square root of time.

Effects of freeze/thaw induced cracking and subsequent healing on chloride transfer were studied by Jacobsen et al. (1996). Well cured OPC concrete was damaged to different degrees by rapid freeze/thaw exposure, and the density of produced cracks was measured on poiished sections. Chloride penetration was estimated using chloride migration cells, which are an electrically accelerated version of a simple diffusion cell. With increasing number of freeze/thaw cycles, both the crack density and the chloride migration rate were increasing. In fact, the migration rate increased by $2.5,4.3$, and 7.9 times respectively after 31,61 , and 95 cycles compared to the uncracked concrete. Self-healing of cracked concrete specimens for three months in water resulted in the $28-35 \%$ decrease in chloride migration rate.

From these studies, it is evident that chloride transfer is proportional to the number of freezing and thawing cycles, however, the key role of the concrete mix design shall always be kept in mind (Saito et al., 1994).

Sandberg and Tang (1994) performed an analysis of core samples drilled from a four year old, high quality concrete marine bridge column for chloride content. Lack of proper heat evolution control in the fresh concrete resulted in microcracking in some parts of the concrete column. Despite of the established self-healing effect of microcracks, diffusivity of cracked concrete was three to five times higher. These results correlate well with previously discussed research (Raharinaivo et al., 1986; Thaulow and Grelk, 1993; Gerard and Marchand, 2000). 
Saito et al. (1994) explored the effect of artificial cracks piercing concrete specimens on the total charge passed during RCPT. Two types of piercing cracks were prepared: an actual crack, resulted from the splitting load applied to a concrete disk, and a model crack, obtained by inserting $0.1-0.5$ nim thick steel plates into fresh concrete. The cracks were characterized by their open area. The advantage of using the steel plates of known size is that the cross-sectional area of the plates could be considered as the open area of the model crack, while the open area of the actual crack had to be carefully quantified under the optical microscope. The results of the testing revealed that the increment in chloride permeability was linearly related to the open area of the piercing crack. The additional significance of these findings is that both actual and model cracks gave fair agreement. This indicates that model or artificial cracks could be successfully used in studying cracked concrete, as they are much easier to characterize and control than actual cracks. However, any models derived from experimenting with artificial cracks should always be calibrated on real concrete structures to assure their reliability.

De Schutter (1999) developed a tentative formula that quantifies the influence of cracks on chloride penetration based on an extensive experimental program on mortar prisms. Artificial cracks with widths up to $0.5 \mathrm{~mm}$ and depths up to $10 \mathrm{~mm}$ were created by placing thin copper sheets on the moulds prior to casting and removing these sheets afterwards. A set of different aggressive environments was considered. The main parameters for quantification were width and depth of the cracks. Some reasonable agreement between the model and experimental data was attained. The creation of cracks by positioning the shims into the mould prior to casting has a drawback in that the crack surface contains more cement than the natural crack would. Other possible developments to the model could be to include the effect of crack self-healing and crack 
roughness, as well as to conduct the same tests on concrete rather than on mortar.

The main points from the literature review on the influence of cracks on chloride ingress into the concrete structures can be summarized as follows:

- Regardless of their cause, size and distribution, cracks do tend to increase the penetration of chloride jons into concrete, with higher chloride content concentrated in the vicinity of cracks. In general, the more severe the damage to the concrete structure, the higher the expected chloride penetration rates.

- Permeation is affected by cracking to a higher degree than diffusion. The increase in permeability can be of several orders of magnitude, while diffusivity in cracked concrete is only raised by a factor of one to ten.

- It appears that chloride penetration usually increases with increasing crack width, nevertheless, there is a divergence in the quantification of this effect in the literature depending on the exposure conditions, materials, and methods used. The critical crack width, the value below which the influence of the cracks is not as pronounced, was mostly found to be in the range of $0.1-0.2 \mathrm{~mm}$. This corresponds to the range of permissible crack widths commonly recommended.

- Load-induced cracking results in a higher concentration of chlorides in the tensile zone. Chloride penetration into the loaded concrete seems to be related to the applied stress. Repeated loading makes the concrete structure more prone to chloride aggression than static loading of the same magnitude. Relatively high compressive stresses (up to 70$90 \%$ of the ultimate stress) can be tolerated by reinforced concrete structures without 
significant increases in chlorides intrusion rates (this conclusion is mostly drawn from RCPT results).

- Various approaches can be taken to quantify the influence of cracking in concrete structures: crack width to concrete cover ratio, crack width and length, specific cracking surface, and so on. There is still a great deal of research required to investigate what approach is the most suitable for which case, however, it is essential to account for such characteristic crack properties as crack roughness and crack healing. 


\subsection{Test Methods Used to Evaluate the Chloride Resistance of Concrete}

The magnitude of the problem associated with corrosion of reinforced concrete structures has led to the development of various test methods that estimate the resistance of concrete to aggression by chloride ions. Most of these methods are focused on measuring chloride diffusion in concrete. The theoretical background and practical considerations of the tests used in the course of this project are discussed below.

\subsubsection{Chloride Bulk Diffusion Test}

The determination of the diffusion coefficient is a convenient and widely adopted approach for characterizing chloride penetration into concrete. The chloride bulk diffusion or chloride ponding test is an experimental method that allows calculation of an apparent diffusion coefficient by non-linear regression analysis based on Fick's second law for unsteady-state diffusion:

$$
\frac{\partial C}{\partial t}=D_{a} \frac{\partial^{2} C}{\partial x^{2}}
$$

The solution to this partial differential equation for boundary conditions $\mathrm{C}_{(x=0,00)}=\mathrm{C}_{0}$, initial condition $\mathrm{C}_{(x>0,(x))}=0$, and infinite point condition $\mathrm{C}_{(x>, 0>0)}=0$, was found by $\mathrm{Crank}$

$$
\frac{C_{(x, t)}}{C_{0}}=1-\operatorname{erf}\left(\frac{x}{\sqrt{4 D_{a t}}}\right)
$$


Where:

$$
\begin{aligned}
& \mathrm{C}_{(\mathrm{x}, \mathrm{t})}=\text { concentration of chlorides at distance } \mathrm{x} \text { and time } \mathrm{t},(\% \text { mass of concrete }) \text {; } \\
& \mathrm{C}_{0}=\text { concentration of chlorides at } \mathrm{x}=0, \mathrm{t}>0 \text {, i.e. the chloride surface } \\
& \text { concentration, ( } \% \text { mass of concrete); } \\
& \text { erf = error function; } \\
& \mathrm{D}_{\mathrm{a}} \quad=\quad \text { the apparent diffusion coefficient }\left(\mathrm{m}^{2} / \mathrm{s}\right),(\mathrm{McGrath}, 1996) \text {. }
\end{aligned}
$$

Values for the surface concentration and apparent diffusion coefficient are obtained through the best fit between the Crank's solution, and the actual chloride concentration profile determined in the concrete sample. Since the underlying assumption with this test is that diffusion solely governs chloride transport, certain steps are usually taken in an attempt to approximate exposure conditions to the model.

When analyzing field drilled cores, the first few millimeters of the core have to be discarded. The chloride concentration in this portion of the concrete structure tends to be too high due to wetting and drying cycles and chloride binding, so it often does not fit the model.

For laboratory testing, concrete samples are first sealed leaving just one face open to ensure a one-dimensional diffusion. Samples also need to be saturated in order to isolate diffusion as the predominant transport mechanism during the test. Then, they are exposed to a salt solution of a known chloride concentration for a predetermined period of time. A chloride concentration profile is obtained by collecting powder samples at different depths of the specimen with their subsequent acid digestion, filtering, and potentiometric titration. The influence of the background chloride concentration (chlorides present in the original concrete constituents) is eliminated by subtracting it from the measured profile.

The most important advantage of the chloride bulk diffusion test is its applicability to 
in-situ concrete structures. In addition, diffusion coefficients can aid in the comparison among different types of concrete and exposure histories.

As with any other model, the chloride ponding test has a number of limitations due to simplifying assumptions that were made to find a solution to Fick's second law. These include:

- $\quad$ linear binding capacity;

- concrete porosity is constant with time;

- diffusion coefficient is independent of the salt concentration (Francois et al., 1998).

The output of the test is also sensitive to the type of cation used in the ponding solution, for example, sodium chloride versus caicium chloride (Bentur et al., 1997). A detailed review of the test limitations and test variables, as well as their effect on the diffusion coefficient, can be found elsewhere (McGrath, 1996).

\subsubsection{Chloride Diffusion Cell}

An alternative method that allows calculation of the chloride diffusion coefficient is a conventional diffusion cell (Figure 2.3). It involves placing a thin concrete sample between two cell compartments, one of which is filled with a salt solution, and the other with a neutral solution (solution free of chloride ions). The two compartments are called upstream and downstream respectively. Saturated calcium hydroxide or alkali hydroxide solutions are normally used as a downstream solution to avoid lime leaching from the concrete (Buenfeld and Newman, 1987).

The gradient between upstream and downstream chloride concentrations becomes the driving force for diffusion. The chloride diffusion coefficient can be derived from Fick's first 


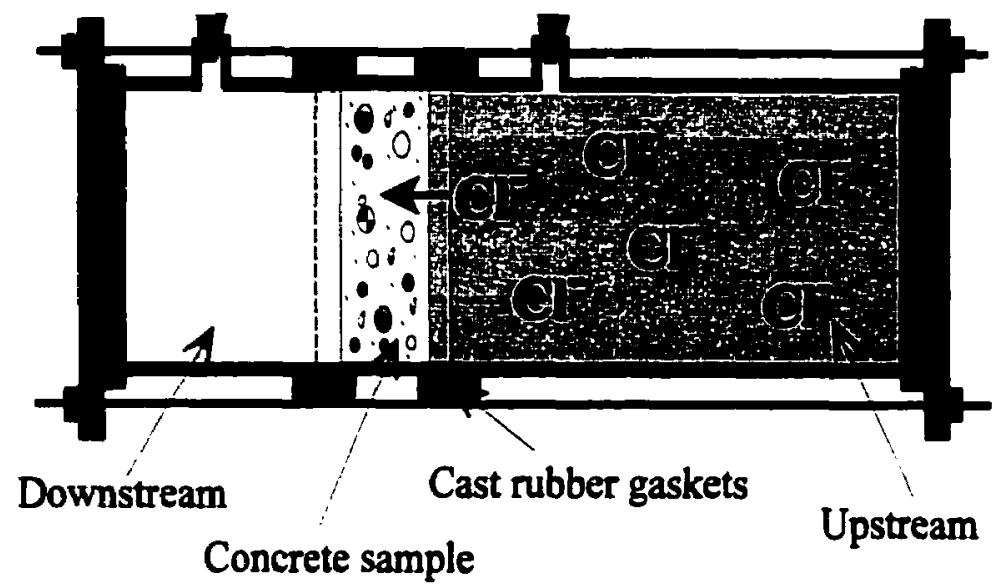

Figure 2.3 Chloride Diffusion Cell.

law for steady-state diffusion (Nilsson, 1993):

$$
J=-D_{e} \frac{\partial C}{\partial x}
$$

Hence,

$$
D_{e}=\frac{J \cdot x}{C_{u}-C_{d}}
$$

Where:

$$
\begin{array}{lll}
\mathrm{J} & = & \text { flow of chloride ions, }\left(\text { mole } / \mathrm{s}^{*} \mathrm{~m}^{2}\right) ; \\
\mathrm{D}_{\mathrm{e}} & = & \text { chloride effective diffusion coefficient, }\left(\mathrm{m}^{2} / \mathrm{s}\right) ; \\
\mathrm{x} & = & \text { thickness of the specimen, }(\mathrm{m}) ; \\
\mathrm{C}_{\mathrm{u}}, \mathrm{C}_{\mathrm{d}}= & \text { respective upstream and downstream chloride concentration, }\left(\mathrm{mole} / \mathrm{m}^{3}\right) .
\end{array}
$$

In order to apply Fick's first law, the concentration gradient is supposed to remain 
constant throughout the experiment. This is hard to accomplish in reality, therefore, the use of relatively large compartments, where changes in chloride concentrations are negligibly small compared to their volume, is a practical solution to this problem (Marchand et al., 1989). The flow of chlorides through the sample is monitored by measuring the concentration of the downstream solution at various diffusion times. As chlorides start propagating towards the downstream compartment, it takes some time for the diffusion to reach a steady state, which is characterized by a linear increase in the chloride concentration of the downstream solution with time. At this point, not only the entire thickness of the sample has been involved in the diffusion, but all the chloride binding capacity of the sample has been satisfied, as well (Page et al., 1981).

The chloride diffusion coefficient obtained from this test is termed effective and differs in relation to the apparent diffusion coefficient derived from unsteady-state tests as it does not take into account the influence of ion binding on diffusion.

The advantages of using a diffusion cell to quantify the ingress of chlorides into the concrete are its simplicity and good reproducibility of the results. The biggest drawbacks of the test are that, firstly, it is extremely time-consuming (it takes a long time for chlorides to break through a concrete sample) and, secondly, it is not applicable to testing concrete in-situ.

\subsubsection{Scanning Electron Microscopy Combined with Energy Dispersive X-Ray Analysis}

The scanning electron microscope (SEM) is an instrument that can provide both topographic and compositional analysis of a material. Its characteristic features are the enhanced resolution, high magnification, and three-dimensional appearance of the texture surfaces. In scanning electron microscopy an electron beam is used to excite the surface of the sample under 
investigation, causing complex interactions between the beam and the atoms of the sample's surface. As a result of these interactions, various types of radiation are produced by the atoms of the material. Each type of the emitted radiation is analyzed with corresponding electron detectors (e.g.: secondary and back-scattered electron detectors).

Most conventional SEM's are equipped with energy-dispersive spectroscopes, that detect $\mathrm{x}$-rays emitted by the sample during the electron-beam excitation. X-rays emitted by each element possess their own characteristic energy, which is measured by the energy-dispersive spectroscope and applied for the element identification. All elements of the periodic table starting from sodium and heavier can be detected using energy-dispersive $\mathrm{x}$-ray analysis (EDX)

The output appears as a spectrum that displays energy peaks of all the elements detected in the material. The obtained $x$-ray energies are matched with the known characteristic energies of chemical elements. The quantitative analysis is performed based on the fact that the intensity of the emitted radiation is proportional to the concentration of the element. A detailed treatment of this subject can be found in specialized literature sources (Goldstein et al., 1981; Gabriel, 1985).

Scanning electron microscopy has many applications in concrete materials science. In particular, SEM/EDX has been used for studying chloride penetration into concrete by several authors (Denes and Buck, 1987; Thaulow and Grelk, 1993). SEM/EDX analysis provides a great benefit over other methods in that it allows to study the distribution of chlorides on a microscopic level. Chlorine $\mathrm{x}$-ray mapping aids in visualizing chloride penetration around cracks and in the interfacial-transition zone between aggregates and cement paste, as well as any other macroscopical dispersion of chlorides that is not possible to detect with other tests. The 
quantitative analysis complements the picture by accurate values of chlorine concentration.

One of the limitations of the SEM/EDX analysis is its inability to identify the ionic state of the element. It only measures the total chlorine content in the sample. Another disadvantage is associated with the low sensitivity to small concentrations. The specimen emits noncharacteristic $\mathrm{x}$-rays that appear as a background. Small concentrations of the element, especially light elements, such as chlorine, can be lost in this background.

The preparation of the samples for SEM investigation is a laborious procedure that can induce potential errors in determination of the chlorine concentration. Chloride movement may occur while the sample is subjected to drying, which leads to distortion of the original chloride distribution. Chlorides can also be partially washed out by the lubricant used during sample cutting. In addition, chlorine in the cutting lubricant or epoxy applied to the concrete to stabilize its structure may contaminate the sample and result in higher chlorine concentrations.

Despite of discussed limitations, SEM/EDX analysis is a powerful tool that can be used in studying chloride ingress into concrete, provided proper care is taken to minimize the impact of sample preparation. 


\section{ChaPTER 3 EXPERIMENTAL}

\subsection{Overview}

Four different studies were conducted to investigate the effect of cracks on chloride ingress into concrete. Two types of cracks, with saw cut 'smooth' surfaces and fractured 'rough' surfaces, having widths ranging from 0.06 to $0.74 \mathrm{~mm}$ were artificially created. A chloride bulk diffusion test was performed to reveal the influence of crack width and crack surface roughness on the chloride diffusion coefficient in concrete. SEM/EDX analysis focused on comparing chloride concentration profiles measured laterally from different points of the crack wall towards the bulk of the sample. A chloride diffusion cell was used to back calculate the surface area of the crack and relate it to the crack width obtained with the aid of an optical microscope. The final work was carried out to examine the relationship between chloride penetration depth and exposure time for both cracked and uncracked concretes.

\subsection{Sample Preparation}

\subsubsection{Materials, Mix Design and Casting}

Ordinary Portland cement and ground pelletized blast furnace slag were used as cementitious materials in this project. Physical and chemical properties of these materials are given in Table 3.1. Stone of two nominal sizes, 10 and $20 \mathrm{~mm}$, and concrete sand were used as coarse and fine aggregate respectively. Table 3.2 summarizes the details of all raw materials, including absorption values for the aggregates.

\section{Infuence of Cracks on Chloride Ingress into Concrete}


Table 3.1 Physical and Chemical Properties of Cementitious Materials.

\begin{tabular}{|c|c|c|}
\hline & Portland Cement T10 & Slag \\
\hline \multicolumn{3}{|l|}{ Physical Properties } \\
\hline Density, $\left(\mathrm{kg} / \mathrm{m}^{3}\right)$ & 3140 & 2866 \\
\hline $\begin{array}{l}\text { Blaine Fineness, } \\
\qquad\left(\mathrm{m}^{2} / \mathrm{kg}\right)\end{array}$ & 391 & - \\
\hline \multicolumn{3}{|c|}{ Chemical Analysis, (\% by mass) } \\
\hline $\mathrm{SiO}_{2}$ & 20.90 & 37.78 \\
\hline $\mathrm{Al}_{2} \mathrm{O}_{3}$ & 4.92 & 9.41 \\
\hline $\mathrm{TiO}_{2}$ & 0.26 & 0.41 \\
\hline $\mathrm{P}_{2} \mathrm{O}_{5}$ & 0.04 & 0.00 \\
\hline $\mathrm{Fe}_{2} \mathrm{O}_{3}$ & 2.31 & 1.30 \\
\hline $\mathrm{CaO}$ & 62.80 & 36.35 \\
\hline $\mathrm{SrO}$ & 0.05 & N/A \\
\hline $\mathrm{MgO}$ & 2.32 & 10.29 \\
\hline $\mathrm{Mn}_{2} \mathrm{O}_{3}$ & 0.02 & N/A \\
\hline $\mathrm{Na}_{2} \mathrm{O}$ & 0.22 & 0.28 \\
\hline $\mathrm{K}_{2} \mathrm{O}$ & 0.46 & 0.32 \\
\hline $\mathrm{SO}_{3}$ & 2.79 & $3.35^{*}$ \\
\hline LOI & 2.88 & N/A \\
\hline Other & - & 1.84 \\
\hline Total & 99.97 & 101.33 \\
\hline
\end{tabular}

* Present as sulfides, but expressed as $\mathrm{SO}_{3}$. 
Table 3.2 Raw Materials.

\begin{tabular}{|c|c|c|}
\hline Material & Source & Comments \\
\hline Portland Cement & Lafarge, Woodstock & Type 10 - CSA AS \\
\hline Slag & Lafarge, Stoney Creek & Type G - CSA A23.5 \\
\hline $\begin{array}{l}\text { Coarse Aggregate, } \\
10 \mathrm{~mm}\end{array}$ & $\begin{array}{l}\text { Dufferin Aggregates, } \\
\text { Milton Quarry }\end{array}$ & CSA A23.1, Absorption - $1.70 \%$ \\
\hline $\begin{array}{l}\text { Coarse Aggregate, } \\
20 \mathrm{~mm}\end{array}$ & $\begin{array}{l}\text { Dufferin Aggregates, } \\
\text { Milton Quarry }\end{array}$ & CSA A23.1, Absorption - $1.80 \%$ \\
\hline Fine Aggregate & $\begin{array}{l}\text { Dufferin Aggregates, } \\
\text { Mosport Pit }\end{array}$ & CSA A23.1, Absorption - $0.53 \%$ \\
\hline Water & Tap Water & \\
\hline Water Reducer & Master Builders, $25 \mathrm{XI}$ & Lignosulphonate based \\
\hline Superplasticizer & Master Builders, SPN & $\begin{array}{l}\text { Sodium naphthalene } \\
\text { formaldehyde condensate }\end{array}$ \\
\hline
\end{tabular}

Two different concrete mix designs chosen for this project are described in Table 3.3. Both mixes have a water to cementitious materials ratio of 0.40 . The first mix contains only ordinary Portland cement as the cementitious material, the second mix has a $25 \%$ replacement of cement by blast furnace slag.

A few days prior to casting, coarse aggregate was washed with water to remove fine dust particles adhering to its surface that could impair the bonding between aggregate and cement paste. The aggregate was allowed to partially air dry on the metal pans that were slightly inclined causing the excess water to drain down. Then, it was batched in sealed buckets until casting. The moisture content of both fine and coarse aggregates was measured just before 
Table 3.3 Mix Designs.

\begin{tabular}{|l|c|c|}
\hline Material & 0.4, OPC & $0.4,25 S L$ \\
\hline Portland Cement, $\left(\mathrm{kg} / \mathrm{m}^{3}\right)$ & 375.00 & 281.3 \\
\hline $\mathrm{Slag},\left(\mathrm{kg} / \mathrm{m}^{3}\right)$ & 0.00 & 93.80 \\
\hline Coarse Aggregate, $20 \mathrm{~mm},\left(\mathrm{~kg} / \mathrm{m}^{3}\right)$ & 739.39 & 736.92 \\
\hline Coarse Aggregate, $10 \mathrm{~mm},\left(\mathrm{~kg} / \mathrm{m}^{3}\right)$ & 369.70 & 368.46 \\
\hline Fine Aggregate, $\left(\mathrm{kg} / \mathrm{m}^{3}\right)$ & 739.39 & 736.92 \\
\hline Water, $\left(\mathrm{kg} / \mathrm{m}^{3}\right)$ & 150.00 & 150.00 \\
\hline Water Reducer, $(\mathrm{g} / 100 \mathrm{~kg})$ & 77.60 & 39.60 \\
\hline Superplasticizer, $(\mathrm{g} / 100 \mathrm{~kg})$ & 95.00 & 71.40 \\
\hline
\end{tabular}

batching, and the amount of mix water was adjusted accordingly.

One batch of 38 liters was cast per mix. The water reducing admixture was pre-blended with the mix water. The materials were added into the flat pan concrete mixer in the following sequence: stone, cement, slag (for slag containing mix), sand, and water. Three minutes of mixing were followed by a two minute pause, three minutes of mixing, two minute pause and, again, one minute of mixing. One half of the superplasticizer was added after 1.5 minutes of mixing, while the other half was added during the second part of the mixing cycle. At the end of mixing, a slump test was performed to check the intended slump of between 150 and $200 \mathrm{~mm}$. Since the measured slump appeared to be satisfactory, the fresh concrete mixture was deemed ready for casting. The portion of the mix used for the slump test was replaced in the pan for one more minute of mixing.

\section{Influence of Cracks on Chloride Ingress into Concrete}


Twenty 100 by $200 \mathrm{~mm}$ concrete cylinders were cast per mix and placed under water soaked burlap for initial curing. Plastic film was used to cover the burlap. After 24 hours, the concrete cylinders were demolded, labeled, and placed for subsequent curing in containers filled with lime water at $23^{\circ} \mathrm{C}$. Keeping the samples in saturated lime water prevents lime from leaching out of the concrete. Saturated lime water can be obtained by dissolving $1.5 \mathrm{~g}$ or more of $\mathrm{Ca}(\mathrm{OH})_{2}$ in one liter of tap water.

To prevent carbonation, concrete samples were stored in lime water until testing, for a total of five months.

\subsubsection{Creation of Artificial Cracks}

Single artificial cracks were the focus of this project for the most part, since studying a unique crack allows to better concentrate on specific characteristics of the crack and investigate the penetration of chlorides through it. As more knowledge is acquired on the influence of a single crack on chloride transport, the problem can be extended to the case of multiple cracks or several sets of cracks. Samples containing two cracks were produced for the last study, where the relationship between chloride penetration depth and exposure time was examined.

To uncover the effect of surface roughness on chloride ingress, two types of cracks, smooth and rough surface cracks, were made using different procedures.

\subsubsection{Smooth Crack Samples}

Single and double smooth crack samples were produced by saw cutting the concrete cylinders longitudinally into two (or three for double crack samples) equal width parts. The inner 
cut surfaces of the cylinders were ground on a Van Norman milling machine to achieve an even surface and allow better control of the crack width. The cracks were created by clamping the cut cylinder parts back together and using brass shims of various thicknesses at the edges to keep the gap open. The target crack widths were about $0.1,0.3$, and $0.5 \mathrm{~mm}$, which correspond to the range of tolerable crack widths presented in the ACI manual of concrete practice (ACI 224R90). The crack width of samples containing two cracks were limited to one size only, namely 0.1 $\mathrm{mm}$. Metal automotive feeler gauges were used to measure the width of the gap, and adjustments were made by either reducing or increasing the clamp pressure.

When the desired width of the opening was achieved, a layer of grey paste epoxy (Cappar Caprock EX Grey) was applied on the surface all around the cylinder to seal the gap. Care was taken not to push the epoxy inside the gap. After allowing 24 hours for the grey epoxy to cure, a $5 \mathrm{~mm}$ thick layer of clear epoxy was cast around the circumference of the cylinder using metal molds. Once completely cured (in about 24 hours), the clear epoxy sealed the annulus securely stabilizing the cut parts of the concrete cylinder and the gap between them. Application of the grey epoxy serves two important purposes. Firstly, it gives an initial stability to the cracked cylinder firm enough to allow release of the clamp and transfer of the cylinder into the clear epoxy mold without disturbing it. Secondly, the layer of grey epoxy prevents fresh clear epoxy that has a very low viscosity from sealing up the crack.

After demolding, the ends of the cylinder, with shims inside, were cut off and discarded. The remainder of the concrete cylinder was then cut into $40 \mathrm{~mm}$ thick discs. Figure 3.1 schematically represents the obtained single and double smooth crack samples. 

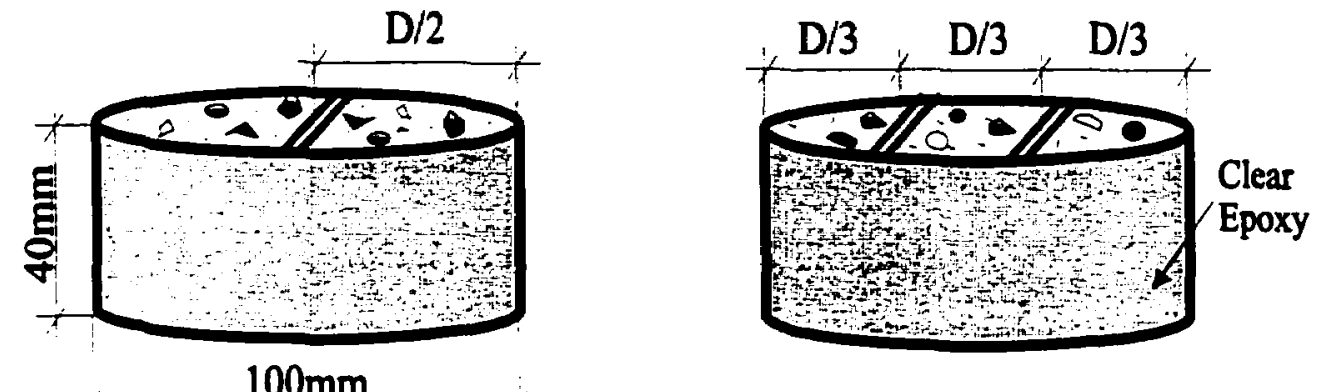

Figure 3.1 Concrete Samples Containing One and Two Smooth Cracks.

\subsubsection{Rough Crack Samples}

For fabricating single rough crack samples (no double rough crack samples were produced), a few millimeters from each edge of the concrete cylinder were cut off, because of their higher cement paste content. The rest of the cylinder was saw cut into smaller $100 \mathrm{~mm}$ in diameter by $60 \mathrm{~mm}$ thick cylinders. Then, each 'mini'-cylinder was placed between the loading platens of the hydraulic Carver laboratory press and compressed until it split open across the vertical diametral plane (Figure 3.2). A knife edge on the upper platen of the machine was used to concentrate the load along the axis of the cylinder. As a result, the concrete cylinders underwent clean splits without any bulk loss. The split surface of the cylinder was a reasonable simulation of real crack walls, that are never smooth or tortuosity free.

From this point, the procedure for making rough crack samples was very similar to that for smooth crack samples with some exceptions. Brass shims had to be replaced by aluminum foil, as the latter had the required flexibility to take the shape of the rough crack surface. Different numbers of aluminum foil layers were used to create various crack widths. After 


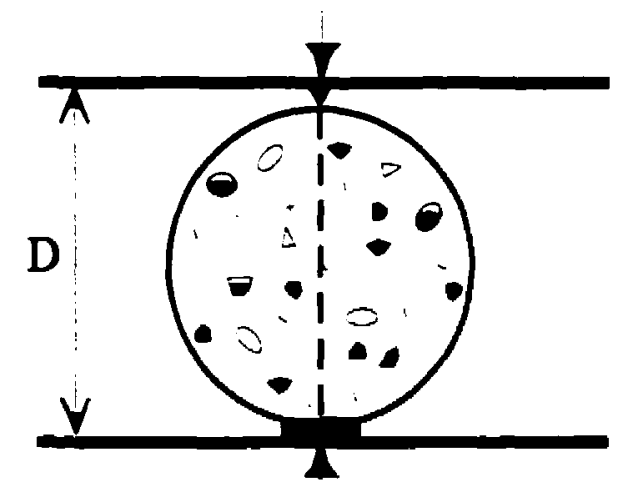

Figure 3.2 Arrangement for the Concrete Cylinder Splitting.

discarding the edges of the cylinder containing the aluminum foil, only one 100 by $40 \mathrm{~mm}$ sample could be obtained per 'mini' cylinder.

\subsubsection{Measurement of Crack Width}

An Olympus BH-2 optical microscope was used to measure the attained crack widths at 4 times magnification. Five readings were taken along the crack and averaged on each side of the concrete disc. The mean of the averages from two sides was considered to be a measured crack width. Standard deviation was also calculated for each sample side and averaged per sample. The microscope was equipped with an Olympus C-35AP-4 camera that enabled picture taking of smooth and rough cracks, as well as cracks of different widths.

\subsubsection{Sample Identification}

For easy identification, all samples were labeled according to their characteristic features 
and intended testing. The first letter of the label indicates the mix design, i.e. ' $\mathrm{P}$ ' for $100 \%$ Portland cement mix, and 'S' for $25 \%$ slag replacement mix. The second letter of the label shows whether the sample contains smooth (S) surface, rough (R) surface, or no $(N)$ cracks. When there is no number in between the first two letters of the label, it means that this sample either has one or no crack. Samples containing two cracks have a digit 2 right after the mix design letter. Cracked samples have an indication of the projected crack width following the type of crack description letter. Since three crack widths, $0.1,0.3$, and $0.5 \mathrm{~mm}$, were produced for this project, the corresponding digits on the labels are 1,3 , and 5 . The next letter defines the test to which the sample has been exposed: $\mathrm{P}$ - ponding or bulk diffusion test, $\mathrm{D}$ - diffusion cell. The last digit is a sequential number among companion samples.

For example, P2SIP2 is a $100 \%$ Portland cement mix sample with two smooth cracks of $0.1 \mathrm{~mm}$ projected width, which has been exposed to chloride ponding. SNDI is a sample from $25 \%$ slag replacement mixture with no crack, which was subjected to the chloride diffusion cell.

\subsubsection{Outline of Experimental Program}

Table 3.4 gives an outline of the entire experimental program. The number of samples per test is listed taking into account just one mix design. It should be noted that SEM/EDX analysis was performed on two specimens taken from one of the rough crack samples of only the slag containing concrete. The rest of the experimental program was identical for both concretes. 
Table 3.4 Experimental Program

\begin{tabular}{|c|c|c|c|c|c|}
\hline & & \multicolumn{4}{|c|}{ Test } \\
\hline \multicolumn{2}{|c|}{$\begin{array}{l}\text { Number of Samples } \\
\text { Containing: }\end{array}$} & $\begin{array}{c}\text { 40-Day } \mathrm{Cl}^{-} \\
\text {Bulk Diffusion } \\
\text { Test }\end{array}$ & $\begin{array}{l}\text { SEM/EDX } \\
\mathrm{Cl}^{-} \text {Profiling }\end{array}$ & $\begin{array}{c}\mathrm{Cl}^{-} \\
\text {Diffusion } \\
\text { Cell }\end{array}$ & $\begin{array}{l}\mathrm{Cl}^{-} \text {Ponding for } \\
3 \text { Different } \\
\text { Times (Depth of } \\
\mathrm{Cl}^{-} \text {Penetration } \\
\text { vs Time) }\end{array}$ \\
\hline \multicolumn{2}{|c|}{ No Crack } & 4 & - & - & 6 \\
\hline \multirow{3}{*}{$\begin{array}{c}\text { Single } \\
\text { Smooth } \\
\text { Crack with } \\
\text { Width at }\end{array}$} & $0.1 \mathrm{~mm}$ & 2 & - & 2 & 6 \\
\hline & $0.3 \mathrm{~mm}$ & 2 & - & 2 & - \\
\hline & $0.5 \mathrm{~mm}$ & 2 & - & 2 & - \\
\hline \multirow{3}{*}{$\begin{array}{c}\text { Single } \\
\text { Rough } \\
\text { Crack with } \\
\text { Width at }\end{array}$} & $0.1 \mathrm{~mm}$ & 2 & - & - & - \\
\hline & $0.3 \mathrm{~mm}$ & 2 & $\begin{array}{l}2 / \text { slag mix } \\
\text { only }\end{array}$ & $\cdot$ & - \\
\hline & $0.5 \mathrm{~mm}$ & 2 & - & - & - \\
\hline \multicolumn{2}{|c|}{$\begin{array}{l}\text { Two, } 0.1 \mathrm{~mm} \text {, } \\
\text { Smooth Cracks }\end{array}$} & - & - & - & 6 \\
\hline \multicolumn{2}{|c|}{ Total/Test/Each Mix } & 16 & 2 & 6 & 18 \\
\hline \multicolumn{2}{|c|}{ Total for the Project } & \multicolumn{4}{|c|}{82} \\
\hline
\end{tabular}




\subsection{Chloride Bulk Diffusion Test}

Single smooth and rough crack concrete samples with three different crack widths were subjected to the chioride bulk diffusion test. Two companion samples were tested for each crack type and size. Four uncracked samples per mix were also tested for comparison purposes.

\subsubsection{Sample Preparation and Exposure}

Concrete samples were sealed on all sides except one (clear epoxy around the circumference and grey epoxy on one tace) to ensure that the diffusion takes place only in one direction. In addition, to investigate the lateral diffusion of chlorides from the walls of the crack into the concrete, one half of the exposed face of the samples was sealed with grey epoxy as well. The experimental details for two companion cracked samples and one uncracked sample are presented in Figure 3.3.

Prior to the experiment, all samples were vacuum saturated with lime water (ASTM C1202-97 conditioning procedure). The procedure of vacuum saturation began with three hours of vacuuming the concrete samples and de-airing the lime water in separate desiccators. Then, lime water was allowed into the desiccator containing the samples under vacuum until they were completely immersed. Vacuum saturation lasted for one and a half hours, after which the vacuum was released, and concrete samples were left in water for eighteen more hours.

The chloride ponding solution had a concentration of $2.82 \mathrm{~mol} / \mathrm{l}$ and was obtained by dissolving $165 \mathrm{~g}$ of dry $\mathrm{NaCl}$ in one liter of solution. This is the chloride concentration used in the NORDTEST NTBUILD 443 bulk diffusion test. Vacuum saturated, surface dry concrete 

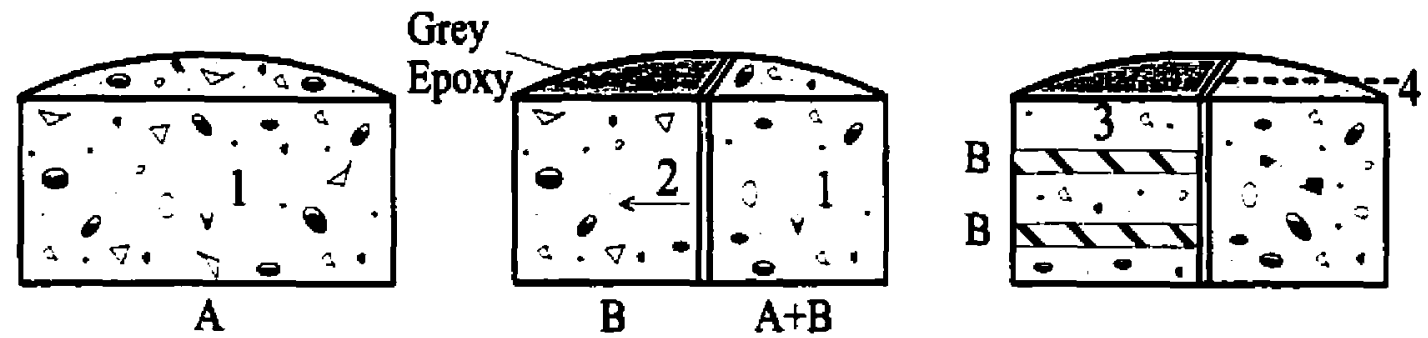

1 - grinding with depth

2 - grinding laterally from the crack

$\leftarrow$ - direction of profile grinding

3 - SEM/EDX analysis

A - profile with depth

4 - spraying with $\mathrm{AgNO}_{3}$

$B$ - lateral profile

$A+B$ - combined profile

Figure 3.3 Chloride Bulk Diffusion Test - Experimental Details.

samples were placed into plastic containers completely filled with the chloride solution and tightly covered with lids. The ratio of the exposed area of the samples in $\mathrm{cm}^{2}$ to the volume of exposure liquid in $\mathrm{dm}^{3}$ was 30 . The duration of the test was 40 days at $23{ }^{\circ} \mathrm{C}$ and it was kept constant for all the samples. During this time, the containers were shaken approximately once a week.

\subsubsection{Experimental Details}

Upon completion of salt exposure, the concrete samples were removed from the containers, wiped with paper towels and sealed into plastic bags. Since it would have been practically impossible to perform all the planned testing right after the end of the chloride exposure, it was of primary importance to prevent any movement of the chlorides within the 
samples until further testing. This was achieved by freezing the samples.

Two out of four uncracked samples were used for determining the depth of chloride penetration, and the remaining two were used for measuring the apparent chloride diffusion coefficient of uncracked concrete. The chloride penetration depth was measured by spraying the freshly split concrete sample surface with a $0.1 \mathrm{~N}$ solution of silver nitrate $\left(\mathrm{AgNO}_{3}\right)$ and observing a white-purple precipitation of silver chloride on the area penetrated by chloride ions. The measured depth was used as a guideline for determining the depth of profile grinding.

Two companion cracked samples were tested in four different ways (Figure 3.3). Clear and grey epoxies that held the sample together were broken along the crack of each sample resulting in four pieces available for testing. Two of them were subjected to chloride diffusion only from the crack wall, and two others - to combined diffusion from both the face of the sample and the crack wall. In Figure 3.3 arrows show the direction of the profile grinding that was conducted to determine the diffusion coefficient. Letters indicate which type of diffusion was measured through the profile grinding.

The chloride diffusion with depth or vertical diffusion was characterized from grinding the uncracked sample (A). The diffusion from the wall of the crack or lateral diffusion was measured by grinding the cracked sample (B). To uncover whether the lateral chloride diffusion was uniform along the length of the crack, two small pieces at two different depths of the slag concrete sample containing the $0.3 \mathrm{~mm}$ rough crack were cut for SEM/EDX examination.

The combined or two dimensional diffusion was quantified by vertical profile grinding (A+B). The last available half of the concrete sample was sprayed with silver nitrate to determine the depth and shape of chloride penetration for 2D diffusion. 


\subsubsection{Obtaining the Chloride Concentration Profile}

For profile grinding the epoxy cover was removed from the concrete using a chisel. The sample was, then, mounted on the Van Norman milling machine and leveled. Powder samples were produced by grinding off $0.75 \mathrm{~mm}$ layers with the aid of a $47.7 \mathrm{~mm}$ diameter diamond core bit. Sometimes, the thickness of the layers were varied depending on the surface area available to collect the required amount of powder. Some of the layers were discarded, as only 6 to 8 points are sufficient to produce a diffusion curve. Throughout the whole process care was taken to prevent contamination of the powder samples either from the previously ground layers or from any other sources.

The powder samples were collected in $60 \mathrm{ml}$ glass bottles and dried in the oven at $110^{\circ} \mathrm{C}$ for at least 24 hours. Hot powder samples were, first, allowed to cool down in the desiccator, and then, sieved through a $315 \mu \mathrm{m}$ sieve to retain any larger pieces of concrete (chips from sides of the cylinders). Approximately $2 \mathrm{~g}$ of powder was weighed in a $200 \mathrm{ml}$ beaker and digested with nitric acid. The nitric acid digestion involved combining $35 \mathrm{ml}$ of distilled water and $7 \mathrm{ml}$ of $1: 1$ water diluted nitric acid with the powder sample. For the mixture containing slag a few drops of hydrogen peroxide were also added to oxidize the sulfides, which interfere with chloride analysis. The solution was stirred for ten seconds to promote the reaction, allowed to stand for four minutes, and then, briefly brought to a boil.

The digested samples were set aside until they cooled down and were ready for filtering. The filtering set up consisted of $250 \mathrm{ml}$ glass filter flasks, $90 \mathrm{~mm}$ plastic Buchner filter funnels, and medium grade filter paper. Initially, the vacuum was tumed on and distilled water was sprinkled onto the filter paper, so as to tightly attach it to the funnel. Then, the digested sample 
solution was slowly poured onto the funnel and allowed to be sucked into the flask. The residue of the sample solution was rinsed out of the beaker onto the funnel with distilled water. The filtered solution from the flask was poured back into the beaker, and the remains, again, were rinsed into the beaker with distilled water.

It should be pointed out that during the whole procedure of chloride analysis, extra care was taken to minimize the impact of the procedure on the original concentration of chlorides in the powder sample. This included keeping all the glassware clean and preventing any loss of the analyzed sample due to handling.

The obtained solution was analyzed for the total chloride content by means of potentiometric titration. A Metrohm DMS 760 automatic titrator and $0.01 \mathrm{~mol} / \mathrm{l}$ silver nitrate as the titrating liquid were used. Sub-samples of the filtered solution were weighed in $100 \mathrm{ml}$ beakers. The size of the sub-samples was varied according to the magnitude of the expected chloride concentration. The general rule for the sample size selection was to keep the amount of titrant dispensed during the titration in a range between 2 and $6 \mathrm{ml}$. When the amount of the titrating liquid used was less than $2 \mathrm{ml}$, the obtained chloride concentration was disregarded as statistically inaccurate. On the other hand, the use of large amounts of titrant leads to its unnecessary waste, as well as to a longer time required for the process.

Knowing the mass of the original powder sample, large beaker, filtered solution, and subsample, the mass of the concrete powder present in the sub-sample was calculated. The chloride concentration in parts per million (ppm) was measured by the titrator. The chloride concentration profile was obtained by plotting the total chloride content expressed by mass of concrete versus depth. The lowest chloride concentration in each profile (except for the results 
obtained with less than $2 \mathrm{ml}$ of titrant) was considered to be the background. The background concentration was subtracted from all the data points prior to plotting the profile.

\subsubsection{Calculation of the Diffusion Coefficient}

The apparent chloride diffusion coefficient was calculated from Equation 2-2 using two different software packages. Jandell-Table Curve allows to obtain values of both the diffusion coefficient and the surface concentration through the best fit of Crank's solution to the experimental data points. The highest value of a correlation coefficient, $r$, gives an indication of the best fit.

The second software package is called Conflux, a finite-difference analysis program developed by Profs. E. Bentz and M.D.A. Thomas at the University of Toronto. It requires input of the value of the surface concentration before the calculation of the diffusion coefficient can be performed. Since the chloride surface concentration can be assumed to be constant for the same concrete and exposure conditions, it can be theoretically calculated based on the porosity of concrete and the amount of bound chlorides. The best fit curve generated by the program intersects this theoretical value of the surface concentration, and the diffusion coefficient is calculated.

The chloride surface concentration was calculated as a sum of both the concentration of free chlorides in the concrete pore solution and that of bound chlorides. The concentration of free chlorides was calculated based on the assumption that the concrete pores were filled with the exposure sait solution of known concentration. The porosity of concrete was estimated using the following expression: 


$$
P=\frac{m_{s s d}-m_{d}}{m_{\text {ssd }}-m_{\text {susp }}} * 100 \%
$$

Where:

$$
\begin{array}{lll}
\mathrm{P} & = & \text { water porosity of concrete, }(\%) ; \\
\mathrm{m}_{\mathrm{ssd}}= & \text { mass of water saturated surface dry concrete, }(\mathrm{g}) ; \\
\mathrm{m}_{\mathrm{d}}= & \text { mass of concrete dried at } 100^{\circ} \mathrm{C},(\mathrm{g}) ; \\
\mathrm{m}_{\text {susp }}= & \text { mass of concrete suspended in water, }(\mathrm{g}) .
\end{array}
$$

The concentration of bound chlorides was estimated from experimental studies conducted on concretes of similar composition by $\mathrm{H}$. Zibara at The University of Toronto (Zibara, 2001). The amount of bound chlorides for the $100 \%$ Portland cement concrete was approximated at $15.5 \mathrm{mg}$ per gram of cementitious materials, and for the slag containing concrete - $18 \mathrm{mg}$ per gram of cementitious materials. 


\subsection{SEM/EDX Chloride Profling}

In order to investigate whether the lateral diffusion of chlorides from the crack wall into the bulk of the concrete sample was uniform along the length of the crack, SEM/EDX chloride concentration profiling was performed on two sections taken from the same chloride bulk diffusion sample at two different depths.

Two $10 \mathrm{~mm}$ slices were cut from the slag concrete sample (SR3P2) containing the 0.32 $\mathrm{mm}$ wide, rough crack 5 and $20 \mathrm{~mm}$ away from the disc surface (Fig. 3.3). They were labeled SR31 and SR32 respectively. No lubricant was used during the cutting, so as to avoid the washout of chlorides from the concrete surface to be examined. The sample preparation procedure included vacuum impregnation with epoxy, polishing, and sputter coating with platinum. Prior to testing, samples were stored in the desiccator containing silica gel. For the microscopical examination the polished sample was fixed on the specimen stub with a two side adhesive conductive tape. A silver paint was applied to the sample and the stub to assure good conductivity. To remove dust or any other adhering particles from the sample surface, compressed air was applied.

A Hitachi model S-4500 field emission SEM was used for the chloride X-ray mapping. It was conducted on an area of approximately 1.5 by $2.8 \mathrm{~mm}$ at the free (chloride exposed) edge of sample SR31 at 40 times magnification. The operating conditions included the following characteristics: accelerating voitage of $20 \mathrm{kV}$, probe current of $20 \mu \mathrm{A}$, and $13 \mathrm{~mm}$ working distance. The duration of the mapping was limited to 151 frames, which took about half an hour to complete. This number of frames was considered to be sufficient to obtain a good signal to 
noise ratio within a reasonable period of time. A micrograph of the same area was also taken.

Quantitative analysis was performed on a Hitachi model S-2460N SEM equipped with an Oxford-Link model S-5104 energy dispersive X-ray (EDX) unit. Backscatter electron (BSE) imaging was used for viewing. Chloride concentration profiling was carried out at $20 \mathrm{kV}$ accelerating voltage and $22 \mathrm{~mm}$ working distance. The ZAF corrections were incorporated in the Oxford ISIS software package. Saturation of the filament with subsequent calibration on a cobalt standard was done every hour. The counting rate was kept to about 4000 counts per seconds on cobalt, which corresponded to approximately 30 to $35 \%$ dead time. The acquisition set-up consisted of preset livetime of 50 seconds, fast counting, process time of 4 , and $30 \mathrm{kV}$ upper energy. Every half an hour the probe current was checked on an alite standard, so that in quantified unnormalized results both the element percent and the compound percent add up to 100.

EDX spectra were collected at 2000 times magnification, which resulted in an area of about 58 by $43 \mu \mathrm{m}$ being analyzed. The chloride concentration was measured at seven depths for sample SR31 and at four for sample SR32. It was not possible to finish the profiling for the second sample due to ongoing maintenance of the microscope. The term 'depth' is used in analogy with the depth of grinding for the chloride bulk diffusion test. Ten measurements were taken at each depth, and the average value of the chloride concentration was calculated. The sample was rotated and aligned in a way that permitted precise determination of the depth at which the chloride concentration was measured. Care was taken to analyze only the cement paste area of the sample, and to ensure that the tested areas had similar porosity and phase composition. This was achieved by avoiding the areas containing aggregates and by keeping the 
calcium to silica ratio and the total amount of the compound percent in unnormalized results as consistent as possible.

The Oxford ISIS software allows calculation of atomic percentages for each element present in the cement paste, using stoichiometry to calculate the atomic percentage for oxygen. Knowing the atomic mass of the chemical elements, it is possible to calculate the element percentages by mass of the analyzed area. Expression 3-2 illustrates how this percentage is calculated for chlorine. Since all the measurements were taken in the cement paste areas only, the obtained percentages could be regarded as percentages by mass of cement paste.

$$
\mathrm{C}_{\mathrm{Cl}}=\frac{\mathrm{n}_{\mathrm{Cl}} * \mathrm{~m}_{\mathrm{Cl}}}{\sum_{\mathrm{i}} \mathrm{n}_{\mathrm{i}} * \mathrm{~m}_{\mathrm{i}}} * 100 \%
$$

Where:

$\mathrm{C}_{\mathrm{Cl}}=$ chlorine concentration by mass of the tested area, (\%);

$\mathrm{n}_{\mathrm{Cl}}=$ atomic percentage of chlorine, (\%);

$\mathrm{m}_{\mathrm{Cl}}=$ atomic mass of chlorine;

$n_{i}=$ atomic percentage of i-element, (\%);

$\mathrm{m}_{\mathrm{i}}=$ atomic mass of $\mathrm{i}$-element.

As mentioned in Section 2.5.3, the SEM/EDX analysis only measures the total chlorine content in the sample. However, since chlorine is present in concrete samples, that were subjected to chloride diffusion, mainly in the form of chloride, the chlorine concentration obtained from SEM/EDX analysis will be further referred to as the chloride concentration. 


\subsection{Chloride Diffusion Cell}

The purpose of the chloride diffusion cell test was to measure the flux of chlorides diffusing through the crack and relate it to the measured crack width. Since the width of the smooth crack could be characterized with a higher degree of precision than the width of the rough crack, only concrete samples containing single smooth cracks of different widths were exposed to the test. Concrete samples with two smooth cracks were not included in this testing in order to keep the set-up as simple as possible.

The sample preparation involved the vacuum saturation of concrete with water as described in Section 3.3.1. The experimental apparatus of the chloride diffusion cell is shown in Figure 2.3. Approximate volumes of the upstream and downstream compartments were 1.5 and 0.6 liters respectively. The exact volume of the downstream solution consisting of $0.3 \mathrm{~mol} / 1$ sodium hydroxide $(\mathrm{NaOH})$ solution was measured and used in the calculations. The upstream solution was a mixture of $0.5 \mathrm{~mol} / \mathrm{l}$ sodium chloride $(\mathrm{NaCl})$ and $0.3 \mathrm{~mol} / \mathrm{l}$ sodium hydroxide solutions. The sodium chloride was dried in the oven at $100^{\circ} \mathrm{C}$ before being weighed.

The concrete sample was placed in between the two cell compartments, so that the crack would run horizontally. To avoid any splashing of chlorides through the crack while the cell was filled with the solutions, each compartment was, first, filled just up to the level of the crack, and then, both solutions were poured simultaneously into the two compartments.

At given time intervals, ten milliliter samples of solution were extracted from the downstream compartment into sealed plastic vials. The duration of the experiment was about six months. During the first day of exposure, measurements were taken every few hours. 
Afterward, the frequency of the measurements was reduced from every other day to once a week. To replenish the volume of the sample solution, $10 \mathrm{ml}$ of the $0.3 \mathrm{~mol} / \mathrm{l}$ sodium hydroxide solution was poured back into the downstream compartment after each measurement. The resulting decrease in the chloride downstream concentration was accounted for in calculations.

The samples were titrated promptly to avoid possible evaporation. The downstream chloride concentration was determined using the potentiometric titration outlined in Section 3.3.3. At the beginning of the test, when the chloride concentration was very low, a blank chloride solution or chloride solution of a known concentration was added to the sample. This technique ensured that the concentration of chlorides in the analyzed sample was high enough, so as to provide a statistically accurate result. The concentration of the blank solution was later subtracted from the obtained reading. When the downstream chloride concentration had increased, smaller samples were used for titration. In order to achieve acidity levels favorable for titration, one drop of methyl orange indicator and concentrated nitric acid were added to the sample until it tumed from yellow to pink.

The mass of chlorides passed through the crack was plotted against time. Then, the surface area of the crack was calculated using Fick's first law. 


\subsection{Depth of Chloride Penetration vs Time}

To compare the relationship between depth of chloride penetration and exposure time for uncracked and cracked concrete, samples containing no crack, one smooth $0.1 \mathrm{~mm}$ wide crack, and two smooth $0.1 \mathrm{~mm}$ cracks were subjected to chloride ponding tests of various durations. Instead of determining the diffusion coefficient, in this case, the depth of chloride penetration was measured.

The sample preparation procedure, as well as the experimental set-up were, for the most part, identical to the chloride bulk diffusion test and described in details in Section 3.3.1. Samples were sealed from three sides, leaving one face of the concrete discs compietely open. Then, they were vacuum saturated with water and exposed to the salt solution for three different periods of time. However, the sets of exposure times were not the same for all the samples.

Concrete samples containing no crack or a single crack were tested for 4,16 , and 36 days. Samples with two cracks were exposed for much shorter periods of time $-1,4$, and 7 days. The test duration had to be reduced for these samples, as two intersecting cracks subdivided them into smaller sections of concrete, requiring less time for complete chloride penetration, in which case, the penetration depth would not be possible to measure. Two companion samples were tested per set of experimental variables.

Following chloride exposure, concrete samples were wiped with paper towels and set aside for a short period of time to allow the solution filling the cracks to drip off or evaporate. This step was necessary to ensure that the exposure solution hidden in the cracks would not run onto the freshly split concrete surface, distorting the shape of the chloride front. 
Samples were split across the cracks, and the fractured surface was sprayed with a $0.1 \mathrm{~N}$ solution of silver nitrate. The white-purple band of formed silver chloride represented the front of chloride penetration. The border of the chloride front was highlighted with a black marker, and scan pictures of the sprayed surfaces were taken. Two sets of measurements were taken on the depth of chloride penetration. First, the actual depth of penetration was measured. Then, all the aggregates falling inside the chloride penetrated area of the sample were highlighted, and the magnitude of the chloride front was measured (excluding the areas where aggregates had interfered with it).

For the uncracked samples, only the vertical depth of chloride penetration was measured. In the case of cracked samples, both vertical and lateral (from the crack wall towards the side of the sample) depths were recorded. Measurements were taken with a conventional ruler at approximately every 2 to $3 \mathrm{~mm}$ along the exposed sample surface and the crack walls. Both halves of the split sample were analyzed. The average depth was calculated for each half, then, the mean of depths from the two balves was taken to be the depth of penetration for this particular sample. The final value of chloride penetration depth was obtained by averaging the results from the two companion samples. 


\section{Chapter 4 Results and Discussion}

\subsection{Measurement of Crack Width}

The crack widths $(\mathrm{Cw})$ obtained with the use of the optical microscope as described in Section 3.2.3 are summarized in Appendix A, along with average standard deviations. Measured crack widths range from 0.06 to $0.74 \mathrm{~mm}$ and deviate from the target crack widths on average by $15.9 \%$, with the largest cracks exhibiting the biggest deviation. Nonetheless, the produced crack widths were considered to satisfactorily represent the range designed for this project.

Photographs taken during crack width measurement on the optical microscope are presented in Figure 4.1 as pictures (a) and (b). Picture (a) shows the $100 \%$ Portland cement concrete sample containing a $0.12 \mathrm{~mm}$ smooth crack. At first glance, the edges of the crack seem to be rather rough. This roughness was caused by some damage to the walls of the crack at the exposed surface which resulted from saw cutting the sample. However, while looking deeper into the crack, beyond this surface effect, one can see right through it noticing the light coming from the opposite side. This indicates that the inside part of the crack is fairly smooth and has a constant gap. The width of the crack was obtained by measuring this internal gap, not the space between the outer broken edges of the crack.

The second picture (b) was taken on the slag concrete sample with a $0.32 \mathrm{~mm}$ rough crack. In this case, the tortuous inside walls of the crack block the view through it. It can also be observed that the crack width is less consistent along the sample. For the rough crack samples, the places with the most consistency in crack width were chosen for the measurement. 
(a)

(b)
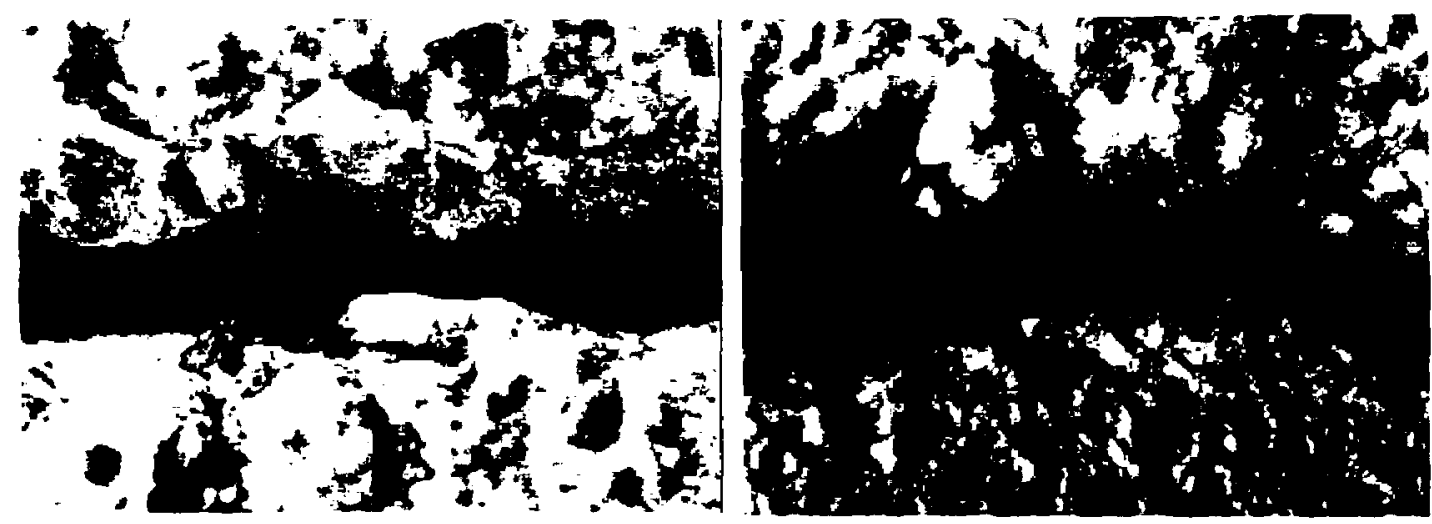

Figure 4.1. Measurement of Crack Width Under the Optical Microscope (4x): (a) Sample PSIDI, Sawcut Smooth Crack, Cw =0.12 mm; (b) - Sample SR3P2, Fracture Rough Crack, $\mathrm{Cw}=0.32 \mathrm{~mm}$. 


\subsection{Chloride Bulk Diffusion Test}

The depth of chloride penetration, as well as the apparent diffusion coefficient, was obtained during the chloride bulk diffusion test. In addition, two-dimensional analysis was performed to characterize the combined diffusion of chlorides from the surface of the sample and the crack wall.

\subsubsection{The Chloride Penetration Depth}

The depth of chloride penetration was determined by spraying the freshly split concrete surface with the silver nitrate solution. The results are summarized in Table 4.1. Both vertical and lateral depths of chloride penetration were measured and denoted as ' $\mathrm{V}$ ' and ' $\mathrm{L}$ ' respectively. Figure 4.2 shows a scan of the $100 \%$ OPC concrete samples containing single smooth cracks of various widths and one control sample containing no crack. The left hand parts of the cracked samples are the ones that were exposed to lateral diffusion (from the crack wall) only.

The shapes of the chloride fronts observed in this picture are typical for all other sample sets. The only difference between the two types of concrete is that the average depth of chloride penetration is smaller for the $25 \%$ slag concrete mixture, which is to be expected for the concrete containing supplementary cementing materials.

It is evident from the picture that the shape of the chloride penetration front is strongly influenced by the presence of coarse aggregate in the penetrated area. This must be considered, when comparing the depths of chloride penetration among the different samples or within the 
Table 4.1 Chloride Bulk Diffusion Test, Depth of Chloride Penetration.

\begin{tabular}{|c|c|c|c|c|c|}
\hline \multirow[t]{2}{*}{ Mix } & \multirow{2}{*}{$\begin{array}{l}\text { Crack } \\
\text { Type }\end{array}$} & \multirow{2}{*}{$\begin{array}{l}\text { Sample } \\
\text { ID }\end{array}$} & \multirow{2}{*}{$\begin{array}{c}\text { Crack } \\
\text { Width, (mm) }\end{array}$} & \multicolumn{2}{|c|}{ Depth of $\mathrm{Cl}^{-}$Penetration, (mm) } \\
\hline & & & & Vertical, V & Lateral, L \\
\hline \multirow{8}{*}{$\begin{array}{l}100 \% \\
\text { OPC }\end{array}$} & \multirow[t]{2}{*}{ - } & PNP2, 10 & - & $11.63^{*}$ & - \\
\hline & & PNPLAT2,4 & - & - & $18.78^{*}$ \\
\hline & \multirow{3}{*}{$\begin{array}{l}\text { Smooth } \\
\text { Surface }\end{array}$} & PSIP2 & 0.09 & 17.70 & 16.30 \\
\hline & & PS3P2 & 0.38 & 12.70 & 17.90 \\
\hline & & PS5P2 & 0.69 & 13.70 & 15.05 \\
\hline & \multirow{3}{*}{$\begin{array}{l}\text { Rough } \\
\text { Surface }\end{array}$} & PR1P2 & 0.10 & 15.00 & 17.36 \\
\hline & & PR3P2 & 0.29 & 11.11 & 26.92 \\
\hline & & PR5P2 & 0.47 & 22.75 & 17.20 \\
\hline \multirow{8}{*}{$\begin{array}{l}25 \% \\
\text { Slag }\end{array}$} & \multirow[t]{2}{*}{-} & SNP2, 10 & - & $7.05^{*}$ & - \\
\hline & & SNPLAT2,4 & - & - & $6.05^{*}$ \\
\hline & \multirow{3}{*}{$\begin{array}{l}\text { Smooth } \\
\text { Surface }\end{array}$} & SSIP2 & 0.10 & 7.70 & 20.40 \\
\hline & & SS3P2 & 0.32 & 4.50 & 14.35 \\
\hline & & SS5P2 & 0.62 & 6.50 & 9.05 \\
\hline & \multirow{3}{*}{$\begin{array}{l}\text { Rough } \\
\text { Surface }\end{array}$} & SRIP2 & 0.10 & 15.80 & 20.74 \\
\hline & & SR3P2 & 0.32 & 9.00 & 18.60 \\
\hline & & SR5P2 & 0.47 & 7.22 & 16.90 \\
\hline
\end{tabular}

* Average depth for two companion samples.

same sample. In other words, a scatter in the obtained results should be partially attributed to the distribution of aggregate within the concrete samples.

After taking this effect into account, it can still be noticed from the results presented in Table 4.1 that some of the concrete samples exhibited much larger lateral chloride penetration 


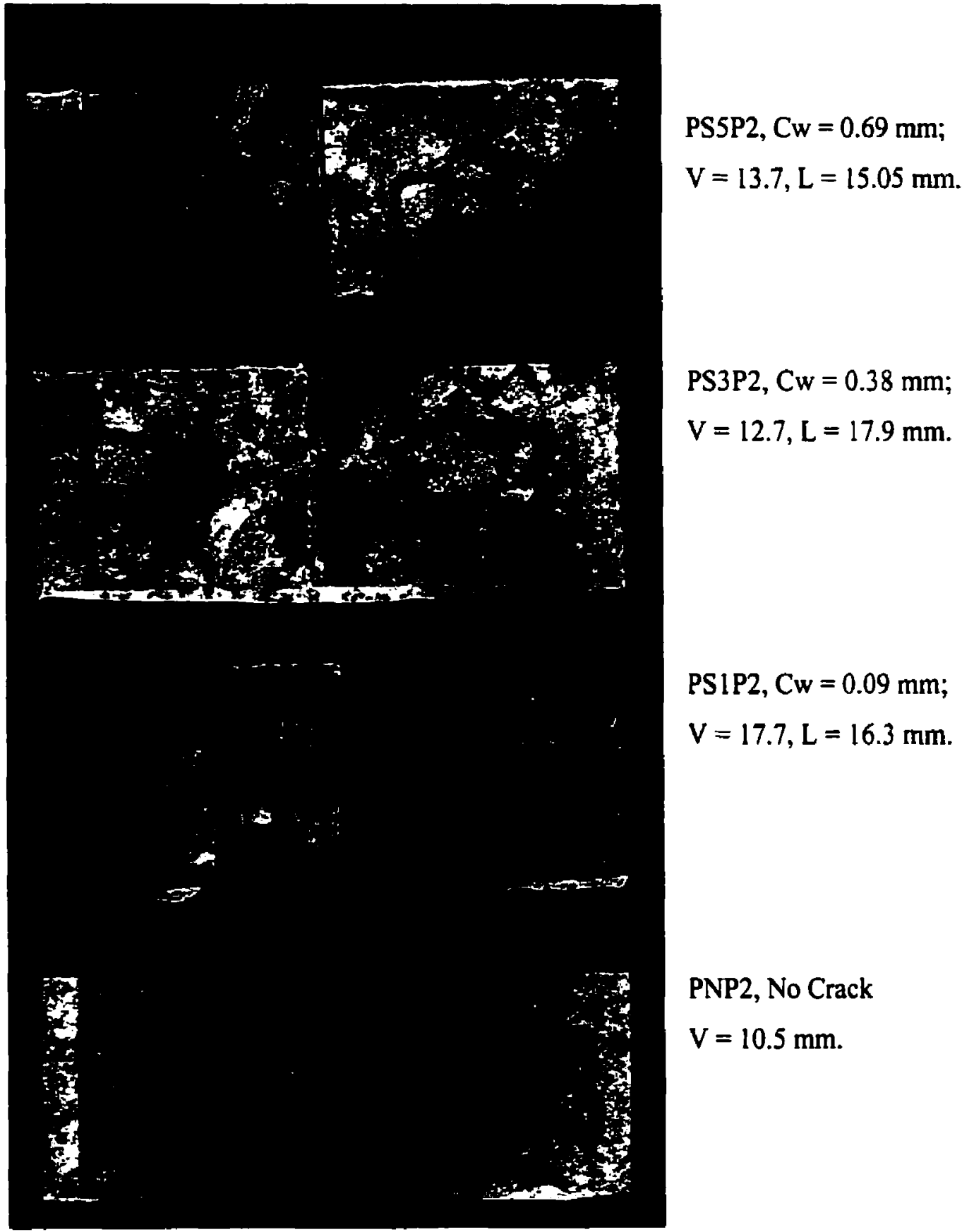

Figure 4.2 Chloride Bulk Diffusion Test, Depth of Chloride Penetration; $100 \%$ OPC Concrete, Single Smooth Cracks. 
than vertical. In order to verify whether the chloride diffusion is dependent on the direction of cast, four additional samples per mix were exposed to the chloride bulk diffusion test. This time, 40 by $100 \mathrm{~mm}$ concrete discs were cut across the diameter and sealed leaving only the newly cut face exposed to the chlorides. This exposure was similar to the case of lateral diffusion from the crack wall, except that the exposed surface was, in fact, a free surface parallel to the casting direction. The samples were labeled PNPLAT1...4 and SNPLAT1. .4 for OPC and slag mixtures respectively. Two out of four companion samples were used for measuring the depth of chloride penetration (results were included in Table 4.1), while two others were used to determine the diffusion coefficient.

Based on the results obtained from spraying the concrete surface with silver nitrate solution, the following conclusions on the influence of cracks on the depth of chloride penetration can be drawn:

- Transecting cracks in the width range studied in this project behave like a free concrete surface exposed to chloride diffusion.

- The depth of chloride penetration is independent of either the crack widths considered or the crack surface roughness.

- Chloride diffusion in the concrete containing the transecting crack becomes a case of two-dimensional diffusion.

\subsubsection{The Chloride Diffusion Coefficient}

Two different software packages were used to calculate the values of the apparent diffusion coefficient from experimental data points. 
Typical curves for a case of one- and two-dimensional diffusion as produced by Table Curve are shown in Figure 4.3. The complete set of raw data and results obtained with the aid of Table Curve are given in Appendix B. The details of the exposed samples, direction of grinding, and the values of the diffusion coefficient, surface concentration, and correlation coefficient are summarized in Tables 4.2 and 4.3 for Portland cement and slag containing mixtures respectively.

It can be noticed that in the case of one-dimensional diffusion, most of the data points fit Fick's second law reasonably well. Points that fell far outside the best-fit curve were not considered in the calculation of the diffusion coefficient. These points were attributed to handling mistakes during the procedure for obtaining the chloride concentration profile. In addition, as it was mentioned in the experimental part, points obtained with the use of less than $2 \mathrm{ml}$ of titrant (usually points below the background concentration) were also disregarded from the analysis.

With respect to the case of two-dimensional diffusion (profiles marked as 'DEP'), a much worse fit to Fick's second diffusion law can be observed. This, of course, is to be expected, since the law describes only the case of one-dimensional diffusion. The discrepancy is evident in the portion of the curve where concentration is supposed to approach zero, which never happens if chlorides penetrate the sample from two sides.

Values of the diffusion coefficient obtained for each concrete from all the samples tested are plotted against crack widths in Figure 4.4. Four different types of concentration profiles were studied, and the attained values of the diffusion coefficient were denoted in accordance with the type of profile. All lateral, as well as vertical, profiles for uncracked samples were produced by 


\section{PNP9/TableCurve}

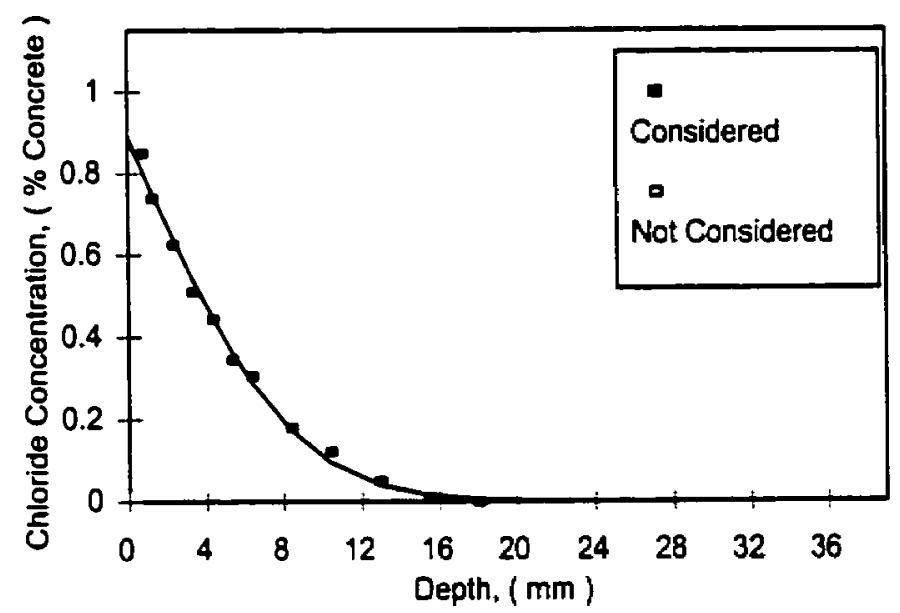

(a) $\mathrm{D}_{\mathrm{a}}=6.05 \mathrm{E}-12 \mathrm{~m}^{2} / \mathrm{s}, \mathrm{C}_{0}=0.89 \%, \mathrm{C}_{\mathrm{b}}=0.070 \%, \mathrm{r}^{2}=0.9948$

\section{SS3P1DEP/TableCurve}

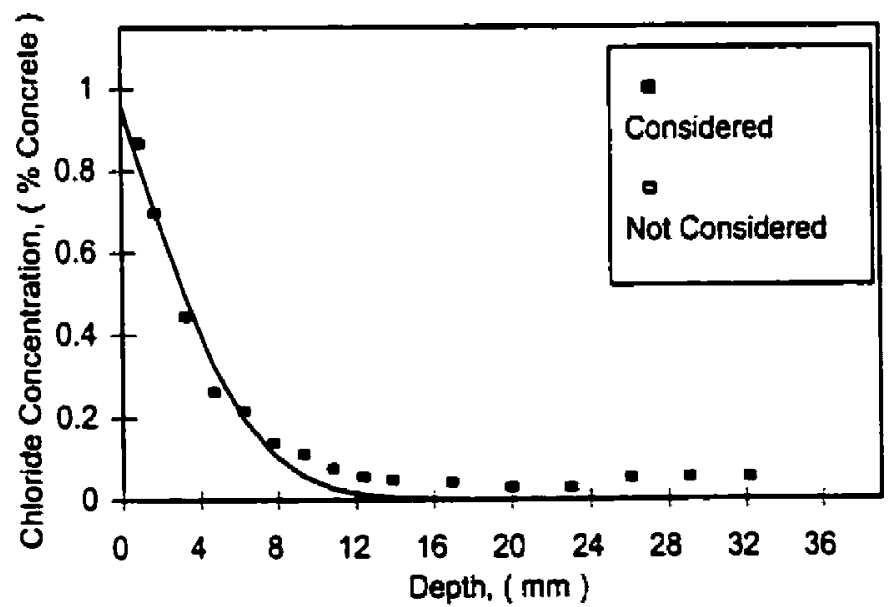

(b) $D_{3}=3.54 \mathrm{E}-12 \mathrm{~m}^{2} / \mathrm{s}, \mathrm{C}_{0}=0.96 \%, \mathrm{C}_{\mathrm{b}}=0.062 \%, \mathrm{r}^{2}=0.9666$

Figure 4.3 Typical Chloride Bulk Diffusion Test Curves, Table Curve: (a) - ID Diffusion; (b) - 2D Diffusion. 
Table 4.2 40 Day Chloride Bulk Diffusion Test Results for $100 \%$ OPC Concrete, Table Curve.

\begin{tabular}{|c|c|c|c|c|c|c|c|c|}
\hline Sample ID & $\begin{array}{l}\text { Crack } \\
\text { Width, } \\
\text { (mm) }\end{array}$ & $\begin{array}{c}\text { Exposed } \\
\text { Surface } \\
\text { Type }\end{array}$ & $\begin{array}{l}\text { Diffusion } \\
\text { Direction }\end{array}$ & $\begin{array}{l}\text { Grinding } \\
\text { Direction }\end{array}$ & $r^{2}$ & $\begin{array}{c}\text { Surface } \\
\text { Concentra- } \\
\text { tion, (\% } \\
\text { Concrete) }\end{array}$ & $\begin{array}{c}\text { Diffusion } \\
\text { Coef- } \\
\text { ficient } \\
\left(\mathrm{m}^{2} / \mathrm{s}\right)\end{array}$ & $\begin{array}{c}\text { Dif. Coef } \\
\text { Labels } \\
\text { Used } \\
\text { in Figures }\end{array}$ \\
\hline PNP1 & - & Smooth & Vertical & Vertical & 0.998 & 0.68 & $8.09 \mathrm{e}-12$ & \multirow[t]{2}{*}{ Dsm.vert. } \\
\hline PNP9 & - & Smooth & Vertical & Vertical & 0.995 & 0.89 & $6.05 e-12$ & \\
\hline PNPLAT 1 & - & Smooth & Lateral & Lateral & 0.988 & 0.60 & $1.20 \mathrm{e}-11$ & \multirow[t]{2}{*}{ Dsm.lat. } \\
\hline PNPLAT3 & - & Smooth & Lateral & Lateral & 0.988 & 0.91 & $8.26 \mathrm{e}-12$ & \\
\hline PSIPILAT & 0.102 & Smooth & Lateral & Lateral & 0.998 & 0.65 & $1.14 \mathrm{e}-11$ & \multirow[t]{3}{*}{ Dsm.lat. } \\
\hline PS3PILAT & 0.370 & Smooth & Lateral & Lateral & 0.998 & 0.69 & $6.39 e-12$ & \\
\hline PSSPILAT & 0.677 & Smooth & Lateral & Lateral & 0.996 & 0.70 & $1.15 \mathrm{e}-11$ & \\
\hline PSIPIDEP & 0.102 & Smooth & Lat+Vert & Vertical & 0.927 & 0.66 & $2.15 e-11$ & \multirow[t]{3}{*}{ Dsm.vert. } \\
\hline PS3PIDEP & 0.370 & Smooth & Lat + Vert & Vertical & 0.944 & 0.87 & $1.06 \mathrm{e}-11$ & \\
\hline PS5P1DEP & 0.677 & Smooth & Lat+Vert & Vertical & 0.947 & 0.65 & $2.91 e-11$ & \\
\hline PRIPILAT & 0.097 & Rough & Lateral & Lateral & 0.951 & 0.73 & $1.59 \mathrm{e}-11$ & \multirow[t]{3}{*}{ Drh.lat. } \\
\hline PR3PILAT & 0.297 & Rough & Lateral & Lateral & 0.999 & 0.87 & $1.23 \mathrm{e}-11$ & \\
\hline PRSPILAT & 0.466 & Rough & Lateral & Lateral & 0.994 & 0.59 & $1.36 \mathrm{e}-11$ & \\
\hline PRIPIDEP & 0.097 & $\begin{array}{l}\text { Rough/ } \\
\text { Smooth }\end{array}$ & Lat +Vert & Vertical & 0.946 & 0.82 & $1.63 \mathrm{e}-11$ & \multirow[t]{3}{*}{ Drh.vert. } \\
\hline PR3P1DEP & 0.297 & $\begin{array}{l}\text { Rough/ } \\
\text { Smooth }\end{array}$ & Lat + Vert & Vertical & 0.947 & 0.78 & $1.17 \mathrm{e}-11$ & \\
\hline PR5PIDEP & 0.466 & $\begin{array}{l}\text { Rough/ } \\
\text { Smooth }\end{array}$ & Lat+Vert & Vertical & 0.952 & 0.65 & $1.05 \mathrm{e}-11$ & \\
\hline
\end{tabular}


Table 4.3 40 Day Chloride Bulk Diffusion Test Results for $25 \%$ Slag Concrete, Table Curve.

\begin{tabular}{|c|c|c|c|c|c|c|c|c|}
\hline Sample ID & $\begin{array}{l}\text { Crack } \\
\text { Width, } \\
\text { (mm) }\end{array}$ & $\begin{array}{c}\text { Exposed } \\
\text { Surface } \\
\text { Type }\end{array}$ & $\begin{array}{l}\text { Diffusion } \\
\text { Direction }\end{array}$ & $\begin{array}{l}\text { Grinding } \\
\text { Direction }\end{array}$ & $r^{2}$ & $\begin{array}{c}\text { Surface } \\
\text { Concentra- } \\
\text { tion, (\% } \\
\text { Concrete) }\end{array}$ & $\begin{array}{c}\text { Diffusion } \\
\text { Coef- } \\
\text { ficient } \\
\left(\mathrm{m}^{2} / \mathrm{s}\right)\end{array}$ & $\begin{array}{c}\text { Dif. Coef. } \\
\text { Labels } \\
\text { Used } \\
\text { in Figures }\end{array}$ \\
\hline SNPI & - & Smooth & Vertical & Vertical & 0.998 & 0.86 & $4.02 \mathrm{e}-12$ & \multirow[t]{2}{*}{ Dsm.vert } \\
\hline SNP9 & $=$ & Smooth & Vertical & Vertical & 0.989 & 1.04 & $1.83 e-12$ & \\
\hline SNPLATI & - & Smooth & Lateral & Lateral & 0.976 & 0.75 & $3.24 \mathrm{e}-12$ & \multirow[t]{2}{*}{ Dsm.lat. } \\
\hline SNPLAT3 & - & Smooth & Lateral & Lateral & 0.998 & 0.97 & $3.41 \mathrm{e}-12$ & \\
\hline SSIPILAT & 0.079 & Smooth & Lateral & Lateral & 0.991 & 0.53 & $5.52 \mathrm{e}-12$ & \multirow[t]{3}{*}{ Dsm.lat. } \\
\hline SS3PILAT & 0.341 & Smooth & Lateral & Lateral & 0.992 & 0.59 & $5.13 e-12$ & \\
\hline SS5PILAT & 0.616 & Smooth & Lateral & Lateral & 0.994 & 0.78 & $2.60 \mathrm{e}-12$ & \\
\hline SSIPIDEP & 0.079 & Smooth & Lat+Vert & Vertical & 0.956 & 0.78 & $6.19 \mathrm{e}-12$ & \multirow[t]{3}{*}{ Dsm.vert } \\
\hline SS3PIDEP & 0.341 & Smooth & Lat+Vert & Vertical & 0.967 & 0.96 & $3.54 \mathrm{e}-12$ & \\
\hline SS5P1DEP & 0.616 & Smooth & Lat+Vert & Vertical & 0.961 & 0.89 & $3.48 \mathrm{e}-12$ & \\
\hline SRIPILAT & 0.099 & Rough & Lateral & Lateral & 0.997 & 0.78 & $3.71 e-12$ & \multirow[t]{3}{*}{ Drh.lat. } \\
\hline SR3PILAT & 0.284 & Rough & Lateral & Lateral & 0.989 & 0.83 & $5.01 \mathrm{e}-12$ & \\
\hline SR5PILAT & 0.472 & Rough & Lateral & Lateral & 0.996 & 0.63 & $5.03 e-12$ & \\
\hline SRIPIDEP & 0.099 & $\begin{array}{l}\text { Rough/ } \\
\text { Smooth }\end{array}$ & Lat+Vert & Vertical & 0.977 & 0.95 & $3.31 \mathrm{e}-12$ & \multirow[t]{3}{*}{ Drh.vert. } \\
\hline SR3PIDEP & 0.284 & $\begin{array}{l}\text { Rough/ } \\
\text { Smooth }\end{array}$ & Lat+Vert & Vertical & 0.970 & 1.24 & $1.80 \mathrm{e}-12$ & \\
\hline SRSPIDEP & 0.472 & $\begin{array}{l}\text { Rough/ } \\
\text { Smooth }\end{array}$ & Lat + Vert & Vertical & 0.961 & 0.89 & $4.19 \mathrm{e}-12$ & \\
\hline
\end{tabular}


(a)

\section{Day Bulk Diffusion Test}

$100 \%$ OPC, Single Crack , Table Curve

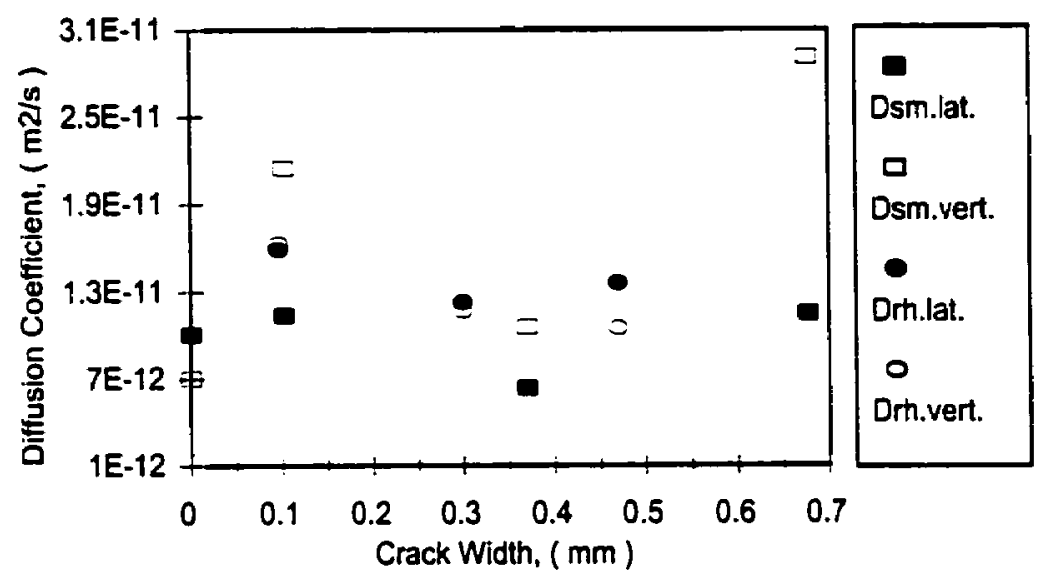

(b)

40 Day Bulk Diffusion Test

$25 \%$ Slag, Single Crack, Table Curve

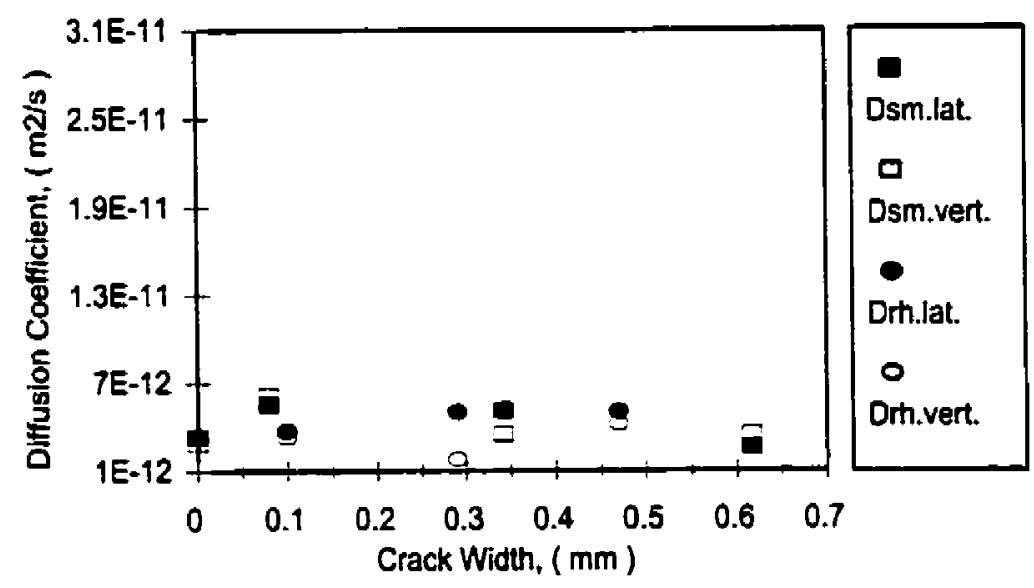

Figure 4.4 Chloride Bulk Diffusion Test Results, Table Curve: (a) - $100 \%$ OPC Concrete; (b) - $25 \%$ Slag Concrete. 
one-dimensional diffusion, while the vertical profiles for cracked samples were the result of twodimensional diffusion. Since two companion samples were tested for uncracked concrete in each case, the average values of the diffusion coefficient were plotted in the charts. The format of these charts was kept constant to facilitate evaluation of the resuits.

While comparing the two mixes, it can be noticed that the domain of diffusion coefficient values for the $100 \%$ OPC mixture lies higher than for the $25 \%$ slag mixture, which points to the fact that concretes containing supplementary cementing materials, such as slag, often possess a better ability to resist aggression by chloride ions. The same trend was observed for the depth of chloride penetration.

The results obtained within the same concrete type do not appear to indicate any particular trend. This is especially true for the slag mixture, for which all the values of the diffusion coefficient are clustered very closely together (Figure 4.4-b), demonstrating a natural variation of results, that could be expected among companion samples, rather than any relationship between test variables. The spread of the results is slightly bigger for the OPC mixture, however, no specific factors governing this scatter could be revealed. Perhaps, the decrease in the quality of concrete as compared with the slag mixture leads to a higher variation in the properties of $100 \%$ OPC concrete.

From the evaluation of calculated values of the diffusion coefficient the following observations can be made:

- There was no detectable influence of either the crack width or the crack surface roughness on the chloride diffusion coefficient among the crack widths examined.

- The walls of the transecting crack behave like a free surface producing diffusion 
coefficients similar to those of uncracked concrete.

- In the case of two-dimensional diffusion, Ficks's second law can be used to obtain values of the diffusion coefficient with a reasonable degree of reliability. However, it is not accurate for predicting the depth and shape of chloride penetration.

These observations are in agreement with preliminary conclusions drawn for the depth of chloride penetration in Section 4.2.1.

The second software package used to calculate values of the diffusion coefficient was ConFlux. The chloride surface concentration was theoretically calculated for both concretes before the program could be applied. The measured water porosity of $100 \% \mathrm{OPC}$ and $25 \%$ slag concretes was 14.83 and $14.44 \%$ respectively. The corresponding amounts of free chlorides constitute 0.54 and $0.52 \%$ by mass of concrete. By combining these with the amount of bound chlorides, the surface concentration was estimated to be about $0.75 \%$ for OPC mixture and 0.77 $\%$ for slag.

The average values of chloride surface concentration calculated by Table Curve based on experimental results are 0.73 and $0.84 \%$, which would indicate a fairly reasonable theoretical estimation.

Figure 4.5 shows best fit curves obtained with ConFlux for the same samples used as an illustration of a typical fit for Table Curve in Figure 4.3. Appendix $C$ provides the complete set of results acquired through ConFlux. It can be seen from the graphs that the fixed value of surface concentration leads to a much poorer fit of the data points to the curves calculated by the program. The closer the theoretically calculated surface concentration to the experimental data points, the better the fit of the curve, and the closer the values of the diffusion coefficient 


\section{PNP9/Conflux}

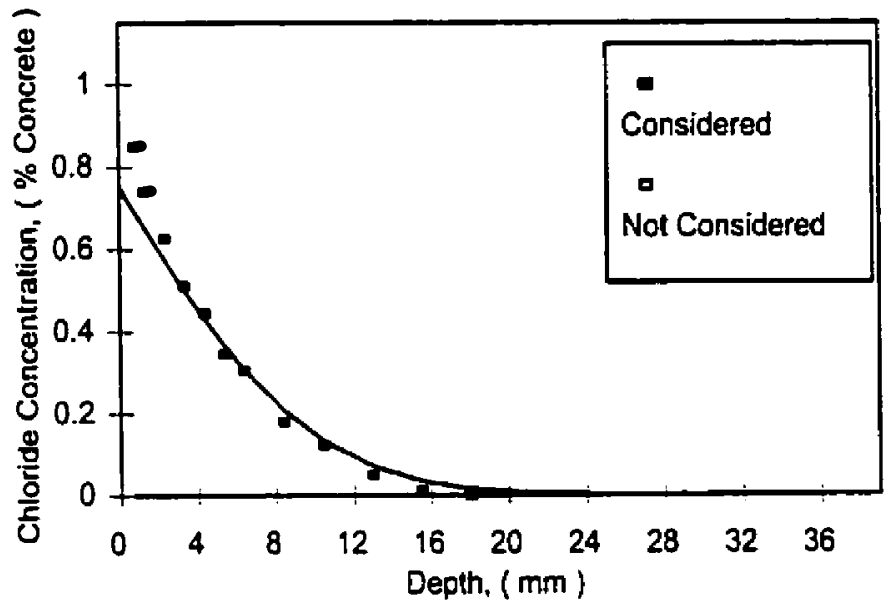

(a) $\mathrm{D}_{\mathrm{a}}=8.66 \mathrm{E}-12 \mathrm{~m}^{2} / \mathrm{s}, \mathrm{C}_{0}=0.75 \%, \mathrm{C}_{\mathrm{b}}=0.070 \%$

\section{SS3P1DEP/Conflux}

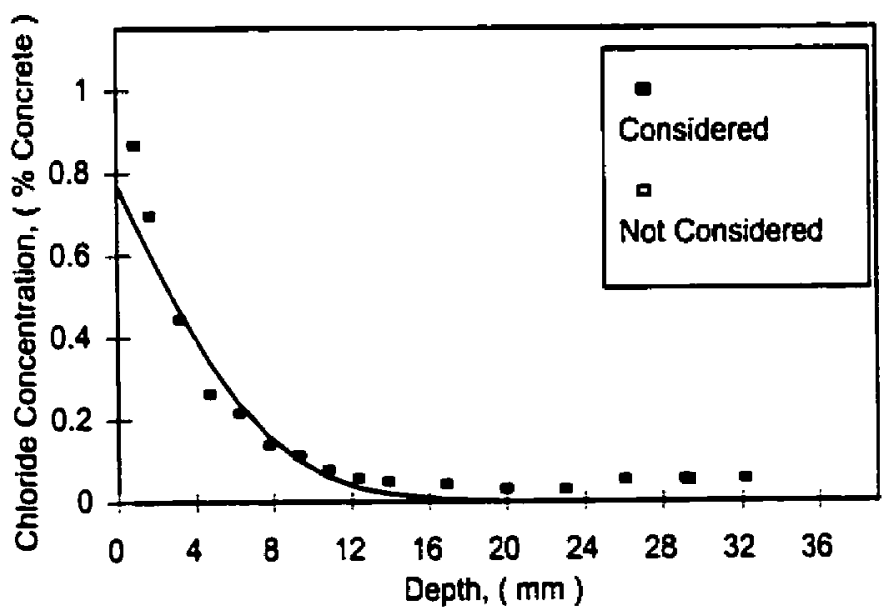

(b) $D_{a}=5.46 \mathrm{E} \cdot 12 \mathrm{~m}^{2} / \mathrm{s}, \mathrm{C}_{0}=0.77 \%, \mathrm{C}_{\mathrm{b}}=0.062 \%$

Figure 4.5 Typical Chloride Bulk Diffusion Test Curves, ConFlux: (a) - ID Diffusion; (b) - 2D Diffusion. 
(a)

\section{Day Bulk Diffusion Test}

$100 \%$ OPC, Single Crack, Confiux

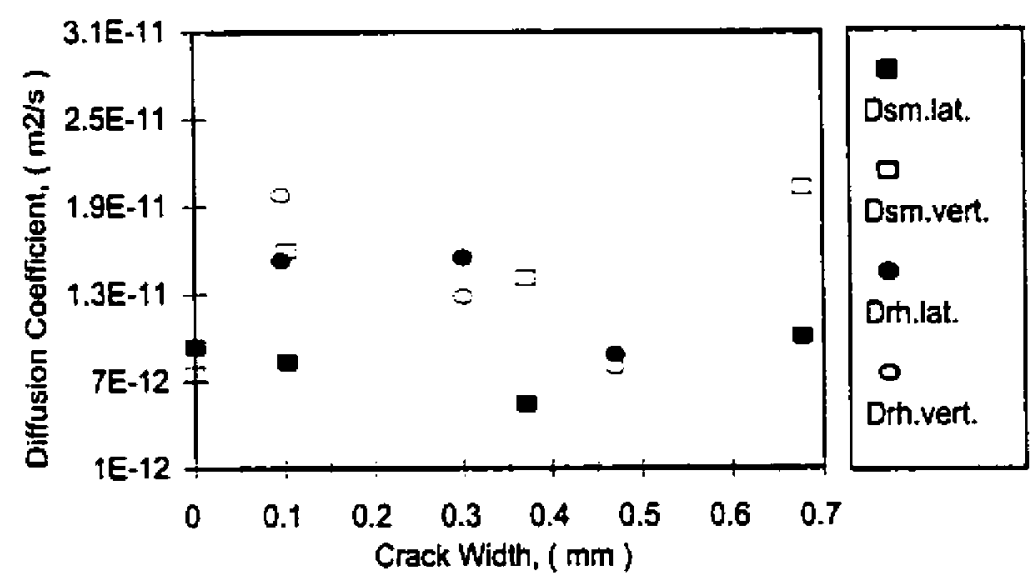

(b)

\section{Day Bulk Diffusion Test}

$25 \%$ Slag, Single Crack, Conflux

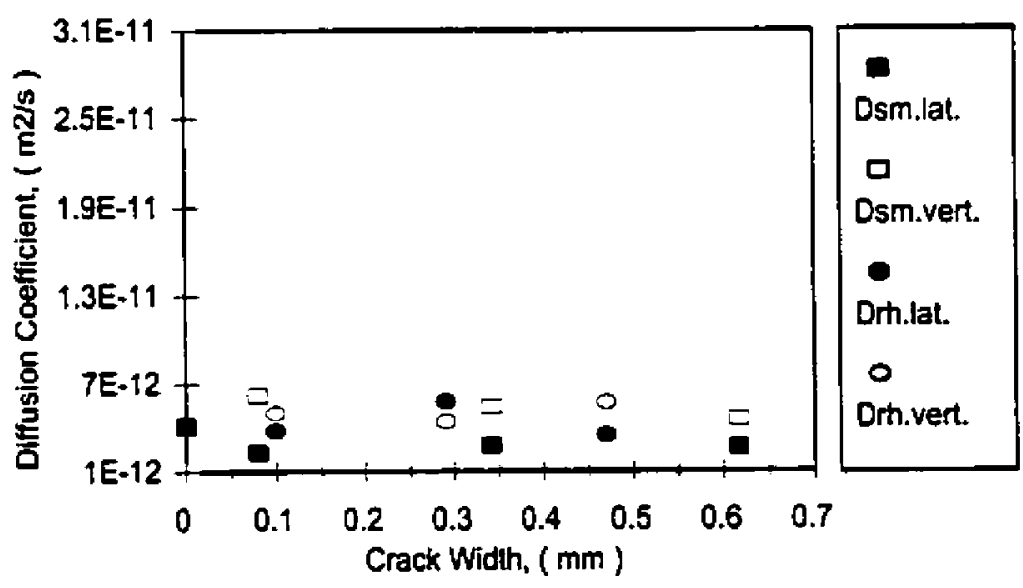

Figure 4.6 Chloride Bulk Diffusion Test Results, ConFlux: (a) - $100 \%$ OPC Concrete;

(b) $-25 \%$ Slag Concrete. 
obtained from the two programs.

Figure 4.6 summarizes the values of diffusion coefficient produced by ConFlux as a function of crack width (similar to Figure 4.4 for Table Curve). Even though ConFlux calculated diffusion coefficients are different from those of Table Curve, the overall picture of results neither changes significantly nor indicates any new findings.

As a concluding remark on these two software packages, it should be pointed it out that, unless a high degree of accuracy can be achieved in estimating the value of the surface concentration to be input into ConFlux, Table Curve produces curves giving a better fit with experimental points and, therefore, more reliable results.

\subsubsection{D Simulations}

As demonstrated in the previous section, Fick's second law can not be used to accurately predict distribution of chlorides in the case of two-dimensional diffusion. A different approach is needed that would account for the effect of ion diffusion from two directions.

When obtaining the chloride concentration profile for the case of one-dimensional diffusion, local variations in concentration are neglected as the average concentration of the layer is measured. In other words, it is assumed that the concentration is constant at given depth. Following this assumption, lines of equal concentration can be drawn for one-dimensional diffusion (Figure 4.7-a). These are, in fact, straight lines parallel to the exposed surface.

In the case of two-dimensional diffusion lines of equal concentration have a hyperbolic shape (Figure 4.7-b) with its extremes approaching straight lines in the areas not affected by combined diffusion. Let us choose a coordinate system $(X, Y)$, so that axis $X$ runs along the 
(a)

1D Diffusion

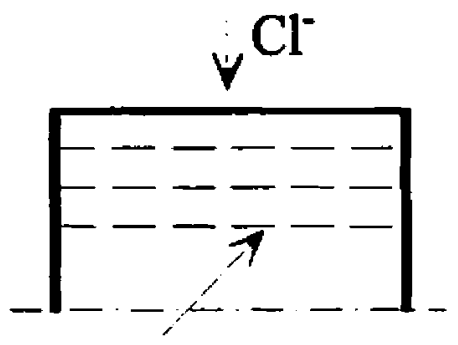

Lines of Equal Concentration (b)

\section{D Diffusion}

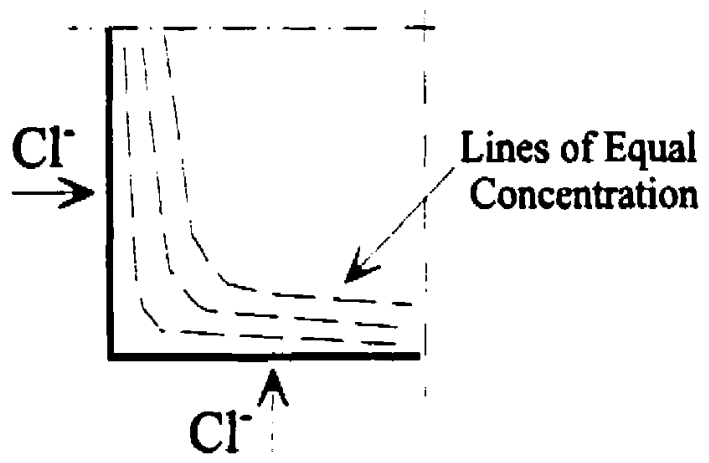

Figure 4.7 Lines of Equal Concentration for One- and Two-Dimensional Diffusion.

crack wall, while axis $\mathrm{Y}$ runs along the sample surface (Figure 4.8). Then, the simplest form of the equation describing lines of equal concentration for the $2 \mathrm{D}$ diffusion can be written as follows:

$$
(x-\Delta)^{*}(y-\Delta)=\Delta
$$

Where:

$$
\begin{aligned}
& \Delta=\quad \text { constant, expressing the distance from the axis to the line of equal } \\
& \text { concentration away from the coordinate system origin. }
\end{aligned}
$$

The average chloride concentration at any given depth $x_{1}$, analogous to the concentration obtained from grinding the sample, can be derived through calculating and averaging concentrations at all points along line $x=x_{1}$ for $y$ ranging from 0 to $d$, where $d$ is the diameter of the core bit equal to $47.7 \mathrm{~mm}$. The step for $y$ variation was arbitrarily chosen to be $0.1 \mathrm{~mm}$. 


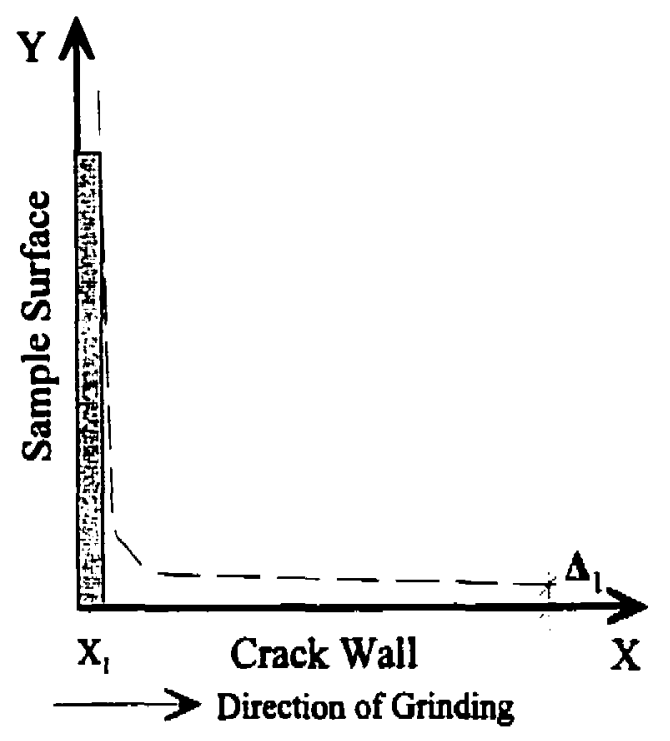

Figure 4.8 Model for Calculating the Average Chloride Concentration at Any Given Depth for the Case of 2D Diffusion.

It is possible that the outcome of the simulations may be sensitive to the $y$ variation step, however, such a sensitivity study would lie beyond the scope of this project.

The chloride concentration at any point $\left(x_{1}, y_{1}\right)$ is calculated by replacing distance $x$ in Crank's solution (Equation 2-2) with the value of constant $\Delta$ that corresponds with the line of equal concentration passing through this point. Since the analytical solution to the integral of the error function was not found, the problem was solved numerically using a conventional spreadsheet. The diffusion coefficient value measured on the uncracked concrete and theoretically calculated value of surface concentration (Section 4.2.2) were used in these simulations.

Figure 4.9 shows a $2 \mathrm{D}$ concentration profile calculated for $100 \%$ OPC concrete, 


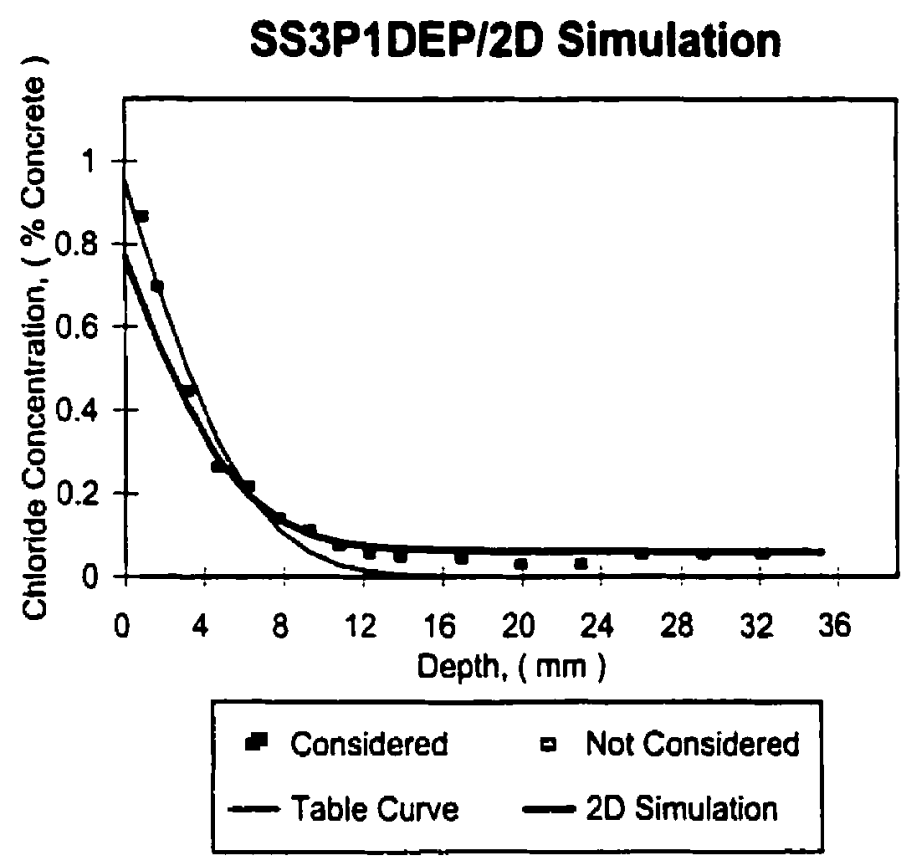

2D Simulation: $\mathrm{D}_{\mathrm{a}, \text { unct }}=2.93 \mathrm{E}-12 \mathrm{~m}^{2} / \mathrm{s}, \mathrm{C}_{0}=0.77 \%$

Figure 4.9 Chloride Bulk Diffusion Test, Table Curve vs 2D Simulation.

experimental data obtained for one of the samples, and the corresponding best fit curve generated by Table Curve. Similar comparison charts are presented in Appendix D for all the samples exposed to 2D diffusion.

It can be seen from these charts that, even though the scatter in experimentally measured surface concentrations greatly affects the fit of the 2D simulated curve, overall, it does fit the data points much better than the corresponding ID curve produced by the Table Curve software package.

The proposed 2D simulation approach can be used for predicting the chloride concentration profiles for the case of two-dimensional diffusion, provided that the concrete 
diffusion coefficient is known and the value of surface concentration can be estimated.

\subsubsection{Chloride Concentration Profile for Rough Surface Samples}

When obtaining the lateral chloride concentration profile for the rough crack samples, the concrete surface subjected to grinding is the rough surface of the crack wall. The irregularity of such surfaces for the rough cracked samples reached up to $5 \mathrm{~mm}$. The question arises as to whether this irregularity could modify the shape of equal-concentration lines (see Section 4.2.3), and, thus, introduce an error in the determined chloride concentration profile.

An approach for obtaining this profile while accounting for the effect of surface roughness was considered and details are discussed in Appendix E. It was discovered that the approach was not suitable for describing chloride diffusion into concrete with irregular surface shape. Therefore, it was abandoned and the conventional method was used to obtain the lateral chloride concentration profiles for rough crack samples. 


\subsection{SEM/EDX Chloride Proffling}

The chloride X-ray map of the free edge of sample SR31 (section taken from the slag concrete sample containing a rough crack, see Section 3.4) is presented in Figure 4.10. The corresponding micrograph of the same area is shown in Figure 4.1l. X-ray map results consist of three windows - a micrograph of the analyzed area, chloride X-ray map, and background. In the X-ray map chlorine manifests itself as bright dots on the dark background of the window.

The chloride X-ray map should be evaluated in conjunction with the background map. The number on the top left comer of each window is a brightness index. It always equals 255 for the micrograph, which is its maximum value. When the brightness index on the $\mathrm{X}$-ray map equals the one on the background map, it indicates that the concentration of the element under analysis is very low or negligible.

From the X-ray map presented in Figure 4.10 it can be noticed that chlorides are concentrated in the areas of the cement paste. The concentration of chlorides in the aggregates appears to be close to the background, which suggests that the chloride ions diffused in concrete through the cement paste avoiding the aggregates. Unfortunately, the decrease in the chloride concentration with depth cannot be observed from this map.

The results of quantitative analysis and a sample of raw data and calculations are attached in Appendix F. Chloride concentration profiles measured with SEM/EDX are presented in Figure 4.12. The profile obtained from grinding with subsequent titration (chemical method) is also included in this chart for comparison purposes. Since the original concentration determined through the chemical method was expressed in percentage by total mass of concrete, 


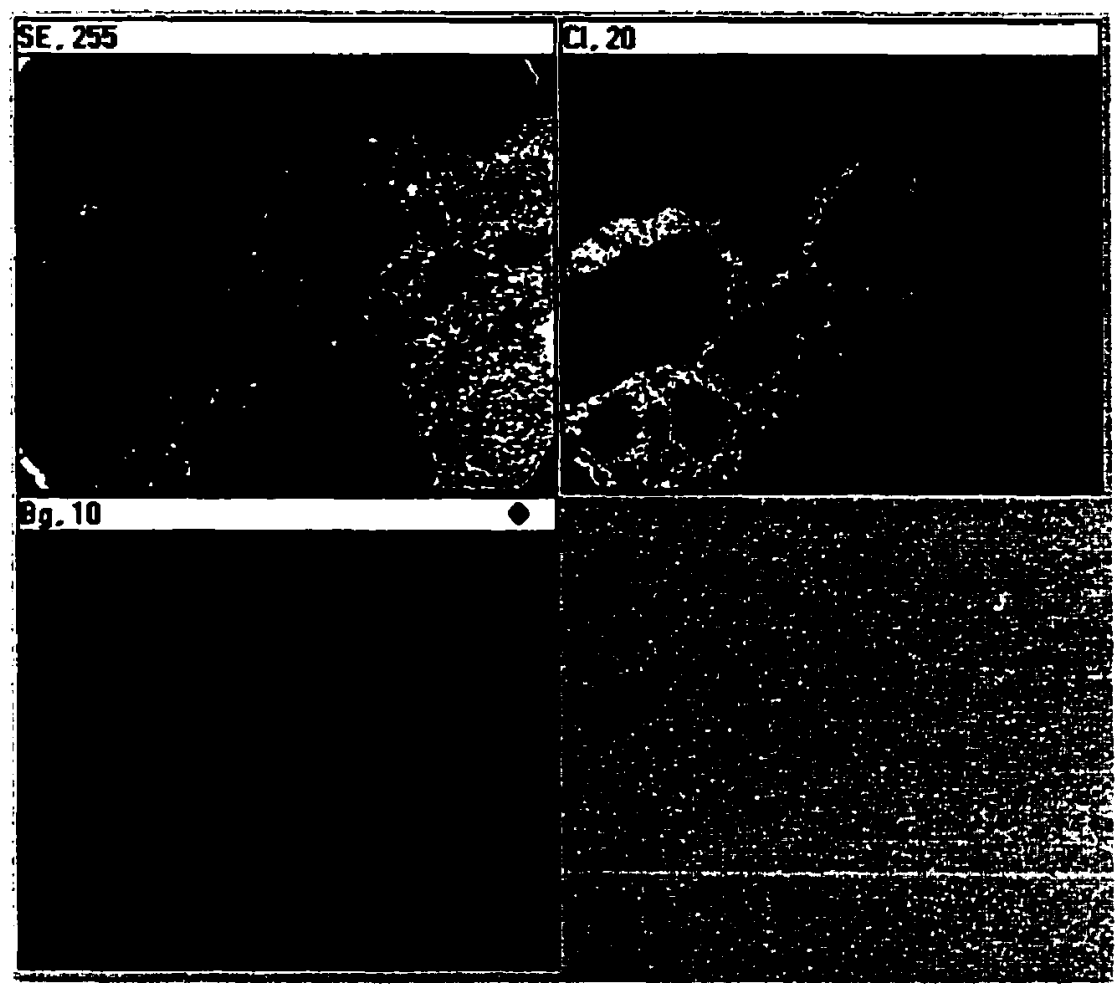

Figure 4.10 X-Ray Map of the Free Edge, Sample SR31 (40x).

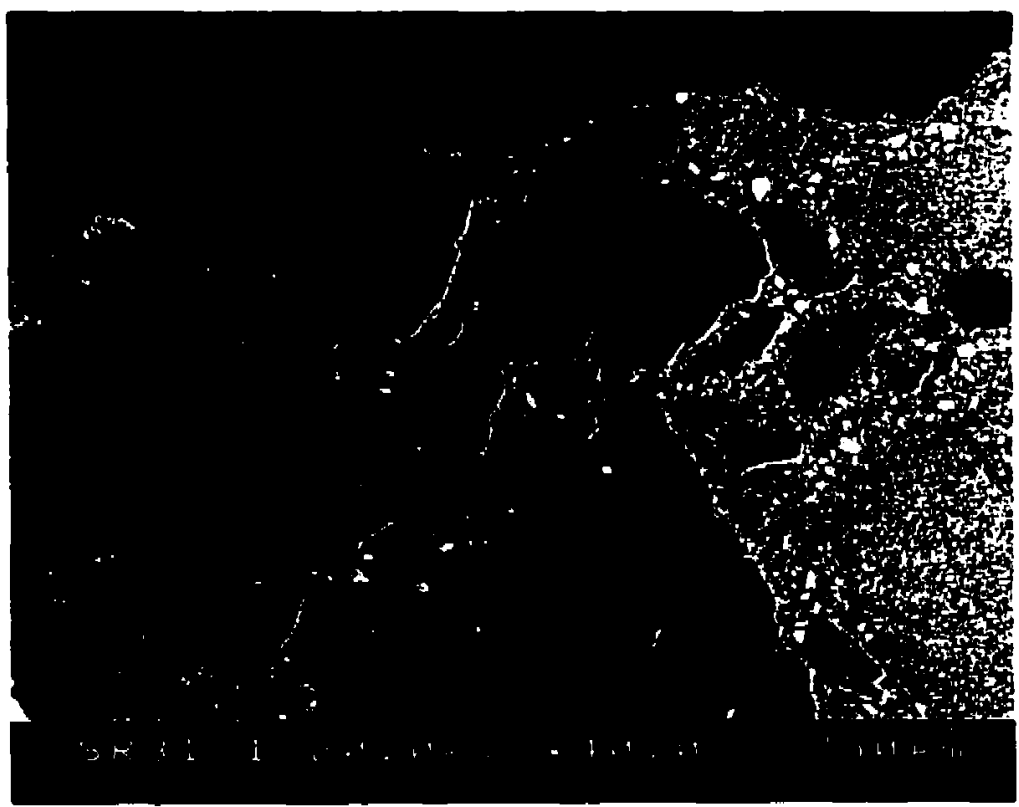

Figure 4.11 Micrograph of the X-Ray Map Area, Sample SR31 (40x). 


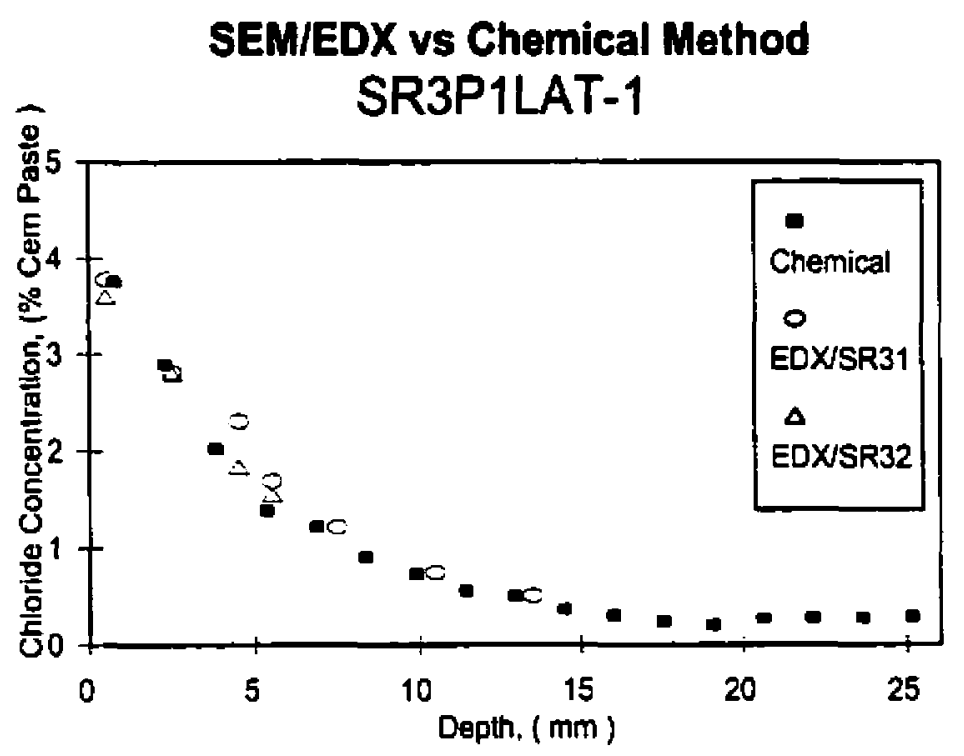

Figure 4.12 Chloride Profiling: SEM/EDX vs Chemical Method.

it had to be converted to percentage by mass of cement paste. This was done by subtracting the mass of aggregates from the mass of concrete based on the values given in the mix design.

It can be seen from the chart that the two SEM/EDX chloride concentration profiles are quite close to each other and to the profile obtained through the chemical method, as well. This observation, supported by the measurement of the chloride penetration depth and the shape of the chloride front, leads to the conclusion that the lateral diffusion of chlorides from the crack wall into the bulk of the concrete sample was, in fact, uniform along the crack length. It should also be pointed out that this statement confirms the previously made conclusion that the walls of the transecting crack behave like a free surface. 


\subsection{Chloride Diffusion Cell}

The chloride diffusion cell testing was originally initiated on the full range of samples containing single smooth cracks. However, it had to be aborted for samples with crack widths from 0.3 to $0.7 \mathrm{~mm}$, as a fault in the experimental set-up was discovered. The concentration of the downstream solution was changing in an unexpected and erratic manner. Instead of increasing steadily, it was jumping up and down with every measurement taken. It was obvious that something was disrupting the diffusion process that was supposed to take place through the crack.

As monitoring of the downstream concentration was the oniy interference with the experiment, the problem was believed to be induced by this procedure. It turned out that the two compartments of the diffusion cell with the cracked sample in between them became a case of two connected vessels, in which fluid levels rapidly responded to any volume changes. Every time, a $10 \mathrm{ml}$ sample solution was extracted from the downstream compartment, it caused a decrease in its volume accompanied by a quick volume recovery from the upstream compartment until the solution levels in both compartments were the same. The reverse process took place when $10 \mathrm{ml}$ of sodium hydroxide was poured back into the downstream compartment. Balancing of the solution levels in the two cell compartments led to irregular changes in the chloride concentration.

The impact of concentration measurement on diffusion was, at first, not so obvious for samples containing smaller cracks. The frequency of measurements was reduced according to the slow changes in concentration of the downstream solution. A comparison of crack widths 
measured with the optical microscope and determined through diffusion cells for these samples is presented in Table 4.4. The complete set of raw data and an example of the calculations are given in Appendix G. Figure 4.13 shows plots of chloride diffusion versus time.

It can be seen from the results that there is a great discrepancy between the two values of crack width for the same sample. All crack widths calculated from Fick's first law are much bigger than the ones measured with the microscope. Moreover, the ranking of crack widths by these two procedures appears to be inconsistent. This allows one to conclude that the concentration measurement in the downstream compartment also interfered with diffusion of chlorides through smaller cracks, resulting in greater chloride flux than could be expected from diffusion alone. A more suitable approach to monitoring concentration of the downstream compartment should be identified before cracked samples can be tested in diffusion cells. 
Table 4.4 Chloride Diffusion Cell, Comparison of Crack Widths.

\begin{tabular}{|c|c|c|}
\hline \multirow{2}{*}{$\begin{array}{c}\text { Sample } \\
\text { ID }\end{array}$} & $\begin{array}{c}\text { Measured with Optical } \\
\text { Microscope }\end{array}$ & $\begin{array}{c}\text { Determined From } \\
\text { Chloride Flux }\end{array}$ \\
\cline { 2 - 3 } & 0.115 & 0.331 \\
\hline PS1D1 & 0.064 & 0.548 \\
\hline PS1D2 & 0.102 & 1.023 \\
\hline SS1D1 & 0.078 & 1.079 \\
\hline SS1D2 &
\end{tabular}

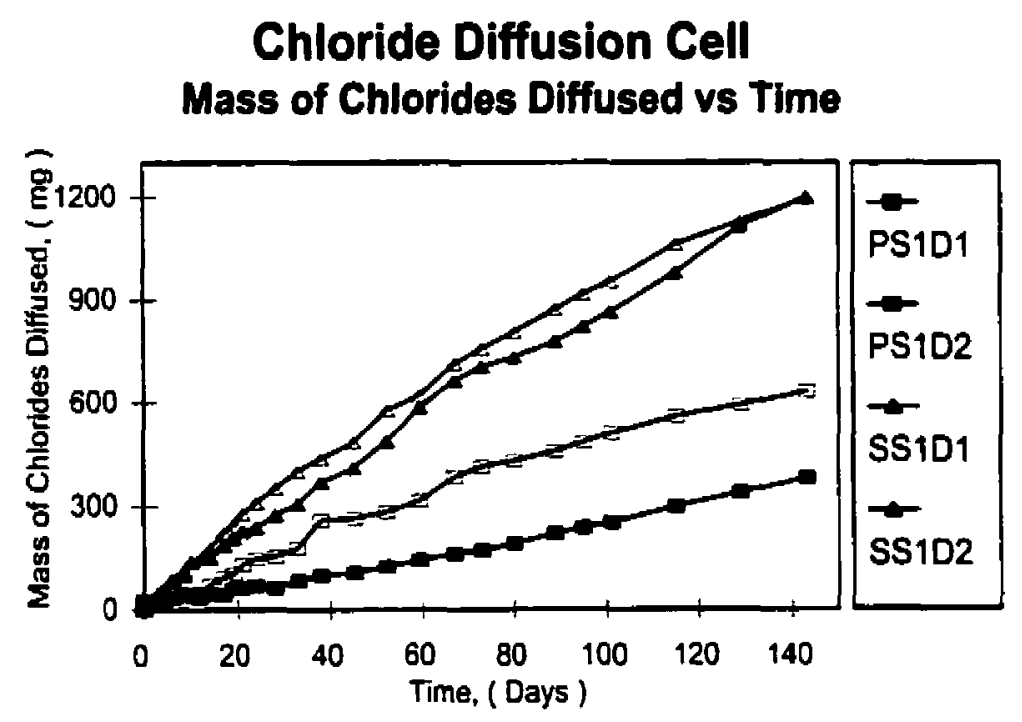

Figure 4.13 Chloride Diffusion Cell, Mass of Chlorides Diffused vs Time. 


\subsection{Depth of Chloride Penetration vs Time}

Figure 4.14 presents scans of a chloride bulk diffusion sample taken before (a) and after (b) coarse aggregate particles falling inside the chloride penetrated area were highlighted. The vertical and lateral depths for both cases are indicated, as well. Results on the chloride penetration depth for various exposure times are summarized in Tables 4.5 and 4.6 for $100 \%$ OPC and $25 \%$ slag concretes respectively. The complete set of scans for all companion samples and values of vertical and lateral depths before $(V, L)$ and after (Ve, Le) exclusion of the aggregate from the measurement are shown in Appendices $\mathrm{H}$ and $\mathrm{I}$ in the order given.

Some of the samples containing pairs of smooth cracks were spoilt and rejected (they were not properly saturated which was discovered after the salt exposure has began). As a result, $25 \%$ slag concrete samples with two cracks were only tested for two exposure times (4 and 7 days). Also, part of a cylinder containing a brass shim was used as one of the $100 \%$ OPC concrete samples (P2SIP8) for 7 day exposure testing. For this sample, the approach taken was to measure the depth of chloride penetration in areas away from the shim.

It can be seen from the scans of the sample surfaces that the shape of the chloride front is strongly affected by the distribution of the coarse aggregate. This observation suggested that it would be appropriate to evaluate the depth of chloride penetration through both scenarios, i.e. including and excluding the influence of the aggregate. Depths of chloride penetration recorded with the aggregate excluded are, for the most part, smaller than depths obtained when the aggregate was included in the measurement. It appears that the coarse aggregate somehow facilitates the ingress of chloride ions into concrete. 
(a)

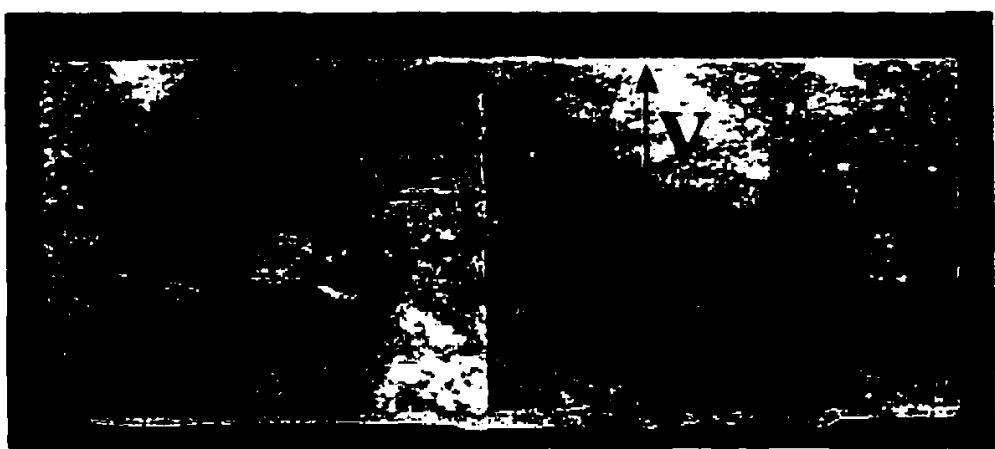

(b)

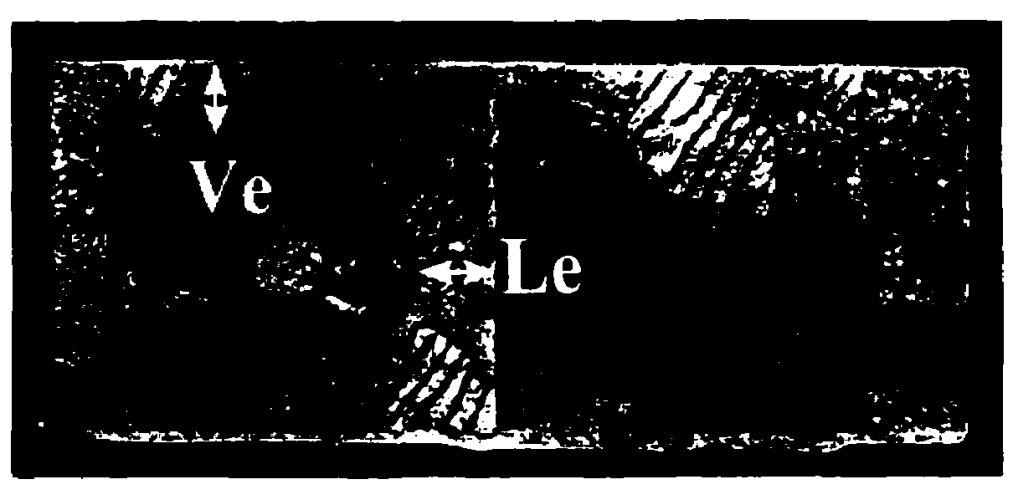

Figure 4.14 Measurement of the Chloride Penetration Depth, Sample PS1P8, $100 \%$ OPC, 16 Day Exposure: (a) - Including Aggregate, (b) - Excluding Aggregate.

The results of chloride X-ray mapping, discussed in Section 4.3, indicated that chlorides diffuse in concrete mainly through the cement paste fraction, as chloride content in the aggregate approached the background. In order to substantiate this finding, additional quantitative SEM/EDX spot analysis was performed. It was established that the concentration of chlorides in the aggregate particles, located inside the chloride diffused areas, is of the same magnitude as the concentration in particles not exposed to chlorides. These concentrations are very small 
Table 4.5 Depth of Chloride Penetration vs Time, $100 \%$ OPC Concrete.

\begin{tabular}{|l|c|c|c|c|c|}
\hline \multirow{2}{*}{$\begin{array}{l}\text { Type of } \\
\text { Crack }\end{array}$} & $\begin{array}{c}\text { Exposure } \\
\text { Time, } \\
\text { (Days) }\end{array}$ & \multicolumn{3}{|c|}{ Depth of Chloride Penetration, (mm) } \\
\cline { 3 - 6 } & & $\begin{array}{c}\text { Vertical } \\
\text { Including } \\
\text { Aggregate, } \\
(\mathrm{V})\end{array}$ & $\begin{array}{c}\text { Excluding } \\
\text { Aggregate, } \\
\text { (Ve) }\end{array}$ & $\begin{array}{c}\text { Including } \\
\text { Aggregate, } \\
\text { (L) }\end{array}$ & $\begin{array}{c}\text { Excluding } \\
\text { Aggregate, } \\
\text { (Le) }\end{array}$ \\
\hline No Crack & 4 & 7.05 & 4.36 & - & - \\
\cline { 2 - 6 } & 16 & 10.56 & 8.52 & - & - \\
\hline Single & 36 & 14.15 & 13.21 & - & - \\
Smooth & 4 & 5.33 & 4.10 & 11.11 & 8.28 \\
\cline { 2 - 6 } & 16 & 10.50 & 7.38 & 13.11 & 10.58 \\
\hline Double & 1 & 12.88 & 11.16 & 11.10 & 11.03 \\
\hline Smooth & 4 & 2.76 & 1.98 & 8.04 & 7.29 \\
\cline { 2 - 6 } & 7 & 8.64 & 3.33 & 9.27 & 7.05 \\
\cline { 2 - 6 } & & & 6.27 & 11.71 & 9.62 \\
\hline
\end{tabular}

and fall below the EDX detection limits ( $0.2 \%$ by mass of analyzed area).

Since it was found from the abovementioned tests that the coarse aggregate particles do not significantly contribute to chloride ingress by acting as a diffusion media, it is likely that the aggregate-cement paste transition zone serves as the accelerating chloride diffusion pathway. To confirm this, it would be useful to measure the chloride content in this zone and compare it with the chloride content in the adjacent cement paste. Such analysis could be performed using SEM/EDX. Unfortunately, the SEM/EDX system was out of service and these tests could not be completed. 
Table 4.6 Depth of Chloride Penetration vs Time, $25 \%$ Slag Concrete.

\begin{tabular}{|c|c|c|c|c|c|}
\hline \multirow{3}{*}{$\begin{array}{l}\text { Type of } \\
\text { Crack }\end{array}$} & \multirow{3}{*}{$\begin{array}{c}\text { Exposure } \\
\text { Time, } \\
\text { (Days) }\end{array}$} & \multicolumn{4}{|c|}{ Depth of Chloride Penetration, (mm) } \\
\hline & & \multicolumn{2}{|c|}{ Vertical } & \multicolumn{2}{|c|}{ Lateral } \\
\hline & & $\begin{array}{l}\text { Including } \\
\text { Aggregate, } \\
\text { (V) }\end{array}$ & $\begin{array}{c}\text { Excluding } \\
\text { Aggregate, } \\
(\mathrm{Ve})\end{array}$ & $\begin{array}{l}\text { Including } \\
\text { Aggregate, } \\
\text { (L) }\end{array}$ & $\begin{array}{c}\text { Excluding } \\
\text { Aggregate, } \\
(\text { Le })\end{array}$ \\
\hline \multirow[t]{3}{*}{ No Crack } & 4 & 4.44 & 1.63 & - & - \\
\hline & 16 & 6.31 & 4.24 & - & - \\
\hline & 36 & 7.94 & 5.49 & - & - \\
\hline \multirow{3}{*}{$\begin{array}{l}\text { Single } \\
\text { Smooth }\end{array}$} & 4 & 3.01 & 1.82 & 8.82 & 6.88 \\
\hline & 16 & 7.69 & 3.45 & 14.57 & 12.62 \\
\hline & 36 & 6.82 & 5.01 & 15.47 & 13.16 \\
\hline \multirow{3}{*}{$\begin{array}{l}\text { Double } \\
\text { Smooth }\end{array}$} & 1 & - & - & - & - \\
\hline & 4 & 4.69 & 3.19 & 6.47 & 5.91 \\
\hline & 7 & 6.97 & 4.74 & 9.58 & 8.15 \\
\hline
\end{tabular}

When comparing chloride penetration depths summarized in Tables 4.5 and 4.6 , a fairly good agreement can be noticed among the depths of penetration for the same concrete type, exposure time, and diffusion direction. With regard to concrete type, the vertical chloride penetration depths for $25 \%$ slag concrete are smaller than for $100 \%$ OPC concrete, which is consistent with chloride bulk diffusion test results. However, the same trend can not be observed for lateral penetration. It must also be noted that lateral depths of chloride penetration (measured from the crack walls towards the bulk of the sample) are generally bigger than corresponding vertical depths. This could be attributed either to the anisotropic nature of concrete or to 
particular properties of the cracks, and will be discussed further.

From Crank's solution (Equation 2-2) to Fick's second law of diffusion, a relationship between chioride penetration depth and time can be derived for a certain chloride concentration (about $0.15 \%$ of soluble chlorides by mass of cement, Otsuki, et al., 1992), at which a change in color of the silver nitrate sprayed concrete surface takes place. That is, the depth of chloride penetration is linearly proportional to the square root of time.

Typical plots of chloride penetration depth, both including and excluding the aggregate, versus the square root of time are presented in Figures 4.15 and 4.16 for vertical and lateral depths respectively. The best fit lines to the chloride penetration depths excluding the aggregate were obtained from regression analysis and are also shown in the graphs. A complete set of such charts for all samples is given in Appendix J.

It can be noticed from the charts that the relationship between vertical depth of chloride penetration excluding the influence of aggregate and square root of time closely follows the theoretically predicted linear proportionality for all samples. That includes the zero penetration depth corresponding to zero exposure time. The plots for vertical depths including the aggregate slightly deviate from the straight line, and do not exactly coincide with the $(0,0)$ coordinates. This limited data would suggest that the presence of coarse aggregate in concrete modifies the diffusion theoretically described by Fick's second law. The use of this law for concrete, then, implies that the influence of aggregate on chloride diffusion is being disregarded.

The plots of lateral depths (both including and excluding aggregate) versus square root of time produced a poorer fit to the theory for all cracked samples, with the exception of the 25 $\%$ slag concrete samples containing two cracks, which were not tested for 1 day chloride 


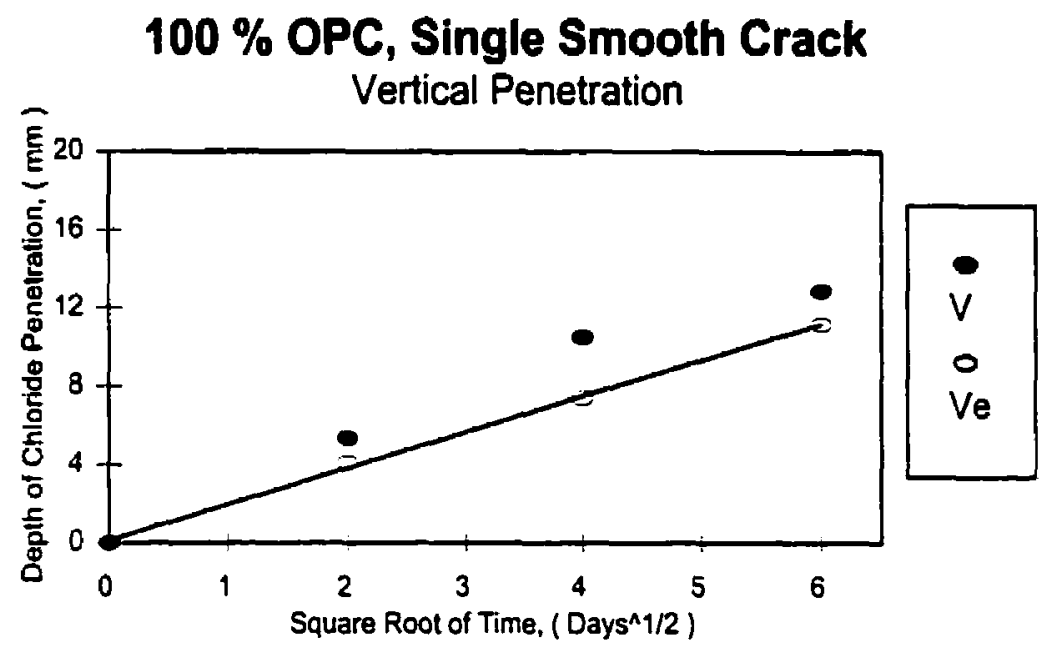

Figure 4.15 Typical Plot of Vertical Chloride Penetration Depth vs Square Root of Time.

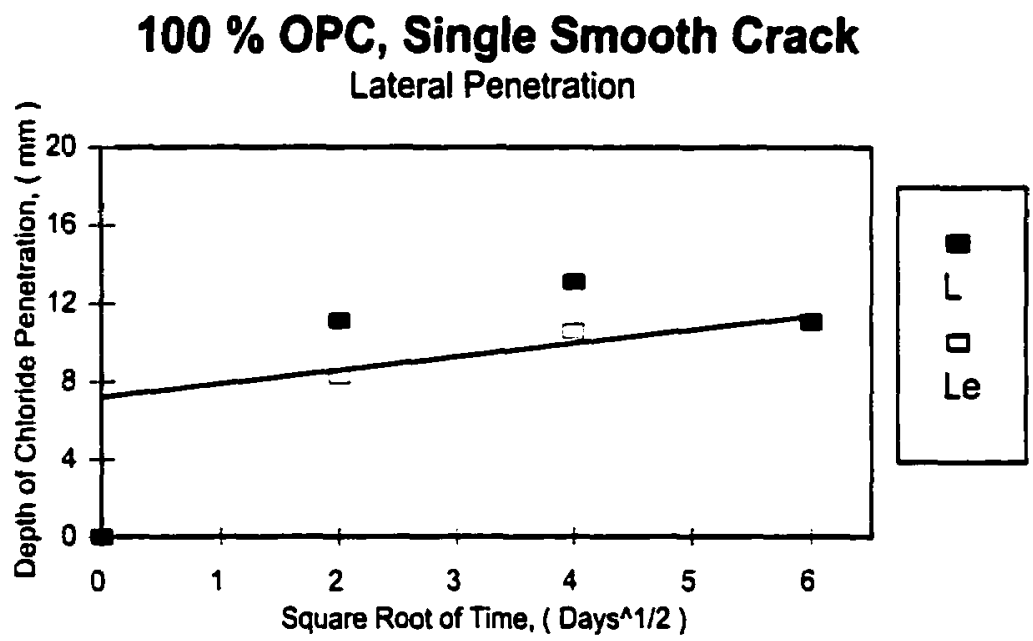

Figure 4.16 Typical Plot of Lateral Chloride Penetration Depth vs Square Root of Time. 
exposure. It is reasonable to assume that if these samples were tested for the third exposure time, the plot would likely show the same trend as for other samples. Since such testing was not performed, it would be unsystematic to compare the $25 \%$ slag double cracked samples set with other sets, and it should be left out of the discussion.

It can also be observed that the best fit straight lines to the lateral penetration depth values excluding the aggregate cross the vertical axis well above zero. This can be attributed to the fact that the obtained lateral depths of chloride penetration are larger than corresponding vertical depths. In order to verify whether the anisotropic nature of concrete could be causing the cracked samples to exhibit variation in chloride penetration depth in different directions (namely in the directions parallel and perpendicular to the casting direction), a further investigation was conducted.

An additional set of samples from each concrete was exposed to the salt solution. Samples were obtained by cutting $100 \mathrm{~mm}$ in diameter by $40 \mathrm{~mm}$ thick concrete discs across the diameter into two halves. Then, they were sealed with grey epoxy, in one case, leaving a newly cut surface exposed (corresponds to the lateral diffusion), and, in another case, leaving one of the half disk faces open (corresponds to the vertical diffusion). After 8.5 and 24 hour exposures, chloride penetration depths including and excluding aggregate were measured. No significant variation between lateral and vertical depths was detected, which points out that the depth of chloride penetration is independent of exposure direction in the uncracked concrete.

Another explanation as to why the lateral chloride penetration depths are bigger than the corresponding vertical ones could be that during the vacuum saturation procedure before the test the crack wall surfaces did not get properly saturated. This could result in some absorption 
taking place at the crack walls in the first few hours (or days) of chloride exposure until samples became completely saturated and pure diffusion replaced the absorption.

If this assumption is correct, then, the obtained values of lateral depths are the result of two transport mechanisms (absorption and diffusion), whereas, the vertical penetration was only governed by diffusion. To obtain an estimate of the chloride penetration depth caused by this possible absorption, the value of 4 day vertical depth excluding the aggregate was subtracted from the corresponding value of lateral depth for samples containing a single crack. For $100 \%$ OPC concrete samples with two cracks, values of 1 day chloride penetration were used. By subtracting the obtained value of penetration depth caused by absorption, the penetration depth resulting from pure diffusion could be found. Figure 4.17 shows an example of the lateral chloride penetration depth calculated in this fashion plotted against the square root of time. The corresponding graphs for these three sets of samples are attached in Appendix $\mathrm{J}$.

It appears that the elimination of the 'absorption component' from the lateral depth of chloride penetration produces a much better fit of results to the theoretical prediction. In an attempt to confirm the hypothetical assumption that the initial absorption in the crack walls contributed to the lateral chloride ingress during the test, a short saturation study was carried out.

Two samples containing single smooth cracks and two uncracked samples per mix were vacuum saturated and placed in salt solution, just like for the test. The masses of the samples were recorded prior to the saturation procedure, and then, they were monitored during five days. The results are given in Appendix J. The average percentage mass gain of two companion samples was calculated and plotted against time (Figure 4.18).

It is evident that a complete saturation of samples does not occur after the initial 24 hour Influence of Cracks on Chloride Ingress into Concrete 


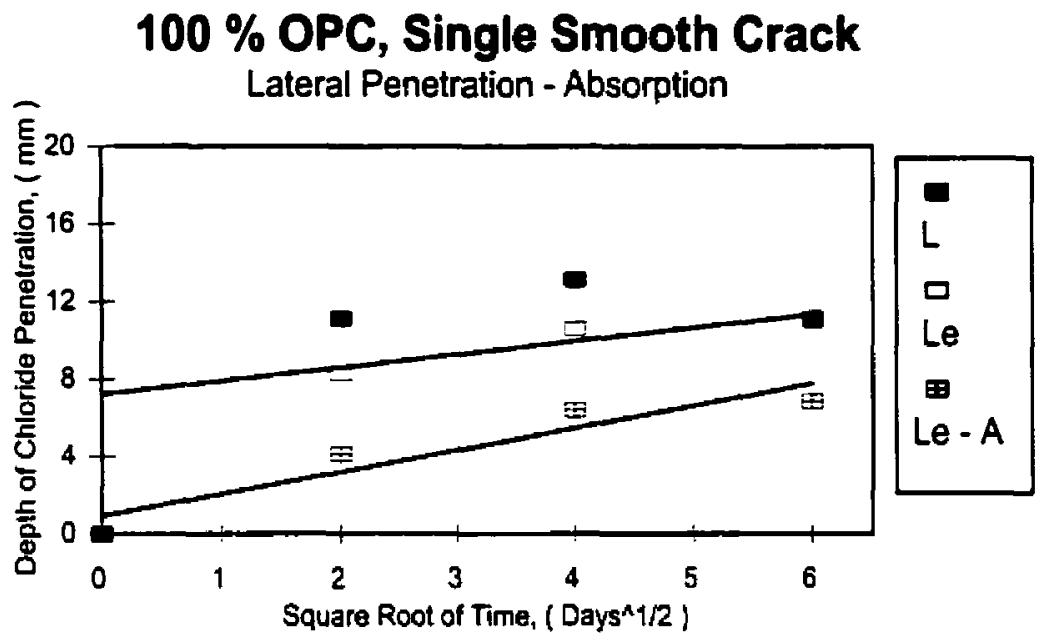

Chloride Penetration Depth Due to Absorption $(A)=\mathrm{Le}_{4}-\mathrm{Ve}_{4}=4.18 \mathrm{~mm}$.

Figure 4.17 Lateral Depth of Chloride Penetration Excluding Absorption Effect vs Square Root of Time.

saturation (ASTM C1202-97 conditioning procedure). In other words, both cracked and uncracked samples are not fully saturated in the beginning of the salt exposure. However, it seems that cracked samples gain less mass in the following 24 hours, which does not indicate that they were saturated to any smaller degree than the uncracked samples prior to testing. This observation does not support the assumption that incomplete saturation could be the cause of the high lateral chloride penetration depths. A more in-depth study is needed to uncover the nature of this phenomena.

The results and discussion on the chloride penetration depth for different exposure times 


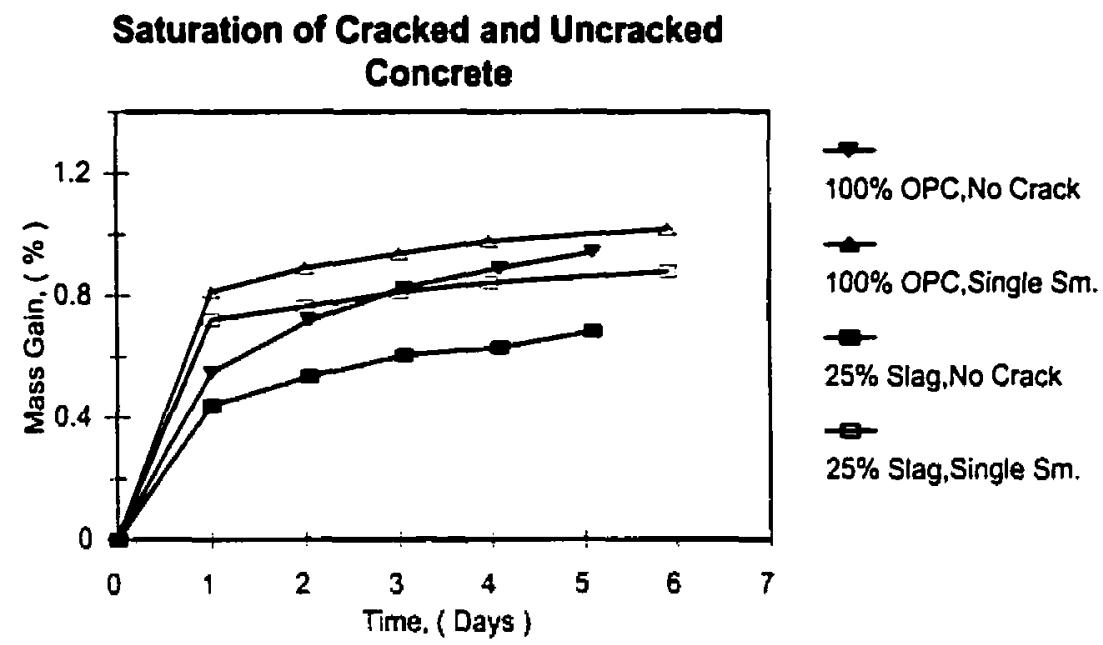

Figure 4.18 Saturation of Samples Containing Single Smooth Crack and No Crack.

can be summarized as follows:

- The shape and depth of the chloride penetration front in concrete are strongly influenced by the distribution of the coarse aggregate. It is likely that the aggregate-cement paste transition zone facilitates a more rapid chloride ingress. Further research on this subject is required.

- For both cracked and uncracked concretes, the relationship between the vertical depth of chloride penetration and the square root of time approaches a linear proportionality with some deviations due to the presence of aggregate.

- The lateral depths of chloride penetration for cracked concrete are bigger than the corresponding vertical ones. The lateral penetration depths are not linearly proportional to the square root of time. It is possible that 24 hour water saturation procedure does not 
provide full saturation of the crack walls in the cracked samples prior to salt exposure. If that is so, incomplete saturation could lead to initial chloride ingress by absorption during the chloride bulk diffusion test and result in higher depths of lateral penetration. Further study on this phenomena is needed. 


\section{Chapter 5 Conclusions and Recommendations}

\subsection{Conclusions}

In this study, specimens from two types of concrete were either saw cut or fractured to produce transecting, parallel-wall cracks with smooth or rough surfaces respectively. The cracked samples were sealed on all faces except one, creating cracks with depth of $40 \mathrm{~mm}$ and widths ranging from 0.06 to $0.74 \mathrm{~mm}$. The results obtained are not necessarily applicable to finer crack widths or near the tips of tapered cracks. Within the above scope, the following conclusions can be made:

1. Based on the results of chloride bulk diffusion testing it can be concluded that chloride diffusion in concrete containing transecting, parallel-wall cracks of the considered widths is independent of either crack width or the crack wall roughness.

2. Transecting, parallel-wall cracks in the range of widths studied in this project behave like free concrete surfaces, greatly contributing to lateral chloride diffusion.

3. Lateral diffusion of cillorides from the crack walls into the bulk of the concrete sample is fairly uniform along the crack length, as shown by SEM/EDX chloride profiling and chloride penetration depth measurement.

4. Chloride diffusion in the concrete containing the transecting crack becomes a case of two-dimensional diffusion.

5. In the case of two-dimensional diffusion, Fick's second law can be used to obtain an estimate of the values of the diffusion coefficient with a reasonable degree of reliability. 
However, it is not accurate for predicting chloride concentration profiles.

6. A 2D simulation approach was proposed for predicting the chloride concentration profile for the case of two-dimensional diffusion.

7. In the case of one-dimensional diffusion, the Jandell-Table Curve software package is more accurate for determining the values of the diffusion coefficient from experimental data points than the ConFlux package.

8. Concrete containing $25 \%$ replacement of cement by blast fumace slag possesses a better ability to resist the ingress of chloride ions than $100 \%$ OPC concrete. Both concretes had a 0.40 water to cementitious materials ratio.

9. The penetration of chloride ions into concrete is greatly affected by the presence of coarse aggregate. It is likely that the aggregate-cement paste transition zone promotes the ingress of chlorides.

10. For both cracked and uncracked concretes, it was demonstrated that the vertical chloride penetration depth is linearly proportional to the square root of time, as can be predicted from Fick's second law.

11. For the chloride bulk diffusion test, the lateral depths of chloride penetration in cracked samples (from the crack wall into the bulk of the sample) were found to be bigger than the corresponding vertical ones. It is possible that the 24 hour water saturation procedure used for this test does not provide complete saturation of the crack surfaces, and, thus, fails to isolate diffusion as the predominant transport mechanism during the test. However, this hypothesis was not confirmed. 


\subsection{Recommendations}

1. In this work the influence of the artificially created, transecting, roughly constant width cracks on the chloride ingress into concrete was studied. The influence of other types of cracks, e.g. V-shape, should be investigated.

2. The smallest crack width considered in this project was in the range of $0.1 \mathrm{~mm}$. Since these cracks were found to greatly contribute to the chloride ingress, a smaller range of transecting cracks needs to be examined.

3. The experimental data obtained during the chloride bulk diffusion test point to the existence of some dispersion in values of surface concentration within the same set of experimental variables. The surface concentration values can deviate by up to $0.3 \%$ by mass of concrete, which complicates the analysis when the surface concentration needs to be accurately estimated (Conflux). It would be heipful to uncover the reasons of such variation.

4. For diffusion cell testing of cracked concrete, a concentration monitoring technique that would not interfere with the diffusion process needs to be identified.

5. The influence of coarse aggregate on chloride ingress should be more extensively studied. It would be useful to measure the chloride content in the aggregate-cement paste transition zone and compare it with the content in the adjacent cement paste. SEM/EDX could facilitate such analysis.

6. In order to more accurately illustrate that the depth of chloride penetration resulting from diffusion is linearly proportional to the square root of time, cement paste or mortar 
samples should be used.

7. Further in-depth research is required to study the causes of high lateral chloride penetration depths during chloride diffusion exposure of cracked samples. 


\section{Chapter 6 References}

ACI Committe 224R-90, Control of Cracking in Concrete Structures, ACI Manual of Concrete Practice, Part 3, American Concrete Institute, Farmington Hills, Michigan, 1998.

ACl Committe 222R-96, Corrosion of Metals in Concrete, ACI Manual of Concrete Practice, Part 1, American Concrete Institute, Farmington Hills, Michigan, 1999.

Aldea, C.M., Shah, S.P., and Karr, A., Permeability of Cracked Concrete, Materials and Structures, Vol. 32, No. 219, Jun. 1999-1, pp. 370-376.

Aldea, C.M., Shah, S.P., and Karr, A., Effect of Cracking on Water and Chloride Permeability of Concrete, Journal of Materials in Civil Engineering, Vol. 11, No. 3, Aug. 1999-2, pp. 181-187.

Arya, C., When Cracks Start to Show, Concrete, Vol. 29, No. 6, Nov.-Dec. 1995, pp.22-23.

Arya, C. and Ofori-Darko, F.K., Influence of Crack Frequency on Reinforcement Corrosion in Concrete, Cement and Concrete Research, Vol. 26, No. 3, Mar. 1996, pp.345-353.

ASTM C1202-97, Standard Test Method for Electrical Indication of Concrete's Ability to Resist Chloride Ion Penetration, Annual Book of ASTM Standards, Vol. 04.02, ASTM, West Conshohocken, PA, 2000, pp. 639-644.

Bentur, A., Diamond, S., and Berke, N.S., Steel Corrosion in Concrete, E\&FN Spon, London, 1997.

Beeby, A.W., Corrosion of Reinforcing Steel in Concrete and its Relation to Cracking, The Structural Engineer, Vol.56A, No. 3, Mar. 1978, pp.77-81.

Borgard, B., Ramirez, C., Somayaji, S., Jones, D., Keeling, D., and Heidersbach, R., Failure Analysis in Concrete Structures: A Comparison of Field Data with Results from Laboratory Exposures, Corrosion, Vol. 47, No.10, Oct. 1991, pp.758-769.

Breysse, D., Gerard, B., and Lasne, M., An Experimental Device to Study Cracking and Deterioration of Concrete, Durability of Concrete, Third International Conference, Nice, France; CANMET/ACI SP-170, Detroit, Michigan,1994, pp. 1013-1032.

Breysse, D. and Gerard, B., Micro-Macro Modeling for Transport in Uncracked and Cracked 
Concrete, Mass-Energy Transfer and Deterioration of Building Components, CSTB/BRI Coll., Paris, Jan. 1995, pp. 69-96.

Breysse, D. and Gerard, B., Transport of Fluids in Cracked Media, Penetration and Permeability of Concrete: Barriers to Organic and Contaminating Liquids, RILEM Report 16, E\&FN Spon, London, 1997, pp. 123-153.

Buenfeld, N.R. and Newman, J.B., Examination of Three Methods for Studying Ion Diffusion in Cement Pastes, Mortars and Concrete, Material and Structures, Vol. 20, No. 115, Jan. 1987, pp. 3-10.

Buenfeld, N.R., Shurafa-Daoudi, M.T., and McLoughlin, I.M., Chloride Transport Due to Wick Action in Concrete, Proceedings of the RILEM International Workshop on Chloride Penetration into Concrete, St-Remy-les-Chevreuse, France, Oct. 15-18, 1995, pp. 315324.

Campbell-Alan, D. and Roper, H., Concrete Structures: Materials, Maintenance and Repair, Longman Scientific and Technical, Harlow, England, 1991.

CRC Handbook of Chemistry and Physics, Chemical Rubber Company Press, Cleveland, Ohio, 1977.

Denes, T. and Buck, A.D., An Experiment to Investigate Chloride Intrusion on Construction Joints in Concrete; Cement, Concrete, and Aggregates, Vol. 9, No. 2, Winter 1987, pp. 80-81.

De Schutter, G., Quantification of the Influence of Cracks in Concrete Structures on Carbonation and Chloride Penetration, Magazine of Concrete Research, Vol. 51, No. 6, Dec. 1999, pp. 427-435.

De Schutter, G., Durability of Marine Concrete Structures Damaged by Early Age Thermal Cracking, International RILEM Workshop on Life Prediction and Aging Management of Concrete Structures, Cannes, France, Oct. 16-17, 2000.

Edvardsen, C., Chloride Penetration into Cracked Concrete, Proceedings of the RILEM Intemational Workshop on Chloride Penetration into Concrete, St-Remy-les-Chevreuse, France, Oct. 15-18, 1995, pp. 243-249.

Edvardsen, C., Water Penetrability and Autogenous Healing of Separation Cracks in Concrete, Betonwerk und Fertigteil Technik-Concrete Precasting Plant and Technology, Vol.62, No. 11, Nov. 1996, pp. 77-85.

Edvardsen, C., Water Permeability and Autogenous Healing of Cracks in Concrete, ACI 
Materials Journal, Vol. 96, No. 4, Jul.-Aug. 1999, pp. 448-454.

Eriksen, K., Thaulow, N., and Grelk, B., Micro-Defects Influence on Chloride Penetration in Concrete, Report 75, A/S Storebalt, Vejdirektoratet, Denmark, 1996.

Frederiksen, J.M., Nilsson, L.O., Sandberg, P., Poulsen, E., Tang, L., and Andersen, A., A System for Estimation of Chloride Ingress into Concrete, Theoretical Background, HETEK Report No. 83, The Danish Road Directorate, 1997.

Francois, R. and Maso, J.C., Effect of Damage in Reinforced Concrete on Carbonation or Chloride Penetration, Cement and Concrete Research, Vol. 18, No. 6, Jun. 1988, pp. 961-970.

Francois, R., Arliguie, G., and Konin, A., Modeling The Modification of Chloride Penetration in Relation to ITZ Damage, The Interfacial Transition Zone in Cementitious Composites, E\&FN Spon, London, UK, 1998, pp. 93-102.

Francois, R. and Arliguie, G., Effect of Microcracking and Cracking on The Development of Corrosion in Reinforced Concrete Members, Magazine of Concrete Research, Vol. $5 \mathrm{I}$, No. 2, Apr. 1999, pp. 143-150.

Gabriel, B.L., SEM: A User's Manual for Materials Science, American Society for Metals, Metals Park, Ohio, 1985.

Gerard, B., Reinhardt, H.W., and Breysse, D., Measured Transport in Cracked Concrete, Penetration and Permeability of Concrete: Barriers to Organic and Contaminating Liquids, RILEM Report 16, E\&FN Spon, London, 1997, pp. 265-324.

Gerard, B., Jacobsen, S., and Marchand, J., Concrete Cracks II: Observation and PermeabilityA Review, Concrete Under Severe Conditions 2, Proceedings of the Second International Conference, Tromso, Norway, Jun. 21-24, 1998; E\&FN Spon, London, pp. 183-197.

Gerard, B. and Marchand, J., Influence of Cracking on the Diffusion Properties of CementBased Materials, Part I: Influence of Continuous Cracks on the Steady-State Regime, Cement and Concrete Research, Vol.30, No.1, Jan. 2000, pp. 37-43.

Goldstein, J.I., Newbury, D.E., Echlin, P., Joy, D.C., Fiori, C., and Lifshin, E., Scanning Electron Microscopy and X-Ray Microanalysis: A Text for Biologists, Material Scientists, and Geologists, Plenum Press, New York, 1981.

Gowripalan, N., Sirivivatnanon, V., and Lim, C.C., Chloride Diffusivity of Concrete Cracked in Flexure, Cement and Concrete Research, Vol. 30, No. 5, May 2000, pp. 725-730. 
Hartl, G. and Lukas, W., Investigation on the Penetration of Chloride into Concrete and on the Effect of Cracks on Chloride-Induced Corrosion of Reinforcement, Betonwerk und Fertigteil Technik-Concrete Precasting Plant and Technology, Vol. 53, No. 7, Jul.1987, pp.497-506.

Hong, K., Cyclic Wetting and Drying and its Effects on Chloride Ingress in Concrete, M.A.Sc. Thesis, University of Toronto, Toronto, Ontario, 1998.

Hooton, R. D. and McGrath, P.F., Issues Related to Recent Developments in Service Life Specifications for Concrete Structures, Proceedings of the RILEM International Workshop on Chloride Penetration into Concrete, St-Remy-les-Chevreuse, France, Oct. 15-18, 1995, pp. 388-397.

Jacobsen, S., Marchand, J., and Boisvert, L., Effect of Cracking and Healing on Chloride Transport in OPC Concrete, Cement and Concrete Research, Vol. 26, No. 6, Jun. 1996, pp. 869-88I.

Jacobsen, S., Marchand, J., and Gerard, B., Concrete Cracks 1: Durability and Self Healing - A Review, Proceedings of the Second International Conference on Concrete under Severe Conditions, Tromso, Norway, Jun. 21-24, 1998, pp.217-231.

Konin, A., Francois, R., and Arliguie, G., Penetration of Chlorides in Relation to the Microcracking State into Reinforced Ordinary and High Strength Concrete, Materials and Structures, Vol. 31, No. 209, Jun. 1998, pp. 310-316.

Lim, C.C., Gowripalan, N., and Sirivivatnanon, V., Microcracking and Chloride Permeability of Concrete under Uniaxial Compression, Cement and Concrete Composites, Vol. 22, No. 5, Oct. 2000, pp. 353-360.

Locoge, P., Massat, M., Ollivier, J. P., and Richet C., Ion Diffusion in Microcracked Concrete, Cement and Concrete Research, Vol. 22, No. 2-3, Mar.-May 1992, pp. 431-438.

Lorentz, T. and French, C., Corrosion of Reinforcing Steel in Concrete: Effects of Material, Mix Composition, and Cracking, ACI Materials Joumal, Vol. 92, No. 2, Mar.-Apr. 1995, pp. $181-190$.

Mailvaganam, N.P., Repair and Protection of Concrete Structures, CRC Press, Boca Raton Ann Arbor, London, 1992.

Mangat, P.S. and Gurusamy, K., Chloride Diffusion in Steel Fibre Reinforced Marine Concrete, Cement and Concrete Research, Vol. 17, No. 3, Mar. 1987, pp. 385-396.

Marchand, J., Gerard, B., and Delagrave, A., Ion Transport Mechanisms in Cement-Based 
Materials, Materials Science of Concrete, American Ceramic Society, Westerville, Ohio, 1989, pp. 307-399.

Marchand, J. and Gerard, B., New Developments in the Modeling of Mass Transport Processes in Cement-Based Composites: A Review, Advances in Concrete Technology, Proceedings of the Second International Symposium, Las-Vegas, Nevada; CANMET/ACI SP-154, Detroit, Michigan, 1995, pp. 169-210.

Mays, G., Durability of Concrete Structures (Investigation, Repair, Protection), E\&FN Spon, London, 1992.

McGrath, P.F., Development of Test Methods for Predicting Chloride Penetration into High Performance Concrete, Ph.D. Thesis, University of Toronto, Toronto, Ontario, 1996.

Neville, A., Chloride Attack of Reinforced Concrete: An Overview, Materials and Structures, Vol. 28, No. 176, Mar. 1995, pp. 63-70.

Nilsson, L-O., Penetration of Chlorides into Concrete Structures - An Introduction and Some Definitions, Nordic Seminar on Chloride Initiated Reinforcement Corrosion in Concrete, Jan. 14-15, 1993, Gothenburg, Sweden, pp. 7-17.

Otsuki, N., Nagataki, S., and Nakashita, K., Evaluation of $\mathrm{AgNO}_{3}$ Solution Spray Method for Measurement of Chloride Penetration into Hardened Cementitious Matrix Materials, ACI Materials Journal, Vol. 89, No. 6, Nov.-Dec. 1992, pp. 587-592.

Otsuki, N., Miyazato, S., Diola, N.B., and Suzuki, H., Influences of Bending Crack and WaterCement Ratio on Chloride-Induced Corrosion of Main Reinforcing Bars and Stirrups, ACI Materials Journal, Vol. 97, No. 4, Jul.-Aug. 2000, pp. 454-464.

Page, C.L., Short, N.R., and El Tarras, A., Diffusion of Chloride Ions in Hardened Cement Pastes, Cement and Concrete Research, Vol. 11, No. 3, Mar. 1981, pp. 395-406.

Pettersson, K., Criteria for Cracks in Connection With Corrosion in High Strength Concrete, Fourth International Symposium on Utilization of High-Strength/High-Performance Concrete, Paris, France, 1996, pp. 509-517.

Pettersson, K. and Sandberg, P., Chloride Threshold Levels, Corrosion Rates and Service Life for Cracked High-Performance Concrete, Durability of Concrete, Fourth International Conference, Sydney, Australia; CANMET/ACI SP-170, Farmington Hills, Michigan, 1997, pp. 451-472.

Raharinaivo, A., Brevet, P., Grimaldi, G., and Pannier, G., Relationship between Concrete Deterioration and Reinforcing-Steel Corrosion, Durability of Building Materials, Vol. 
4,1986, pp. $97-112$

RILEM, Damage Classification of Concrete Structures, Draft Recommendation, Materials and Structures, Vol. 27, No. 170, Jul. 1994, pp. 362-369.

Saito, M., Obta, M., and Ishimori, H., Chloride Permeability of Concrete Subjected to FreezeThaw Damage, Cement and Concrete Composites, Vol.16, No. 4, 1994, pp. 233-239.

Saito, M. and Ishimori, H., Chloride Permeability of Concrete under Static and Repeated Compressive Loading, Cement and Concrete Research, Vol. 25, No. 4, Apr. 1995, pp. 803-808.

Samaha, H.R. and Hover, K.C., Influence of Microcracking on the Mass Transport Properties of Concrete, ACI Materials Journal, Vol. 89, No. 4, Jul.-Aug. 1992, pp. 416-424.

Sandberg, P. and Tang, L., A Field Study of the Penetration of Chlorides and Other Ions into a High Quality Concrete Marine Bridge Column, Durability of Concrete, Third International Conference, Nice, France; ACI SP-145, Detroit, Michigan, 1994, pp. 557571.

Sakai, K. and Sasaki, S., Ten Year Exposure Test of Precracked Reinforced Concrete in a Marine Environment, Durability of Concrete, Third International Conference, Nice, France; ACI SP-145, Detroit, Michigan, 1994, pp. 353-369.

Schiessl, P. and Raupach, M., Laboratory Studies and Calculations on the Influence of Crack Width on Chloride-Induced Corrosion of Steel in Concrete, ACI Materials Journal, Vol. 94, No. 1, Jan.-Feb. 1997, pp.56-62.

Suryavanshi, A.K., Swamy, R.N., and McHugh, S., Chloride Penetration into Reinforced Concrete Slabs, Canadian Journal of Civil Engineering, Vol. 25, No. 1, Feb. 1998, pp. 87-95.

Suzuki, K., Ohno, Y., Praparntanatorn, S., Ninomiya, H., and Tamura, H., Influence of Flexural Crack on Corrosion of Steel in Concrete, Technology Reports of the Osaka University, Vol.39, No. 1953, Apr. 1989, pp. 49-57.

Suzuki, K., Ohno, Y., Praparntanatom, S., and Tamura, H., Mechanism of Steel Corrosion in Cracked Concrete, Corrosion of Reinforcement in Concrete Construction, Third International Symposium, Wishaw, UK; Elsevier Applied Science, 1990, pp. 19-28.

Thaulow, N. and Grelk, B., Micro Defects Influence on Chloride Ingress into Concrete, Phase 1.1: Preliminary Tests on Chloride Ingress by Diffusion and Penetration, Technical Report, Storebeltsforbindelsen A/S (Great Belt Link A/S), Copenhagen, Apr. 
1993.

Thuresson, T., Hansson, C.M., Seabrook, P.T., and Tullmin, M., Effect of Cracking and Accelerated Curing on the Corrosion of Steel Embedded in High Performance Concretes Exposed to an Industrial Effluent, Fourth International Conference, Sydney, Australia; CANMET/ACI SP-170, Farmington Hills, Michigan, 1997, pp. 965-986.

Volkwein, A., Penetration of Chlorides into Concrete - Phenomena and Consequences. Points of View Based on 20 Years Research and Site Experience with Deicing Salts, Proceedings of the RILEM Intemational Workshop on Chloride Penetration into Concrete, St-Remy-les-Chevreuse, France, Oct. 15-18, 1995, pp. 325-333.

Wang, K., Igusa, T., and Shah, S.P., Permeability of Concrete - Relationships to Its Mix Proportion, Microstructure and Microcracks, Materials Science of Concrete: The Sidney Diamond Symposium, American Ceramic Society, Westerville, Ohio, 1998, pp. 45-54.

Wilkins, N.J.M. and Stiliwell, J.A., The Corrosion of Steel Reinforcement in Cracked Concrete Immersed in Seawater, International Conference on Concrete in the Marine Environment, London, Sep. 22-24, 1986; The Concrete Society, pp.143-156.

Zibara, H., Personal Communication, PhD Candidate, University of Toronto, Toronto, Ontario, 2001 . 


\section{APPENDIX A}

\section{CRACK WIDTH MEASUREMENT}


Crack Widths for Single Smooth Crack Samples

\begin{tabular}{|l|c|c|l|l|c|}
\hline \multicolumn{3}{|c|}{0.4, OPC } & \multicolumn{3}{c|}{$0.4,25 S L$} \\
\hline $\begin{array}{l}\text { Sample } \\
\text { ID }\end{array}$ & $\begin{array}{c}\text { Crack } \\
\text { Width, } \\
(\mathrm{mm})\end{array}$ & $\begin{array}{c}\text { Avg. Stand. } \\
\text { Deviation, } \\
\text { (mm) }\end{array}$ & $\begin{array}{l}\text { Sample } \\
\text { ID }\end{array}$ & $\begin{array}{c}\text { Crack } \\
\text { Width, } \\
\text { (mm) }\end{array}$ & $\begin{array}{c}\text { Avg. Stand. } \\
\text { Deviation, } \\
\text { (mm) }\end{array}$ \\
\hline PS1P1 & 0.102 & 0.036 & SS1P1 & 0.079 & 0.044 \\
\hline PS1P2 & 0.091 & 0.020 & SS1P2 & 0.099 & 0.039 \\
\hline PS1P3 & 0.113 & 0.010 & SS1P3 & 0.133 & 0.018 \\
\hline PS1P4 & 0.135 & 0.020 & SS1P4 & 0.121 & 0.021 \\
\hline PS1P5 & 0.113 & 0.010 & SS1P5 & 0.106 & 0.017 \\
\hline PS1P6 & 0.114 & 0.013 & SS1P6 & 0.106 & 0.017 \\
\hline PS1P7 & 0.120 & 0.021 & SS1P7 & 0.118 & 0.011 \\
\hline PS1P8 & 0.113 & 0.018 & SS1P8 & 0.098 & 0.012 \\
\hline PS3P1 & 0.370 & 0.025 & SS3P1 & 0.341 & 0.038 \\
\hline PS3P2 & 0.383 & 0.048 & SS3P2 & 0.319 & 0.040 \\
\hline PS5P1 & 0.677 & 0.038 & SS5P1 & 0.616 & 0.026 \\
\hline PS5P2 & 0.685 & 0.045 & SS5P2 & 0.616 & 0.022 \\
\hline PS1D1 & 0.115 & 0.031 & SS1D1 & 0.102 & 0.022 \\
\hline PS1D2 & 0.064 & 0.032 & SS1D2 & 0.078 & 0.027 \\
\hline PS3D1 & 0.361 & 0.033 & SS3D1 & 0.334 & 0.027 \\
\hline PS3D2 & 0.354 & 0.030 & SS3D2 & 0.350 & 0.042 \\
\hline PS5D1 & 0.737 & 0.057 & SS5D1 & 0.642 & 0.036 \\
\hline PS5D2 & 0.675 & 0.047 & SS5D2 & 0.619 & 0.024 \\
\hline
\end{tabular}


Crack Widths for Single Rough Crack Samples

\begin{tabular}{|c|c|c|c|c|c|}
\hline \multicolumn{3}{|c|}{$0.4, \mathrm{OPC}$} & \multicolumn{3}{|c|}{$0.4,25 \mathrm{SL}$} \\
\hline $\begin{array}{l}\text { Sample } \\
\text { ID }\end{array}$ & $\begin{array}{l}\text { Crack } \\
\text { Width, } \\
\text { (mm) }\end{array}$ & $\begin{array}{l}\text { Avg. Stand. } \\
\text { Deviation, } \\
\text { (mm) }\end{array}$ & $\begin{array}{l}\text { Sample } \\
\text { ID }\end{array}$ & $\begin{array}{l}\text { Crack } \\
\text { Width, } \\
\text { (mm) }\end{array}$ & $\begin{array}{l}\text { Avg. Stand. } \\
\text { Deviation, } \\
\text { (mm) }\end{array}$ \\
\hline PRIPI & 0.097 & 0.019 & SRIPI & 0.099 & 0.017 \\
\hline PRIP2 & 0.104 & 0.019 & SRIP2 & 0.100 & 0.026 \\
\hline PR3PI & 0.297 & 0.021 & SR3PI & 0.284 & 0.037 \\
\hline PR3P2 & 0.286 & 0.013 & SR3P2 & 0.323 & 0.026 \\
\hline PRSPI & 0.466 & 0.035 & SR5PI & 0.472 & 0.028 \\
\hline PR5P2 & 0.471 & 0.039 & SR5P2 & 0.467 & 0.054 \\
\hline
\end{tabular}


Crack Widths for Double Smooth Crack Samples

\begin{tabular}{|c|c|c|c|c|c|}
\hline \multicolumn{3}{|c|}{$0.4, \mathrm{OPC}$} & \multicolumn{3}{|c|}{$0.4,25 \mathrm{SL}$} \\
\hline $\begin{array}{l}\text { Sample } \\
\text { ID }\end{array}$ & $\begin{array}{l}\text { Crack } \\
\text { Width, } \\
\text { (mm) }\end{array}$ & $\begin{array}{l}\text { Avg. Stand. } \\
\text { Deviation, } \\
\text { (mm) }\end{array}$ & $\begin{array}{l}\text { Sample } \\
\text { ID }\end{array}$ & $\begin{array}{l}\text { Crack } \\
\text { Width, } \\
(\mathrm{mm})\end{array}$ & $\begin{array}{l}\text { Avg. Stand. } \\
\text { Deviation, } \\
(\mathrm{mm})\end{array}$ \\
\hline \multirow[t]{2}{*}{ P2S1P3 } & 0.123 & 0.013 & \multirow[t]{2}{*}{ S2S!P3 } & 0.148 & 0.015 \\
\hline & 0.101 & 0.015 & & 0.112 & 0.016 \\
\hline \multirow[t]{2}{*}{ P2S1P4 } & 0.110 & 0.015 & \multirow[t]{2}{*}{ S2S1P4 } & 0.133 & 0.010 \\
\hline & 0.113 & 0.013 & & 0.113 & 0.015 \\
\hline \multirow[t]{2}{*}{ P2SIP5 } & 0.106 & 0.011 & \multirow[t]{2}{*}{ S2S1P5 } & 0.089 & 0.016 \\
\hline & 0.092 & 0.008 & & 0.132 & 0.013 \\
\hline \multirow[t]{2}{*}{ P2S1P6 } & 0.089 & 0.012 & \multirow[t]{2}{*}{ S2SIP6 } & 0.125 & 0.010 \\
\hline & 0.094 & 0.011 & & 0.094 & 0.016 \\
\hline \multirow[t]{2}{*}{ P2SIP7 } & 0.106 & 0.011 & \multirow[t]{2}{*}{ S2S1P7 } & 0.165 & 0.027 \\
\hline & 0.123 & 0.008 & & 0.118 & 0.013 \\
\hline \multirow[t]{2}{*}{ P2SIP8 } & 0.106 & 0.012 & \multirow[t]{2}{*}{ S2SIP8 } & 0.124 & 0.011 \\
\hline & 0.100 & 0.011 & & 0.130 & 0.012 \\
\hline
\end{tabular}




\title{
APPENDIX B
}

\section{ChLORIDE BULK DIfFUSION TEST}

\author{
TABLE CURVE
}


Diffusion Coefficient: $\quad 8.09 \mathrm{E}-12 \mathrm{~m}^{2} / \mathrm{s}$

Surface Concentration: $\quad 0.68 \%$ by Mass of Concretc

Background:

$0.069 \%$ by Mass of Concrete $r^{2}$

0.9977

\section{Data}

\begin{tabular}{|c|c|}
\hline $\begin{array}{c}\text { Depth, } \\
\text { (mm) }\end{array}$ & $\begin{array}{c}\text { Chloride Concentration, } \\
\text { (\% by Mass of Concrete) }\end{array}$ \\
\hline 0.76 & 0.64 \\
\hline 1.27 & 0.59 \\
\hline 2.29 & 0.51 \\
\hline 3.30 & 0.43 \\
\hline 4.32 & 0.37 \\
\hline 5.33 & 0.32 \\
\hline 6.35 & 0.27 \\
\hline 8.38 & 0.20 \\
\hline 10.41 & 0.11 \\
\hline 12.95 & 0.05 \\
\hline 15.49 & 0.02 \\
\hline 18.03 & 0.01 \\
\hline 20.57 & 0.00 \\
\hline
\end{tabular}

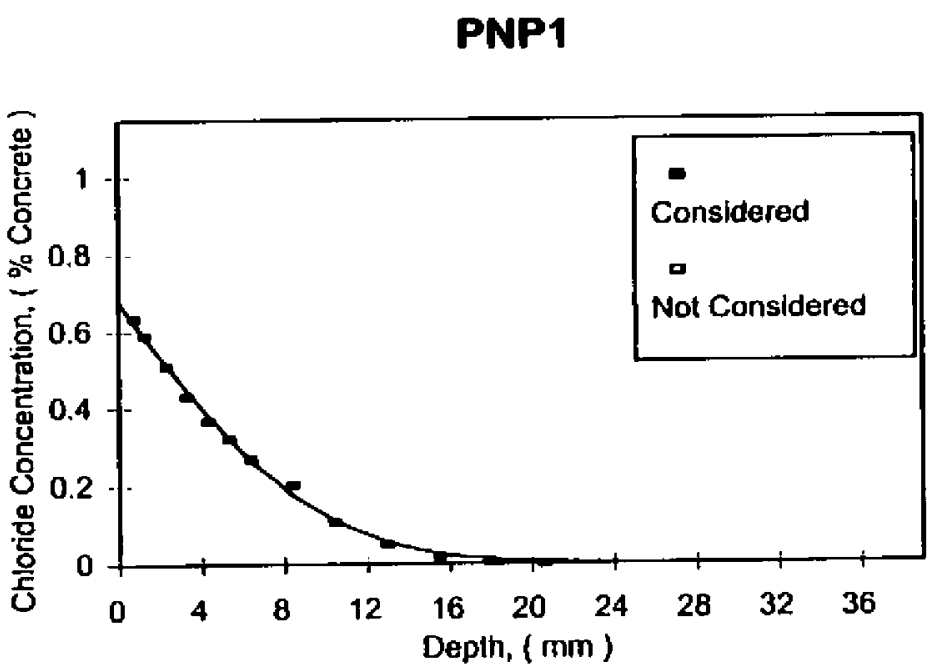


Sample: PNP9

$100 \%$ OPC, No Crack

Diffusion Coefficient:

Surface Concentration:

Background:

$r^{2}$ :

Test: Bulk Diffusion

Duration: 40 Days

$6.05 \mathrm{E}-12 \mathrm{~m}^{2} / \mathrm{s}$

$0.89 \%$ by Mass of Concretc

$0.070 \%$ by Mass of Concrete

0.9948

Data

\begin{tabular}{|c|c|}
\hline $\begin{array}{c}\text { Depth, } \\
(\mathrm{mm})\end{array}$ & $\begin{array}{c}\text { Chloride Concentration, } \\
\text { (\% by Mass of Concrete) }\end{array}$ \\
\hline 0.76 & 0.85 \\
\hline 1.27 & 0.74 \\
\hline 2.29 & 0.63 \\
\hline 3.30 & 0.51 \\
\hline 4.32 & 0.44 \\
\hline 5.33 & 0.35 \\
\hline 6.35 & 0.31 \\
\hline 8.38 & 0.18 \\
\hline 10.41 & 0.12 \\
\hline 12.95 & 0.05 \\
\hline 15.49 & 0.01 \\
\hline 18.03 & 0.00 \\
\hline 20.57 & -0.02 \\
\hline
\end{tabular}

PNP9

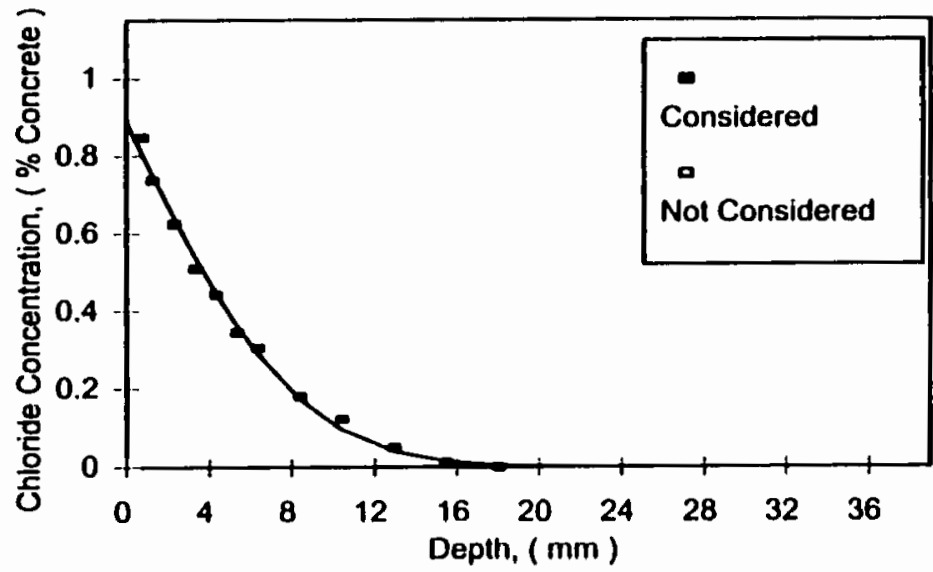


$4.02 \mathrm{E}-12 \mathrm{~m}^{2} / \mathrm{s}$

$0.86 \%$ by Mass of Concrete

$0.076 \%$ by Mass of Concrete

0.9977

\section{Data}

\begin{tabular}{|c|c|}
\hline $\begin{array}{c}\text { Depth, } \\
(\mathbf{m m})\end{array}$ & $\begin{array}{c}\text { Chloride Concentration, } \\
\text { (\% by Mass of Concrete) }\end{array}$ \\
\hline 0.76 & 0.77 \\
\hline 1.27 & 0.71 \\
\hline 1.78 & 0.65 \\
\hline 2.29 & 0.55 \\
\hline 3.30 & 0.43 \\
\hline 4.32 & 0.35 \\
\hline 5.84 & 0.24 \\
\hline 6.35 & 0.21 \\
\hline 8.38 & 0.11 \\
\hline 10.41 & 0.05 \\
\hline 12.95 & 0.01 \\
\hline 15.49 & 0.00 \\
\hline
\end{tabular}

SNP1

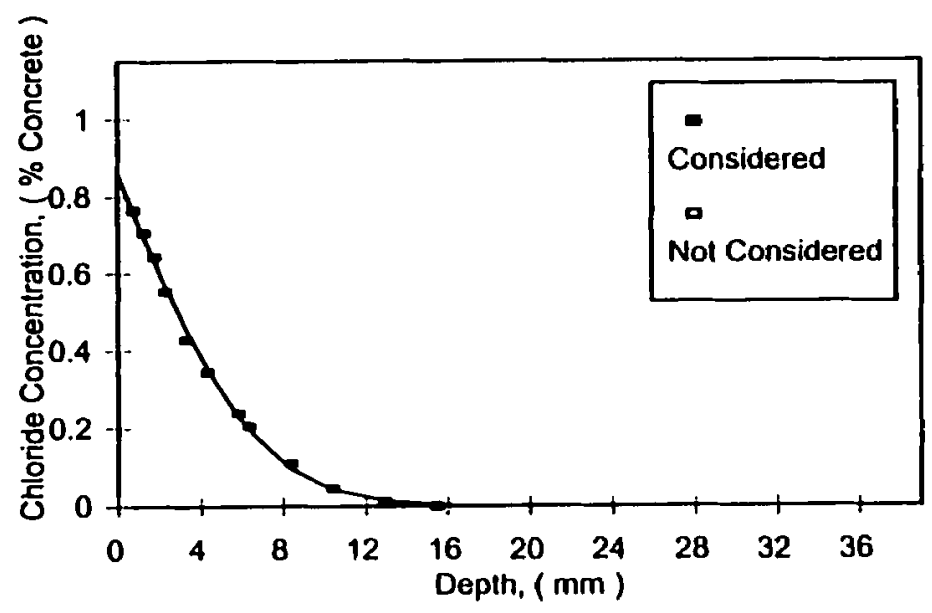


Sample: SNP9

$25 \%$ SL, No Crack

Diffusion Coefficient:

Surface Concentration:

Background:

$r^{2}$ :
Test: Bulk Diffusion

Duration: 40 Days

$1.83 \mathrm{E}-12 \mathrm{~m}^{2} / \mathrm{s}$

$1.04 \%$ by Mass of Concrete

$0.067 \%$ by Mass of Concrete

0.9890

\section{Data}

\begin{tabular}{|c|c|}
\hline $\begin{array}{c}\text { Depth, } \\
\text { (mm) }\end{array}$ & $\begin{array}{c}\text { Chloride Concentration, } \\
\text { (\% by Mass of Concrete) }\end{array}$ \\
\hline 0.76 & 0.91 \\
\hline 1.27 & 0.74 \\
\hline 2.29 & 0.49 \\
\hline 3.30 & 0.33 \\
\hline 4.32 & 0.25 \\
\hline 5.33 & 0.16 \\
\hline 6.35 & 0.12 \\
\hline 8.38 & 0.06 \\
\hline 10.41 & 0.03 \\
\hline 12.95 & 0.01 \\
\hline 15.49 & 0.01 \\
\hline 18.03 & 0.01 \\
\hline 20.57 & 0.00 \\
\hline
\end{tabular}

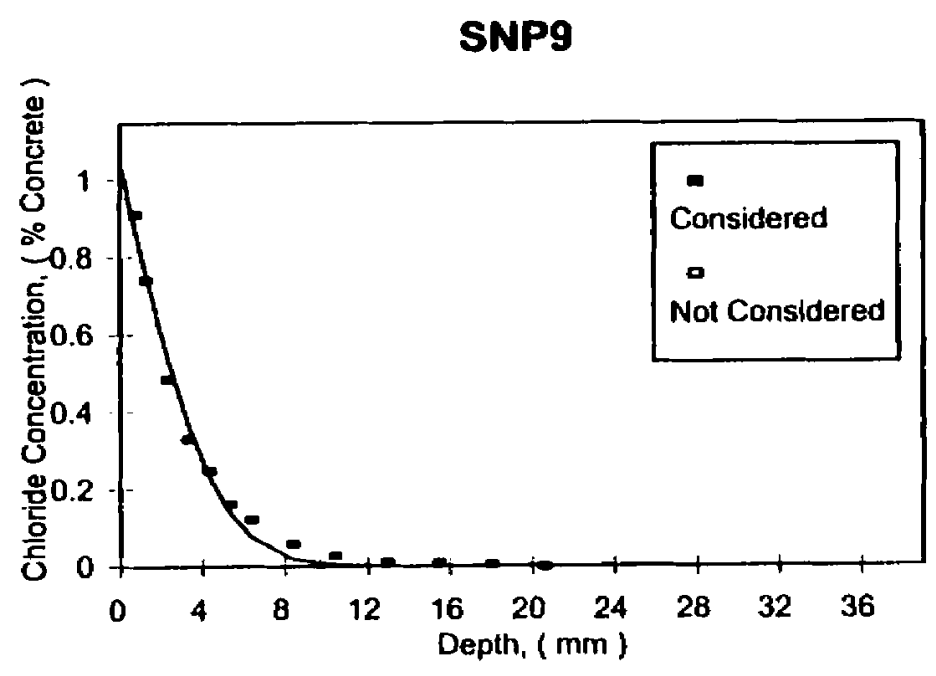


Sample: PNPLAT!

Test: Bulk Diffusion

Duration: 40 Days

$100 \%$ OPC, No Crack

Diffusion Coefficient:

$1.20 \mathrm{E}-11 \mathrm{~m}^{2} / \mathrm{s}$

Surface Concentration:

$0.60 \%$ by Mass of Concretc

Background:

$0.057 \%$ by Mass of Concrete

$r^{2}:$

0.9884

\section{Data}

\begin{tabular}{|c|c|}
\hline $\begin{array}{c}\text { Depth, } \\
(\mathrm{mm})\end{array}$ & $\begin{array}{c}\text { Chloride Concentration, } \\
\text { (\% by Mass of Concrete) }\end{array}$ \\
\hline 0.89 & 0.60 \\
\hline 1.65 & 0.48 \\
\hline 3.18 & 0.41 \\
\hline 4.70 & 0.34 \\
\hline 6.22 & 0.29 \\
\hline 7.75 & 0.23 \\
\hline 9.27 & 0.20 \\
\hline 10.80 & 0.15 \\
\hline 13.08 & 0.10 \\
\hline 15.37 & 0.06 \\
\hline 17.65 & 0.03 \\
\hline 19.94 & 0.02 \\
\hline 22.23 & 0.00 \\
\hline
\end{tabular}

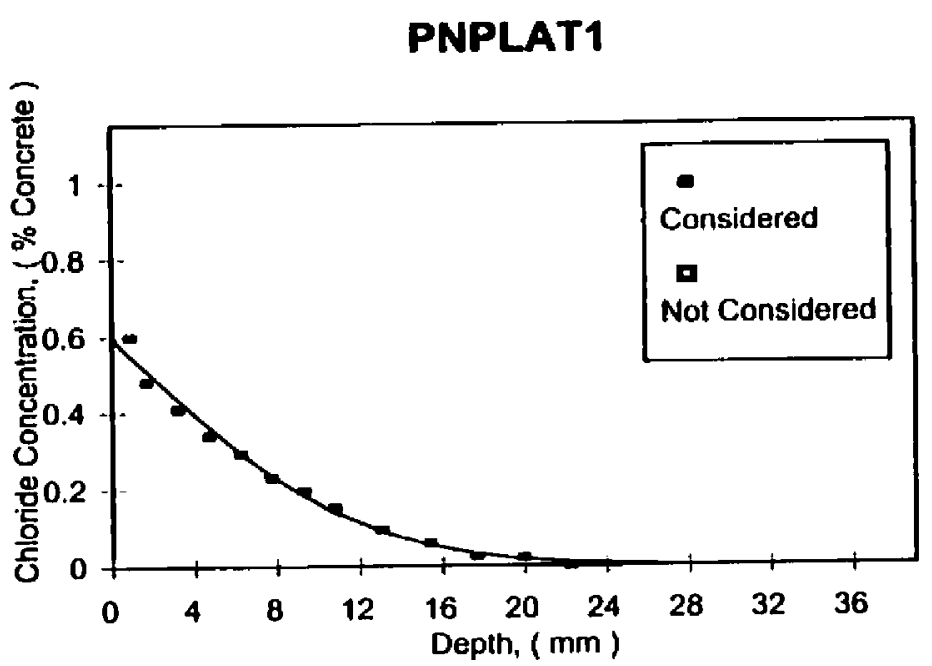


$8.26 \mathrm{E}-12 \mathrm{~m}^{2} / \mathrm{s}$

Diffusion Coefficient:

\section{$8.26 \mathrm{E}-12 \mathrm{~m} / \mathrm{s}$}

Surface Concentration:

$0.91 \%$ by Mass of Concrete

Background:

$0.063 \%$ by Mass of Concrete

$r^{2}$ :

0.9884

\section{Data}

\begin{tabular}{|c|c|}
\hline $\begin{array}{c}\text { Depth, } \\
(\mathbf{m m})\end{array}$ & $\begin{array}{c}\text { Chloride Concentration, } \\
\text { (\% by Mass of Concrete) }\end{array}$ \\
\hline 0.89 & 0.88 \\
\hline 1.65 & 0.69 \\
\hline 3.18 & 0.56 \\
\hline 4.70 & 0.50 \\
\hline 6.22 & 0.37 \\
\hline 7.75 & 0.30 \\
\hline 9.27 & 0.24 \\
\hline 10.80 & 0.12 \\
\hline 13.08 & 0.06 \\
\hline 15.37 & 0.02 \\
\hline 17.65 & 0.00 \\
\hline 19.94 & 0.00 \\
\hline 22.32 & 0.00 \\
\hline 24.51 & 0.01 \\
\hline
\end{tabular}

PNPLAT3

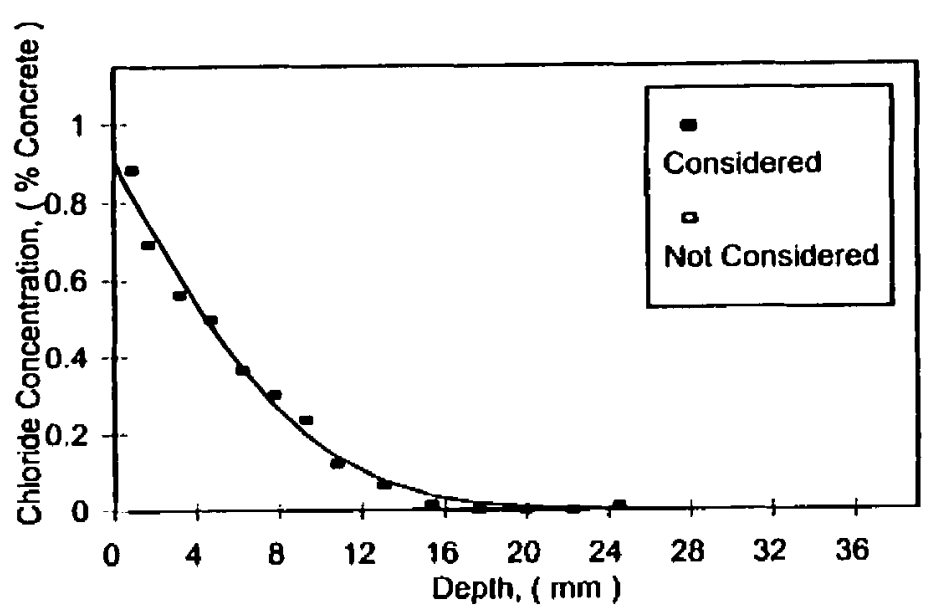


Diffusion Coefficient:

$3.24 \mathrm{E}-12 \mathrm{~m}^{2} / \mathrm{s}$

Surface Concentration:

$0.75 \%$ by Mass of Concrele

Background:

$0.072 \%$ by Mass of Concrete

$r^{2}:$

0.9757

\section{Data}

\begin{tabular}{|c|c|}
\hline $\begin{array}{c}\text { Depth, } \\
\text { (mm) }\end{array}$ & $\begin{array}{c}\text { Chloride Concentration, } \\
\text { (\% by Mass of Concrete) }\end{array}$ \\
\hline 0.89 & 0.68 \\
\hline 1.65 & 0.53 \\
\hline 3.18 & 0.31 \\
\hline 4.70 & 0.22 \\
\hline 6.22 & 0.16 \\
\hline 7.75 & 0.10 \\
\hline 9.27 & 0.08 \\
\hline 10.80 & 0.06 \\
\hline 13.08 & 0.04 \\
\hline 15.37 & 0.01 \\
\hline 17.65 & 0.00 \\
\hline 19.94 & 0.01 \\
\hline 22.23 & 0.00 \\
\hline
\end{tabular}

SNPLAT1

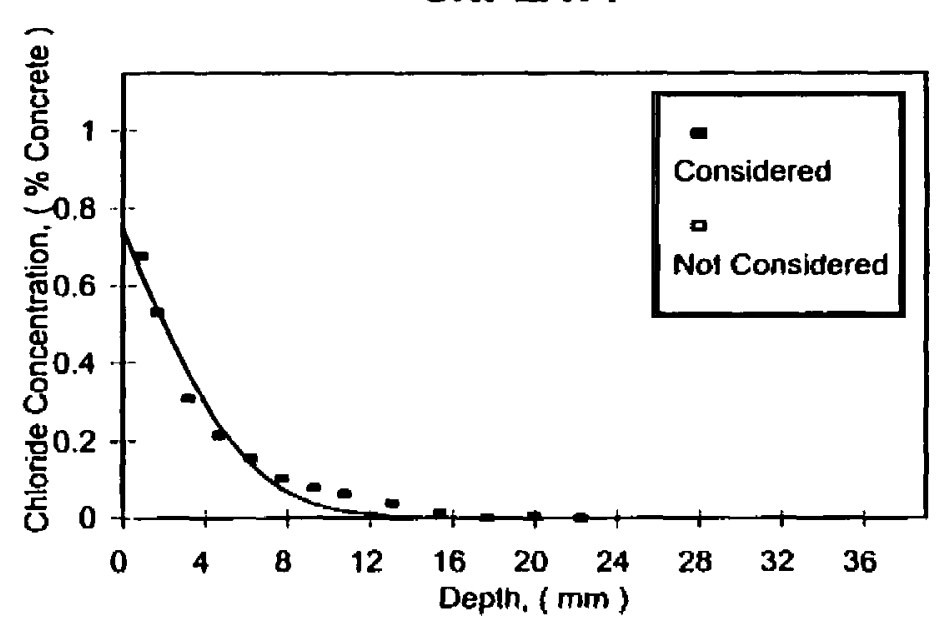




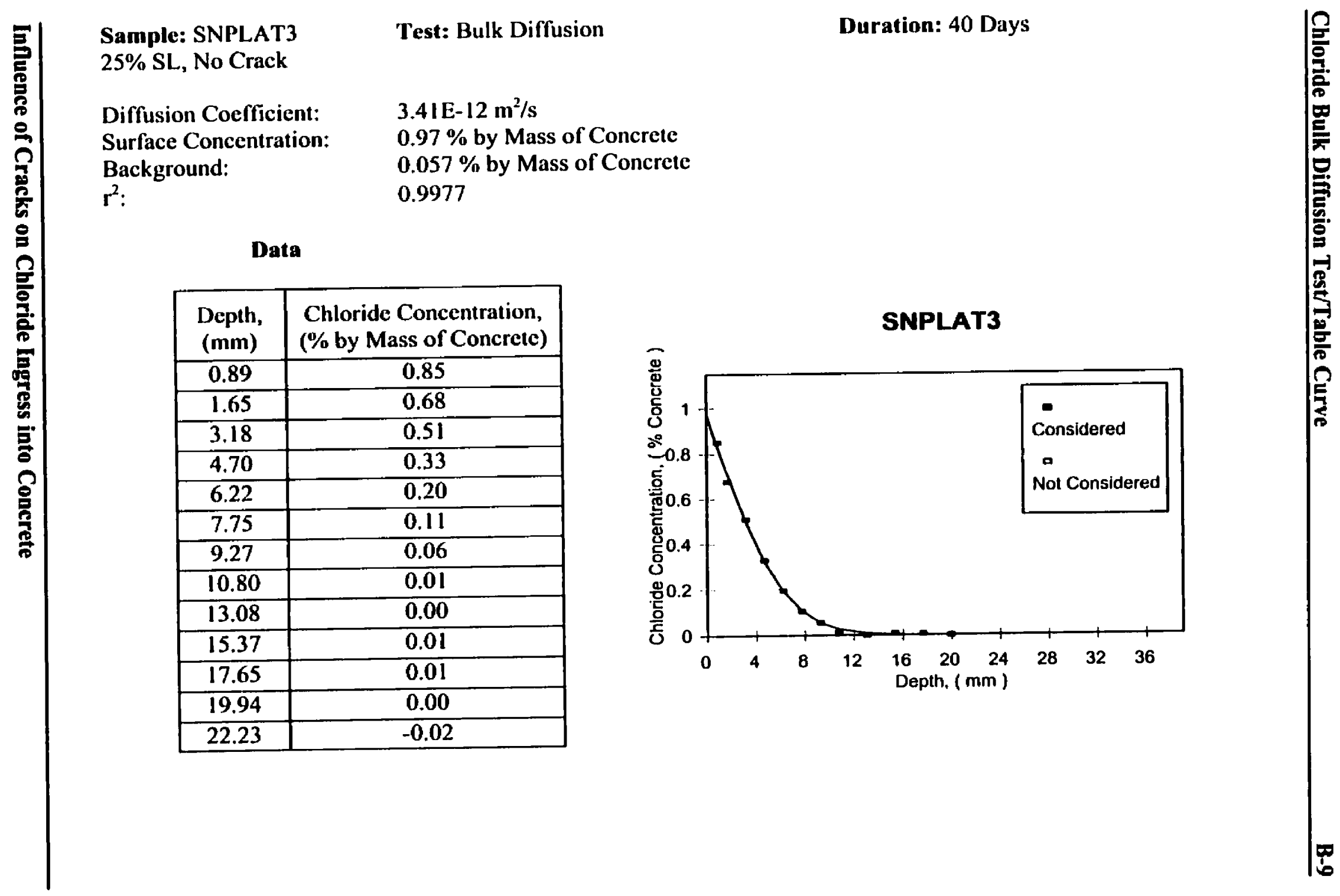


Diffusion Coefficient:

Surface Concentration:

Background:

$r^{2}$ :

$1.14 \mathrm{E}-11 \mathrm{~m}^{2} / \mathrm{s}$

$0.65 \%$ by Mass of Concrete

$0.074 \%$ by Mass of Concrete

0.9975

Data

\begin{tabular}{|c|c|}
\hline $\begin{array}{c}\text { Depth, } \\
\text { (mm) }\end{array}$ & $\begin{array}{c}\text { Chloride Concentration, } \\
\text { (\% by Mass of Concrete) }\end{array}$ \\
\hline 0.89 & 0.60 \\
\hline 1.65 & 0.53 \\
\hline 3.18 & 0.48 \\
\hline 4.70 & 0.38 \\
\hline 6.22 & 0.32 \\
\hline 7.75 & 0.23 \\
\hline 9.27 & 0.18 \\
\hline 10.80 & 0.16 \\
\hline 13.08 & 0.09 \\
\hline 14.61 & 0.06 \\
\hline 17.65 & 0.02 \\
\hline 19.94 & 0.01 \\
\hline 22.23 & 0.01 \\
\hline 24.51 & 0.01 \\
\hline 26.80 & 0.00 \\
\hline 29.08 & 0.00 \\
\hline 31.37 & 0.01 \\
\hline
\end{tabular}

PS1P1LAT

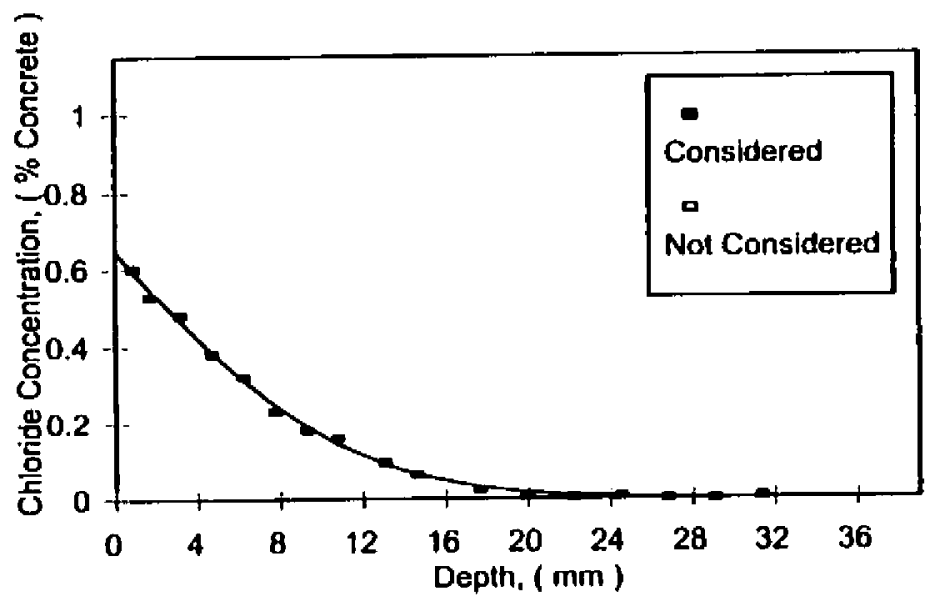


Test: Bulk Diffusion

Diffusion Coefficient:

Surface Concentration:

$6.39 \mathrm{E}-12 \mathrm{~m}^{2} / \mathrm{s}$

$0.69 \%$ by Mass of Concrete

Background:

$0.066 \%$ by Mass of Concretc

$r^{2}$ :

0.9981

\section{Data}

\begin{tabular}{|c|c|}
\hline $\begin{array}{c}\text { Depth, } \\
\text { (mm) }\end{array}$ & $\begin{array}{c}\text { Chloride Concentration, } \\
\text { (\% by Mass of Concrete) }\end{array}$ \\
\hline 0.89 & 0.61 \\
\hline 1.65 & 0.57 \\
\hline 3.18 & 0.45 \\
\hline 4.70 & 0.32 \\
\hline 6.22 & 0.23 \\
\hline 7.75 & 0.17 \\
\hline 9.27 & 0.11 \\
\hline 10.80 & 0.08 \\
\hline 13.08 & 0.04 \\
\hline 15.37 & 0.02 \\
\hline 17.65 & 0.01 \\
\hline 19.94 & 0.00 \\
\hline 22.23 & 0.00 \\
\hline 24.51 & 0.01 \\
\hline
\end{tabular}

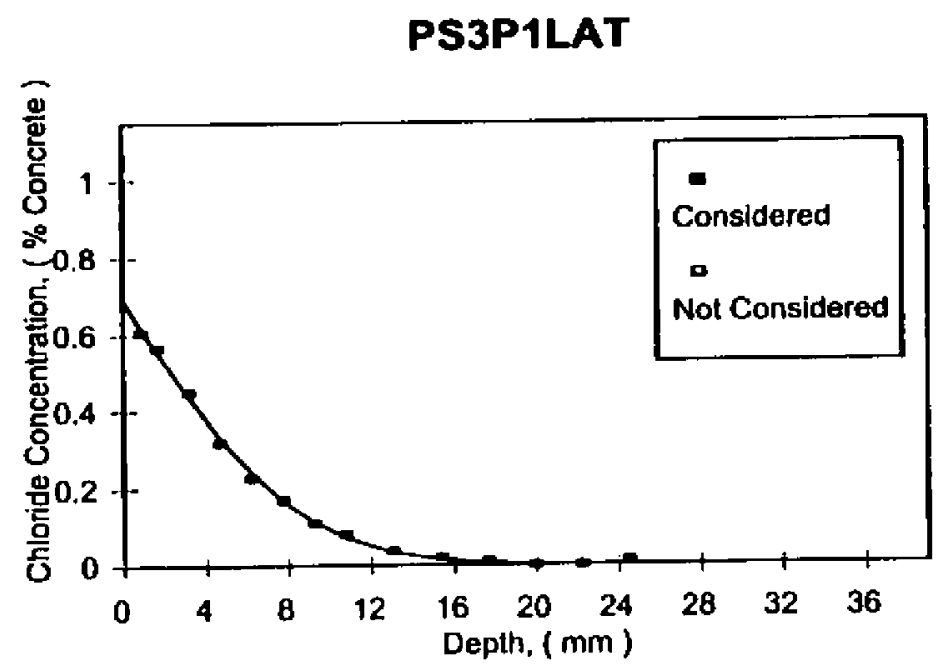


Diffusion Coefficient:

1. $15 \mathrm{E}-11 \mathrm{~m}^{2} / \mathrm{s}$

Surface Concentration:

$0.70 \%$ by Mass of Concrete

Background:

$0.063 \%$ by Mass of Concrete

$r^{2}:$

0.9964

\section{Data}

\begin{tabular}{|c|c|}
\hline $\begin{array}{c}\text { Depth, } \\
\text { (mm) }\end{array}$ & $\begin{array}{c}\text { Chloride Concentration, } \\
\text { (\% by Mass of Concrete) }\end{array}$ \\
\hline 0.89 & 0.53 \\
\hline 1.65 & 0.60 \\
\hline 3.18 & 0.50 \\
\hline 4.70 & 0.39 \\
\hline 7.75 & 0.28 \\
\hline 9.27 & 0.21 \\
\hline 10.80 & 0.18 \\
\hline 13.08 & 0.09 \\
\hline 15.37 & 0.05 \\
\hline 17.65 & 0.02 \\
\hline 19.94 & 0.03 \\
\hline 22.23 & 0.02 \\
\hline 24.51 & 0.01 \\
\hline 26.80 & 0.00 \\
\hline 29.08 & 0.02 \\
\hline 31.37 & 0.00 \\
\hline
\end{tabular}

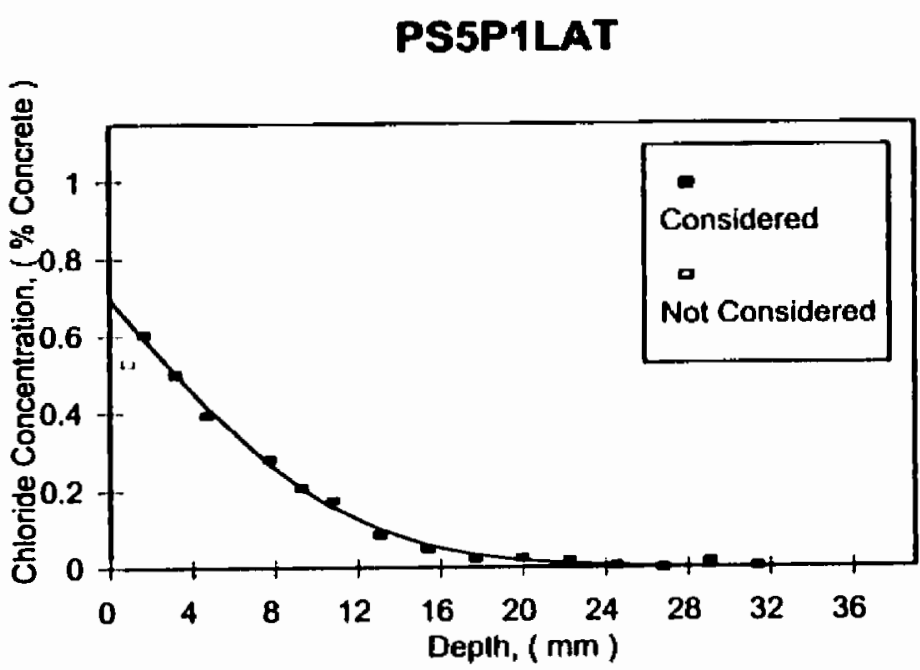


Diffusion Coefficient:

Surface Concentration:

Background:

$r^{2}$ :

$5.52 \mathrm{E}-12 \mathrm{~m}^{2} / \mathrm{s}$

$0.53 \%$ by Mass of Concrete

$0.065 \%$ by Mass of Concrete

0.9909

Data

\begin{tabular}{|c|c|}
\hline $\begin{array}{c}\text { Depth, } \\
\text { (mm) }\end{array}$ & $\begin{array}{c}\text { Chloride Concentration, } \\
\text { (\% by Mass of Concrete) }\end{array}$ \\
\hline 0.89 & 0.48 \\
\hline 1.65 & 0.44 \\
\hline 3.18 & 0.29 \\
\hline 4.70 & 0.22 \\
\hline 6.22 & 0.15 \\
\hline 7.75 & 0.13 \\
\hline 9.27 & 0.09 \\
\hline 10.80 & 0.06 \\
\hline 13.08 & 0.03 \\
\hline 15.37 & 0.02 \\
\hline 17.65 & 0.01 \\
\hline 19.94 & 0.01 \\
\hline 22.23 & 0.00 \\
\hline 24.51 & 0.01 \\
\hline 26.80 & 0.01 \\
\hline 29.08 & 0.00 \\
\hline
\end{tabular}

SS1P1LAT

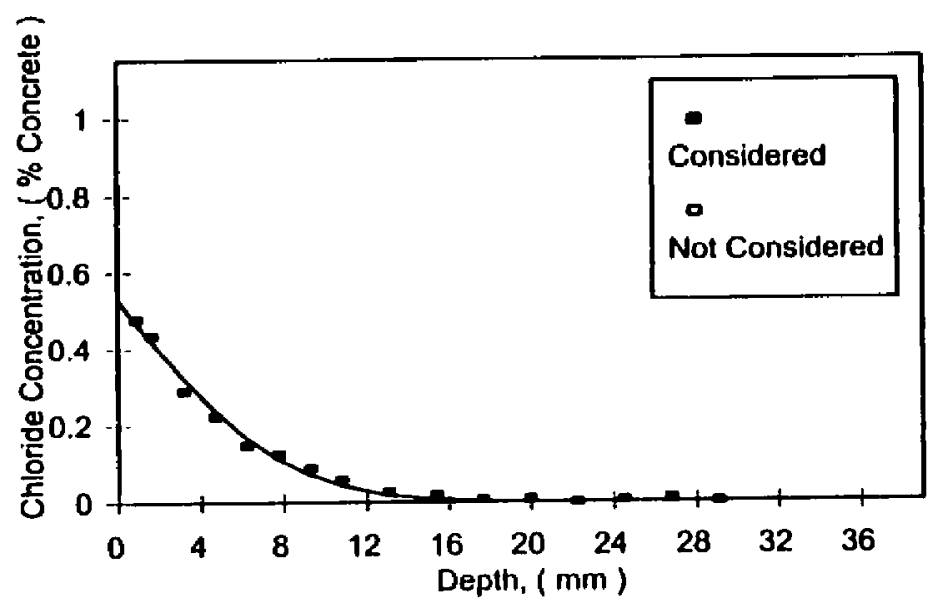


Test: Bulk Diffusion

Duration: 40 Days

$25 \%$ SL, $0.341 \mathrm{~mm}$ Smooth Crack

Diffusion Coefficient:

$5.13 \mathrm{E}-12 \mathrm{~m}^{2} / \mathrm{s}$

Surface Concentration:

$0.59 \%$ by Mass of Concrete

Background:

$0.062 \%$ by Mass of Concrete

$r^{2}:$

0.9923

Data

\begin{tabular}{|c|c|}
\hline $\begin{array}{c}\text { Depth, } \\
\text { (mm) }\end{array}$ & $\begin{array}{c}\text { Chloride Concentration, } \\
\text { (\% by Mass of Concretc) }\end{array}$ \\
\hline 0.89 & 0.55 \\
\hline 1.65 & 0.43 \\
\hline 3,18 & 0.34 \\
\hline 4.70 & 0.24 \\
\hline 6.22 & 0.17 \\
\hline 7.75 & 0.14 \\
\hline 9.27 & 0.15 \\
\hline 10.80 & 0.12 \\
\hline 13.08 & 0.03 \\
\hline 15.37 & 0.03 \\
\hline 17.65 & 0.01 \\
\hline 19.94 & 0.00 \\
\hline 22.23 & 0.00 \\
\hline 24.51 & 0.01 \\
\hline 26.80 & 0.00 \\
\hline 29.08 & 0.00 \\
\hline 31.37 & 0.00 \\
\hline
\end{tabular}

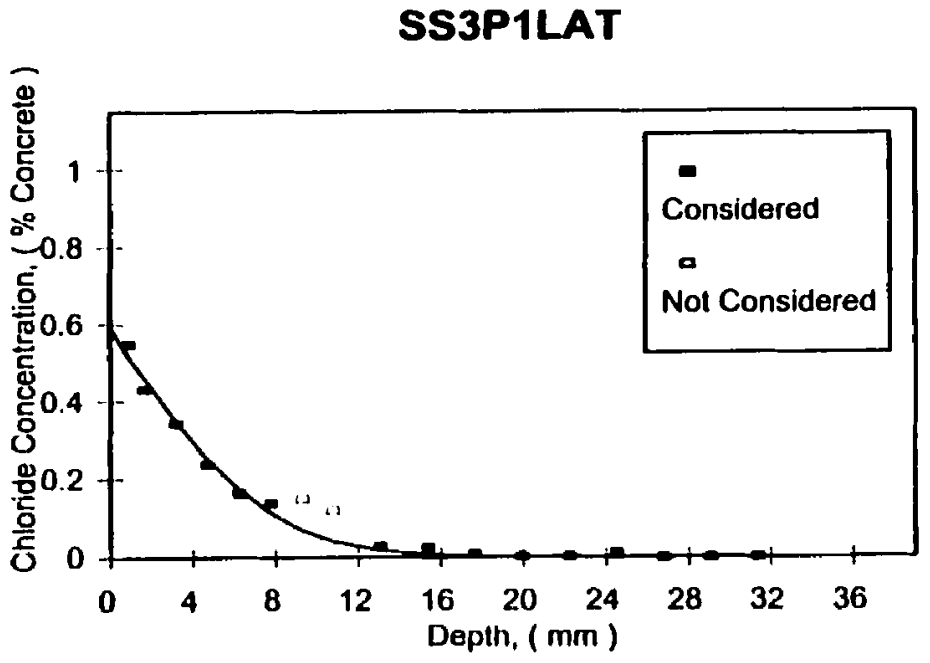


Diffusion Coefficient:

Surface Concentration:

Background:

$r^{2}:$
$2.60 \mathrm{E}-12 \mathrm{~m}^{2} / \mathrm{s}$

$0.78 \%$ by Mass of Concrete

$0.057 \%$ by Mass of Concretc

0.9942

\section{Data}

\begin{tabular}{|c|c|}
\hline $\begin{array}{c}\text { Depth, } \\
\text { (mm) }\end{array}$ & $\begin{array}{c}\text { Chloride Concentration, } \\
\text { (\% by Mass of Concrete) }\end{array}$ \\
\hline 0.89 & 0.68 \\
\hline 1.65 & 0.52 \\
\hline 3.18 & 0.33 \\
\hline 4.70 & 0.22 \\
\hline 6.22 & 0.11 \\
\hline 7.75 & 0.07 \\
\hline 9.27 & 0.03 \\
\hline 10.80 & 0.03 \\
\hline 13.08 & 0.01 \\
\hline 15.37 & 0.01 \\
\hline 17.65 & 0.01 \\
\hline 19.94 & 0.01 \\
\hline 22.23 & 0.01 \\
\hline 24.51 & 0.00 \\
\hline 26.80 & 0.01 \\
\hline 29.08 & 0.01 \\
\hline 31.37 & 0.02 \\
\hline
\end{tabular}

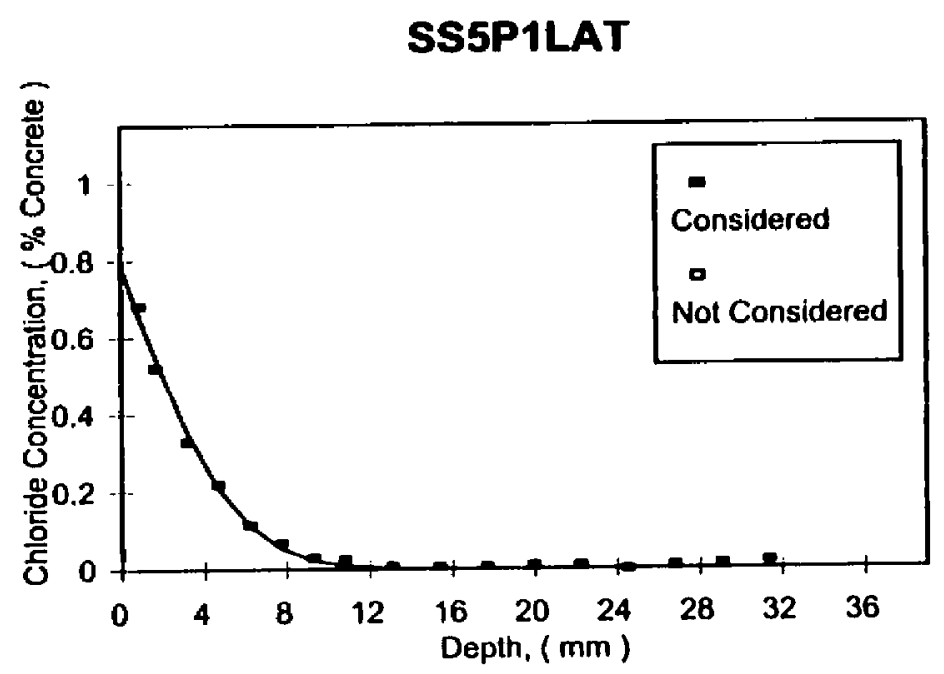


$100 \%$ OPC, $0.102 \mathrm{~mm}$ Smooth Crack

Diffusion Cocfficient:

$2.15 \mathrm{E}-11 \mathrm{~m}^{2} / \mathrm{s}$

Surface Concentration:

$0.66 \%$ by Mass of Concrete

Background:

$0.074 \%$ by Mass of Concrete

$r^{2}$ :

0.9267

Data

\begin{tabular}{|c|c|c|c|}
\hline $\begin{array}{c}\text { Depth, } \\
(\mathrm{mm})\end{array}$ & $\begin{array}{c}\text { Chloride } \\
\text { Concentration, } \\
\text { (\% by Mass of } \\
\text { Concrete) }\end{array}$ & $\begin{array}{c}\text { Depth, } \\
(\mathrm{mm})\end{array}$ & $\begin{array}{c}\text { Chloride } \\
\text { Concentration, } \\
\text { (\% by Mass of } \\
\text { Concrete })\end{array}$ \\
\hline 0.89 & 0.66 & 19.94 & 0.08 \\
\hline 1.65 & 0.64 & 21.46 & 0.08 \\
\hline 3.18 & 0.51 & 22.99 & 0.10 \\
\hline 4.70 & 0.45 & 24.51 & 0.07 \\
\hline 6.22 & 0.35 & 26.04 & 0.07 \\
\hline 7.75 & 0.30 & 27.56 & 0.07 \\
\hline 9.27 & 0.26 & 29.08 & 0.07 \\
\hline 10.80 & 0.23 & 30.61 & 0.06 \\
\hline 13.08 & 0.18 & 32.13 & 0.06 \\
\hline 13.84 & 0.16 & 33.66 & 0.09 \\
\hline 15.37 & 0.12 & 35.18 & 0.09 \\
\hline 16.89 & 0.10 & 36.70 & 0.10 \\
\hline 18.42 & 0.07 & 38.23 & 0.08 \\
\hline
\end{tabular}

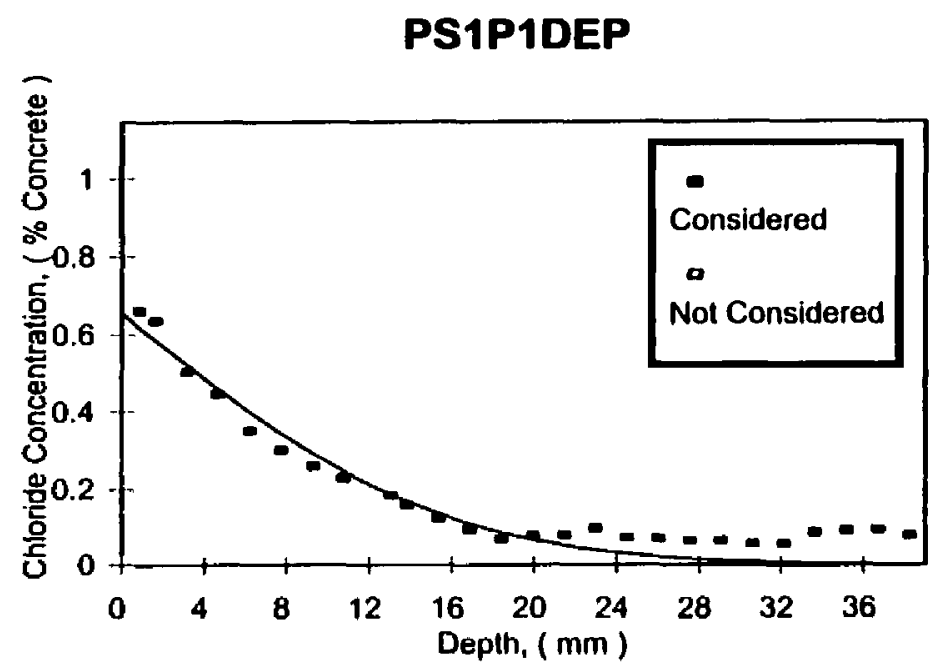


$100 \%$ OPC, $0.370 \mathrm{~mm}$ Smooth Crack

Diffusion Coefficient:

$1.06 \mathrm{E}-11 \mathrm{~m}^{2} / \mathrm{s}$

Surface Concentration:

$0.87 \%$ by Mass of Concrete

Background:

$0.066 \%$ by Mass of Concretc

$r^{2}$ :

0.9444

Data

\begin{tabular}{|c|c|}
\hline $\begin{array}{c}\text { Depth, } \\
\text { (mm) }\end{array}$ & $\begin{array}{c}\text { Chloride Concentration, } \\
\text { (\% by Mass of Concrete) }\end{array}$ \\
\hline 0.89 & 0.85 \\
\hline 1.65 & 0.76 \\
\hline 3.18 & 0.59 \\
\hline 4.70 & 0.44 \\
\hline 6.22 & 0.39 \\
\hline 7.75 & 0.25 \\
\hline 9.27 & 0.22 \\
\hline 10.80 & 0.19 \\
\hline 12.32 & 0.20 \\
\hline 13.84 & 0.13 \\
\hline 16.89 & 0.07 \\
\hline 19.94 & 0.11 \\
\hline 22.99 & 0.12 \\
\hline 26.04 & 0.08 \\
\hline 29.08 & 0.06 \\
\hline 32.13 & 0.30 \\
\hline 35.18 & 0.26 \\
\hline
\end{tabular}

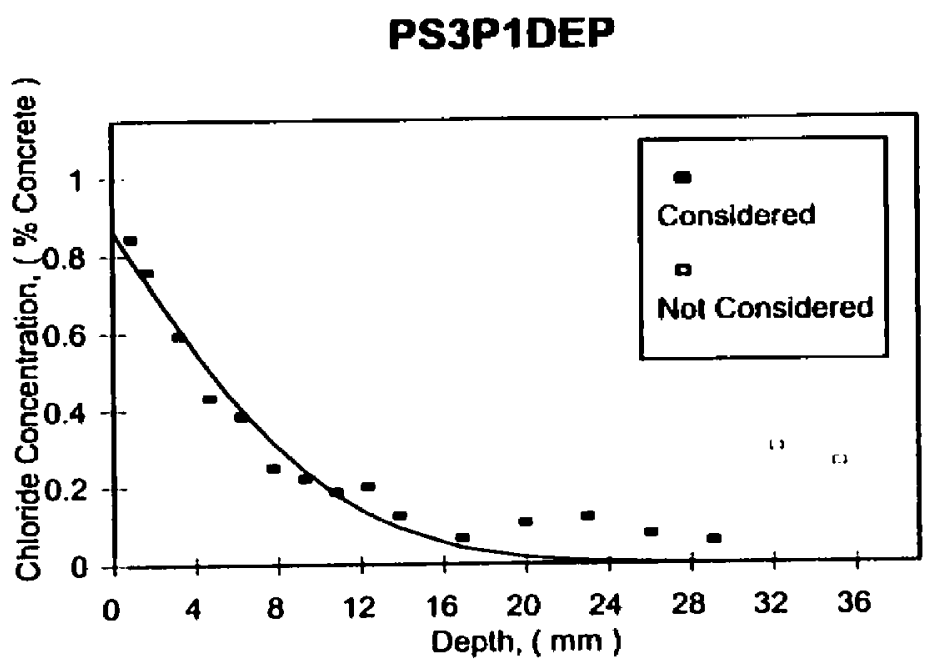


Diffusion Coefficient:

Surface Concentration:

Background:

$r^{2}:$

$2.91 \mathrm{E}-11 \mathrm{~m}^{2} / \mathrm{s}$

$0.65 \%$ by Mass of Concrete

$0.063 \%$ by Mass of Concrete

0.9474

\section{Data}

\begin{tabular}{|c|c|}
\hline $\begin{array}{c}\text { Depth, } \\
(\mathrm{mm})\end{array}$ & $\begin{array}{c}\text { Chloride Concentration, } \\
\text { (\% by Mass of Concretc) }\end{array}$ \\
\hline 0.89 & 0.59 \\
\hline 1.65 & 0.62 \\
\hline 3.18 & 0.55 \\
\hline 4.70 & 0.46 \\
\hline 6.22 & 0.30 \\
\hline 7.75 & 0.37 \\
\hline 9.27 & 0.32 \\
\hline 10.80 & 0.26 \\
\hline 12.32 & 0.20 \\
\hline 16.89 & 0.14 \\
\hline 19.94 & 0.12 \\
\hline 22.99 & 0.07 \\
\hline 26.04 & 0.09 \\
\hline 29.08 & 0.04 \\
\hline 32.13 & 0.11 \\
\hline 35.18 & 0.09 \\
\hline 38.23 & 0.07 \\
\hline
\end{tabular}

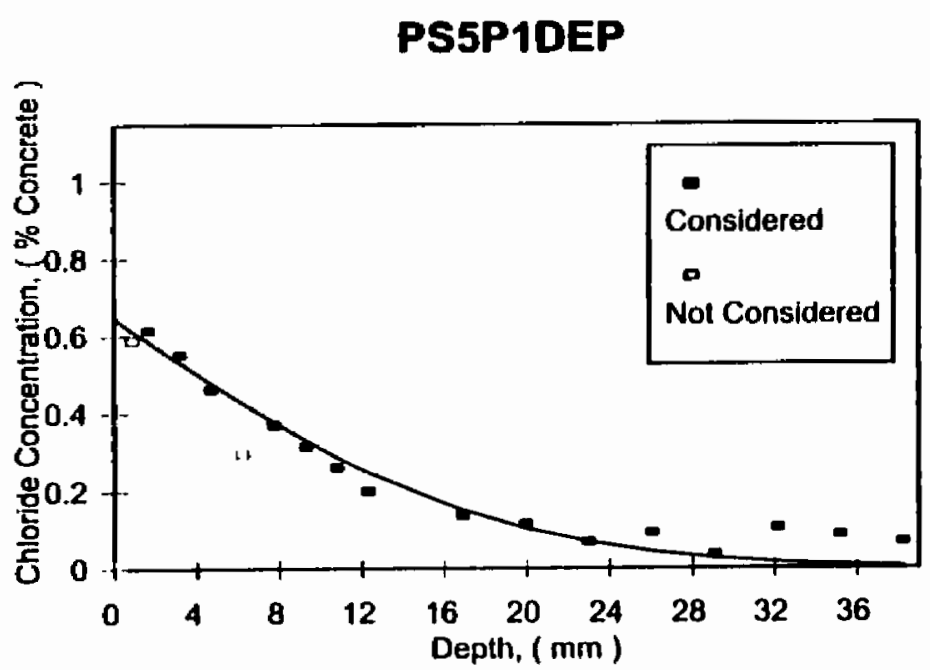


Diffusion Coefficient:

Surface Concentration:

Background:

$r^{2}$ :

$6.19 \mathrm{E}-12 \mathrm{~m}^{2} / \mathrm{s}$

$0.78 \%$ by Mass of Concrete $0.065 \%$ by Mass of Concrete 0.9564

\section{Data}

\begin{tabular}{|c|c|}
\hline $\begin{array}{c}\text { Depth, } \\
(\mathrm{mm})\end{array}$ & $\begin{array}{c}\text { Chloride Concentration, } \\
\text { (\% by Mass of Concrete) }\end{array}$ \\
\hline 0.89 & 0.74 \\
\hline 1.65 & 0.63 \\
\hline 3.18 & 0.47 \\
\hline 4.70 & 0.30 \\
\hline 6.22 & 0.22 \\
\hline 7.75 & 0.16 \\
\hline 9.27 & 0.15 \\
\hline 10.80 & 0.12 \\
\hline 12.32 & 0.10 \\
\hline 13.84 & 0.10 \\
\hline 16.89 & 0.05 \\
\hline 19.94 & 0.04 \\
\hline 22.99 & 0.04 \\
\hline 26.04 & 0.06 \\
\hline 29.08 & 0.04 \\
\hline 32.13 & 0.05 \\
\hline 35.15 & 0.03 \\
\hline
\end{tabular}

SS1P1DEP

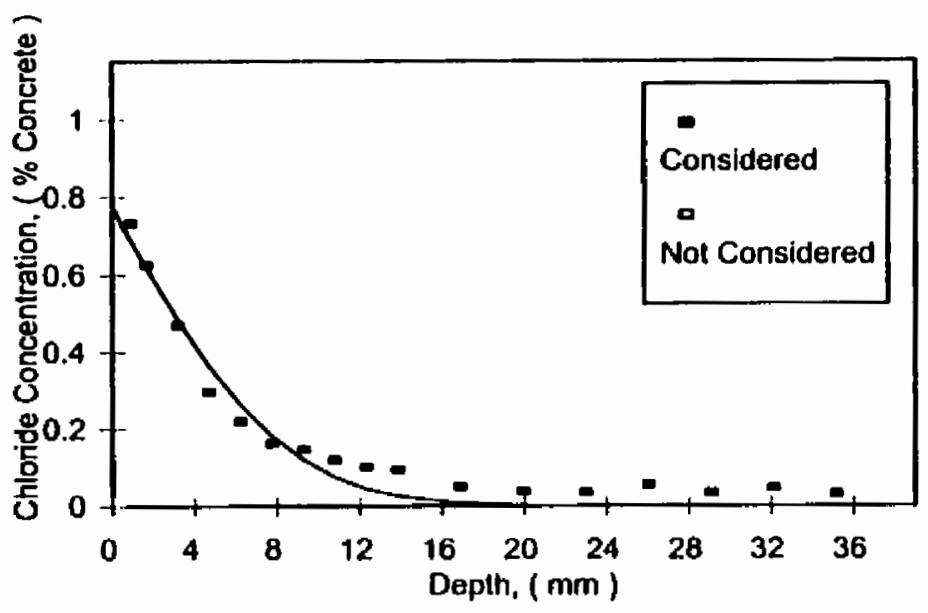


Diffusion Coefficient:

Surface Concentration:

Background:

$\mathbf{r}^{2}$ :

$3.54 \mathrm{E}-12 \mathrm{~m}^{2} / \mathrm{s}$

$0.96 \%$ by Mass of Concretc

$0.062 \%$ by Mass of Concrete

0.9666

Data

\begin{tabular}{|c|c|}
\hline $\begin{array}{c}\text { Depth, } \\
(\mathbf{m m})\end{array}$ & $\begin{array}{c}\text { Chloride Concentration, } \\
\text { (\% by Mass of Concrete) }\end{array}$ \\
\hline 0.89 & 0.87 \\
\hline 1.65 & 0.70 \\
\hline 3.18 & 0.45 \\
\hline 4.70 & 0.26 \\
\hline 6.22 & 0.22 \\
\hline 7.75 & 0.14 \\
\hline 9.27 & 0.11 \\
\hline 10.80 & 0.08 \\
\hline 12.32 & 0.06 \\
\hline 13.84 & 0.05 \\
\hline 16.89 & 0.04 \\
\hline 19.94 & 0.03 \\
\hline 22.99 & 0.03 \\
\hline 26.04 & 0.05 \\
\hline 29.08 & 0.06 \\
\hline 32.13 & 0.06 \\
\hline
\end{tabular}

SS3P1DEP

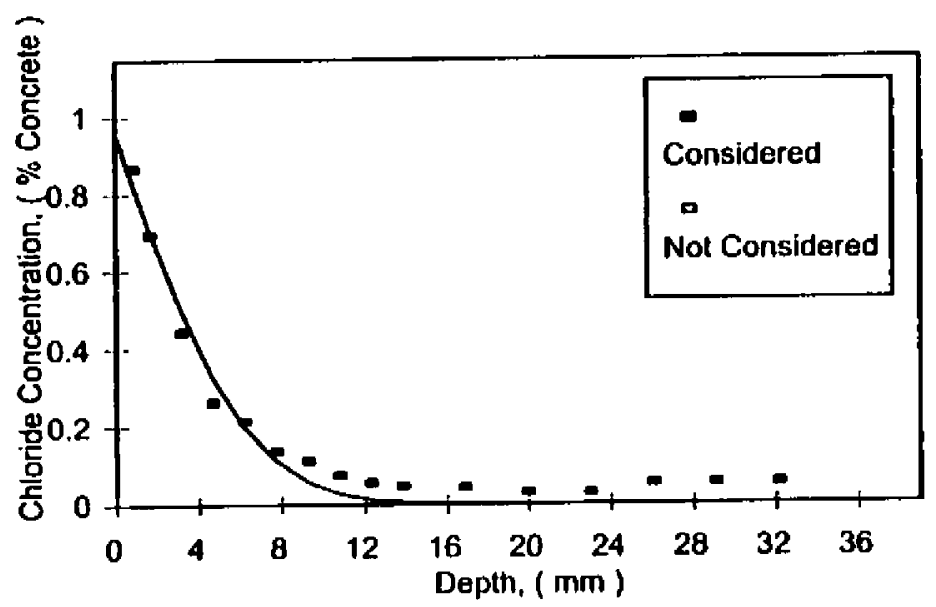



$25 \%$ SL, $0.616 \mathrm{~mm}$ Smooth Crack

Diffusion Coefficient:

$3.48 \mathrm{E}-12 \mathrm{~m}^{2} / \mathrm{s}$

Surface Concentration: $0.89 \%$ by Mass of Concrete

Background:

$0.057 \%$ by Mass of Concrete

$r^{2}$ :

0.9612

Data

\begin{tabular}{|c|c|}
\hline $\begin{array}{c}\text { Depth, } \\
(\mathbf{m m})\end{array}$ & $\begin{array}{c}\text { Chloride Concentration, } \\
\text { (\% by Mass of Concretc) }\end{array}$ \\
\hline 0.89 & 0.78 \\
\hline 1.65 & 0.65 \\
\hline 3.18 & 0.48 \\
\hline 4.70 & 0.25 \\
\hline 6.22 & 0.14 \\
\hline 7.75 & 0.12 \\
\hline 9.27 & 0.10 \\
\hline 10.80 & 0.08 \\
\hline 12.32 & 0.04 \\
\hline 13.84 & 0.05 \\
\hline 16.89 & 0.04 \\
\hline 19.94 & 0.04 \\
\hline 22.99 & 0.07 \\
\hline 26.04 & 0.07 \\
\hline 29.08 & 0.06 \\
\hline 32.13 & 0.05 \\
\hline 35.18 & 0.04 \\
\hline
\end{tabular}

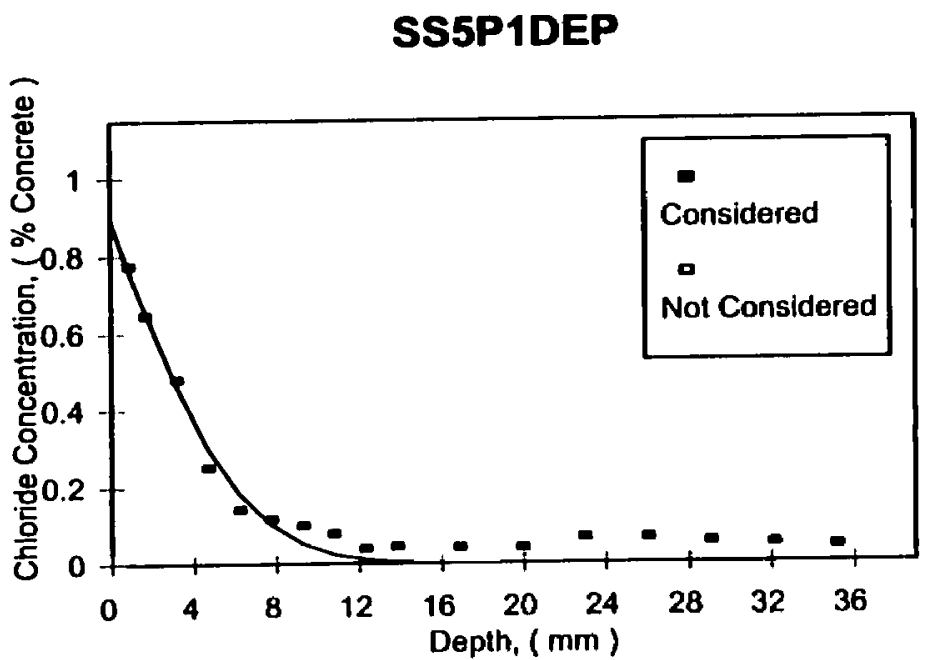


Test: Bulk Diffusion

Duration: 40 Days

100\% OPC, $0.097 \mathrm{~mm}$ Rough Crack

Diffusion Coefficient:

Surface Concentration:

Background:

$r^{2}$ :

$1.59 \mathrm{E}-11 \mathrm{~m}^{2} / \mathrm{s}$

$0.73 \%$ by Mass of Concrete

$0.052 \%$ by Mass of Concrete

0.9511

\section{Data}

\begin{tabular}{|c|c|c|c|}
\hline $\begin{array}{c}\text { Depth, } \\
(\mathrm{mm})\end{array}$ & $\begin{array}{c}\text { Chloride } \\
\text { Concentration, } \\
\text { (\% by Mass of } \\
\text { Concrete) }\end{array}$ & $\begin{array}{c}\text { Depth, } \\
(\mathrm{mm})\end{array}$ & $\begin{array}{c}\text { Chloride } \\
\text { Concentration, } \\
\text { (\% by Mass of } \\
\text { Concrete) }\end{array}$ \\
\hline 0.51 & 0.62 & 12.70 & 0.15 \\
\hline 1.52 & 0.61 & 13.72 & 0.12 \\
\hline 2.54 & 0.58 & 14.73 & 0.08 \\
\hline 3.56 & 0.56 & 15.75 & 0.04 \\
\hline 4.57 & 0.57 & 16.76 & 0.02 \\
\hline 5.59 & 0.52 & 17.78 & 0.00 \\
\hline 6.60 & 0.48 & 18.80 & -0.01 \\
\hline 7.62 & 0.41 & 19.81 & 0.01 \\
\hline 8.64 & 0.33 & 20.83 & 0.00 \\
\hline 9.65 & 0.28 & 21.84 & -0.01 \\
\hline 10.67 & 0.22 & 22.86 & -0.01 \\
\hline 11.68 & 0.18 & 23.88 & -0.03 \\
\hline
\end{tabular}

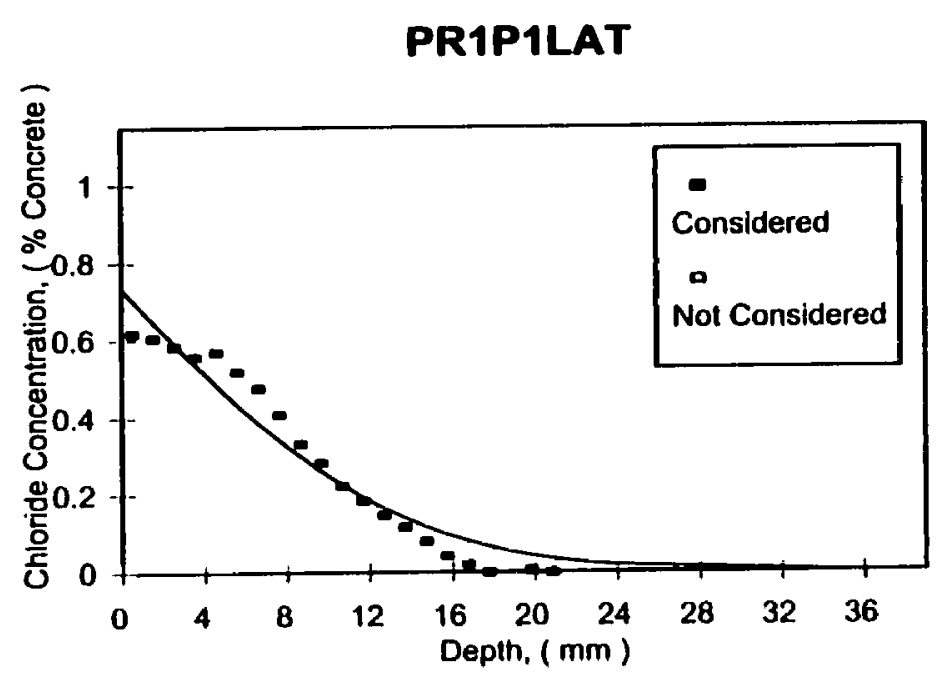


Test: Bulk Diffusion

Duration: 40 Days

$100 \%$ OPC, $0.297 \mathrm{~mm}$ Rough Crack

Diffusion Coefficient:

$1.23 \mathrm{E}-11 \mathrm{~m}^{2} / \mathrm{s}$

Surface Concentration:

$0.87 \%$ by Mass of Concrete

Background:

$0.057 \%$ by Mass of Concretc

$r^{2}$ :

0.9987

Data

\begin{tabular}{|c|c|c|c|}
\hline $\begin{array}{c}\text { Depth, } \\
(\mathrm{mm})\end{array}$ & $\begin{array}{c}\text { Chloride } \\
\text { Concentration, } \\
\text { (\% by Mass of } \\
\text { Concrete) }\end{array}$ & $\begin{array}{c}\text { Depth, } \\
(\mathrm{mm})\end{array}$ & $\begin{array}{c}\text { Chloride } \\
\text { Concentration, } \\
\text { (\% by Mass of } \\
\text { Concrete) }\end{array}$ \\
\hline 0.51 & 1.09 & 12.70 & 0.15 \\
\hline 1.52 & 0.77 & 13.72 & 0.11 \\
\hline 2.54 & 0.67 & 14.73 & 0.10 \\
\hline 3.56 & 0.60 & 15.75 & 0.07 \\
\hline 4.57 & 0.53 & 16.76 & 0.05 \\
\hline 5.59 & 0.47 & 17.78 & 0.05 \\
\hline 6.60 & 0.41 & 18.80 & 0.04 \\
\hline 7.62 & 0.36 & 19.81 & 0.01 \\
\hline 8.64 & 0.32 & 20.83 & 0.01 \\
\hline 9.65 & 0.26 & 21.84 & 0.02 \\
\hline 10.67 & 0.23 & 22.86 & 0.01 \\
\hline 11.68 & 0.17 & 23.88 & 0.00 \\
\hline
\end{tabular}

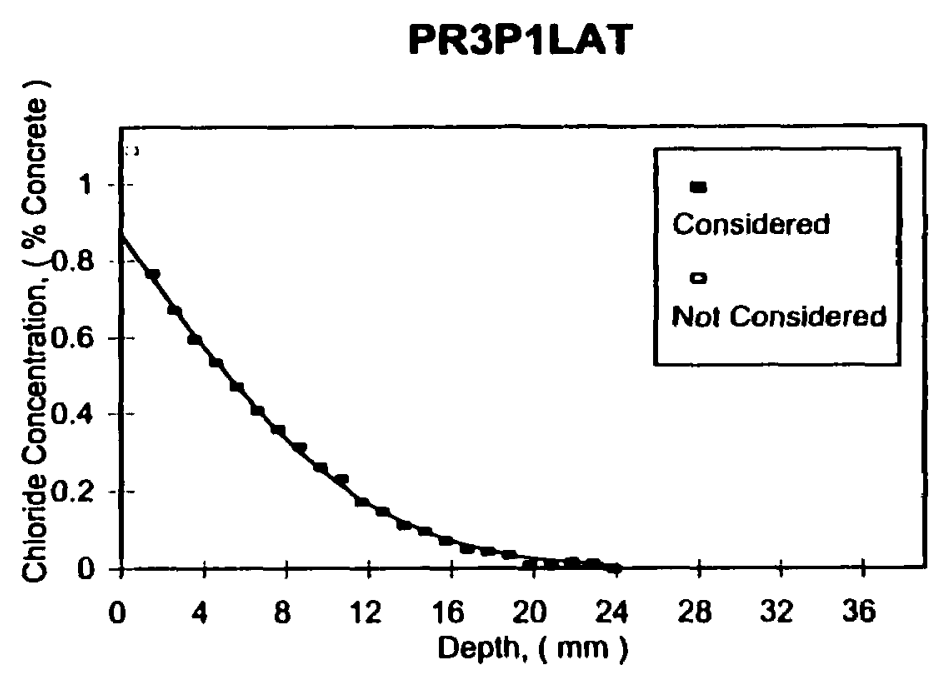




\begin{tabular}{|c|c|c|c|}
\hline \multicolumn{2}{|c|}{$\begin{array}{l}\text { Diffusion Coefficient: } \\
\text { Surface Concentration: } \\
\text { Background: } \\
r^{2}:\end{array}$} & \multicolumn{2}{|c|}{$\begin{array}{l}1.36 \mathrm{E}-11 \mathrm{~m}^{2} / \mathrm{s} \\
0.59 \% \text { by Mass of Concre } \\
0.075 \% \text { by Mass of Concr } \\
0.9939\end{array}$} \\
\hline $\begin{array}{l}\text { Depth, } \\
\text { (mm) }\end{array}$ & $\begin{array}{c}\text { Chloride } \\
\text { Concentration, } \\
\text { (\% by Mass of } \\
\text { Concrete) }\end{array}$ & $\begin{array}{l}\text { Depth, } \\
(\mathrm{mm})\end{array}$ & $\begin{array}{c}\text { Chloride } \\
\text { Concentration, } \\
\text { (\% by Mass of } \\
\text { Concrete) }\end{array}$ \\
\hline 0.25 & 0.60 & 9.91 & 0.20 \\
\hline 0.76 & 0.57 & 10.41 & 0.15 \\
\hline 1.27 & 0.54 & 10.92 & 0.14 \\
\hline 1.78 & 0.48 & 11.43 & 0.15 \\
\hline 2.29 & 0.46 & 11.94 & 0.14 \\
\hline 2.79 & 0.44 & 12.45 & 0.12 \\
\hline 3.30 & 0.41 & 12.95 & 0.11 \\
\hline 3.81 & 0.46 & 13.46 & 0.11 \\
\hline 4.32 & 0.40 & 13.97 & 0.10 \\
\hline 4.83 & 0.41 & 14.48 & 0.08 \\
\hline 5.84 & 0.35 & 14.99 & 0.07 \\
\hline 6.35 & 0.33 & 16.51 & 0.04 \\
\hline 6.86 & 0.28 & 18.03 & 0.03 \\
\hline 7.37 & 0.26 & 19.56 & 0.00 \\
\hline 7.87 & 0.25 & 21.08 & 0.01 \\
\hline 8.38 & 0.23 & 22.61 & 0.00 \\
\hline 8.89 & 0.22 & 24.13 & 0.00 \\
\hline 9.40 & 0.22 & 25.65 & 0.00 \\
\hline
\end{tabular}

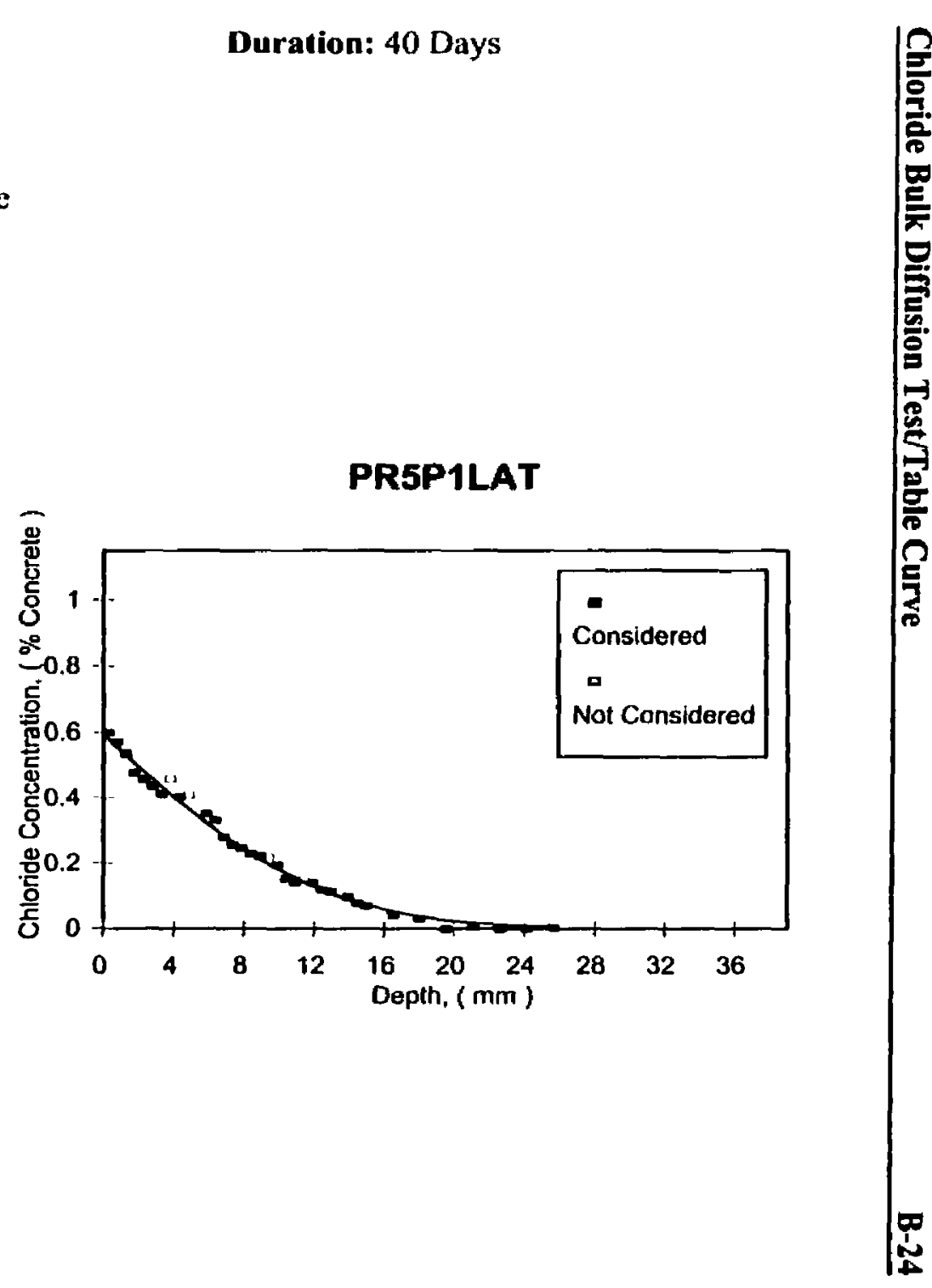


Diffusion Coefficient:

Surface Concentration:

Background:

$r^{2}$ :

$3.71 \mathrm{E}-12 \mathrm{~m}^{2} / \mathrm{s}$

$0.78 \%$ by Mass of Concrete $0.064 \%$ by Mass of Concrete 0.9971

Data

\begin{tabular}{|c|c|c|c|}
\hline $\begin{array}{c}\text { Depth, } \\
(\mathrm{mm})\end{array}$ & $\begin{array}{c}\text { Chloride } \\
\text { Concentration, } \\
\text { (\% by Mass of } \\
\text { Concrete) }\end{array}$ & $\begin{array}{c}\text { Depth, } \\
(\mathrm{mm})\end{array}$ & $\begin{array}{c}\text { Chloride } \\
\text { Concentration, } \\
\text { (\% by Mass of } \\
\text { Concrete) }\end{array}$ \\
\hline 0.25 & 0.73 & 7.87 & 0.09 \\
\hline 0.76 & 0.69 & 8.38 & 0.07 \\
\hline 1.27 & 0.64 & 8.89 & 0.05 \\
\hline 1.78 & 0.57 & 9.40 & 0.04 \\
\hline 2.29 & 0.51 & 9.91 & 0.05 \\
\hline 2.79 & 0.46 & 10.41 & 0.04 \\
\hline 3.30 & 0.41 & 10.92 & 0.03 \\
\hline 3.81 & 0.38 & 11.43 & 0.02 \\
\hline 4.32 & 0.33 & 11.94 & 0.02 \\
\hline 4.83 & 0.26 & 12.45 & 0.00 \\
\hline 5.33 & 0.22 & 12.95 & 0.02 \\
\hline 5.84 & 0.20 & 13.46 & 0.02 \\
\hline 6.35 & 0.14 & 13.97 & 0.00 \\
\hline 6.86 & 0.12 & 14.48 & 0.01 \\
\hline 7.37 & 0.11 & 14.99 & 0.01 \\
\hline
\end{tabular}

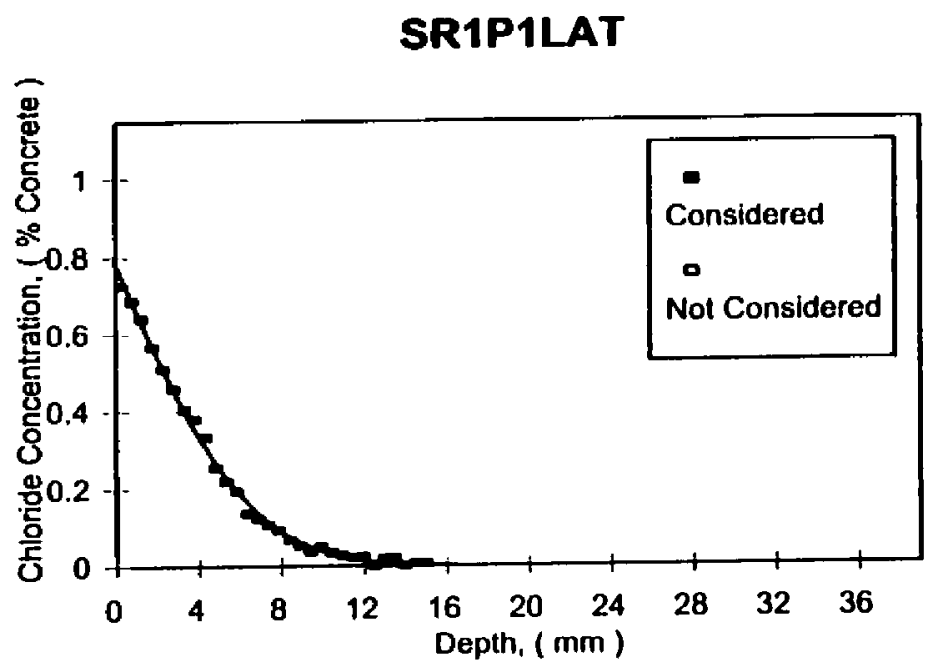


$25 \%$ SL, $0.284 \mathrm{~mm}$ Rough Crack

Diffusion Coefficient:

Surface Concentration:

Background:

$r^{2}$

$5.01 \mathrm{E}-12 \mathrm{~m}^{2} / \mathrm{s}$

$0.83 \%$ by Mass of Concrete

$0.054 \%$ by Mass of Concrete

0.9890

\section{Data}

\begin{tabular}{|c|c|}
\hline $\begin{array}{c}\text { Depth, } \\
\text { (mm) }\end{array}$ & $\begin{array}{c}\text { Chloride Concentration, } \\
\text { (\% by Mass of Concretc) }\end{array}$ \\
\hline 0.76 & 0.77 \\
\hline 2,29 & 0.58 \\
\hline 3.81 & 0.39 \\
\hline 5.33 & 0.25 \\
\hline 6.86 & 0.22 \\
\hline 8.38 & 0.15 \\
\hline 9.91 & 0.11 \\
\hline 11.43 & 0.07 \\
\hline 12.95 & 0.06 \\
\hline 14.48 & 0.03 \\
\hline 16.00 & 0.01 \\
\hline 17.53 & 0.00 \\
\hline 19.05 & -0.01 \\
\hline 20.57 & 0.01 \\
\hline 22.10 & 0.01 \\
\hline 23.62 & 0.01 \\
\hline 25.15 & 0.01 \\
\hline
\end{tabular}

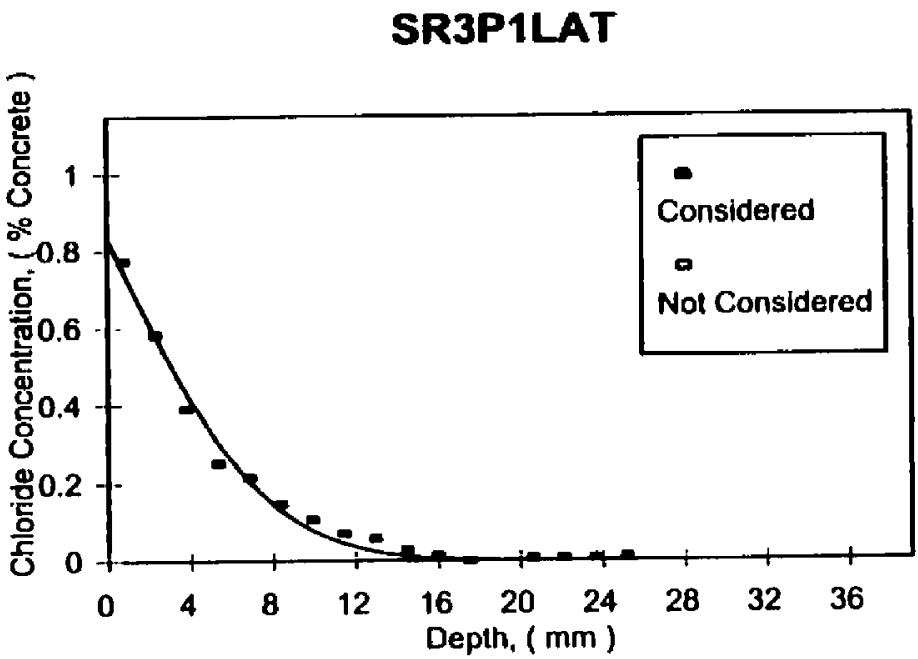


Diffusion Coefficient:

$5.03 \mathrm{E}-12 \mathrm{~m}^{2} / \mathrm{s}$

Surface Concentration:

$0.63 \%$ by Mass of Concrete

Background:

$0.080 \%$ by Mass of Concrete

$r^{2}:$

0.9960

\section{Data}

\begin{tabular}{|c|c|}
\hline $\begin{array}{c}\text { Depth, } \\
\text { (mm) }\end{array}$ & $\begin{array}{c}\text { Chloride Concentration, } \\
\text { (\% by Mass of Concrete) }\end{array}$ \\
\hline 0.51 & 0.59 \\
\hline 1.52 & 0.50 \\
\hline 2.54 & 0.44 \\
\hline 3.56 & 0.32 \\
\hline 4.57 & 0.27 \\
\hline 5.59 & 0.21 \\
\hline 6.60 & 0.18 \\
\hline 7.62 & 0.12 \\
\hline 8.64 & 0.11 \\
\hline 9.65 & 0.06 \\
\hline 10.67 & 0.01 \\
\hline 11.68 & 0.03 \\
\hline 12.70 & 0.01 \\
\hline 13.72 & 0.01 \\
\hline 14.73 & 0.00 \\
\hline 15.75 & 0.00 \\
\hline 16.76 & 0.01 \\
\hline
\end{tabular}

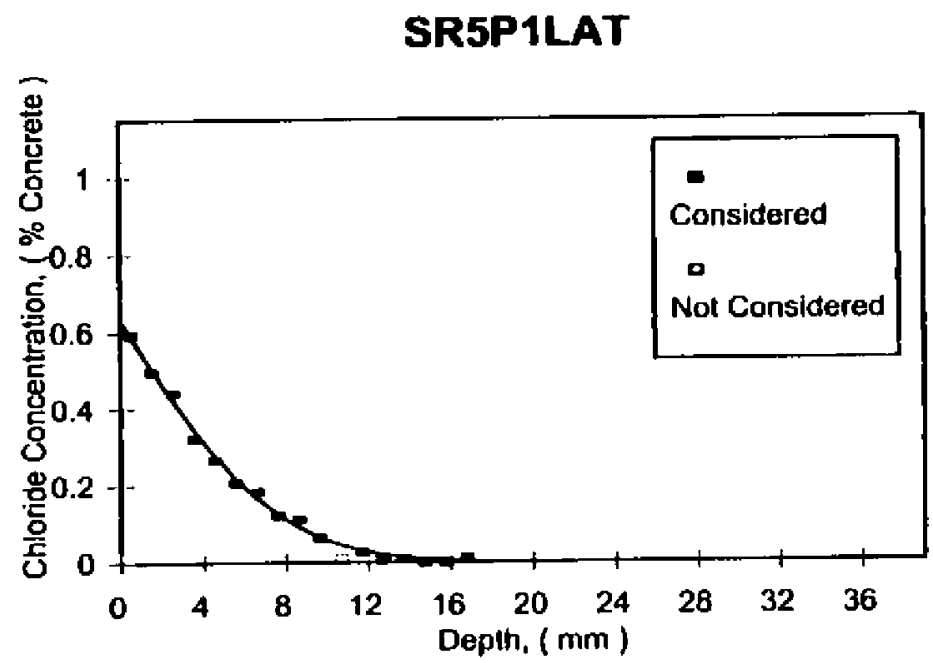


Diffusion Coefficient:

Surface Concentration:

Background:

$r^{2}$

$1.63 \mathrm{E}-11 \mathrm{~m}^{2} / \mathrm{s}$

$0.82 \%$ by Mass of Concrete

$0.052 \%$ by Mass of Concretc

0.9460

Data

\begin{tabular}{|c|c|}
\hline $\begin{array}{c}\text { Depth, } \\
(\mathbf{m m})\end{array}$ & $\begin{array}{c}\text { Chloride Concentration, } \\
\text { (\% by Mass of Concretc) }\end{array}$ \\
\hline 0.89 & 0.79 \\
\hline 1.65 & 0.76 \\
\hline 3.18 & 0.63 \\
\hline 4.70 & 0.48 \\
\hline 6.22 & 0.43 \\
\hline 7.75 & 0.35 \\
\hline 9.27 & 0.31 \\
\hline 10.80 & 0.25 \\
\hline 12.32 & 0.21 \\
\hline 13.84 & 0.13 \\
\hline 16.89 & 0.09 \\
\hline 19.94 & 0.14 \\
\hline 22.99 & 0.06 \\
\hline 26.04 & 0.08 \\
\hline 29.08 & 0.12 \\
\hline 32.13 & 0.09 \\
\hline 35.18 & 0.09 \\
\hline
\end{tabular}

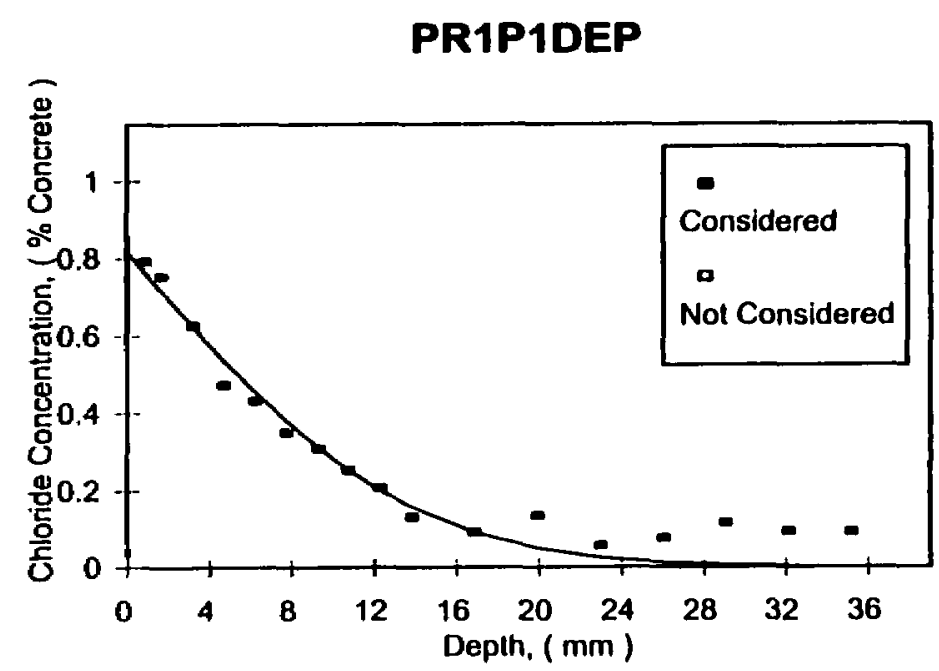


100\% OPC, $0.297 \mathrm{~mm}$ Rough Crack

Diffusion Coefficient:

Surface Concentration:

Background:

$r^{2}$ :

$1.17 \mathrm{E}-11 \mathrm{~m}^{2} / \mathrm{s}$

$0.78 \%$ by Mass of Concrete

$0.057 \%$ by Mass of Concrete

0.9466

Data

\begin{tabular}{|c|c|}
\hline $\begin{array}{c}\text { Depth, } \\
\text { (mm) }\end{array}$ & $\begin{array}{c}\text { Chloride Concentration, } \\
\text { (\% by Mass of Concrete) }\end{array}$ \\
\hline 0.89 & 0.80 \\
\hline 1.65 & 0.69 \\
\hline 3.18 & 0.49 \\
\hline 4.70 & 0.43 \\
\hline 6.22 & 0.34 \\
\hline 7.75 & 0.28 \\
\hline 9.27 & 0.25 \\
\hline 10.80 & 0.19 \\
\hline 12.32 & 0.16 \\
\hline 13.84 & 0.12 \\
\hline 16.89 & 0.09 \\
\hline 19.94 & 0.05 \\
\hline 22.99 & 0.08 \\
\hline 26.04 & 0.06 \\
\hline 29.08 & 0.08 \\
\hline 32.13 & 0.06 \\
\hline 35.18 & 0.07 \\
\hline
\end{tabular}

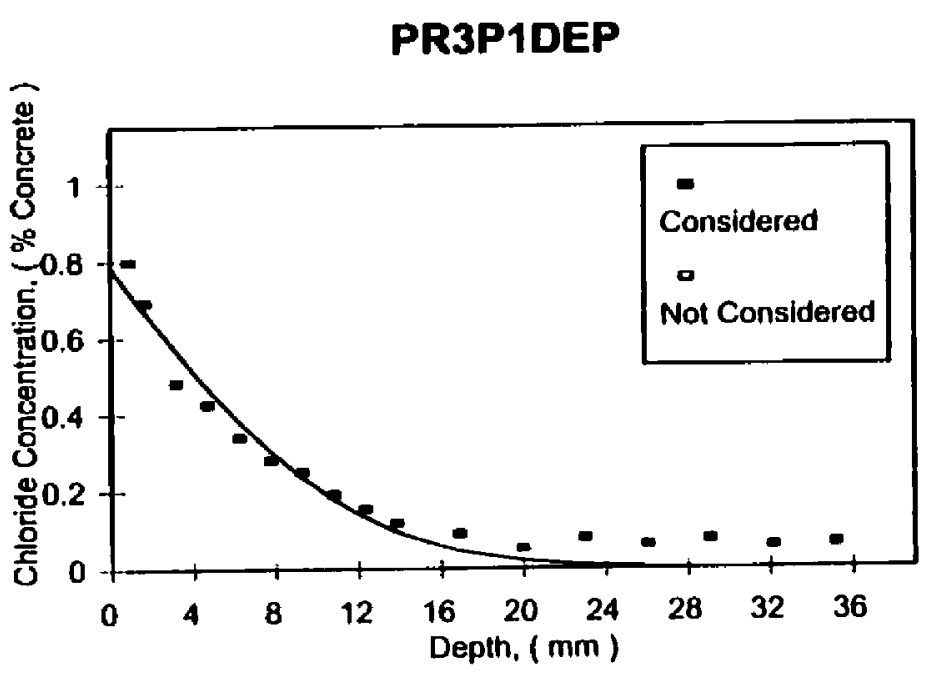


Diffusion Coefficient:

Surface Concentration:

Background:

$r^{2}:$

$1.05 \mathrm{E}-11 \mathrm{~m}^{2} / \mathrm{s}$

$0.65 \%$ by Mass of Concrete

$0.075 \%$ by Mass of Concrete

0.9521

\section{Data}

\begin{tabular}{|c|c|}
\hline $\begin{array}{c}\text { Depth, } \\
(\mathrm{mm})\end{array}$ & $\begin{array}{c}\text { Chloride Concentration, } \\
\text { (\% by Mass of Concretc) }\end{array}$ \\
\hline 0.89 & 0.66 \\
\hline 1.65 & 0.65 \\
\hline 3.18 & 0.42 \\
\hline 4.70 & 0.34 \\
\hline 6.22 & 0.30 \\
\hline 7.75 & 0.20 \\
\hline 9.27 & 0.17 \\
\hline 10.80 & 0.15 \\
\hline 12.32 & 0.12 \\
\hline 13.84 & 0.11 \\
\hline 16.89 & 0.06 \\
\hline 19.94 & 0.04 \\
\hline 22.99 & 0.04 \\
\hline 26.04 & 0.04 \\
\hline 29.08 & 0.05 \\
\hline 32.13 & 0.03 \\
\hline 35.18 & 0.05 \\
\hline
\end{tabular}

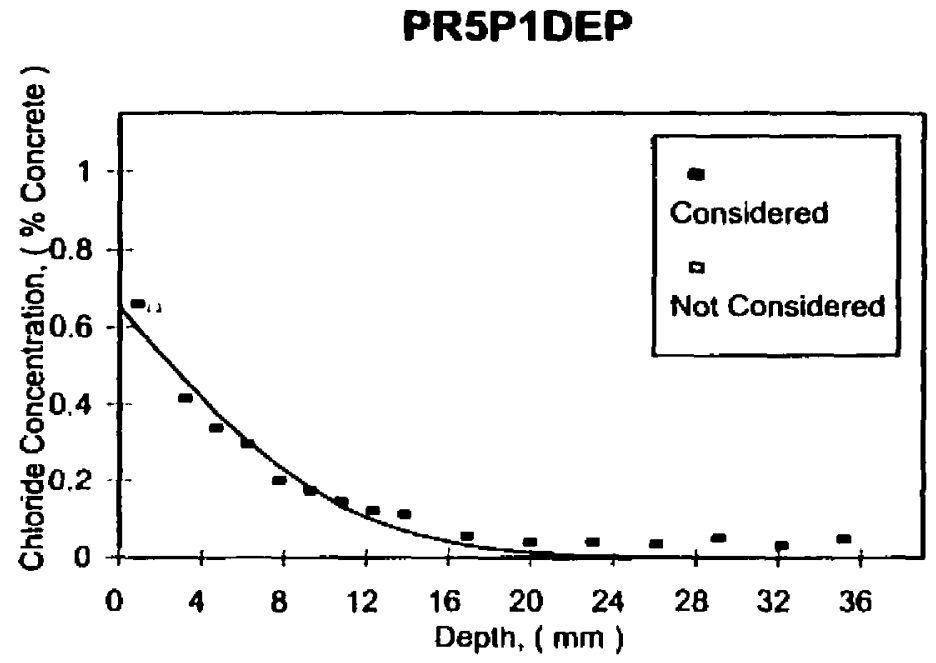


Diffusion Coefficient:

Surface Concentration:

Background:

$r^{2}$ :
$3.31 \mathrm{E}-12 \mathrm{~m}^{2} / \mathrm{s}$

$0.95 \%$ by Mass of Concrete

$0.064 \%$ by Mass of Concrete

0.9765

\section{Data}

\begin{tabular}{|c|c|}
\hline $\begin{array}{c}\text { Depth, } \\
\text { (mm) }\end{array}$ & $\begin{array}{c}\text { Chloride Concentration, } \\
\text { (\% by Mass of Concrete) }\end{array}$ \\
\hline 0.89 & 0.88 \\
\hline 1.65 & 0.66 \\
\hline 3.18 & 0.41 \\
\hline 4.70 & 0.30 \\
\hline 6.22 & 0.21 \\
\hline 7.75 & 0.14 \\
\hline 9.27 & 0.06 \\
\hline 10.80 & 0.06 \\
\hline 12.32 & 0.05 \\
\hline 13.84 & 0.04 \\
\hline 16.89 & 0.05 \\
\hline 19.94 & 0.02 \\
\hline 22.99 & 0.02 \\
\hline 26.04 & 0.03 \\
\hline 29.08 & 0.02 \\
\hline 32.13 & 0.01 \\
\hline 35.18 & 0.01 \\
\hline
\end{tabular}

SR1P1DEP

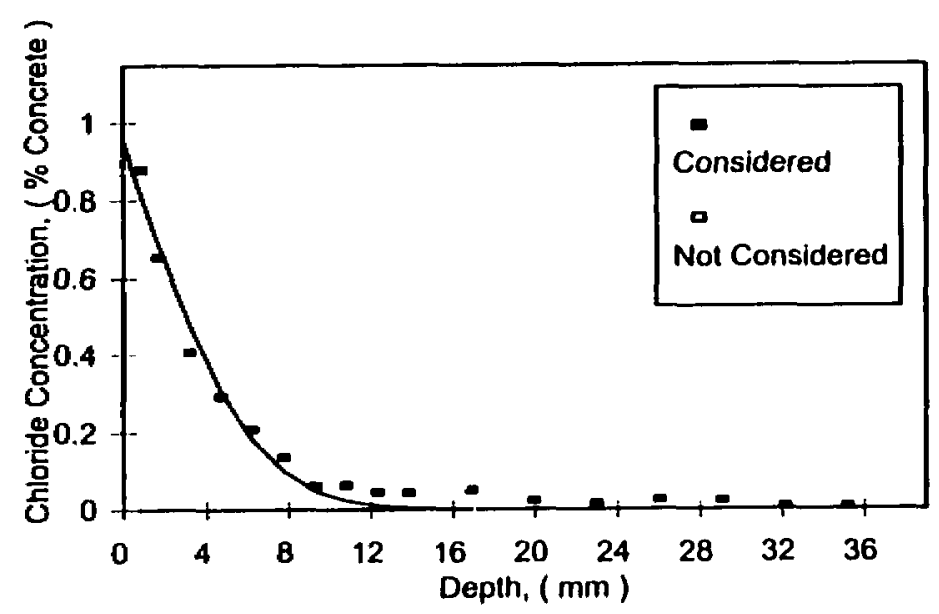


Diffusion Cocfficient:

Surface Concentration:

Background:

$r^{2}$ :
$1.80 \mathrm{E}-12 \mathrm{~m}^{2} / \mathrm{s}$ $1.24 \%$ by Mass of Concrete $0.054 \%$ by Mass of Concrete 0.9696

\section{Data}

\begin{tabular}{|c|c|}
\hline $\begin{array}{c}\text { Depth, } \\
\text { (mm) }\end{array}$ & $\begin{array}{c}\text { Chloride Concentration, } \\
\text { (\% by Mass of Concretc) }\end{array}$ \\
\hline 0.89 & 1.03 \\
\hline 1.65 & 0.77 \\
\hline 3.18 & 0.39 \\
\hline 4.70 & 0.23 \\
\hline 6.22 & 0.14 \\
\hline 7.75 & 0.07 \\
\hline 9.27 & 0.06 \\
\hline 10.80 & 0.07 \\
\hline 12.32 & 0.07 \\
\hline 13.84 & 0.07 \\
\hline 16.89 & 0.05 \\
\hline 19.94 & 0.05 \\
\hline 22.99 & 0.04 \\
\hline 26.04 & 0.05 \\
\hline 29.08 & 0.04 \\
\hline 32.13 & 0.04 \\
\hline 35.18 & 0.04 \\
\hline
\end{tabular}

SR3P1DEP

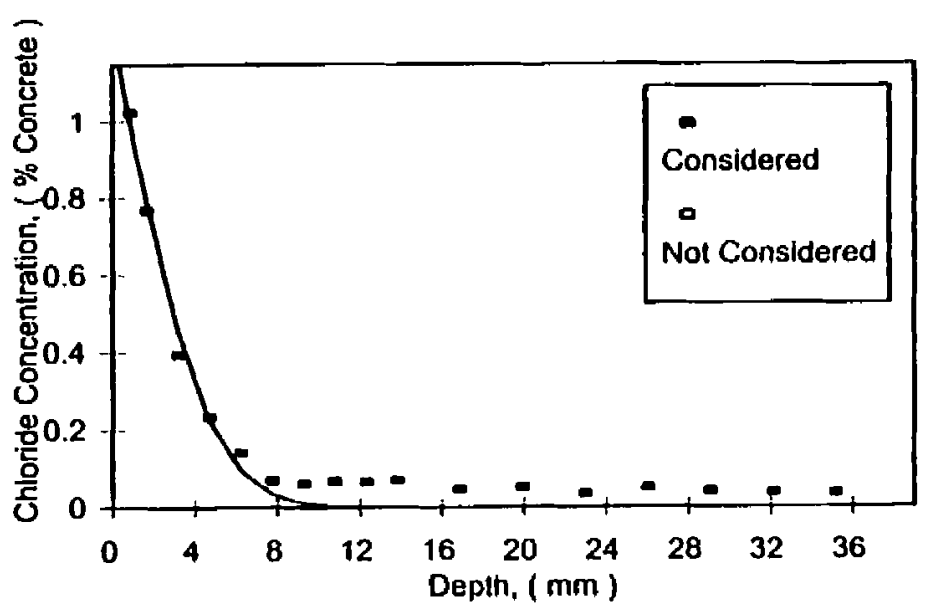




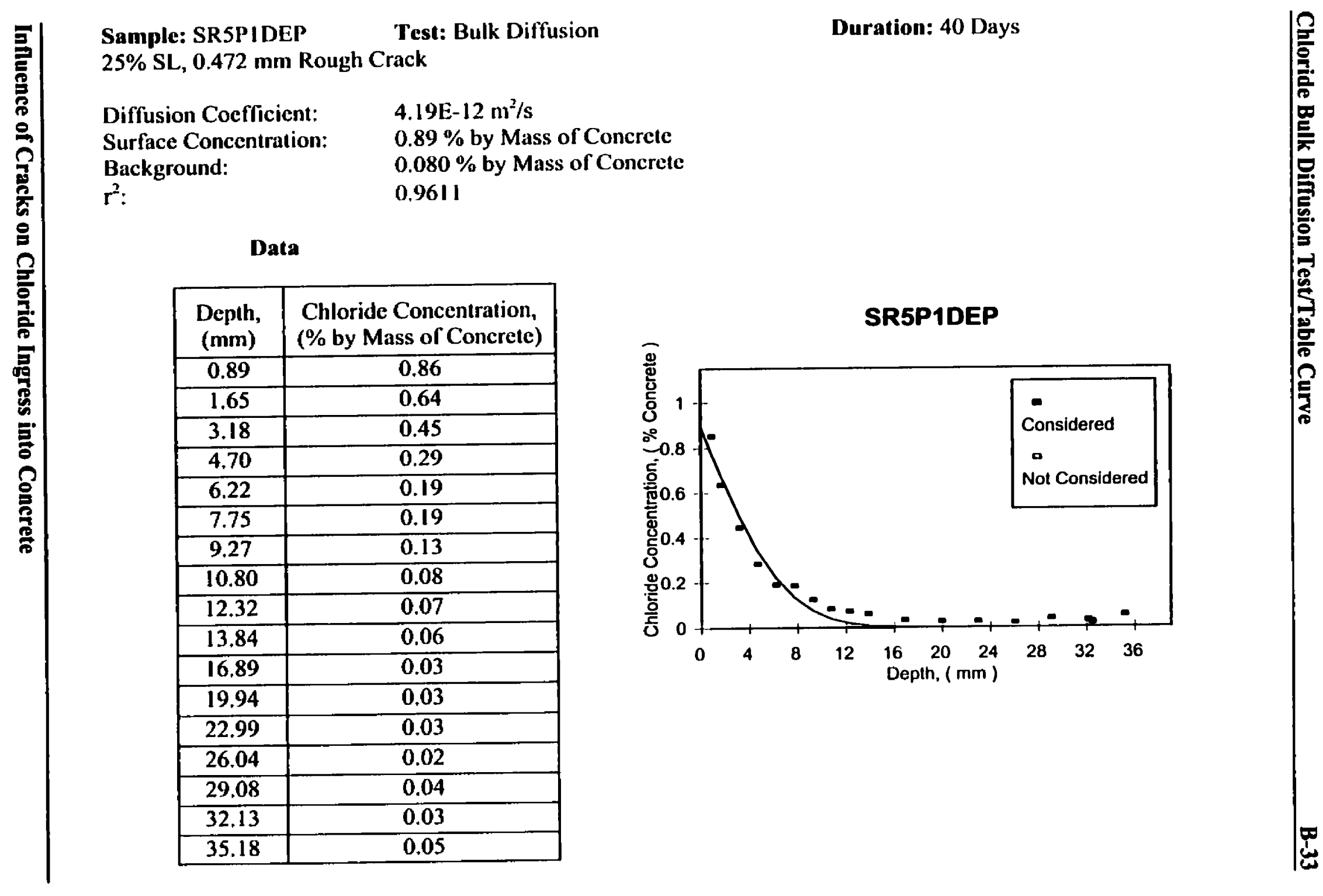




\section{APPENDIX C}

\section{ChLORIDE Bulk Diffusion TEST}

\section{CONFLUX}


Diffusion Coefficient:

$6.40 \mathrm{E}-12 \mathrm{~m}^{2} / \mathrm{s}$

Surface Concentration:

$0.75 \%$ by Mass of Concrete

Background:

$0.069 \%$ by Mass of Concrete

\section{Data}

\begin{tabular}{|c|c|}
\hline $\begin{array}{c}\text { Depth, } \\
\text { (mm) }\end{array}$ & $\begin{array}{c}\text { Chloride Concentration, } \\
\text { (\% by Mass of Concrete) }\end{array}$ \\
\hline 0.76 & 0.64 \\
\hline 1.27 & 0.59 \\
\hline 2.29 & 0.51 \\
\hline 3.30 & 0.43 \\
\hline 4.32 & 0.37 \\
\hline 5.33 & 0.32 \\
\hline 6.35 & 0.27 \\
\hline 8.38 & 0.20 \\
\hline 10.41 & 0.11 \\
\hline 12.95 & 0.05 \\
\hline 15.49 & 0.02 \\
\hline 18.03 & 0.01 \\
\hline 20.57 & 0.00 \\
\hline
\end{tabular}

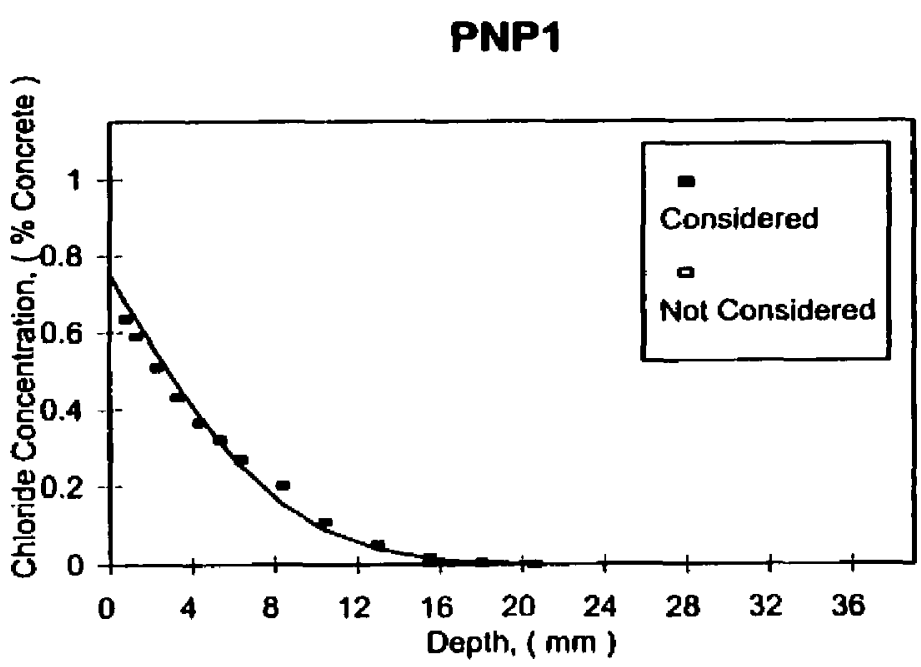


Sample: PNP9

Test: Bulk Diffusion

Duration: 40 Days

$100 \%$ OPC, No Crack

Diffusion Coefficient:

Surface Concentration:

Background:

$8.66 \mathrm{E}-12 \mathrm{~m}^{2} / \mathrm{s}$

$0.75 \%$ by Mass of Concrele

$0.070 \%$ by Mass of Concrete

Data

\begin{tabular}{|c|c|}
\hline $\begin{array}{c}\text { Depth, } \\
(\mathbf{m m})\end{array}$ & $\begin{array}{c}\text { Chloride Concentration, } \\
\text { (\% by Mass of Concrete) }\end{array}$ \\
\hline 0.76 & 0.85 \\
\hline 1.27 & 0.74 \\
\hline 2.29 & 0.63 \\
\hline 3.30 & 0.51 \\
\hline 4.32 & 0.44 \\
\hline 5.33 & 0.35 \\
\hline 6.35 & 0.31 \\
\hline 8.38 & 0.18 \\
\hline 10.41 & 0.12 \\
\hline 12.95 & 0.05 \\
\hline 15.49 & 0.01 \\
\hline 18.03 & 0.00 \\
\hline 20.57 & -0.02 \\
\hline
\end{tabular}

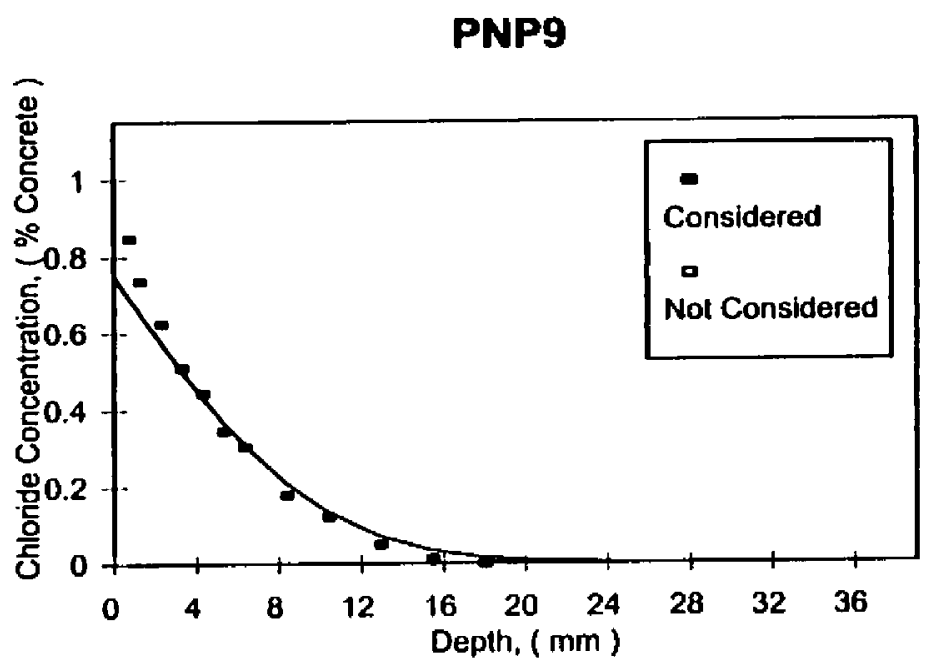


$5.16 \mathrm{E}-12 \mathrm{~m}^{2} / \mathrm{s}$

Diffusion Coefficient:

Surface Concentration:

$0.77 \%$ by Mass of Concrete

Background:

$0.076 \%$ by Mass of Concrete

\section{Data}

\begin{tabular}{|c|c|}
\hline $\begin{array}{c}\text { Depth, } \\
\text { (mm) }\end{array}$ & $\begin{array}{c}\text { Chloride Concentration, } \\
\text { (\% by Mass of Concrete) }\end{array}$ \\
\hline 0.76 & 0.77 \\
\hline 1.27 & 0.71 \\
\hline 1.78 & 0.65 \\
\hline 2.29 & 0.55 \\
\hline 3.30 & 0.43 \\
\hline 4.32 & 0.35 \\
\hline 5.84 & 0.24 \\
\hline 6.35 & 0.21 \\
\hline 8.38 & 0.11 \\
\hline 10.41 & 0.05 \\
\hline 12.95 & 0.01 \\
\hline 15.49 & 0.00 \\
\hline
\end{tabular}

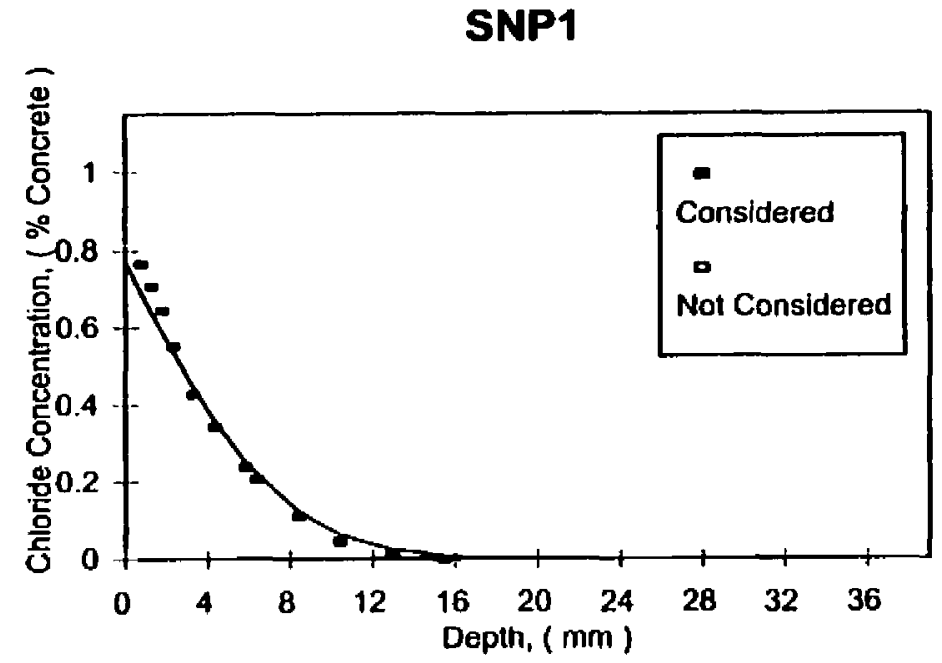


$3.25 \mathrm{E}-12 \mathrm{~m}^{2} / \mathrm{s}$

Diffusion Coefficient:

$0.77 \%$ by Mass of Concrete

Surface Concentration

$\mathbf{0 . 0 6 7 \%}$ by Mass of Concretc

Background:

\section{Data}

\begin{tabular}{|c|c|}
\hline $\begin{array}{c}\text { Depth, } \\
(\mathrm{mm})\end{array}$ & $\begin{array}{c}\text { Chloride Concentration, } \\
\text { (\% by Mass of Concrete) }\end{array}$ \\
\hline 0.76 & 0.91 \\
\hline 1.27 & 0.74 \\
\hline 2.29 & 0.49 \\
\hline 3.30 & 0.33 \\
\hline 4.32 & 0.25 \\
\hline 5.33 & 0.16 \\
\hline 6.35 & 0.12 \\
\hline 8.38 & 0.06 \\
\hline 10.41 & 0.03 \\
\hline 12.95 & 0.01 \\
\hline 15.49 & 0.01 \\
\hline 18.03 & 0.01 \\
\hline 20.57 & 0.00 \\
\hline
\end{tabular}

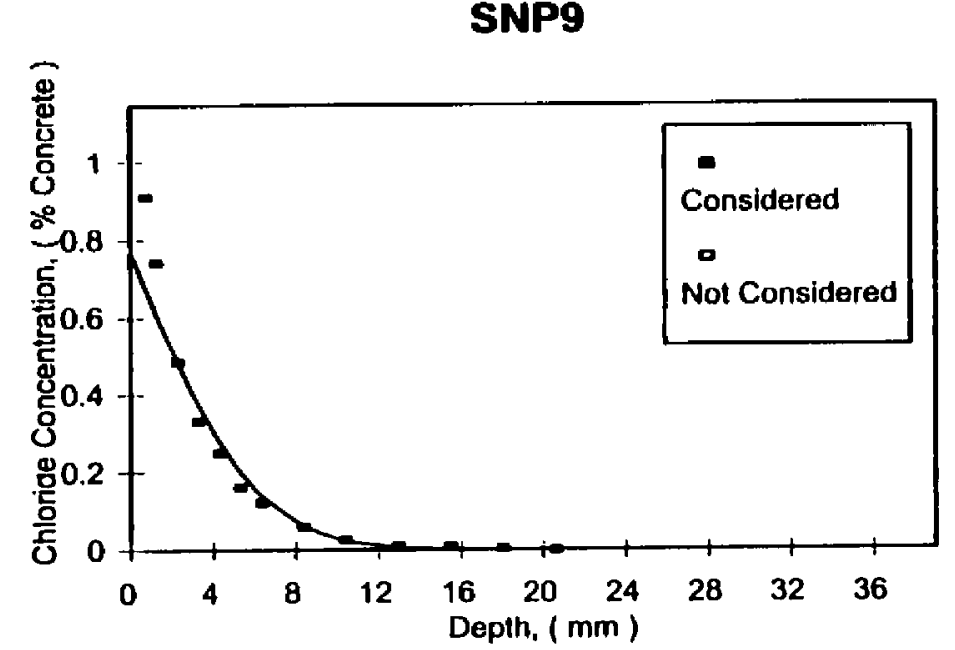


Sample: PNPLAT1

$100 \%$ OPC, No Crack

Diffusion Coefficient:

Surface Concentration:

Background:
Tesı: Bulk Diffusion

Duration: 40 Days

$7.41 \mathrm{E}-12 \mathrm{~m}^{2} / \mathrm{s}$

$0.75 \%$ by Mass of Concrete

$0.057 \%$ by Mass of Concrete

Data

\begin{tabular}{|c|c|}
\hline $\begin{array}{c}\text { Depth, } \\
(\mathrm{mm})\end{array}$ & $\begin{array}{c}\text { Chioride Concentration, } \\
\text { (\% by Mass of Concrete) }\end{array}$ \\
\hline 0.89 & 0.60 \\
\hline 1.65 & 0.48 \\
\hline 3.18 & 0.41 \\
\hline 4.70 & 0.34 \\
\hline $\mathbf{0 . 2 2}$ & 0.29 \\
\hline 7.75 & 0.23 \\
\hline 9.27 & 0.20 \\
\hline 10.80 & 0.15 \\
\hline 13.08 & 0.10 \\
\hline 15.37 & 0.06 \\
\hline 17.65 & 0.03 \\
\hline 19.94 & 0.02 \\
\hline 22.23 & 0.00 \\
\hline
\end{tabular}

PNPLAT1

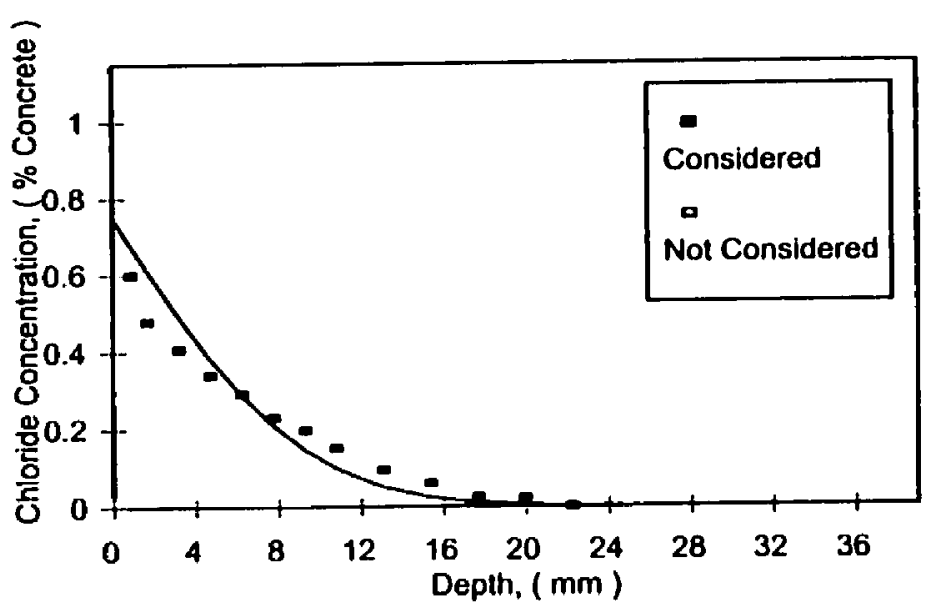


Sample: PNPLAT3

100\% OPC, No Crack

Diffusion Coefficient:

Surface Concentration:

Background:
Test: Bulk Diffusion

Duration: 40 Days

$1.14 \mathrm{E}-11 \mathrm{~m}^{2} / \mathrm{s}$

$0.75 \%$ by Mass of Concrete

$0.063 \%$ by Mass of Concrete

\section{Data}

\begin{tabular}{|c|c|}
\hline $\begin{array}{c}\text { Depth, } \\
\text { (mm) }\end{array}$ & $\begin{array}{c}\text { Chloride Concentration, } \\
\text { (\% by Mass of Concrete) }\end{array}$ \\
\hline 0.89 & 0.88 \\
\hline 1.65 & 0.69 \\
\hline 3.18 & 0.56 \\
\hline 4.70 & 0.50 \\
\hline 6.22 & 0.37 \\
\hline 7.75 & 0.30 \\
\hline 9.27 & 0.24 \\
\hline 10.80 & 0.12 \\
\hline 13.08 & 0.06 \\
\hline 15.37 & 0.02 \\
\hline 17.65 & 0.00 \\
\hline 19.94 & 0.00 \\
\hline 22.32 & 0.00 \\
\hline 24.51 & 0.01 \\
\hline
\end{tabular}

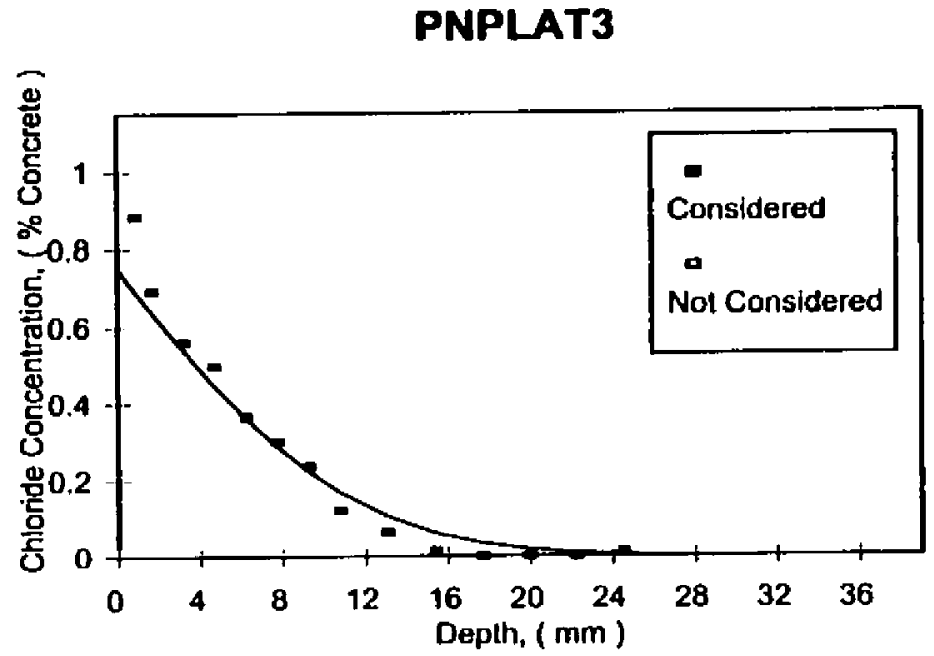


Diffusion Coefficient:

Surface Concentration:

$0.77 \%$ by Mass of Concrete

Background:

$0.072 \%$ by Mass of Concrete

\begin{tabular}{|c|c|}
\hline $\begin{array}{l}\text { Depth, } \\
\text { (mm) }\end{array}$ & $\begin{array}{l}\text { Chloride Concentration, } \\
\text { ( } \% \text { hy Mass of Concrete) }\end{array}$ \\
\hline 0.89 & 0.68 \\
\hline 1.65 & 0.53 \\
\hline 3.18 & 0.31 \\
\hline 4.70 & $0 . \overline{22}$ \\
\hline 6.22 & 0.16 \\
\hline 7.75 & 0.10 \\
\hline 9.27 & 0.08 \\
\hline 10.80 & 0.06 \\
\hline 13.08 & 0.04 \\
\hline 15.37 & 0.01 \\
\hline 17.65 & 0.00 \\
\hline 19.94 & 0.01 \\
\hline 22.23 & 0.00 \\
\hline
\end{tabular}

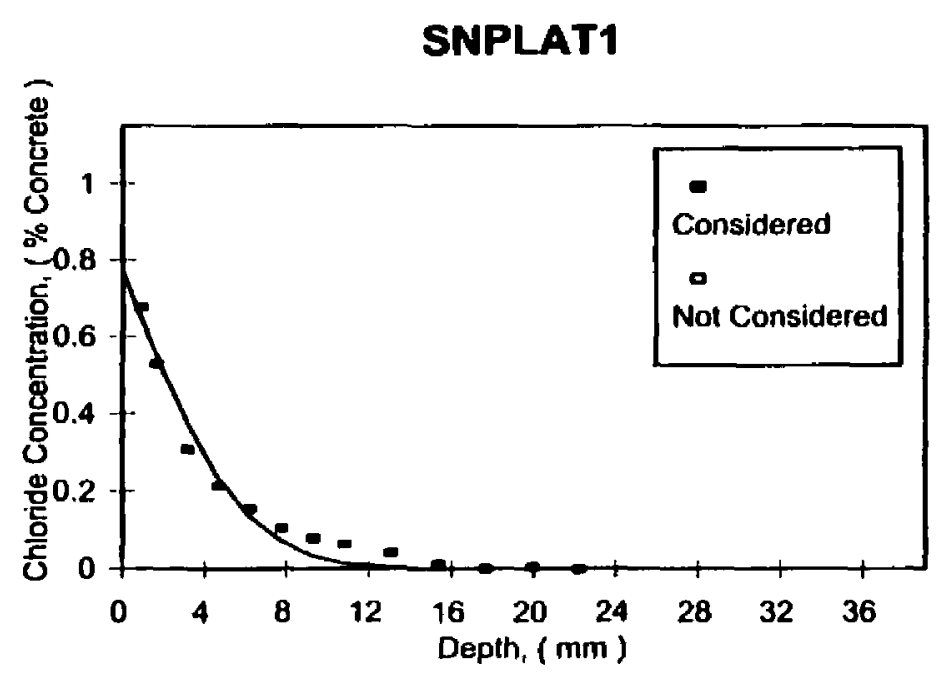




\begin{tabular}{|c|c|c|}
\hline \multicolumn{2}{|c|}{$\begin{array}{l}\text { Sample: SNPLAT3 } \\
25 \% \text { SL, No Crack } \\
\\
\text { Diffusion Coefficient: } \\
\text { Surface Concentration: } \\
\text { Background: }\end{array}$} & $\begin{array}{l}\text { Test: Bulk Diffusi } \\
5.10 \mathrm{E}-12 \mathrm{~m}^{2} / \mathrm{s} \\
0.77 \% \text { by Mass of } \\
0.057 \% \text { by Mass }\end{array}$ \\
\hline $\begin{array}{l}\text { Depth, } \\
\text { (mm) }\end{array}$ & $\begin{array}{l}\text { Chl } \\
(\% \mathrm{t}\end{array}$ & $\begin{array}{l}\text { Concentration, } \\
\text { ass of Concrete) }\end{array}$ \\
\hline 0.89 & & 0.85 \\
\hline 1.65 & & 0.68 \\
\hline 3.18 & & 0.51 \\
\hline 4.70 & & 0.33 \\
\hline 6.22 & & 0.20 \\
\hline 7.75 & & 0.11 \\
\hline 9.27 & & 0.06 \\
\hline 10.80 & & 0.01 \\
\hline 13.08 & & 0.00 \\
\hline 15.37 & & 0.01 \\
\hline 17.65 & & 0.01 \\
\hline 19.94 & & 0.00 \\
\hline 22.23 & & -0.02 \\
\hline
\end{tabular}


Diffusion Coefficient:

Surface Concentration:

Background:
$8.39 \mathrm{E}-12 \mathrm{~m}^{2} / \mathrm{s}$

$0.75 \%$ by Mass of Concretc

$0.074 \%$ by Mass of Concrete

\section{Data}

\begin{tabular}{|c|c|}
\hline $\begin{array}{c}\text { Depth, } \\
\text { (mm) }\end{array}$ & $\begin{array}{c}\text { Chloride Concentration, } \\
\text { (\% by Mass of Concretc) }\end{array}$ \\
\hline 0.89 & 0.60 \\
\hline 1.65 & 0.53 \\
\hline 3.18 & 0.48 \\
\hline 4.70 & 0.38 \\
\hline 6.22 & 0.32 \\
\hline 7.75 & 0.23 \\
\hline 9.27 & 0.18 \\
\hline 10.80 & 0.16 \\
\hline 13.08 & 0.09 \\
\hline 14.61 & 0.06 \\
\hline 17.65 & 0.02 \\
\hline 19.94 & 0.01 \\
\hline 22.23 & 0.01 \\
\hline 24.51 & 0.01 \\
\hline 26.80 & 0.00 \\
\hline 29.08 & 0.00 \\
\hline 31.37 & 0.01 \\
\hline
\end{tabular}

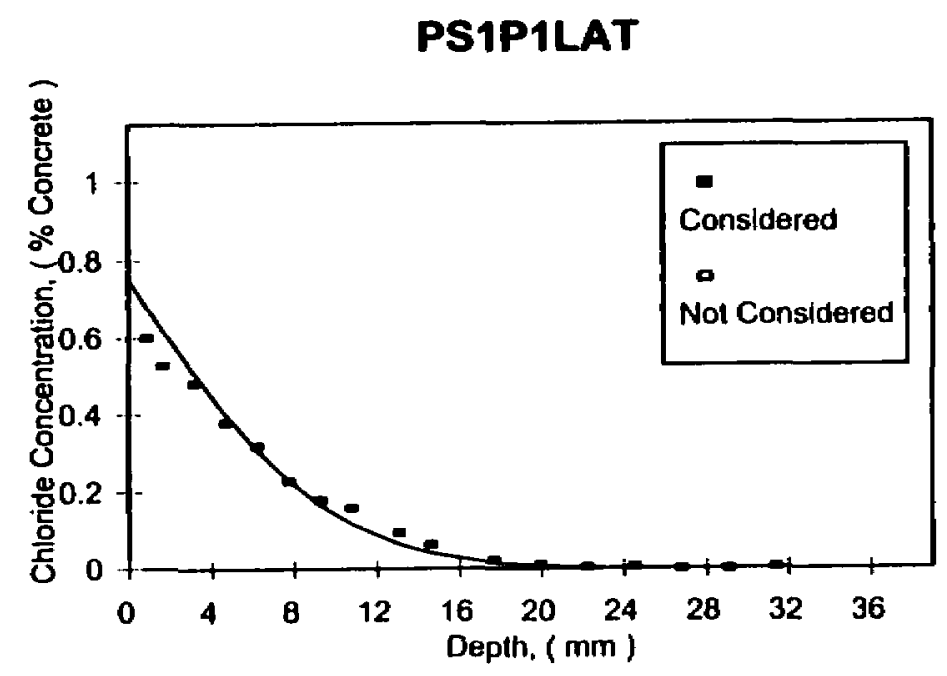


Diffusion Coefficient:

Surface Concentration:

Background:

$5.48 \mathrm{E}-12 \mathrm{~m}^{2} / \mathrm{s}$

$0.75 \%$ by Mass of Concrete

$0.066 \%$ by Mass of Concrete

\section{Data}

\begin{tabular}{|c|c|}
\hline $\begin{array}{c}\text { Depth, } \\
\text { (mm) }\end{array}$ & $\begin{array}{c}\text { Chloride Concentration, } \\
\text { (\% by Mass of Concrete) }\end{array}$ \\
\hline 0.89 & 0.61 \\
\hline 1.65 & 0.57 \\
\hline 3.18 & 0.45 \\
\hline 4.70 & 0.32 \\
\hline 6.22 & 0.23 \\
\hline 7.75 & 0.17 \\
\hline 9.27 & 0.11 \\
\hline 10.80 & 0.08 \\
\hline 13.08 & 0.04 \\
\hline 15.37 & 0.02 \\
\hline 17.65 & 0.01 \\
\hline 19.94 & 0.00 \\
\hline 22.23 & 0.00 \\
\hline 24.51 & 0.01 \\
\hline
\end{tabular}

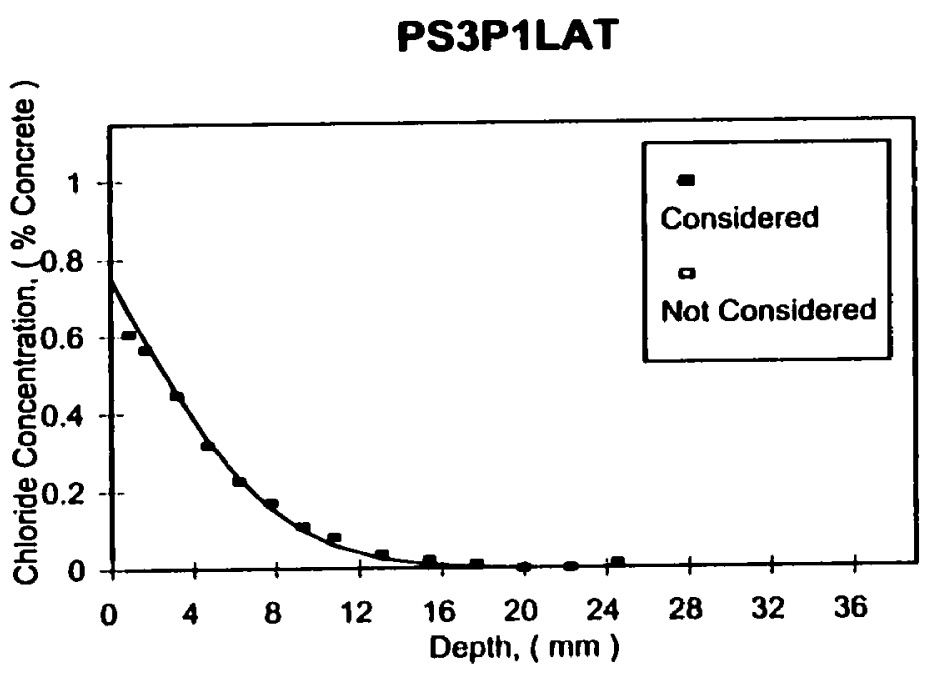


Sample: PS5PILAT

Test: Bulk Diffusion

Duration: 40 Days

100\% OPC, $0.677 \mathrm{~mm}$ Smooth Crack

Diffusion Coefficient:

Surface Concentration:

Background:

$1.01 \mathrm{E}-11 \mathrm{~m}^{2} / \mathrm{s}$

$0.75 \%$ by Mass of Concrete

$0.063 \%$ by Mass of Concrete

\begin{tabular}{|c|c|}
\hline $\begin{array}{l}\text { Depth, } \\
(\mathbf{m m})\end{array}$ & $\begin{array}{l}\text { Chloride Concentration, } \\
\text { (\% by Mass of Concrete) }\end{array}$ \\
\hline 0.89 & 0.53 \\
\hline 1.65 & 0.60 \\
\hline 3.18 & 0.50 \\
\hline 4.70 & 0.39 \\
\hline 7.75 & 0.28 \\
\hline 9.27 & 0.21 \\
\hline 10.80 & 0.18 \\
\hline 13.08 & 0.09 \\
\hline 15.37 & 0.05 \\
\hline 17.65 & 0.02 \\
\hline 19.94 & 0.03 \\
\hline 22.23 & 0.02 \\
\hline 24.51 & 0.01 \\
\hline 26.80 & 0.00 \\
\hline 29.08 & 0.02 \\
\hline 31.37 & 0.00 \\
\hline
\end{tabular}

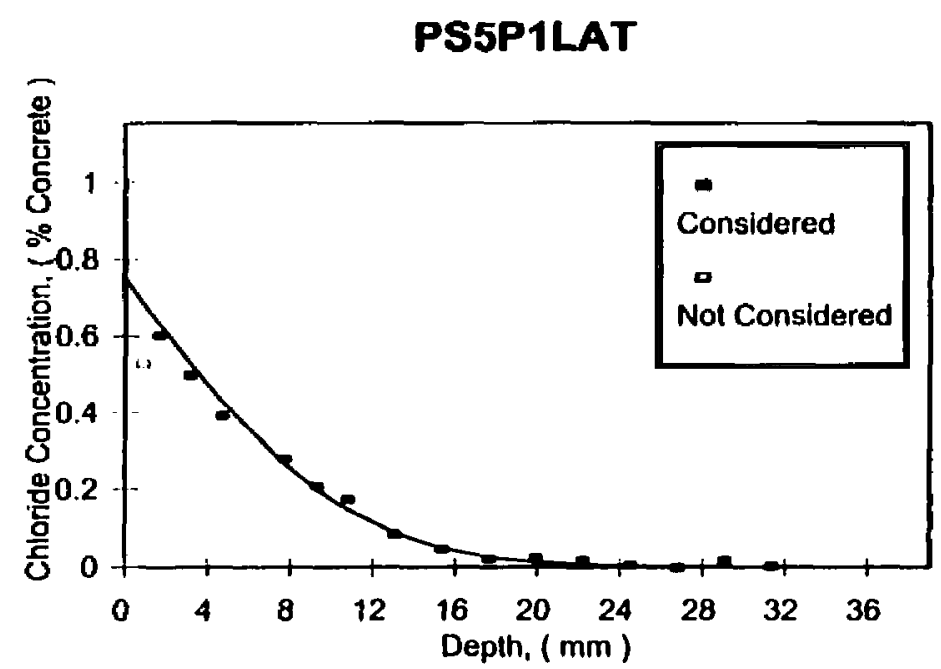


Test: Bulk Diffusion

$25 \%$ SL, $0.079 \mathrm{~mm}$ Smooth Crack

Diffusion Coefficient:

$2.23 \mathrm{E}-12 \mathrm{~m}^{2} / \mathrm{s}$

Surface Concentration:

$0.77 \%$ by Mass of Concretc

Background:

$0.065 \%$ by Mass of Concrete

\section{Data}

\begin{tabular}{|c|c|}
\hline $\begin{array}{c}\text { Depth, } \\
\text { (mm) }\end{array}$ & $\begin{array}{c}\text { Chloride Concentration, } \\
\text { (\% by Mass of Concrete) }\end{array}$ \\
\hline 0.89 & 0.48 \\
\hline 1.65 & 0.44 \\
\hline 3.18 & 0.29 \\
\hline 4.70 & 0.22 \\
\hline 6.22 & 0.15 \\
\hline 7.75 & 0.13 \\
\hline 9.27 & 0.09 \\
\hline 10.80 & 0.06 \\
\hline 13.08 & 0.03 \\
\hline 15.37 & 0.02 \\
\hline 17.65 & 0.01 \\
\hline 19.94 & 0.01 \\
\hline 22.23 & 0.00 \\
\hline 24.51 & 0.01 \\
\hline 26.80 & 0.01 \\
\hline 29.08 & 0.00 \\
\hline
\end{tabular}

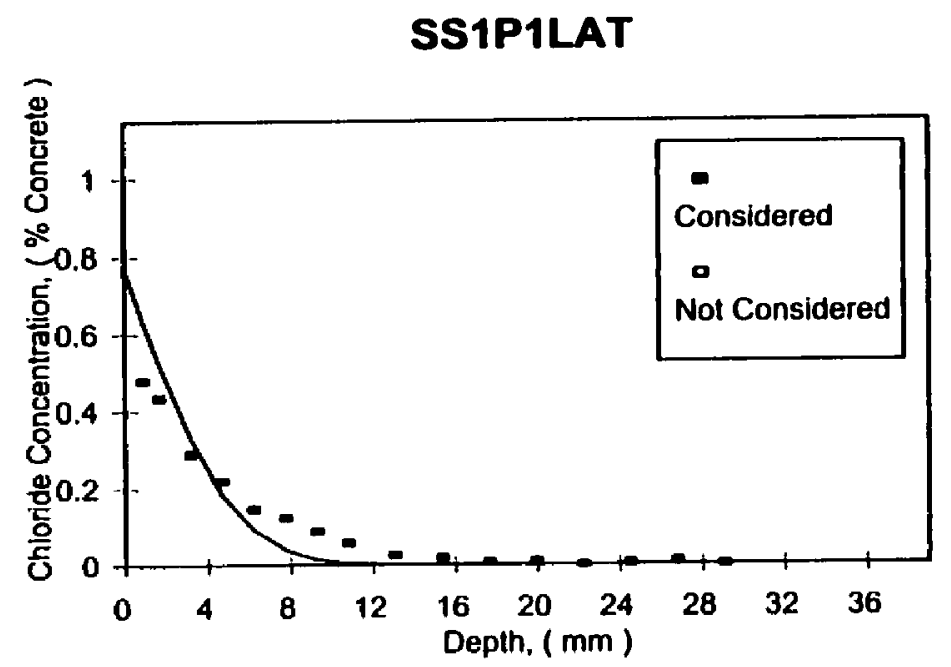


Diffusion Coefficient:

Surface Concentration:

Background:
$2.77 \mathrm{E}-12 \mathrm{~m}^{2} / \mathrm{s}$

$0.77 \%$ by Mass of Concrete

$0.062 \%$ by Mass of Concrete

\section{Data}

\begin{tabular}{|c|c|}
\hline $\begin{array}{c}\text { Depth, } \\
(\mathrm{mm})\end{array}$ & $\begin{array}{c}\text { Chloride Concentration, } \\
\text { (\% by Mass of Concrete) }\end{array}$ \\
\hline 0.89 & 0.55 \\
\hline 1.65 & 0.43 \\
\hline 3.18 & 0.34 \\
\hline 4.70 & 0.24 \\
\hline 6.22 & 0.17 \\
\hline 7.75 & 0.14 \\
\hline 9.27 & 0.15 \\
\hline 10.80 & 0.12 \\
\hline 13.08 & 0.03 \\
\hline 15.37 & 0.03 \\
\hline 17.65 & 0.01 \\
\hline 19.94 & 0.00 \\
\hline 22.23 & 0.00 \\
\hline 24.51 & 0.01 \\
\hline 26.80 & 0.00 \\
\hline 29.08 & 0.00 \\
\hline 31.37 & 0.00 \\
\hline
\end{tabular}

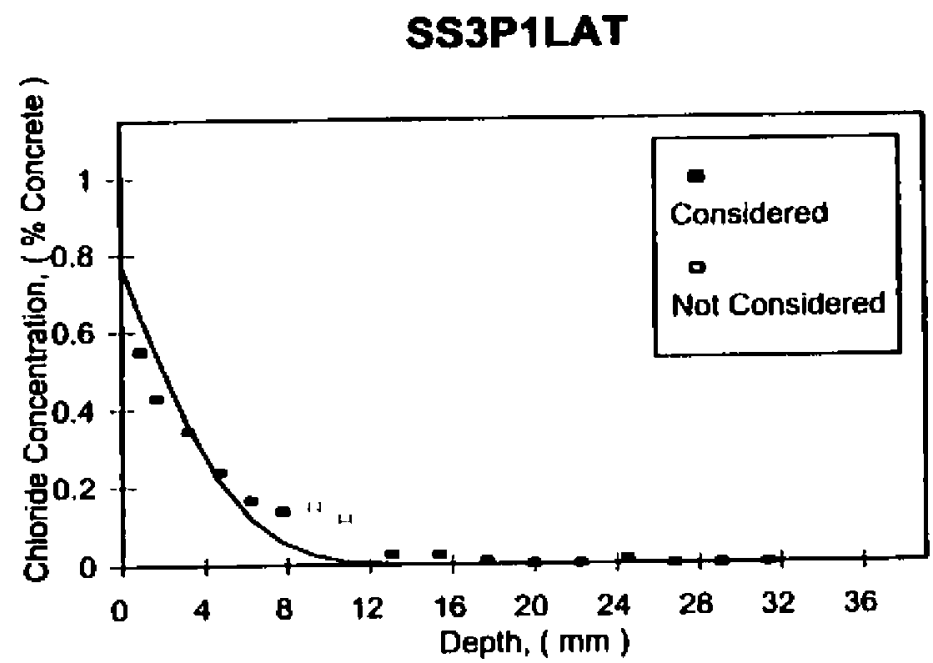


Diffusion Coefficient:

$2.66 \mathrm{E}-12 \mathrm{~m}^{2} / \mathrm{s}$

Surface Concentration:

$0.77 \%$ by Mass of Concrete

Background:

$0.057 \%$ by Mass of Concrete

Data

\begin{tabular}{|c|c|}
\hline $\begin{array}{c}\text { Depth, } \\
\text { (mm) }\end{array}$ & $\begin{array}{c}\text { Chloride Concentration, } \\
\text { (\% by Mass of Concrete) }\end{array}$ \\
\hline 0.89 & 0.68 \\
\hline 1.65 & 0.52 \\
\hline 3.18 & 0.33 \\
\hline 4.70 & 0.22 \\
\hline 6.22 & 0.11 \\
\hline 7.75 & 0.07 \\
\hline 9.27 & 0.03 \\
\hline 10.80 & 0.03 \\
\hline 13.08 & 0.01 \\
\hline 15.37 & 0.01 \\
\hline 17.65 & 0.01 \\
\hline 19.94 & 0.01 \\
\hline 22.23 & 0.01 \\
\hline 24.51 & 0.00 \\
\hline 26.80 & 0.01 \\
\hline 29.08 & 0.01 \\
\hline 31.37 & 0.02 \\
\hline
\end{tabular}

SS5P1LAT

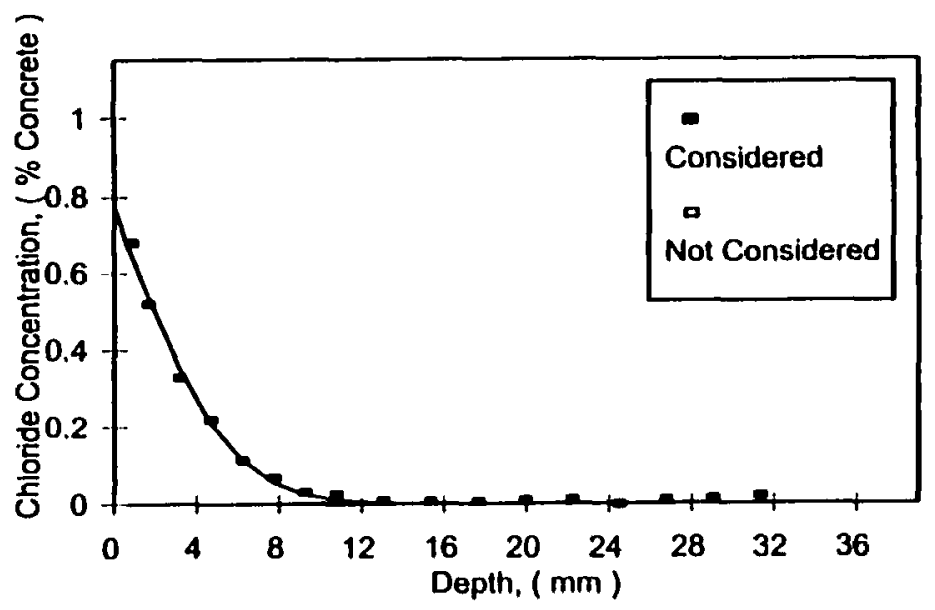




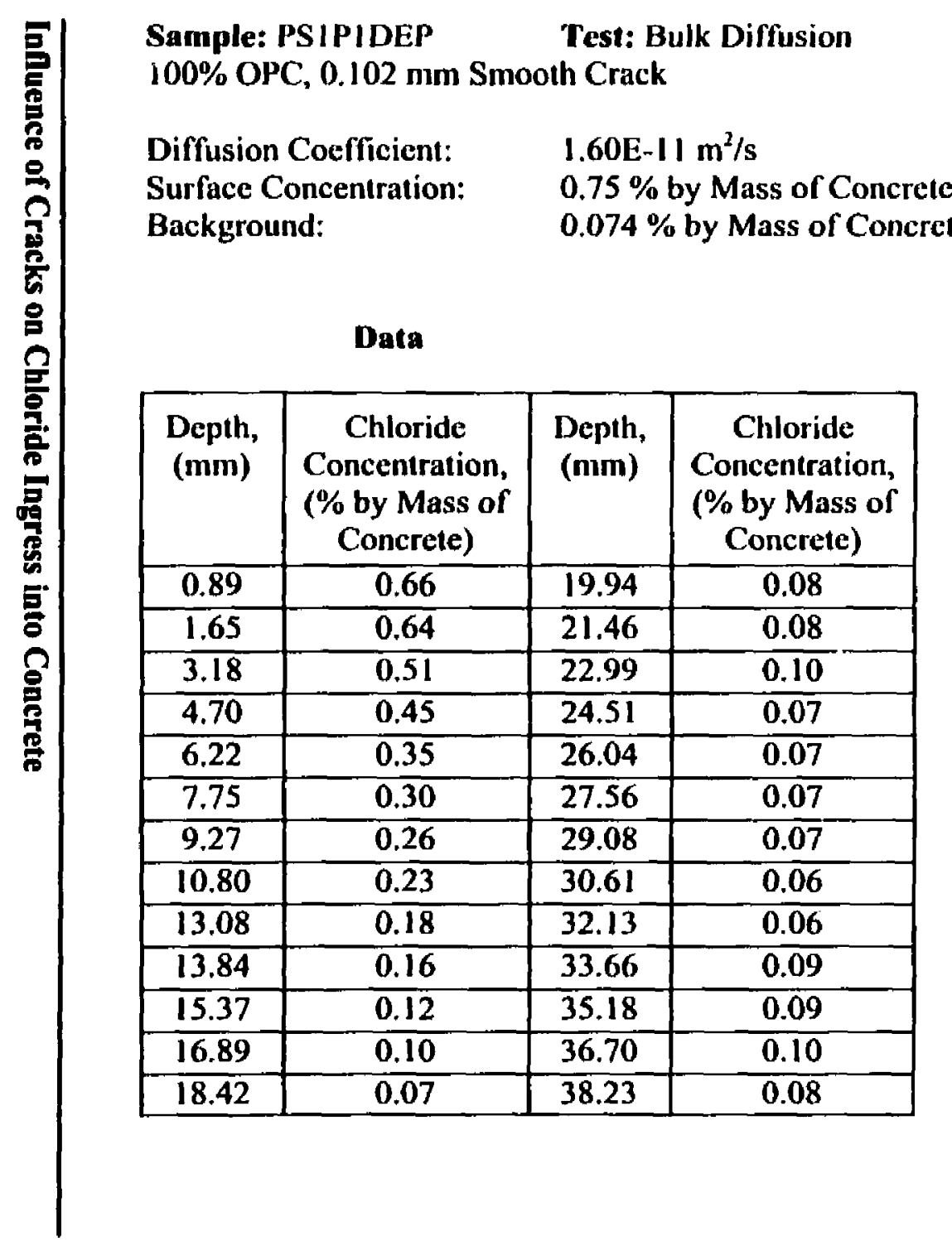

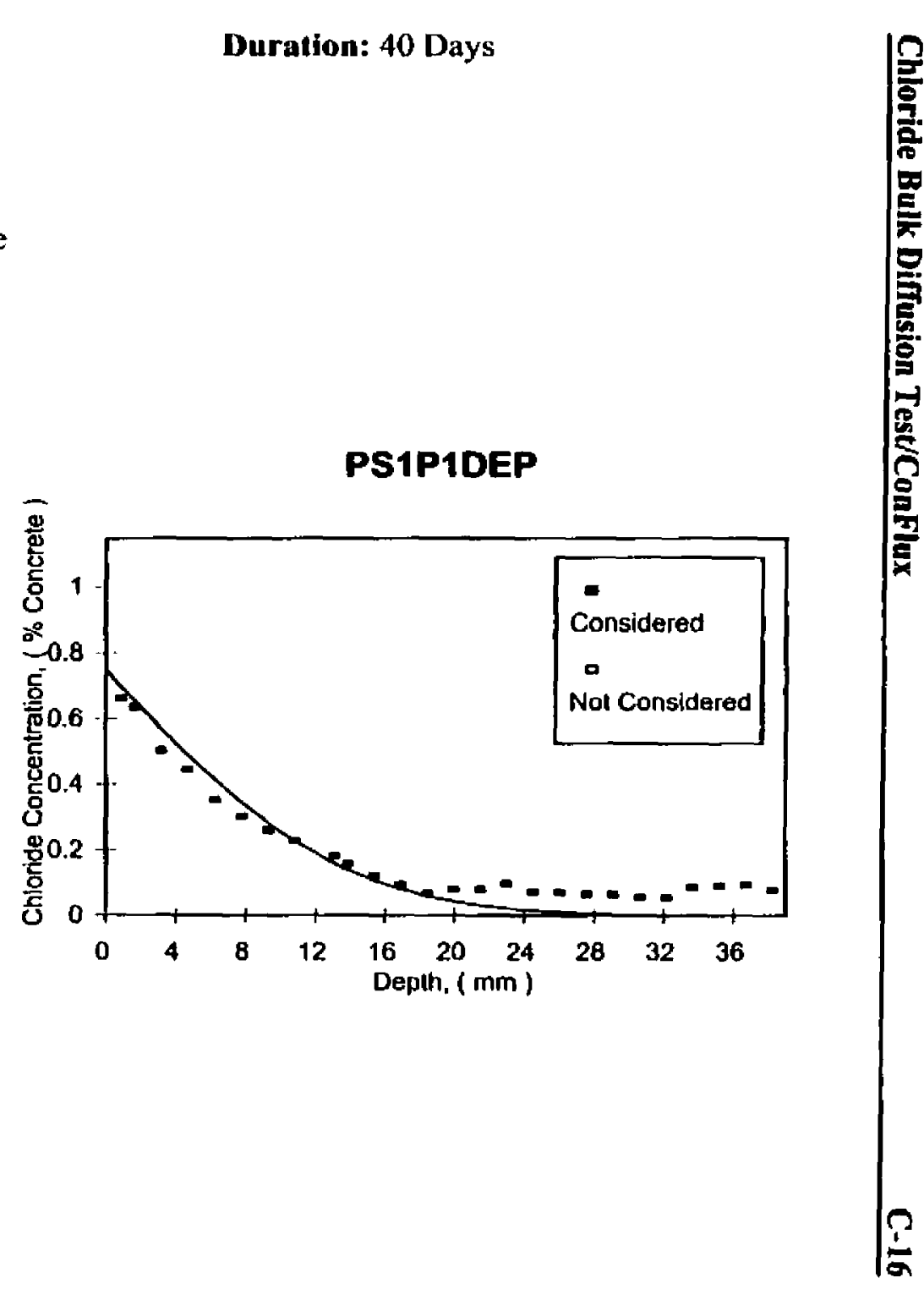


Test: Bulk Diffusion

Duration: 40 Days

100\% OPC, $0.370 \mathrm{~mm}$ Smooth Crack

Diffusion Coefficient:

Surface Concentration:

$1.41 \mathrm{E}-11 \mathrm{~m}^{2} / \mathrm{s}$

$0.75 \%$ by Mass of Concrete

Background:

$0.066 \%$ by Mass of Concrete

Data

\begin{tabular}{|c|c|}
\hline $\begin{array}{c}\text { Depth, } \\
(\mathrm{mm})\end{array}$ & $\begin{array}{c}\text { Chloride Concentration, } \\
\text { (\% by Mass of Concrete) }\end{array}$ \\
\hline 0.89 & 0.85 \\
\hline 1.65 & 0.76 \\
\hline 3.18 & 0.59 \\
\hline 4.70 & 0.44 \\
\hline 6.22 & 0.39 \\
\hline 7.75 & 0.25 \\
\hline 9.27 & 0.22 \\
\hline 10.80 & 0.19 \\
\hline 12.32 & 0.20 \\
\hline 13.84 & 0.13 \\
\hline 16.89 & 0.07 \\
\hline 19.94 & 0.11 \\
\hline 22.99 & 0.12 \\
\hline 26.04 & 0.08 \\
\hline 29.08 & 0.06 \\
\hline 32.13 & 0.30 \\
\hline 35.18 & 0.26 \\
\hline
\end{tabular}

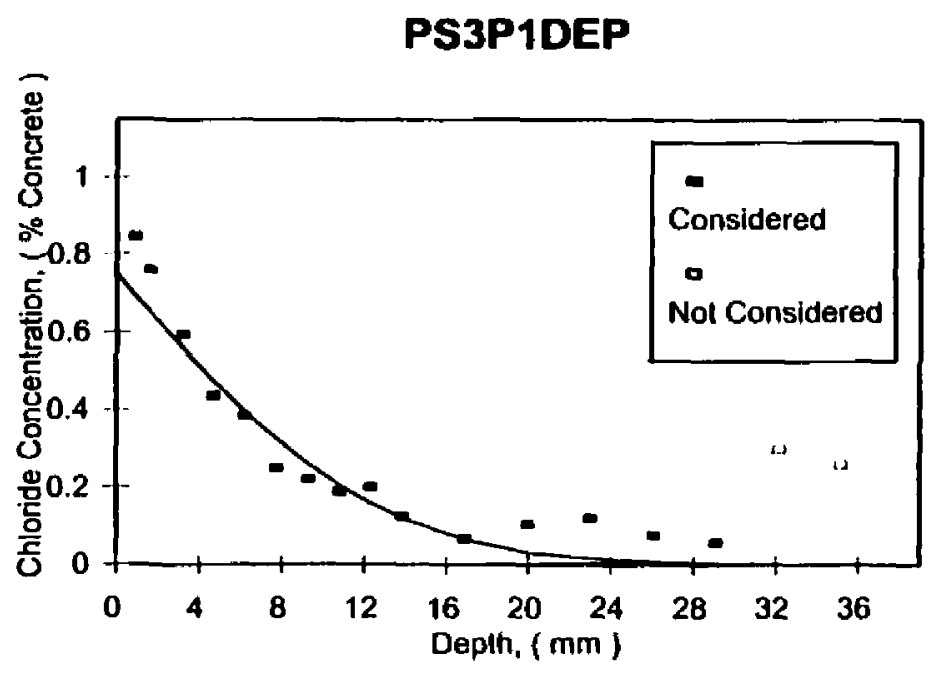


Diffusion Coefficient:

Surface Concentration:

Background:
$2.03 \mathrm{E}-11 \mathrm{~m}^{2} / \mathrm{s}$

$0.75 \%$ by Mass of Concrete

$0.063 \%$ by Mass of Concrete

\section{Data}

\begin{tabular}{|c|c|}
\hline $\begin{array}{c}\text { Depth, } \\
\text { (mm) }\end{array}$ & $\begin{array}{c}\text { Chloride Concentration, } \\
\text { (\% by Mass of Concretc) }\end{array}$ \\
\hline 0.89 & 0.59 \\
\hline 1.65 & 0.62 \\
\hline 3.18 & 0.55 \\
\hline 4.70 & 0.46 \\
\hline 6.22 & 0.30 \\
\hline 7.75 & 0.37 \\
\hline 9.27 & 0.32 \\
\hline 10.80 & 0.26 \\
\hline 12.32 & 0.20 \\
\hline 16.89 & 0.14 \\
\hline 19.94 & 0.12 \\
\hline 22.99 & 0.07 \\
\hline 26.04 & 0.09 \\
\hline 29.08 & 0.04 \\
\hline 32.13 & 0.11 \\
\hline 35.18 & 0.09 \\
\hline 38.23 & 0.07 \\
\hline
\end{tabular}

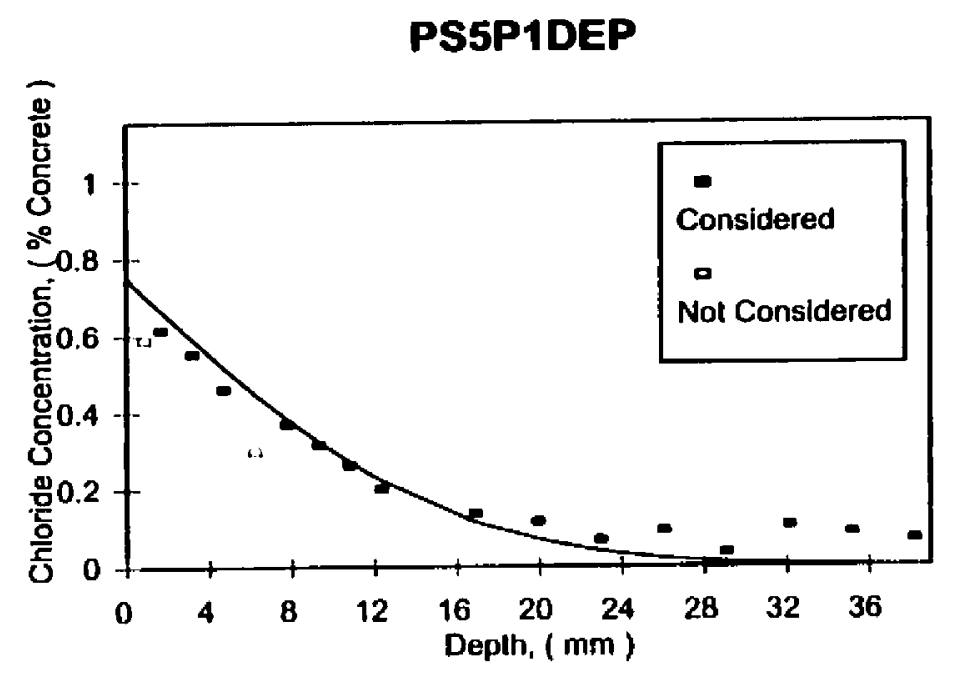


Diffusion Coefficient:

$6.23 \mathrm{E}-12 \mathrm{~m}^{2} / \mathrm{s}$

Surface Concentration: $\quad 0.77 \%$ by Mass of Concrete

Background:

$0.065 \%$ by Mass of Concrete

Data

\begin{tabular}{|c|c|}
\hline $\begin{array}{c}\text { Depth, } \\
(\mathrm{mm})\end{array}$ & $\begin{array}{c}\text { Chloride Concentration, } \\
\text { (\% by Mass of Concrete) }\end{array}$ \\
\hline 0.89 & 0.74 \\
\hline 1.65 & 0.63 \\
\hline 3.18 & 0.47 \\
\hline 4.70 & 0.30 \\
\hline 6.22 & 0.22 \\
\hline 7.75 & 0.16 \\
\hline 9.27 & 0.15 \\
\hline 10.80 & 0.12 \\
\hline 12.32 & 0.10 \\
\hline 13.84 & 0.10 \\
\hline 16.89 & 0.05 \\
\hline 19.94 & 0.04 \\
\hline 22.99 & 0.04 \\
\hline 26.04 & 0.06 \\
\hline 29.08 & 0.04 \\
\hline 32.13 & 0.05 \\
\hline 35.15 & 0.03 \\
\hline
\end{tabular}

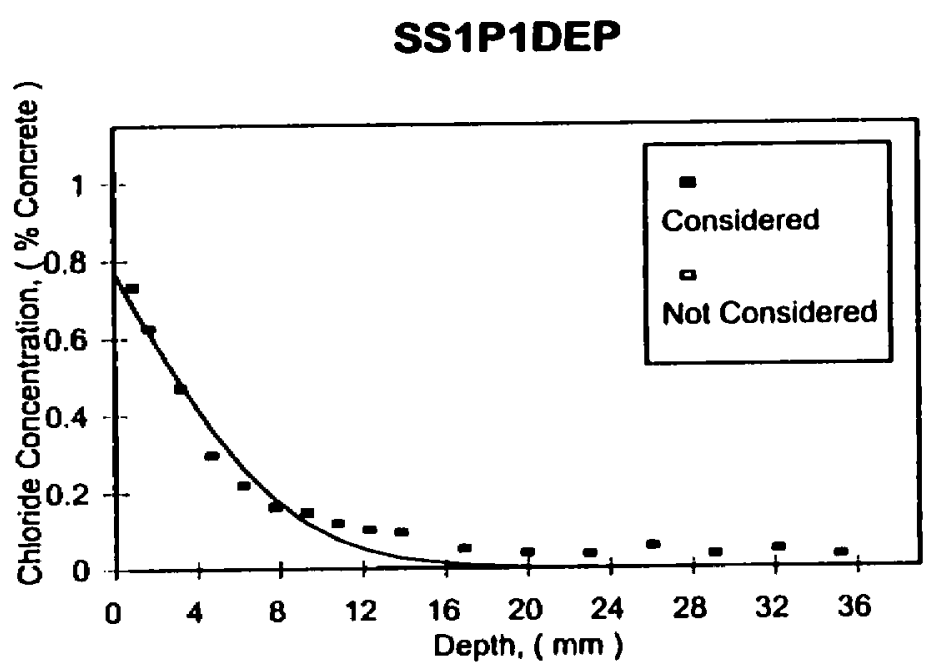




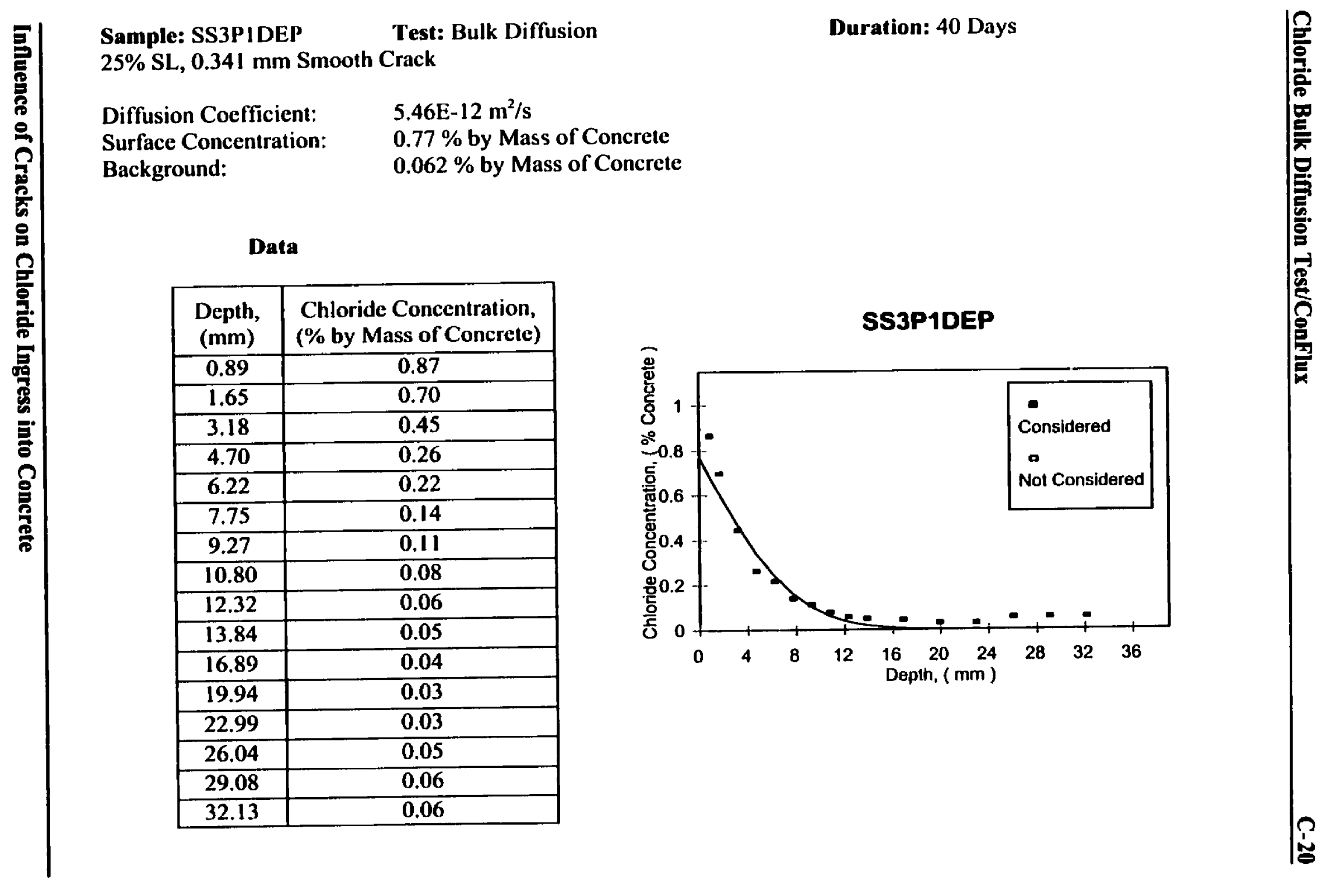


Diffusion Coefficient:

Surface Concentration:

Background:
$4.59 \mathrm{E}-12 \mathrm{~m}^{2} / \mathrm{s}$

$0.77 \%$ by Mass of Concrete

$\mathbf{0 . 0 5 7} \%$ by Mass of Concrete

\section{Data}

\begin{tabular}{|c|c|}
\hline $\begin{array}{c}\text { Depth, } \\
\text { (mm) }\end{array}$ & $\begin{array}{c}\text { Chloride Concentration, } \\
\text { (\% by Mass of Concrete) }\end{array}$ \\
\hline 0.89 & 0.78 \\
\hline 1.65 & 0.65 \\
\hline 3.18 & 0.48 \\
\hline 4.70 & 0.25 \\
\hline 6.22 & 0.14 \\
\hline 7.75 & 0.12 \\
\hline 9.27 & 0.10 \\
\hline 10.80 & 0.08 \\
\hline 12.32 & 0.04 \\
\hline 13.84 & 0.05 \\
\hline 16.89 & 0.04 \\
\hline 19.94 & 0.04 \\
\hline 22.99 & 0.07 \\
\hline 26.04 & 0.07 \\
\hline 29.08 & 0.06 \\
\hline 32.13 & 0.05 \\
\hline 35.18 & 0.04 \\
\hline
\end{tabular}

SS5P1DEP

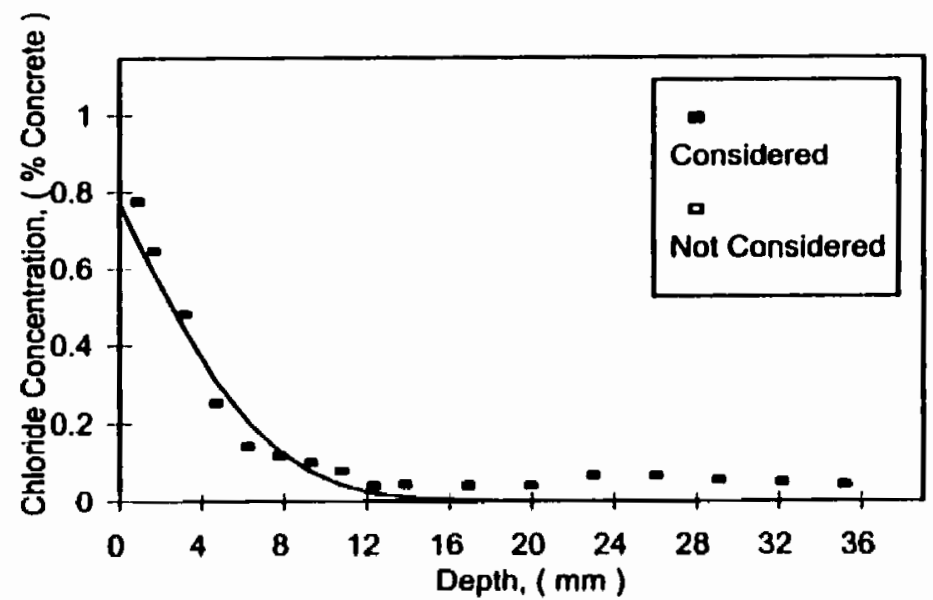


Diffusion Coefficient:

$1.53 \mathrm{E}-11 \mathrm{~m}^{2} / \mathrm{s}$

Surface Concentration: $\quad 0.75 \%$ by Mass of Concrete

Background:

$0.052 \%$ by Mass of Concrete

Data

\begin{tabular}{|c|c|c|c|}
\hline $\begin{array}{c}\text { Depth, } \\
(\mathrm{mm})\end{array}$ & $\begin{array}{c}\text { Chloride } \\
\text { Concentration, } \\
\text { (\% by Mass of } \\
\text { Concrete) }\end{array}$ & $\begin{array}{c}\text { Depth, } \\
(\mathrm{mm})\end{array}$ & $\begin{array}{c}\text { Chloride } \\
\text { Concentration, } \\
\text { (\% by Mass of } \\
\text { Concrete) }\end{array}$ \\
\hline 0.51 & 0.62 & 12.70 & 0.15 \\
\hline 1.52 & 0.61 & 13.72 & 0.12 \\
\hline 2.54 & 0.58 & 14.73 & 0.08 \\
\hline 3.56 & 0.56 & 15.75 & 0.04 \\
\hline 4.57 & 0.57 & 16.76 & 0.02 \\
\hline 5.59 & 0.52 & 17.78 & 0.00 \\
\hline 6.60 & 0.48 & 18.80 & -0.01 \\
\hline 7.62 & 0.41 & 19.81 & 0.01 \\
\hline 8.64 & 0.33 & 20.83 & 0.00 \\
\hline 9.65 & 0.28 & 21.84 & -0.01 \\
\hline 10.67 & 0.22 & 22.86 & -0.01 \\
\hline 11.68 & 0.18 & 23.88 & -0.03 \\
\hline
\end{tabular}

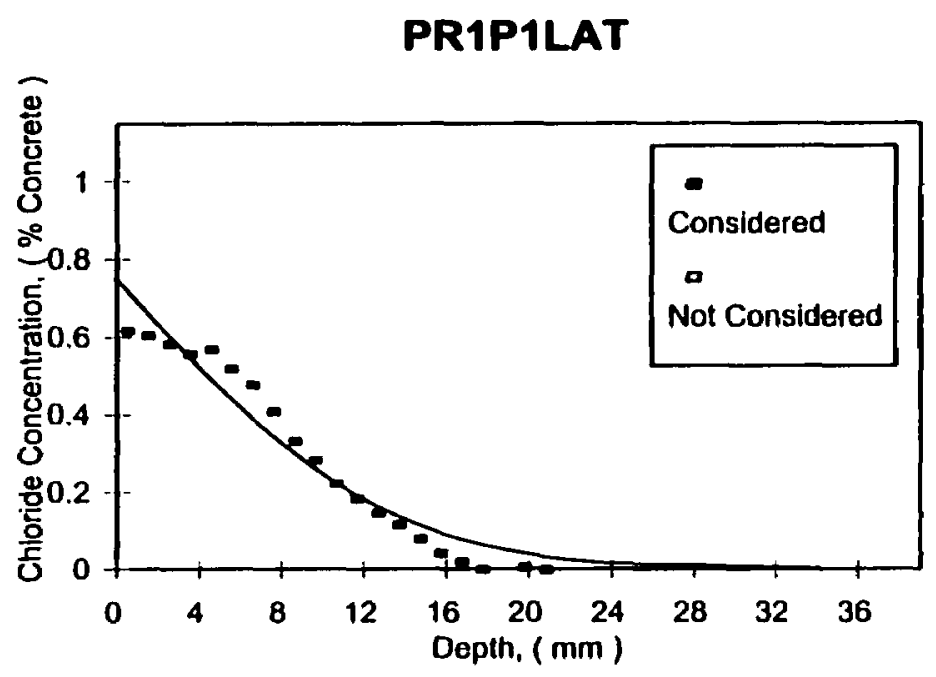




\begin{tabular}{|c|c|c|c|}
\hline \multicolumn{2}{|c|}{$\begin{array}{l}\text { Diffusion Coefficient: } \\
\text { Surface Concentration: } \\
\text { Background: }\end{array}$} & \multicolumn{2}{|c|}{$\begin{array}{l}1.55 \mathrm{E}-11 \mathrm{~m}^{2} / \mathrm{s} \\
0.75 \% \text { by Mass of Concret } \\
0.057 \% \text { by Mass of Concre }\end{array}$} \\
\hline \multicolumn{4}{|l|}{ 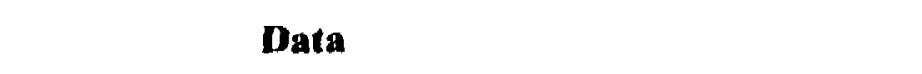 } \\
\hline $\begin{array}{c}\text { Depth, } \\
\text { (mm) }\end{array}$ & $\begin{array}{c}\text { Chloride } \\
\text { Concentration, } \\
\text { (\% by Mass of } \\
\text { Concrete) }\end{array}$ & $\begin{array}{c}\text { Depth, } \\
\text { (mm) }\end{array}$ & $\begin{array}{c}\text { Chloride } \\
\text { Concentration, } \\
\text { (\% by Mass of } \\
\text { Concrete) }\end{array}$ \\
\hline 0.51 & 1.09 & 12.70 & 0.15 \\
\hline 1.52 & 0.77 & 13.72 & 0.11 \\
\hline 2.54 & 0.67 & 14.73 & 0.10 \\
\hline 3.56 & 0.60 & 15.75 & 0.07 \\
\hline 4.57 & 0.53 & 16.76 & 0.05 \\
\hline 5.59 & 0.47 & 17.78 & 0.05 \\
\hline 6.60 & $\overline{0.41}$ & 18.80 & 0.04 \\
\hline $7 . \overline{62}$ & 0.36 & 19.81 & 0.01 \\
\hline 8.64 & 0.32 & 20.83 & 0.01 \\
\hline 9.65 & 0.26 & 21.84 & 0.02 \\
\hline 10.67 & 0.23 & 22.86 & 0.01 \\
\hline 11.68 & 0.17 & 23.88 & 0.00 \\
\hline
\end{tabular}

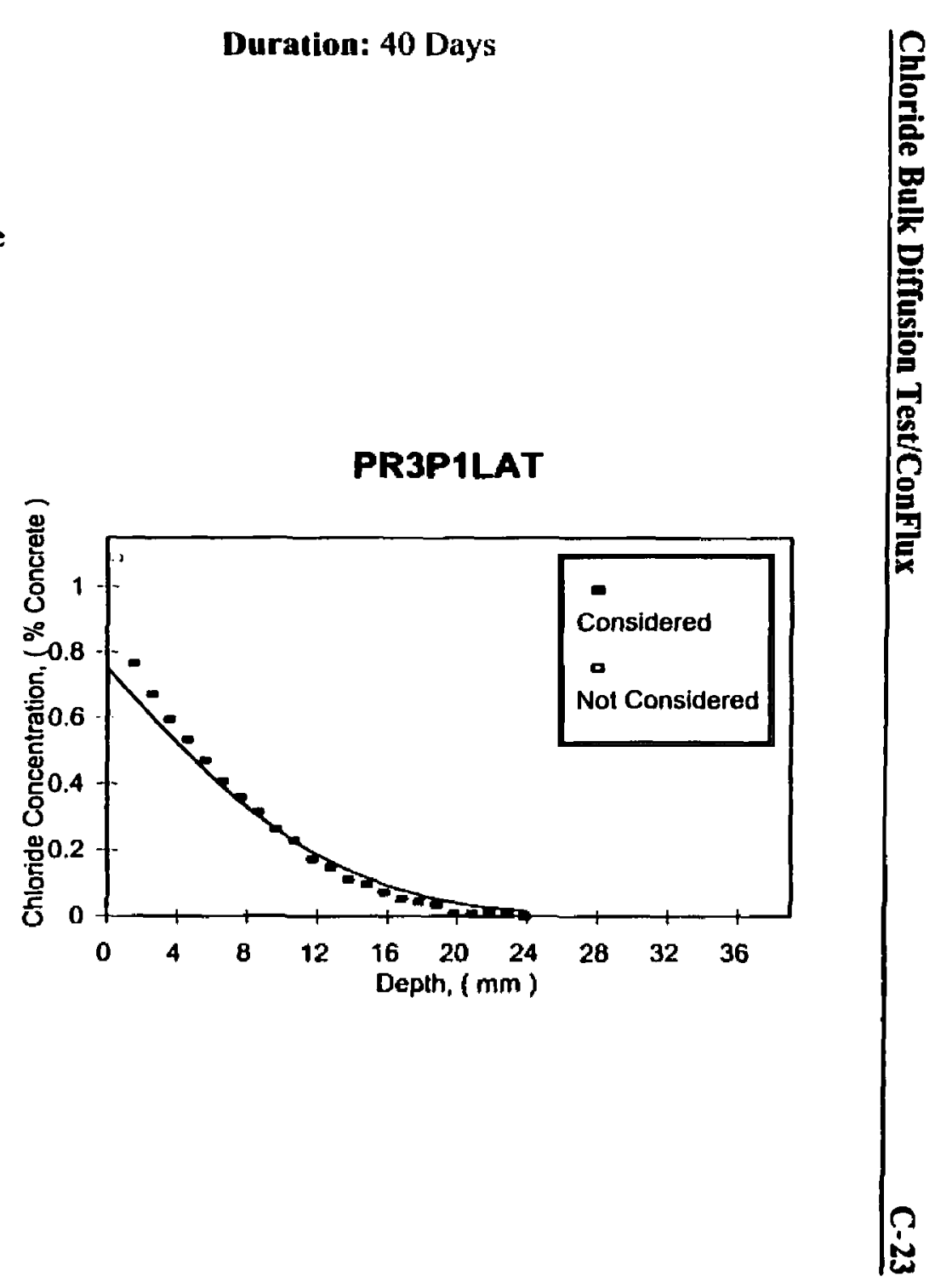


$100 \%$ OPC, $0.466 \mathrm{~mm}$ Rough Crack

Diffusion Cocfficient: $\quad 8.84 \mathrm{E}-12 \mathrm{~m}^{2} / \mathrm{s}$

Surface Concentration: $\quad 0.75 \%$ by Mass of Concrete

Background: $\quad 0.075 \%$ by Mass of Concrete

\begin{tabular}{|c|c|c|c|}
\hline $\begin{array}{c}\text { Depth, } \\
(\mathrm{mm})\end{array}$ & $\begin{array}{c}\text { Chloride } \\
\text { Concentration, } \\
\text { (\% by Mass of } \\
\text { Concrete) }\end{array}$ & $\begin{array}{c}\text { Depth, } \\
\text { (mm) }\end{array}$ & $\begin{array}{c}\text { Chloride } \\
\text { Concentration, } \\
\text { (\% by Mass of } \\
\text { Concrete) }\end{array}$ \\
\hline 0.25 & 0.60 & 9.91 & 0.20 \\
\hline 0.76 & 0.57 & 10.41 & 0.15 \\
\hline 1.27 & 0.54 & 10.92 & 0.14 \\
\hline 1.78 & 0.48 & 11.43 & 0.15 \\
\hline 2.29 & 0.46 & 11.94 & 0.14 \\
\hline 2.79 & 0.44 & 12.45 & 0.12 \\
\hline 3.30 & 0.41 & 12.95 & 0.11 \\
\hline 3.81 & 0.46 & 13.46 & 0.11 \\
\hline 4.32 & 0.40 & 13.97 & 0.10 \\
\hline 4.83 & 0.41 & 14.48 & 0.08 \\
\hline 5.84 & 0.35 & 14.99 & 0.07 \\
\hline 6.35 & 0.33 & 16.51 & 0.04 \\
\hline 6.86 & 0.28 & 18.03 & 0.03 \\
\hline 7.37 & 0.26 & 19.56 & 0.00 \\
\hline 7.87 & 0.25 & 21.08 & 0.01 \\
\hline 8.38 & 0.23 & 22.61 & 0.00 \\
\hline 8.89 & 0.22 & 24.13 & 0.00 \\
\hline 9.40 & 0.22 & 25.65 & 0.00 \\
\hline
\end{tabular}

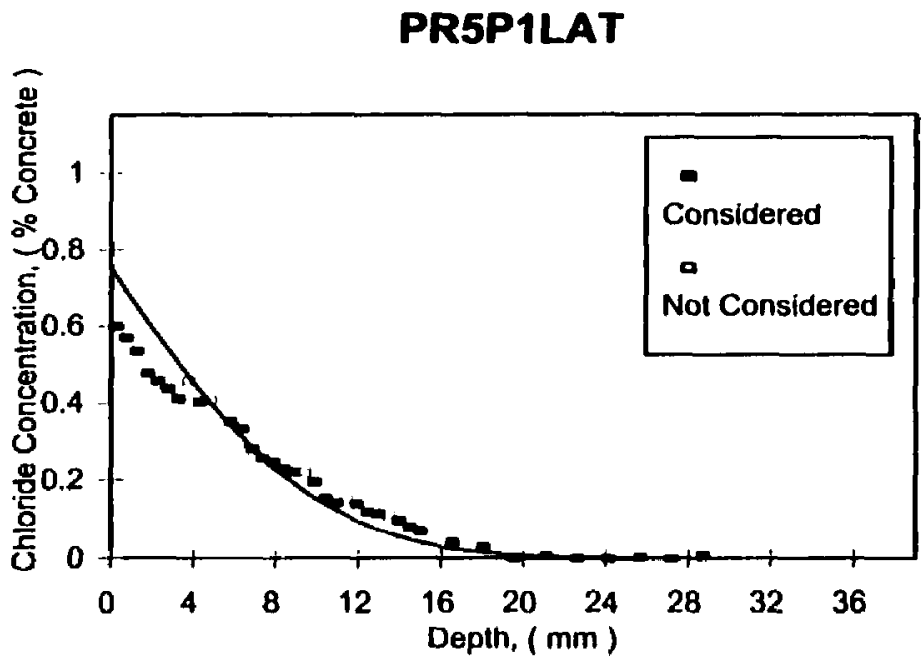




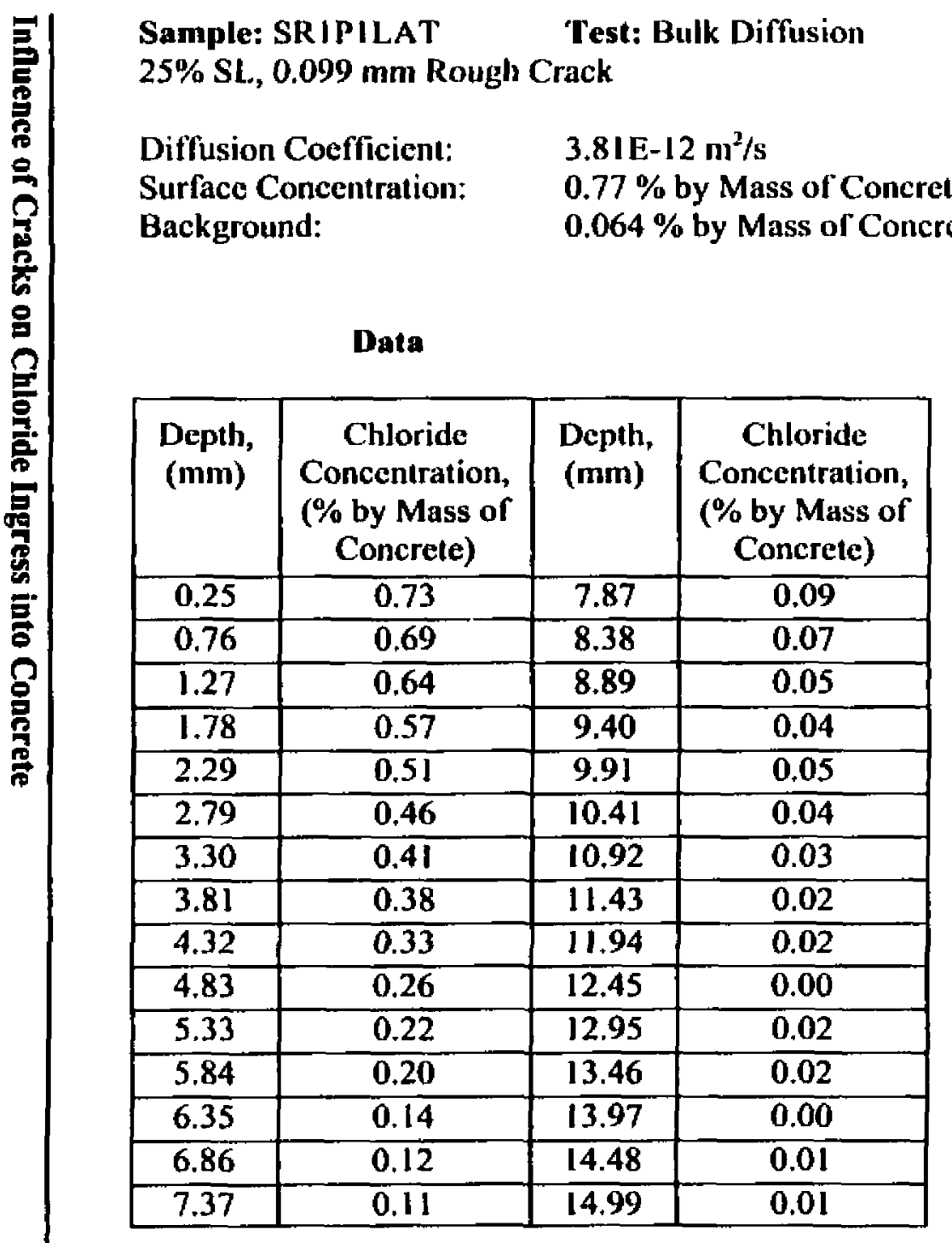

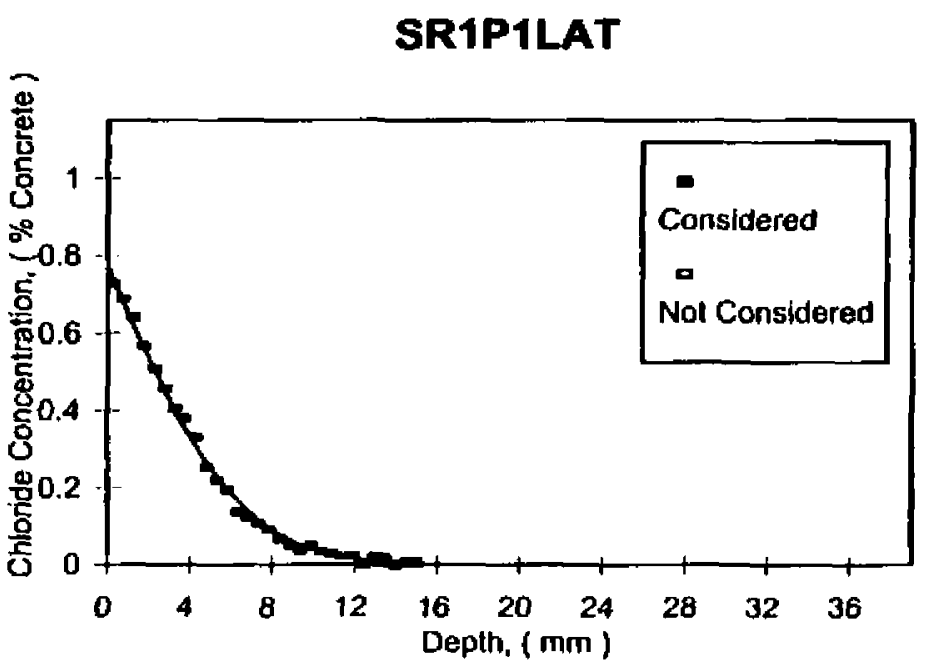


Diffusion Coefficient:

Surface Concentration:

Background:

$5.78 \mathrm{E}-12 \mathrm{~m}^{2} / \mathrm{s}$

$0.77 \%$ by Mass of Concretc

$0.054 \%$ by Mass of Concrete

\section{Data}

\begin{tabular}{|c|c|}
\hline $\begin{array}{c}\text { Depth, } \\
(\mathrm{mm})\end{array}$ & $\begin{array}{c}\text { Chloride Concentration, } \\
\text { (\% by Mass of Concrete) }\end{array}$ \\
\hline 0.76 & 0.77 \\
\hline 2.29 & 0.58 \\
\hline 3.81 & 0.39 \\
\hline 5.33 & 0.25 \\
\hline 6.86 & 0.22 \\
\hline 8.38 & 0.15 \\
\hline 9.91 & 0.11 \\
\hline 11.43 & 0.07 \\
\hline 12.95 & 0.06 \\
\hline 14.48 & 0.03 \\
\hline 16.00 & 0.01 \\
\hline 17.53 & 0.00 \\
\hline 19.05 & -0.01 \\
\hline 20.57 & 0.01 \\
\hline 22.10 & 0.01 \\
\hline 23.62 & 0.01 \\
\hline 25.15 & 0.01 \\
\hline
\end{tabular}

SR3P1LAT

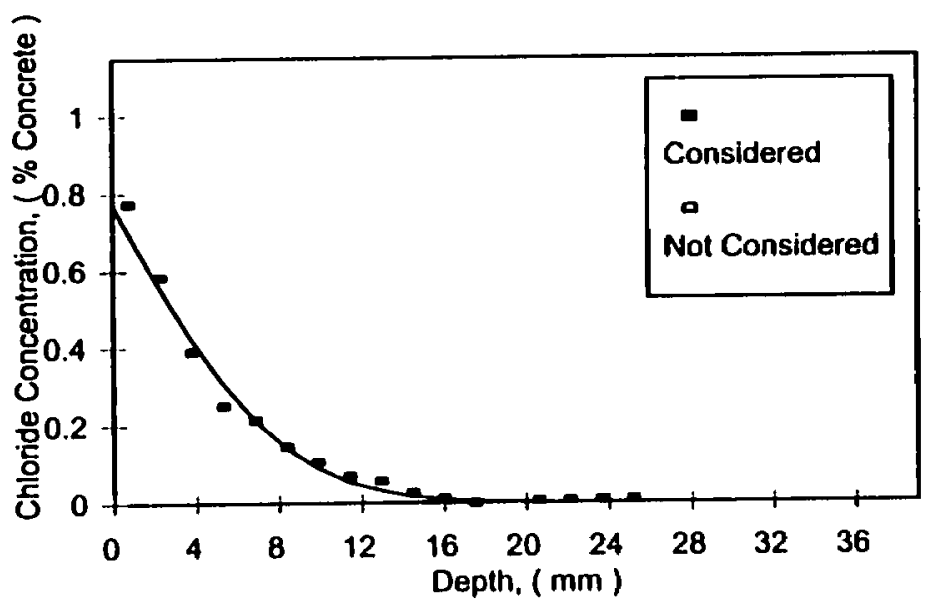


Diffusion Coefficient:

Surface Concentration:

Background:
$3.48 \mathrm{E}-12 \mathrm{~m}^{2} / \mathrm{s}$

$0.77 \%$ by Mass of Concretc

$0.080 \%$ by Mass of Concretc

\section{Data}

\begin{tabular}{|c|c|}
\hline $\begin{array}{c}\text { Depth, } \\
\text { (mm) }\end{array}$ & $\begin{array}{c}\text { Chloride Concentration, } \\
\text { (\% by Mass of Concrete) }\end{array}$ \\
\hline 0.51 & 0.59 \\
\hline 1.52 & 0.50 \\
\hline 2.54 & 0.44 \\
\hline 3.56 & 0.32 \\
\hline 4.57 & 0.27 \\
\hline 5.59 & 0.21 \\
\hline 6.60 & 0.18 \\
\hline 7.62 & 0.12 \\
\hline 8.64 & 0.11 \\
\hline 9.65 & 0.06 \\
\hline 10.67 & 0.01 \\
\hline 11.68 & 0.03 \\
\hline 12.70 & 0.01 \\
\hline 13.72 & 0.01 \\
\hline 14.73 & 0.00 \\
\hline 15.75 & 0.00 \\
\hline 16.76 & 0.01 \\
\hline
\end{tabular}

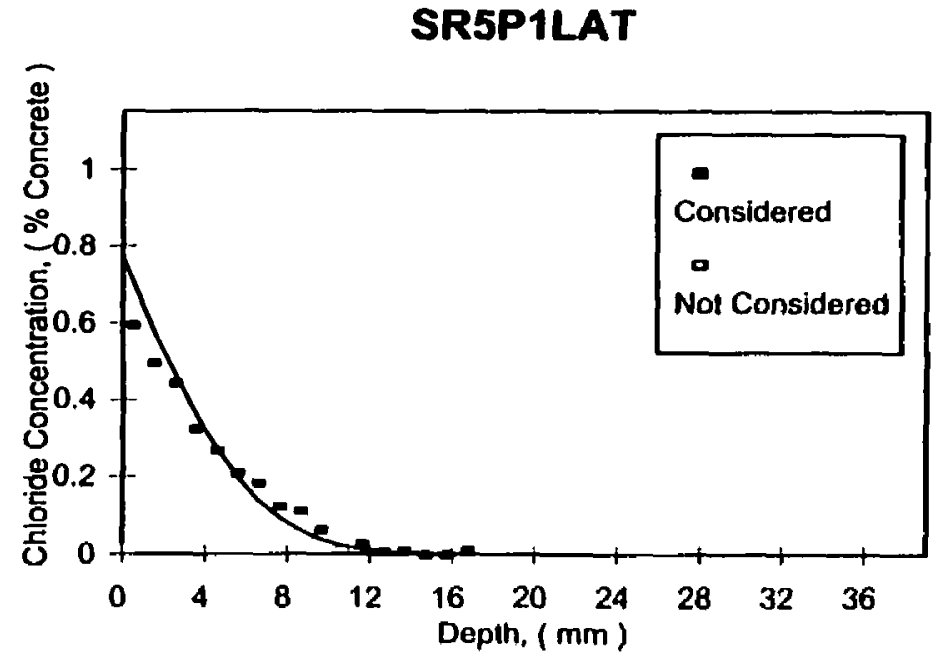


Diffusion Coefficient:

Surface Concentration:

$1.98 \mathrm{E}-11 \mathrm{~m}^{2} / \mathrm{s}$

$0.75 \%$ by Mass of Concrete

Background:

\section{Data}

\begin{tabular}{|c|c|}
\hline $\begin{array}{c}\text { Depth, } \\
\text { (mm) }\end{array}$ & $\begin{array}{c}\text { Chloride Concentration, } \\
\text { (\% by Mass of Concrete) }\end{array}$ \\
\hline 0.89 & 0.79 \\
\hline 1.65 & 0.76 \\
\hline 3.18 & 0.63 \\
\hline 4.70 & 0.48 \\
\hline 6.22 & 0.43 \\
\hline 7.75 & 0.35 \\
\hline 9.27 & 0.31 \\
\hline 10.80 & 0.25 \\
\hline 12.32 & 0.21 \\
\hline 13.84 & 0.13 \\
\hline 16.89 & 0.09 \\
\hline 19.94 & 0.14 \\
\hline 22.99 & 0.06 \\
\hline 26.04 & 0.08 \\
\hline 29.08 & 0.12 \\
\hline 32.13 & 0.09 \\
\hline 35.18 & 0.09 \\
\hline
\end{tabular}

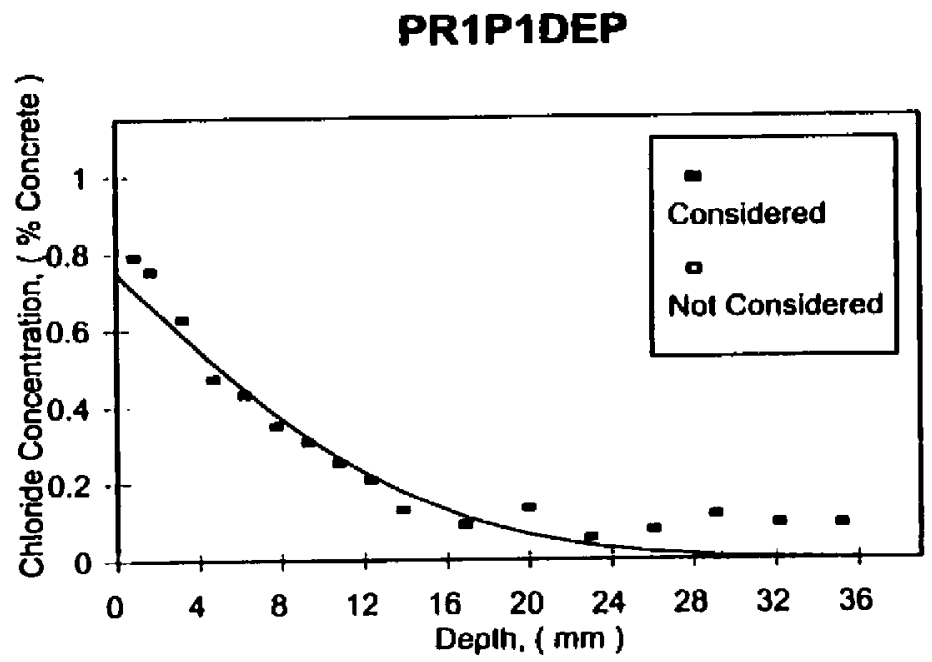


Diffusion Coefficient:

Surface Concentration:

Background:

$1.28 \mathrm{E}-11 \mathrm{~m}^{2} / \mathrm{s}$

$0.75 \%$ by Mass of Concrete

$0.057 \%$ by Mass of Concrete

\section{Data}

\begin{tabular}{|c|c|}
\hline $\begin{array}{c}\text { Depth, } \\
(\mathrm{mm})\end{array}$ & $\begin{array}{c}\text { Chloride Concentration, } \\
\text { (\% by Mass of Concrete) }\end{array}$ \\
\hline 0.89 & 0.80 \\
\hline 1.65 & 0.69 \\
\hline 3.18 & 0.49 \\
\hline 4.70 & 0.43 \\
\hline 6.22 & 0.34 \\
\hline 7.75 & 0.28 \\
\hline 9.27 & 0.25 \\
\hline 10.80 & 0.19 \\
\hline 12.32 & 0.16 \\
\hline 13.84 & 0.12 \\
\hline 16.89 & 0.09 \\
\hline 19.94 & 0.05 \\
\hline 22.99 & 0.08 \\
\hline 26.04 & 0.06 \\
\hline 29.08 & 0.08 \\
\hline 32.13 & 0.06 \\
\hline 35.18 & 0.07 \\
\hline
\end{tabular}

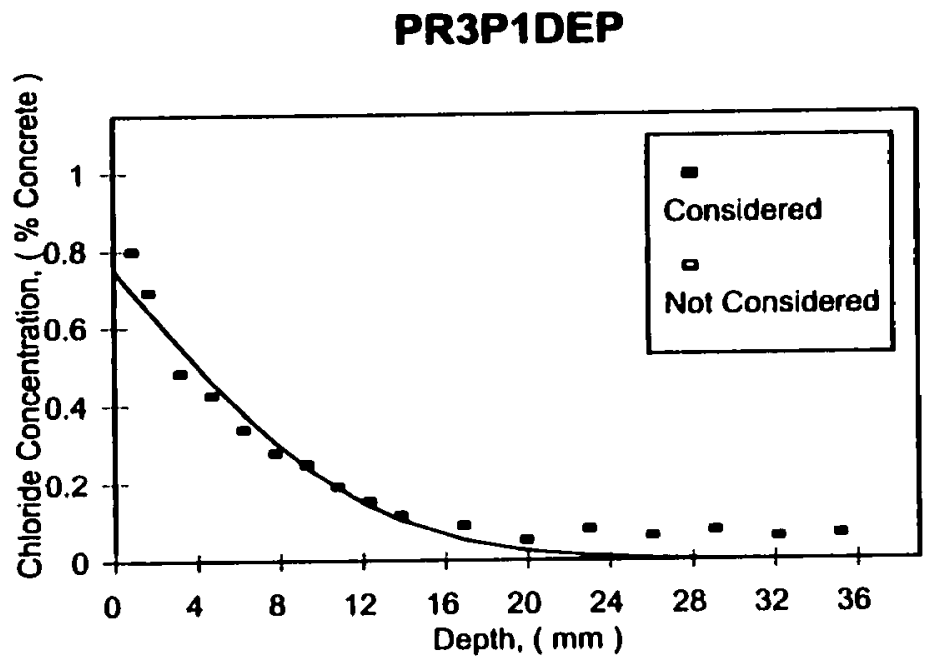


Diffusion Coefficient:

Surface Concentration:

Background:
$7.99 \mathrm{E}-12 \mathrm{~m}^{2} / \mathrm{s}$

$0.75 \%$ by Mass of Concretc

$0.075 \%$ by Mass of Concrete

\section{Data}

\begin{tabular}{|c|c|}
\hline $\begin{array}{c}\text { Depth, } \\
\text { (nm) }\end{array}$ & $\begin{array}{c}\text { Chloride Concentration, } \\
\text { (\% by Mass of Concretc) }\end{array}$ \\
\hline 0.89 & 0.66 \\
\hline 1.65 & 0.65 \\
\hline 3.18 & 0.42 \\
\hline 4.70 & 0.34 \\
\hline 6.22 & 0.30 \\
\hline 7.75 & 0.20 \\
\hline 9.27 & 0.17 \\
\hline 10.80 & 0.15 \\
\hline 12.32 & 0.12 \\
\hline 13.84 & 0.11 \\
\hline 16.89 & 0.06 \\
\hline 19.94 & 0.04 \\
\hline 22.99 & 0.04 \\
\hline 26.04 & 0.04 \\
\hline 29.08 & 0.05 \\
\hline 32.13 & 0.03 \\
\hline 35.18 & 0.05 \\
\hline
\end{tabular}

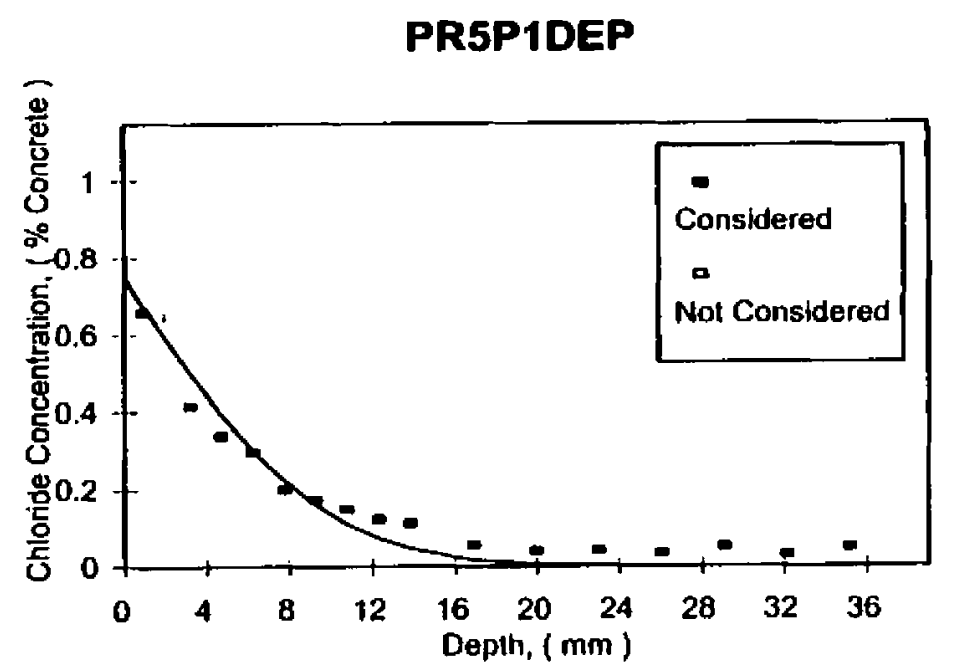


Sample: SR IPIDEP

Test: Bulk Diffusion

Duration: 40 Days

25\% SL, 0.099 mm Rough Crack

Diffusion Coefficient:

$5.01 \mathrm{E}-12 \mathrm{~m}^{2} / \mathrm{s}$

Surface Concentration: $\quad 0.77 \%$ by Mass of Concrete

Background:

$0.064 \%$ by Mass of Concrete

Data

\begin{tabular}{|c|c|}
\hline $\begin{array}{c}\text { Depth, } \\
\text { (mm) }\end{array}$ & $\begin{array}{c}\text { Chloride Concentration, } \\
\text { (\% by Mass of Concrete) }\end{array}$ \\
\hline 0.89 & 0.88 \\
\hline 1.65 & 0.66 \\
\hline 3.18 & 0.41 \\
\hline 4.70 & 0.30 \\
\hline 6.22 & 0.21 \\
\hline 7.75 & 0.14 \\
\hline 9.27 & 0.06 \\
\hline 10.80 & 0.06 \\
\hline 12.32 & 0.05 \\
\hline 13.84 & 0.04 \\
\hline 16.89 & 0.05 \\
\hline 19.94 & 0.02 \\
\hline 22.99 & 0.02 \\
\hline 26.04 & 0.03 \\
\hline 29.08 & 0.02 \\
\hline 32.13 & 0.01 \\
\hline 35.18 & 0.01 \\
\hline
\end{tabular}

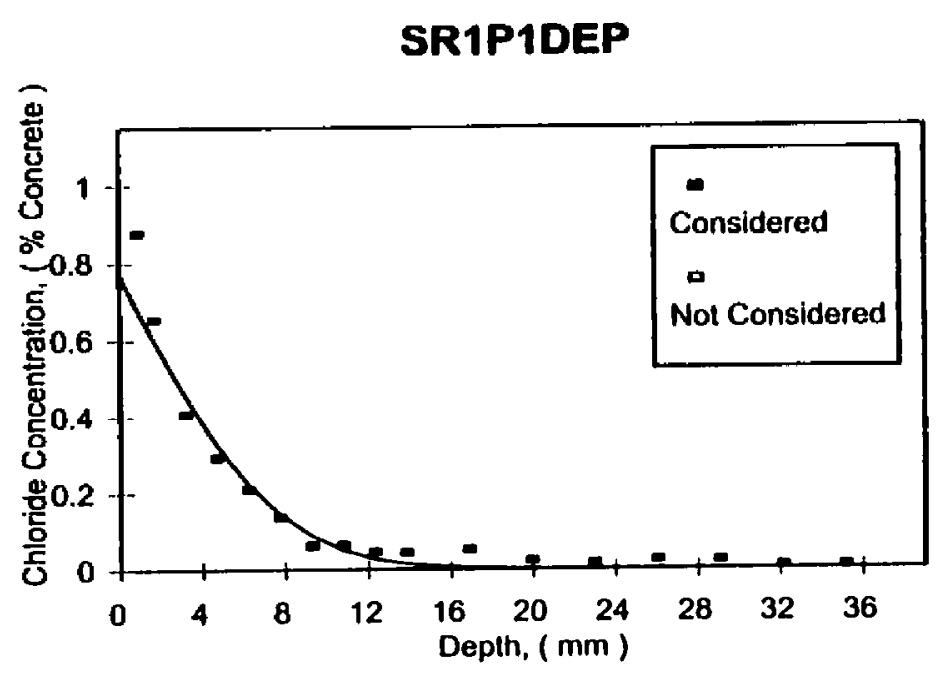


Sample: SR3PIDEP

Test: Bulk Diffusion

Duration: 40 Days

$25 \% \mathrm{SL}, 0.284 \mathrm{~mm}$ Rough Crack

Diffusion Coefficient:

$4.41 \mathrm{E}-12 \mathrm{~m}^{2} / \mathrm{s}$

Surface Concentration:

$0.77 \%$ by Mass of Concrete

Background:

$0.054 \%$ by Mass of Concrete

Data

\begin{tabular}{|c|c|}
\hline $\begin{array}{c}\text { Depth, } \\
\text { (mm) }\end{array}$ & $\begin{array}{c}\text { Chloride Concentration, } \\
\text { (\% by Mass of Concrete) }\end{array}$ \\
\hline 0.89 & 1.03 \\
\hline 1.65 & 0.77 \\
\hline 3.18 & 0.39 \\
\hline 4.70 & 0.23 \\
\hline 6.22 & 0.14 \\
\hline 7.75 & 0.07 \\
\hline 9.27 & 0.06 \\
\hline 10.80 & 0.07 \\
\hline 12.32 & 0.07 \\
\hline 13.84 & 0.07 \\
\hline 16.89 & 0.05 \\
\hline 19.94 & 0.05 \\
\hline 22.99 & 0.04 \\
\hline 26.04 & 0.05 \\
\hline 29.08 & 0.04 \\
\hline 32.13 & 0.04 \\
\hline 35.18 & 0.04 \\
\hline
\end{tabular}

SR3P1DEP

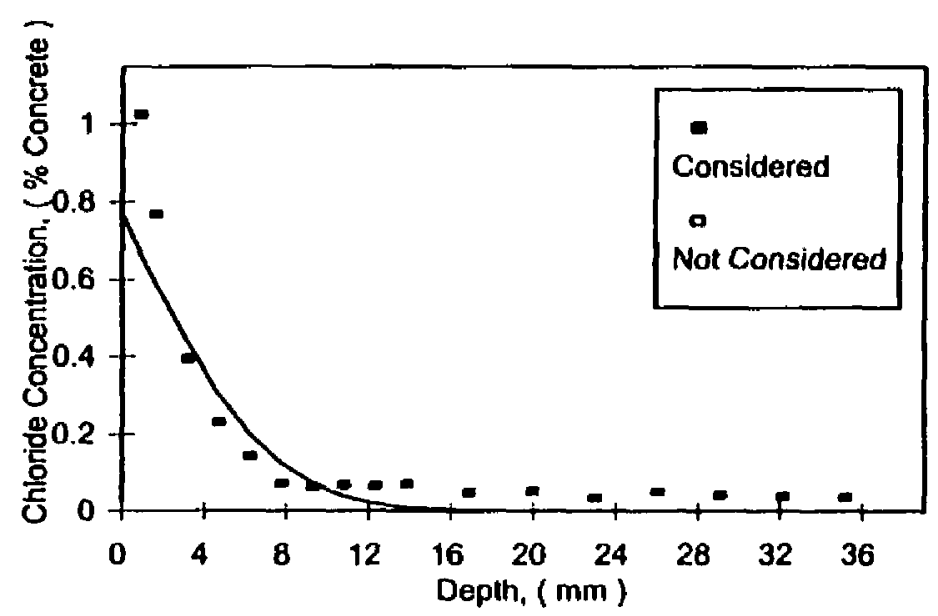


Diffusion Coefficient:

$5.73 \mathrm{E}-12 \mathrm{~m}^{2} / \mathrm{s}$

Surface Concentration:

$0.77 \%$ by Mass of Concretc

Background:

$0.080 \%$ by Mass of Concretc

\section{Data}

\begin{tabular}{|c|c|}
\hline $\begin{array}{c}\text { Depth, } \\
(\mathbf{m m})\end{array}$ & $\begin{array}{c}\text { Chloride Concentration, } \\
\text { (\% by Mass of Concrete) }\end{array}$ \\
\hline 0.89 & 0.86 \\
\hline 1.65 & 0.64 \\
\hline 3.18 & 0.45 \\
\hline 4.70 & 0.29 \\
\hline 6.22 & 0.19 \\
\hline 7.75 & 0.19 \\
\hline 9.27 & 0.13 \\
\hline 10.80 & 0.08 \\
\hline 12.32 & 0.07 \\
\hline 13.84 & 0.06 \\
\hline 16.89 & 0.03 \\
\hline 19.94 & 0.03 \\
\hline 22.99 & 0.03 \\
\hline 26.04 & 0.02 \\
\hline 29.08 & 0.04 \\
\hline 32.13 & 0.03 \\
\hline 35.18 & 0.05 \\
\hline
\end{tabular}

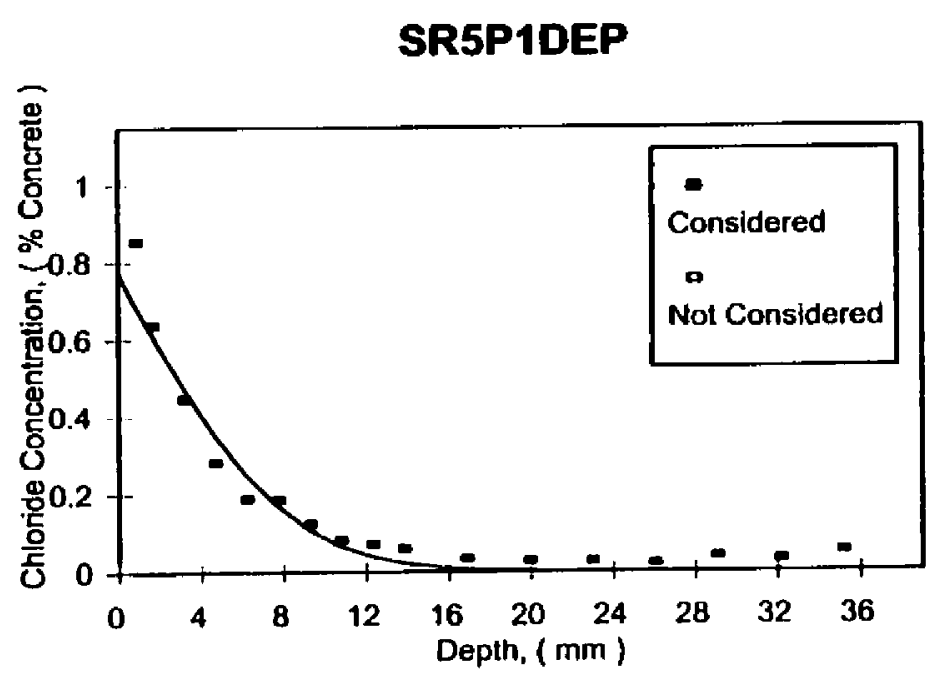




\section{APPENDIX D}

\section{ChLORIDE BULK DIFfusion TEST}

2D Simulations 


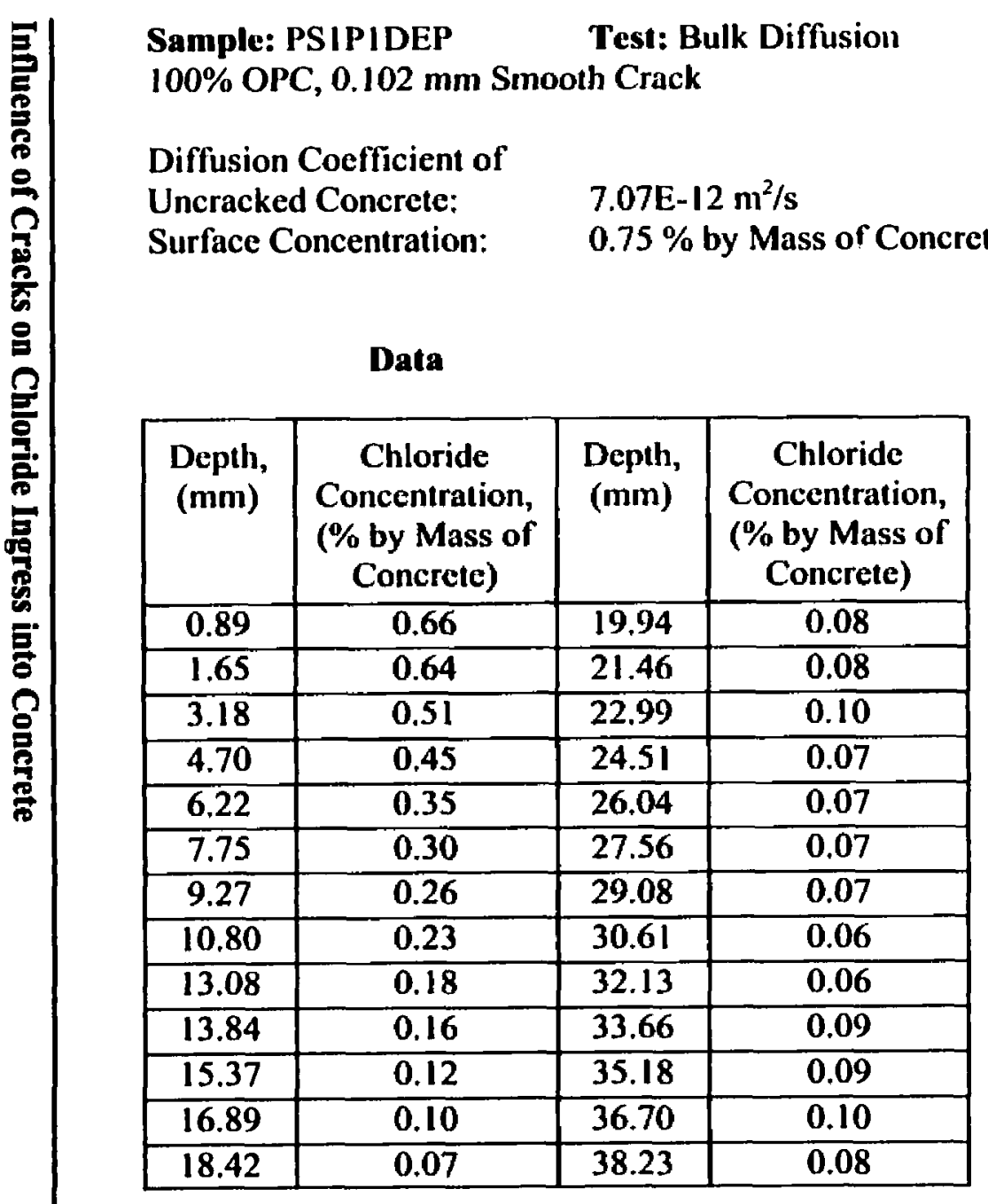


Diffusion Coefficient of

Uncracked Concrete:

7.07E- $12 \mathrm{~m}^{2} / \mathrm{s}$

Surface Concentration:

$0.75 \%$ by Mass of Concrete

\section{Data}

\begin{tabular}{|c|c|}
\hline $\begin{array}{c}\text { Depth, } \\
\text { (nim) }\end{array}$ & $\begin{array}{c}\text { Chloride Concentration, } \\
\text { (\% by Mass of Concrete) }\end{array}$ \\
\hline 0.89 & 0.85 \\
\hline 1.65 & 0.76 \\
\hline 3.18 & 0.59 \\
\hline 4.70 & 0.44 \\
\hline 6.22 & 0.39 \\
\hline 7.75 & 0.25 \\
\hline 9.27 & 0.22 \\
\hline 10.80 & 0.19 \\
\hline 12.32 & 0.20 \\
\hline 13.84 & 0.13 \\
\hline 16.89 & 0.07 \\
\hline 19.94 & 0.11 \\
\hline 22.99 & 0.12 \\
\hline 26.04 & 0.08 \\
\hline 29.08 & 0.06 \\
\hline 32.13 & 0.30 \\
\hline 35.18 & 0.26 \\
\hline
\end{tabular}

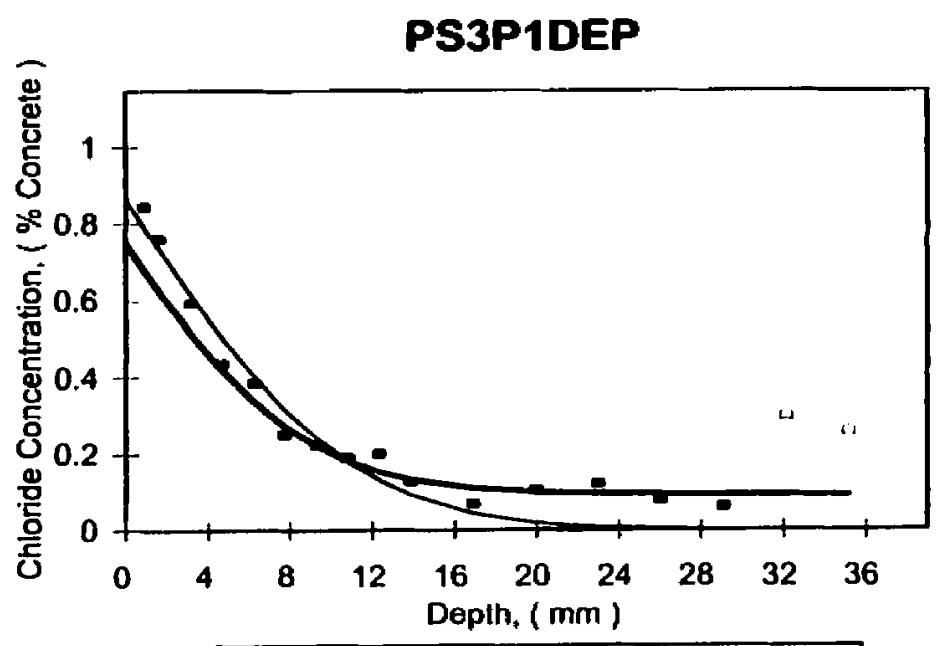

$$
\begin{array}{ll}
\text { - Considered } & \text { - Nol Considered } \\
\text { - Table Curve } & \text { 2D Simulation }
\end{array}
$$


Diffusion Coefficient of

Uncracked Concrete:

$7.07 \mathrm{E}-12 \mathrm{~m}^{2} / \mathrm{s}$

Surface Concentration:

$0.75 \%$ by Mass of Concrete

Data

\begin{tabular}{|c|c|}
\hline $\begin{array}{c}\text { Depth, } \\
\text { (mm) }\end{array}$ & $\begin{array}{c}\text { Chloride Concentration, } \\
\text { (\% by Mass of Concrete) }\end{array}$ \\
\hline 0.89 & 0.59 \\
\hline 1.65 & 0.62 \\
\hline 3.18 & 0.55 \\
\hline 4.70 & 0.46 \\
\hline 6.22 & 0.30 \\
\hline 7.75 & 0.37 \\
\hline 9.27 & 0.32 \\
\hline 10.80 & 0.26 \\
\hline 12.32 & 0.20 \\
\hline 16.89 & 0.14 \\
\hline 19.94 & 0.12 \\
\hline 22.99 & 0.07 \\
\hline 26.04 & 0.09 \\
\hline 29.08 & 0.04 \\
\hline 32.13 & 0.11 \\
\hline 35.18 & 0.09 \\
\hline 38.23 & 0.07 \\
\hline
\end{tabular}

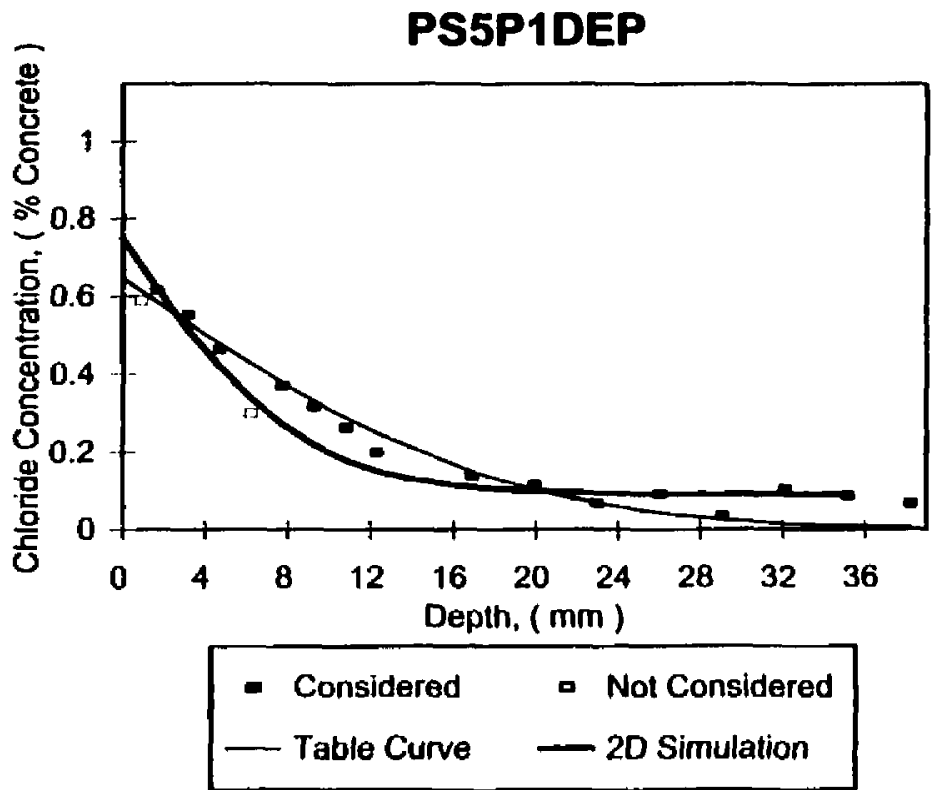


25\% SL, $0.079 \mathrm{~mm}$ Smooth Crack

Diffusion Coefficient of

Uncracked Concrete:

$2.93 \mathrm{E}-12 \mathrm{~m}^{2} / \mathrm{s}$

Surface Concentration:

$0.77 \%$ by Mass of Concrete

Data

\begin{tabular}{|c|c|}
\hline $\begin{array}{c}\text { Depth, } \\
(\mathrm{mm})\end{array}$ & $\begin{array}{c}\text { Chloride Concentration, } \\
\text { (\% by Mass of Concrete) }\end{array}$ \\
\hline 0.89 & 0.74 \\
\hline 1.65 & 0.63 \\
\hline 3.18 & 0.47 \\
\hline 4.70 & 0.30 \\
\hline 6.22 & 0.22 \\
\hline 7.75 & 0.16 \\
\hline 9.27 & 0.15 \\
\hline 10.80 & 0.12 \\
\hline 12.32 & 0.10 \\
\hline 13.84 & 0.10 \\
\hline 16.89 & 0.05 \\
\hline 19.94 & 0.04 \\
\hline 22.99 & 0.04 \\
\hline 26.04 & 0.06 \\
\hline 29.08 & 0.04 \\
\hline 32.13 & 0.05 \\
\hline 35.15 & 0.03 \\
\hline
\end{tabular}

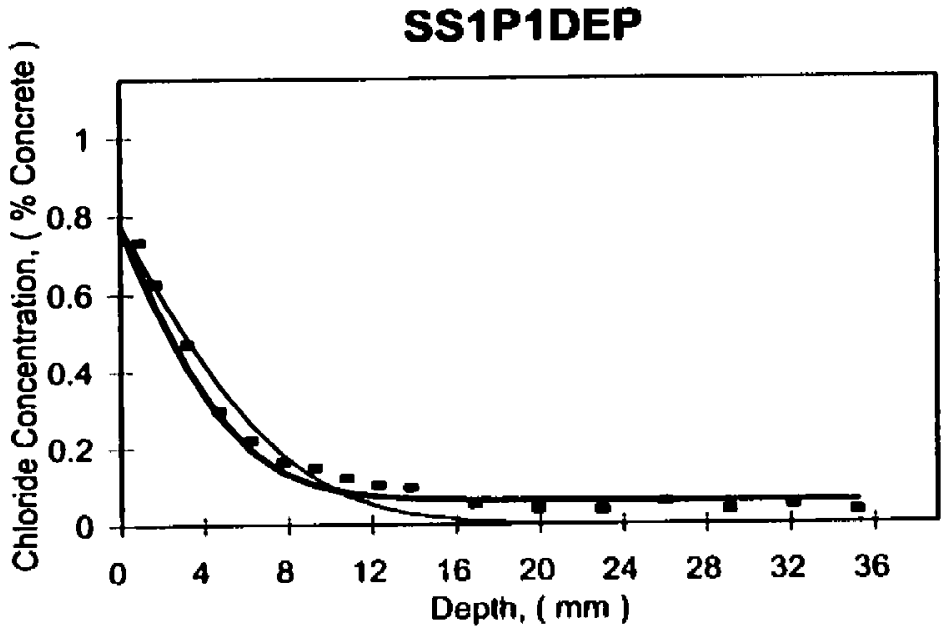


Diffusion Coefficient of

Uncracked Concrete:

$2.93 \mathrm{E}-12 \mathrm{~m}^{2} / \mathrm{s}$

Surface Concentration:

$0.77 \%$ by Mass of Concrete

\section{Data}

\begin{tabular}{|c|c|}
\hline $\begin{array}{c}\text { Depth, } \\
\text { (mm) }\end{array}$ & $\begin{array}{c}\text { Chloride Concentration, } \\
\text { (\% by Mass of Concrete) }\end{array}$ \\
\hline 0.89 & 0.87 \\
\hline 1.65 & 0.70 \\
\hline 3.18 & 0.45 \\
\hline 4.70 & 0.26 \\
\hline 6.22 & 0.22 \\
\hline 7.75 & 0.14 \\
\hline 9.27 & 0.11 \\
\hline 10.80 & 0.08 \\
\hline 12.32 & 0.06 \\
\hline 13.84 & 0.05 \\
\hline 16.89 & 0.04 \\
\hline 19.94 & 0.03 \\
\hline 22.99 & 0.03 \\
\hline 26.04 & 0.05 \\
\hline 29.08 & 0.06 \\
\hline 32.13 & 0.06 \\
\hline
\end{tabular}

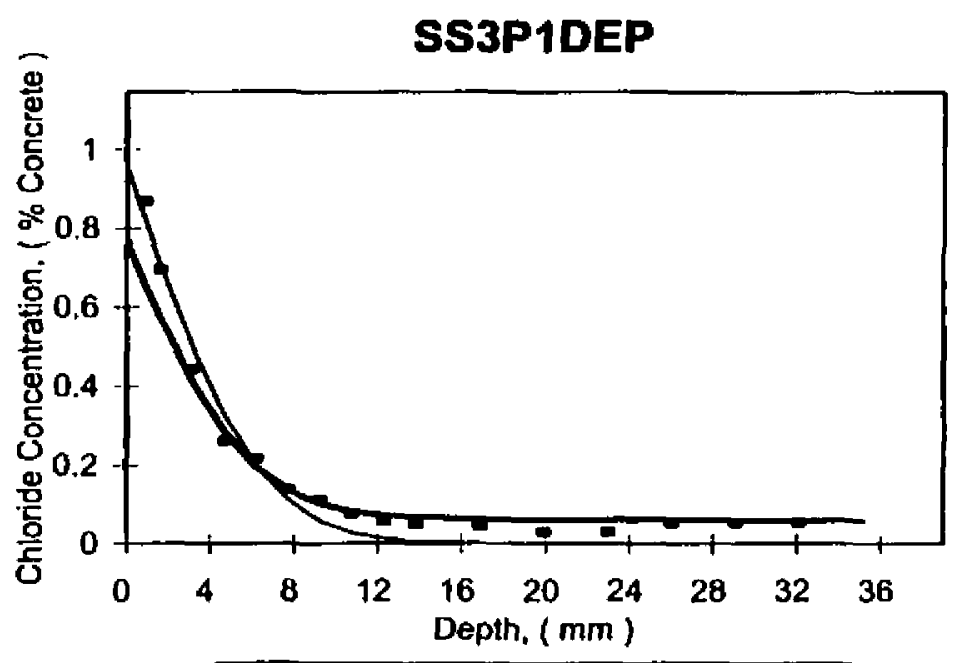

$$
\begin{array}{cc}
\text { - Considered } & \text { - Nol Considered } \\
\text { - Table Curve } & -20 \text { Simulation }
\end{array}
$$


Diffusion Coefficient of

Uncracked Concrete:

2.93E- $12 \mathrm{~m}^{2} / \mathrm{s}$

Surface Concentration:

$0.77 \%$ by Mass of Concrete

\section{Data}

\begin{tabular}{|c|c|}
\hline $\begin{array}{c}\text { Depth, } \\
\text { (mm) }\end{array}$ & $\begin{array}{c}\text { Chloride Concentration, } \\
\text { (\% by Mass of Concrete) }\end{array}$ \\
\hline 0.89 & 0.78 \\
\hline 1.65 & 0.65 \\
\hline 3.18 & 0.48 \\
\hline 4.70 & 0.25 \\
\hline 6.22 & 0.14 \\
\hline 7.75 & 0.12 \\
\hline 9.27 & 0.10 \\
\hline 10.80 & 0.08 \\
\hline 12.32 & 0.04 \\
\hline 13.84 & 0.05 \\
\hline 16.89 & 0.04 \\
\hline 19.94 & 0.04 \\
\hline 22.99 & 0.07 \\
\hline 26.04 & 0.07 \\
\hline 29.08 & 0.06 \\
\hline 32.13 & 0.05 \\
\hline 35.18 & 0.04 \\
\hline
\end{tabular}

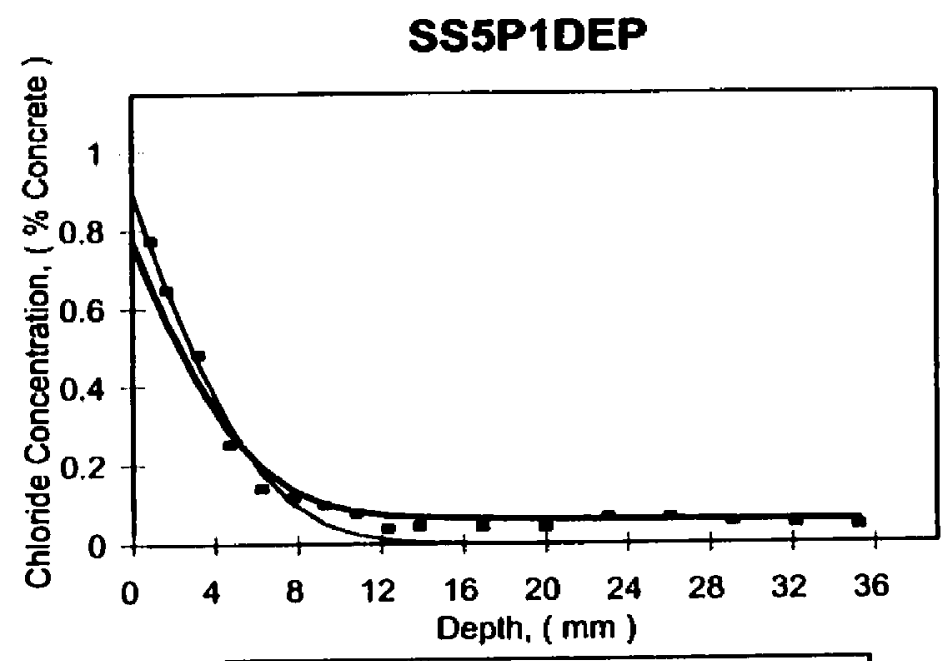

$$
\begin{array}{ll}
\text { - Considered } & \text { - Nol Considered } \\
\text { - Table Curve } & \text { 2D Simulation }
\end{array}
$$


Diffusion Coefficient of

Uncracked Concrete:

$7.07 \mathrm{E}-12 \mathrm{~m}^{2} / \mathrm{s}$

Surface Concentration: $\quad 0.75 \%$ by Mass of Concrete

\section{Data}

\begin{tabular}{|c|c|}
\hline $\begin{array}{c}\text { Derth, } \\
(\mathrm{mm})\end{array}$ & $\begin{array}{c}\text { Chloride Cuncentration, } \\
\text { (\% by Mass of Concrete) }\end{array}$ \\
\hline 0.89 & 0.79 \\
\hline 1.65 & 0.76 \\
\hline 3.18 & 0.63 \\
\hline 4.70 & 0.48 \\
\hline 6.22 & 0.43 \\
\hline 7.75 & 0.35 \\
\hline 9.27 & 0.31 \\
\hline 10.80 & 0.25 \\
\hline 12.32 & 0.21 \\
\hline 13.84 & 0.13 \\
\hline 16.89 & 0.09 \\
\hline 19.94 & 0.14 \\
\hline 22.99 & 0.06 \\
\hline 26.04 & 0.08 \\
\hline 29.08 & 0.12 \\
\hline 32.13 & 0.09 \\
\hline 35.18 & 0.09 \\
\hline
\end{tabular}

PR1P1DEP

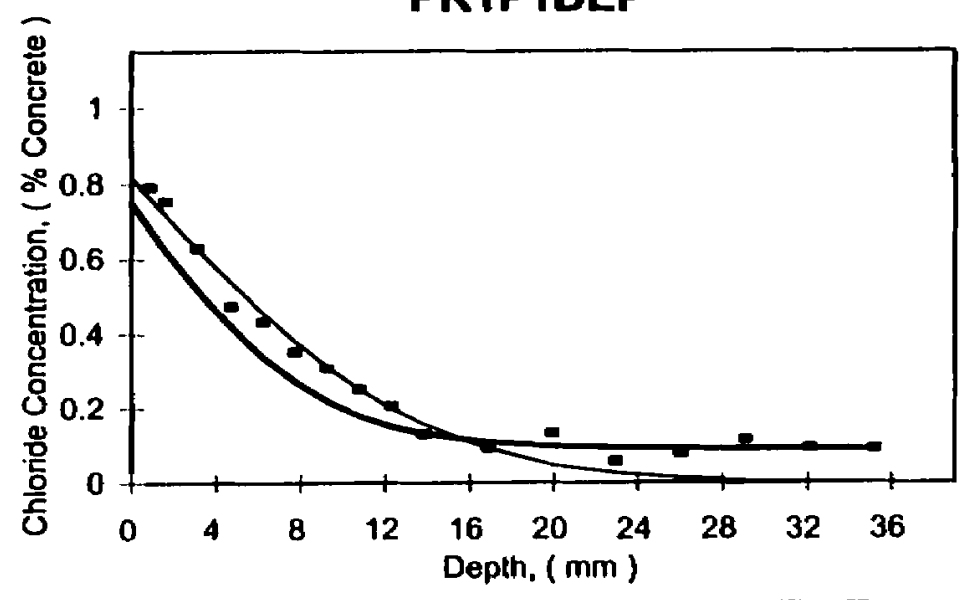

- Considered

- Not Considered

- Table Curve 2D Simulation 
$100 \%$ OPC, $0.297 \mathrm{~mm}$ Rough Crack

Diffusion Coefficient of

Uncracked Concrete:

$7.07 \mathrm{E}-12 \mathrm{~m}^{2} / \mathrm{s}$

Surface Concentration:

$0.75 \%$ by Mass of Concrete

\section{Data}

\begin{tabular}{|c|c|}
\hline $\begin{array}{c}\text { Depth, } \\
(\mathrm{mm})\end{array}$ & $\begin{array}{c}\text { Chloride Concentration, } \\
\text { (\% by Mass of Concrete) }\end{array}$ \\
\hline 0.89 & 0.80 \\
\hline 1.65 & 0.69 \\
\hline 3.18 & 0.49 \\
\hline 4.70 & 0.43 \\
\hline 6.22 & 0.34 \\
\hline 7.75 & 0.28 \\
\hline 9.27 & 0.25 \\
\hline 10.80 & 0.19 \\
\hline 12.32 & 0.16 \\
\hline 13.84 & 0.12 \\
\hline 16.89 & 0.09 \\
\hline 19.94 & 0.05 \\
\hline 22.99 & 0.08 \\
\hline 26.04 & 0.06 \\
\hline 29.08 & 0.08 \\
\hline 32.13 & 0.06 \\
\hline 35.18 & 0.07 \\
\hline
\end{tabular}

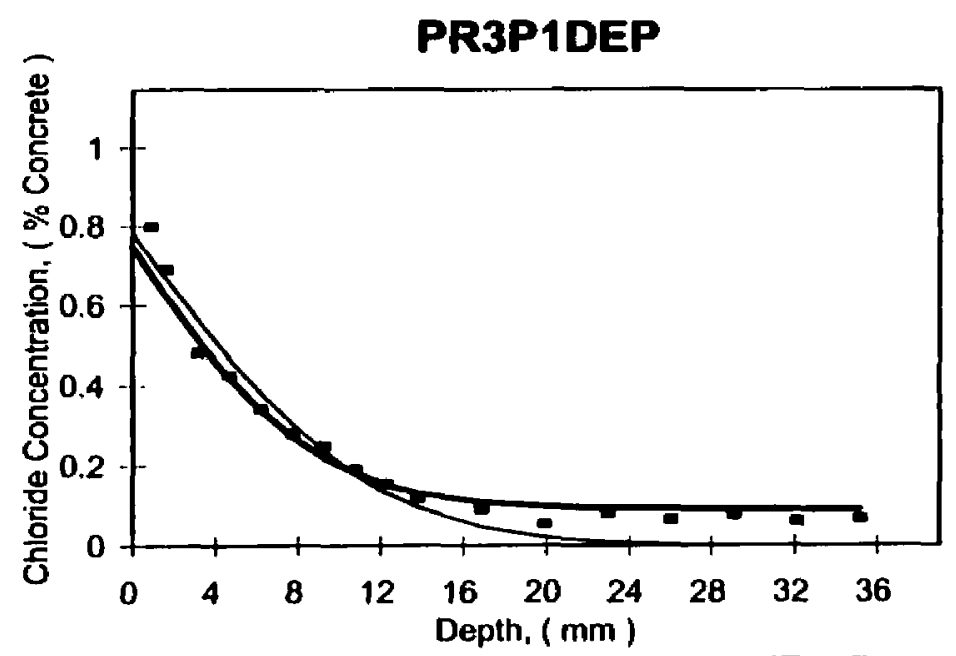

- Considered a Not Considered

- Table Curve -20 Simulation 
Test: Bulk Diffusion

Duration: 40 Days

Sample: PR5PIDEP h Crack

Diffusion Coefficient of

Uncracked Concrete:

$7.07 \mathrm{E}-12 \mathrm{~m}^{2} / \mathrm{s}$

Surface Concentration: $\quad 0.75 \%$ by Mass of Concrete

Data
\begin{tabular}{|c|c|}
\hline $\begin{array}{c}\text { Depth, } \\
\text { (mm) }\end{array}$ & $\begin{array}{c}\text { Chloride Concentration, } \\
\text { (\% by Mass of Concretc) }\end{array}$ \\
\hline 0.89 & 0.66 \\
\hline 1.65 & 0.65 \\
\hline 3.18 & 0.42 \\
\hline 4.70 & 0.34 \\
\hline 6.22 & 0.30 \\
\hline 7.75 & 0.20 \\
\hline 9.27 & 0.17 \\
\hline 10.80 & 0.15 \\
\hline 12.32 & 0.12 \\
\hline 13.84 & 0.11 \\
\hline 16.89 & 0.06 \\
\hline 19.94 & 0.04 \\
\hline 22.99 & 0.04 \\
\hline 26.04 & 0.04 \\
\hline 29.08 & 0.05 \\
\hline 32.13 & 0.03 \\
\hline 35.18 & 0.05 \\
\hline
\end{tabular}

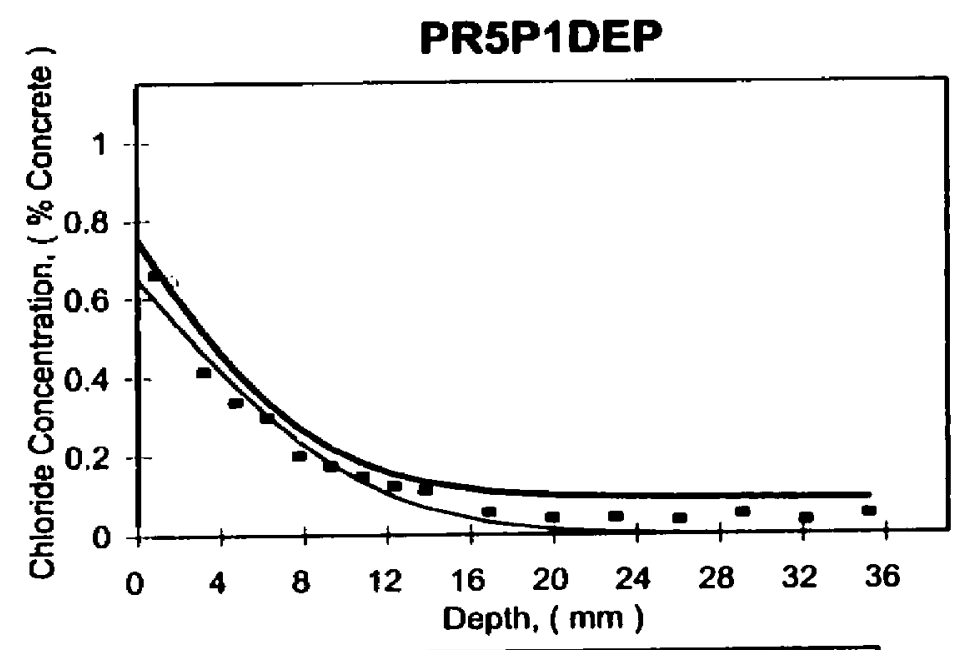

- Considered a Not Considered

- Table Curve -2D Simulation 
Diffusion Coefficient of

Uncracked Concrete:

$2.93 \mathrm{E}-12 \mathrm{~m}^{2} / \mathrm{s}$

Surface Concentration:

$0.77 \%$ by Mass of Concrete

Data

\begin{tabular}{|c|c|}
\hline $\begin{array}{c}\text { Depth, } \\
(\mathbf{m m})\end{array}$ & $\begin{array}{c}\text { Chloride Concentration, } \\
\text { (\% by Mass of Concrete) }\end{array}$ \\
\hline 0.89 & 0.88 \\
\hline 1.65 & 0.66 \\
\hline 3.18 & 0.41 \\
\hline 4.70 & 0.30 \\
\hline 6.22 & 0.21 \\
\hline 7.75 & 0.14 \\
\hline 9.27 & 0.06 \\
\hline 10.80 & 0.06 \\
\hline 12.32 & 0.05 \\
\hline 13.84 & 0.04 \\
\hline 16.89 & 0.05 \\
\hline 19.94 & 0.02 \\
\hline 22.99 & 0.02 \\
\hline 26.04 & 0.03 \\
\hline 29.08 & 0.02 \\
\hline 32.13 & 0.01 \\
\hline 35.18 & 0.01 \\
\hline
\end{tabular}

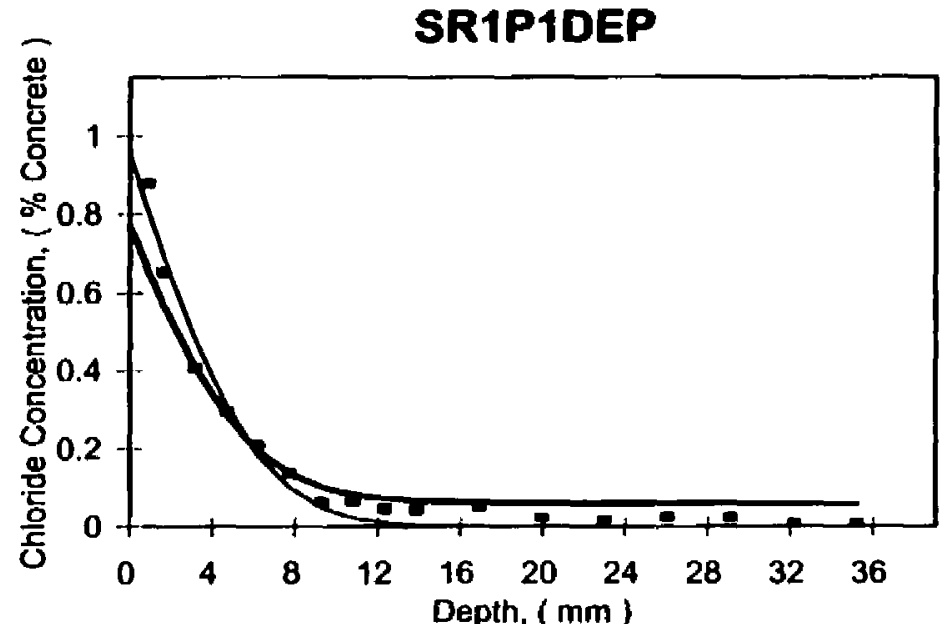

- Considered

- Not Considered

- Table Curve

-2D Simulation 
Diffusion Coefficient of

Uncracked Concrete:

2.93E- $12 \mathrm{~m}^{2} / \mathrm{s}$

Surface Concentration: $\quad 0.77 \%$ by Mass of Concrete

Data

\begin{tabular}{|c|c|}
\hline $\begin{array}{c}\text { Depth, } \\
\text { (mm) }\end{array}$ & $\begin{array}{c}\text { Chloride Concentration, } \\
\text { (\% by Mass of Concretc) }\end{array}$ \\
\hline 0.89 & 1.03 \\
\hline 1.65 & 0.77 \\
\hline 3.18 & 0.39 \\
\hline 4.70 & 0.23 \\
\hline 6.22 & 0.14 \\
\hline 7.75 & 0.07 \\
\hline 9.27 & 0.06 \\
\hline 10.80 & 0.07 \\
\hline 12.32 & 0.07 \\
\hline 13.84 & 0.07 \\
\hline 16.89 & 0.05 \\
\hline 19.94 & 0.05 \\
\hline 22.99 & 0.04 \\
\hline 26.04 & 0.05 \\
\hline 29.08 & 0.04 \\
\hline 32.13 & 0.04 \\
\hline 35.18 & 0.04 \\
\hline
\end{tabular}

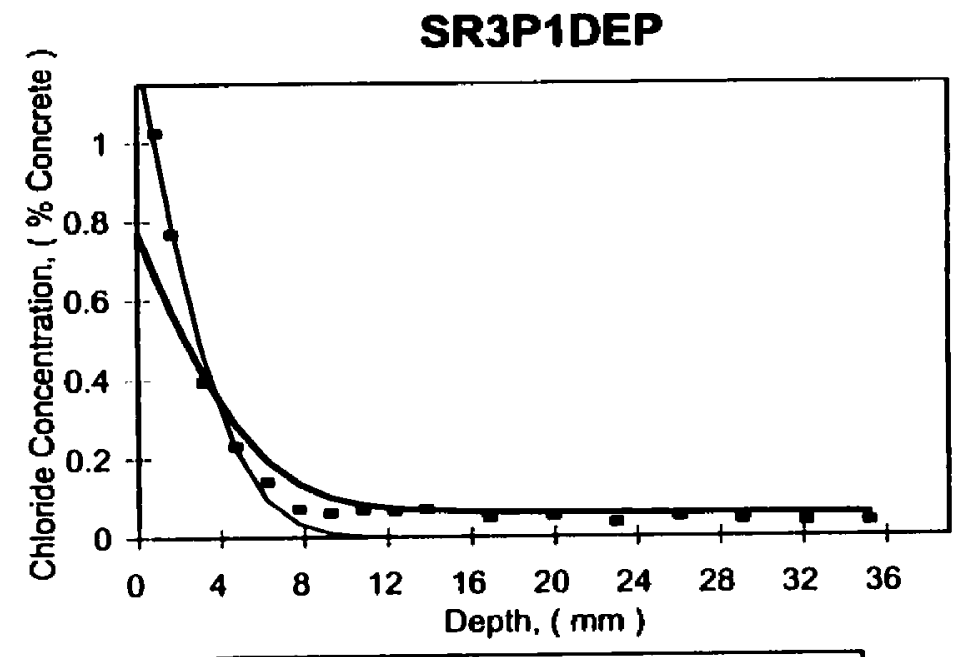
- Considered
- Not Considered
Table Curve
20 Simulation 
Diffusion Coefficient of

Uncracked Concrete:

$2.93 \mathrm{E}-12 \mathrm{~m}^{2} / \mathrm{s}$

Surface Concentration:

$0.77 \%$ by Mass of Concrete

Data

\begin{tabular}{|c|c|}
\hline $\begin{array}{c}\text { Depth, } \\
(\mathbf{m m})\end{array}$ & $\begin{array}{c}\text { Chloride Concentration, } \\
\text { (\% by Mass of Concrete) }\end{array}$ \\
\hline 0.89 & 0.86 \\
\hline 1.65 & 0.64 \\
\hline 3.18 & 0.45 \\
\hline 4.70 & 0.29 \\
\hline 6.22 & 0.19 \\
\hline 7.75 & 0.19 \\
\hline 9.27 & 0.13 \\
\hline 10.80 & 0.08 \\
\hline 12.32 & 0.07 \\
\hline 13.84 & 0.06 \\
\hline 16.89 & 0.03 \\
\hline 19.94 & 0.03 \\
\hline 22.99 & 0.03 \\
\hline 26.04 & 0.02 \\
\hline 29.08 & 0.04 \\
\hline 32.13 & 0.03 \\
\hline 35.18 & 0.05 \\
\hline
\end{tabular}

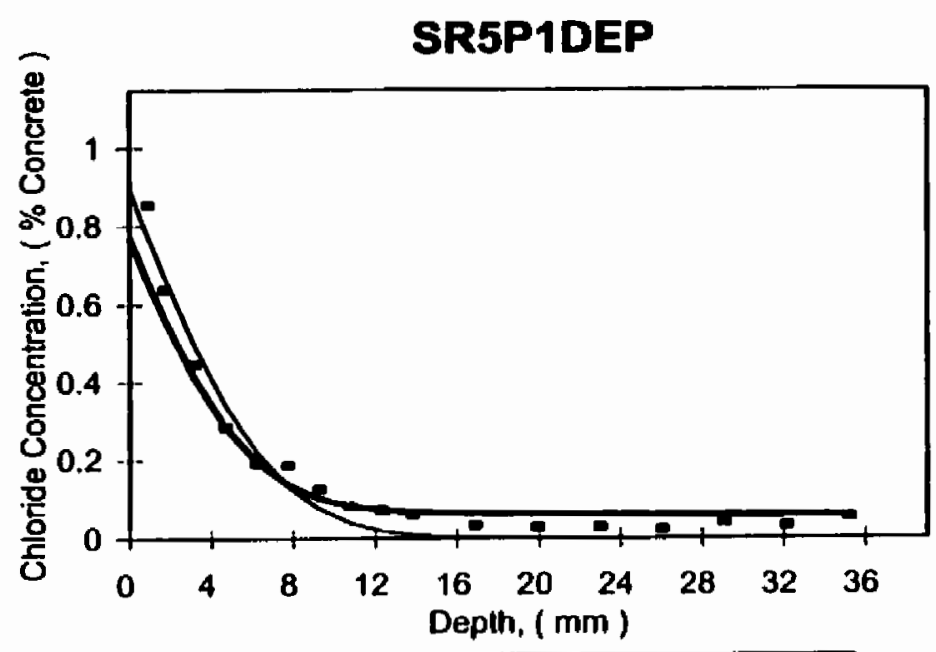




\title{
APPENDIX E
}

\section{ChLORIDE DIFFUSION IN}

\author{
ROUGH SURFACE SAMPLES
}


Since for the smooth surface samples it is assumed that the lines of equal concentration run parallel to the exposed surface (Figure E.l-a), it would be logical to make an analogous assumption for the rough surface samples, that is, the lines of equal concentration take the shape of the exposed surface (Figure E.1-b). The set-up of the milling machine only allows grinding of concrete layers perpendicular to the core bit axis. Hence, for the case of the rough surface sample, the grinding planes do not coincide with the lines (or planes) of equal concentration (Figure E.2). In other words, the resulting chloride concentration of each layer, except for the first one, combines concentrations from different equal-concentration layers. If this assumption is correct, then, the obtained concentration profile will not characterize the case of one dimensional diffusion, uniess the actual concentrations of the equal-chloride content layers can be calculated.

Let us consider the grinding of the rough surface sample layer by layer (Figure E.2). The first layer has a mass $m_{1}$ and a corresponding chloride concentration $C_{1}$ that coincides with the concentration of the first equal-chloride content layer. The second layer has a mass $m_{2}$ and concentration $\mathrm{C}_{2}$. Then, the concentration of the second equal-chloride content layer $\left(\mathrm{C}_{\mathrm{e} 2}\right)$ can be derived from the following expression:

$$
m_{2} * C_{2}=m_{1} * C_{e 2}+m_{2}^{\prime} * C_{1}
$$

Where:

$$
\begin{gathered}
\mathrm{m}_{2}^{\prime}=\text { mass of the second ground layer portion that corresponds to the first layer } \\
\text { of equal concentration, } \mathrm{m}_{2}-\mathrm{m}_{1} .
\end{gathered}
$$


(a)

Smooth Surface Sample

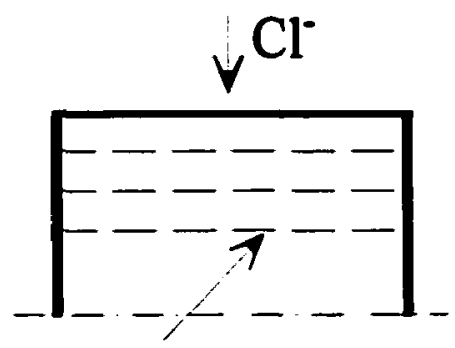

Lines of Equal Concentration (b)

$$
\text { Rough Surface Sample }
$$

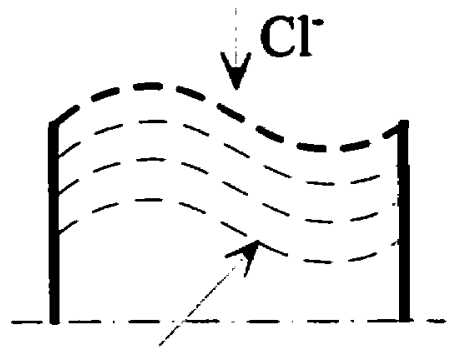

Lines of Equal Concentration

Figure E.I Lines of Equal Concentration for Smooth and Rough Surface Samples.

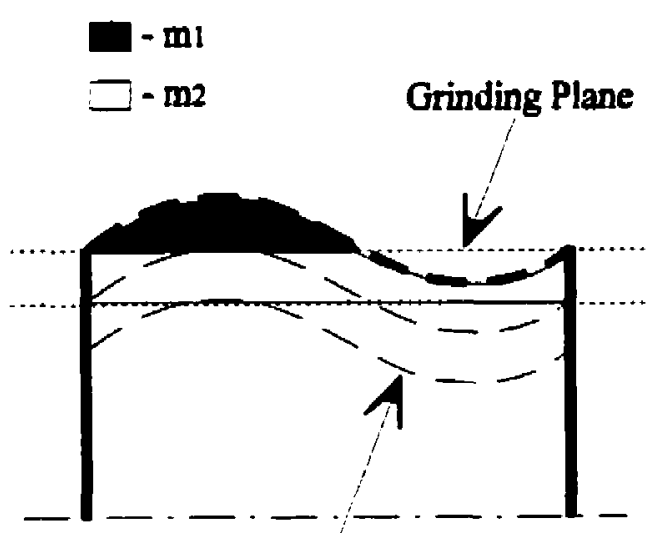

Lines of Equal Concentration

Figure E.2 Grinding the Rough Surface Sample. 
Each following $\mathrm{j}$-ground layer has a $\mathrm{j}$-number of mass components corresponding to a $j$-number of different equal-concentration layers until the entire irregularity is ground (the layer mass and the number of mass components become constant). Each new mass component $\left(\mathrm{m}_{\mathrm{j}}^{\prime}\right)$ initially assumes the concentration of the first layer of equal chloride content $\left(C_{i}\right)$, and then, subsequent concentration values of all the equal-chloride content layers $\left(C_{e j}, j\right.$ ranges from 2 to $\mathrm{n}$, where $\mathrm{n}$ is the number of ground layers).

The described approach was applied for obtaining the lateral chloride concentration profiles for rough crack samples. Care was taken to collect all the ground powder for each layer and weigh it prior to sieving. In order to study the sensitivity of the proposed model to the layer thickness, three thicknesses were tested $(0.5,1$, and $1.5 \mathrm{~mm})$ for different profiles.

The measured values of layer mass and concentration were used to back calculate the concentration of the layers of equal chloride content. However, the obtained results did not show the anticipated trend in the chloride concentrations. The calculated concentration values for the equal-chloride content layers were fluctuating in a bizarre manner, falling down to nonsensical negative values and jumping back to high concentrations. From analyzing the first few layers of the rough surface sample, it was obvious that this model was not adequate for describing chloride diffusion into concrete with irregular surface shape. Figure E.3 demonstrates an example of the measured and calculated concentration profiles for one of the samples.

One disadvantage of this approach could be that it is too simplistic and underestimates the complicated geometry of the rough surface. For instance, the diffusion that takes place at the convex and concave parts of the concrete surface is three-dimensional, while at the flat surface portions it is one-dimensional.

Influence of Cracks on Chloride Ingress into Concrete 


\section{PR3P1LAT}

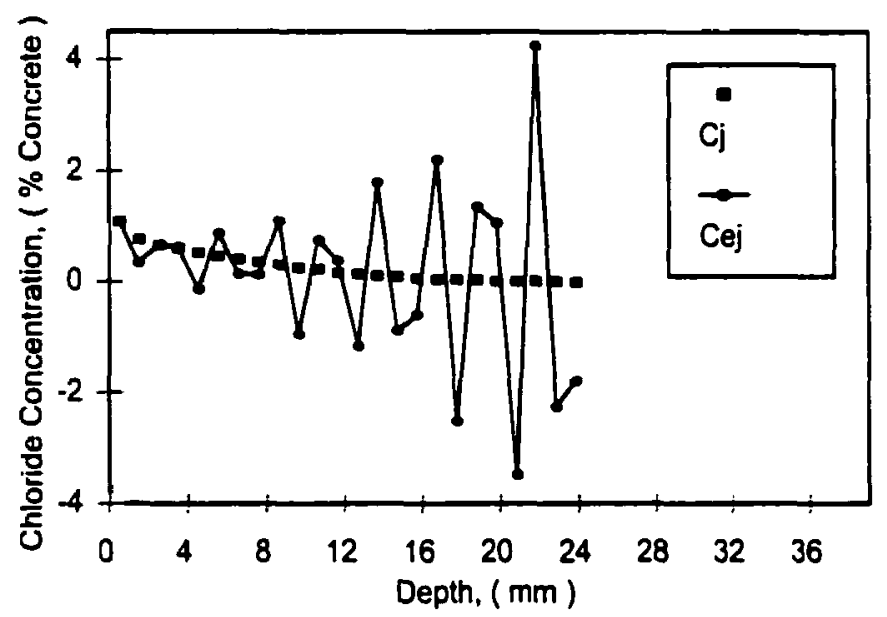

Figure E.3 Example of Measured and Calculated Concentration Profiles: $\mathrm{C}_{\mathrm{i}}$ - Chloride Concentration of the Ground Layers, $\mathrm{C}_{\mathrm{ej}}$ - Chloride Concentration of the Equal-Chloride Content Layers.

Therefore, this approach was abandoned and the lateral chloride concentration profiles for rough crack samples were simply obtained using the conventional approach by setting a zero grinding depth at the top of the first layer and plotting the measured chloride concentrations of the ground layers against the corresponding depths. Five out of a total six (with the exception of sample PRIPILAT) lateral chloride profiles exhibited a very good fit to the curve generated by the Table Curve software package (Appendix B). The values of the diffusion coefficient determined from these rough concrete surface profiles lie within the domain of the diffusion coefficient values obtained for the corresponding concrete type. 


\section{APPENDIX F}

\section{SEM/EDX CHLORIDE PROFILING}


SEM/EDX Chloride Profiling Results

\begin{tabular}{|c|c|c|}
\hline \multirow{2}{*}{$\begin{array}{c}\text { Depth, } \\
\text { (mm) }\end{array}$} & \multicolumn{2}{|c|}{$\begin{array}{c}\text { Chloride Concentration, } \\
\text { (\% by Mass of Cem. Paste) }\end{array}$} \\
\cline { 2 - 3 } & SR31 & SR32 \\
\hline 0.5 & 3.78 & 3.61 \\
\hline 2.5 & 2.82 & 2.81 \\
\hline 4.5 & 2.31 & 1.84 \\
\hline 5.5 & 1.69 & 1.55 \\
\hline 7.5 & 1.22 & - \\
\hline 10.5 & 0.75 & - \\
\hline 13.5 & 0.51 & - \\
\hline
\end{tabular}


SEMrEDX Chloride Profiling, Sample of Raw Data and Calculations, Specimen SR32, Depth $=4.5 \mathrm{~mm}$

Elmt App. Conc. St. Sigma Fit Index Int, Corm. Sid. Corm. Elmt \% Sigma \% Elmt Atom. \% Atom.mass At\%*A.m. Conc by m.\%

$\begin{array}{llllllllllll} & 0.248 & 0.062 & 0.167 & 0.757 & 1.000 & 0.327 & 0.081 & N a & 0.561 & 22.990 & 12.887\end{array}$

$\begin{array}{llllllllllll}\mathrm{Mg} & 0.841 & 0.037 & 0.000 & 0.490 & 1.000 & 1.715 & 0.076 & \mathrm{Mg} & 2.779 & 24.310 & 67.558\end{array}$

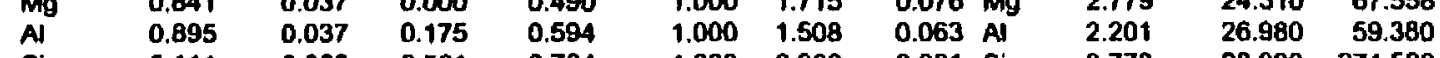

$\begin{array}{lllllll}\text { Si } & 5.111 & 0.060 & 0.561 & 0.734 & 1.000 & 6.968\end{array}$

$\begin{array}{lllllll}S & 1.135 & 0.083 & 0.804 & 1.129 & 1.000 & 1.005\end{array}$

$\begin{array}{lllll}\text { Cl } & 1.185 & 0.058 & 0.979 & 0.988\end{array}$

$\begin{array}{lllll}K & 0.046 & 0.046 & 1.000 & 0.973\end{array}$

\begin{tabular}{lllllll} 
Ti $\quad 0.110$ & 0.094 & 0.266 & 0.742 & 1.000 & 20.995 \\
\hline & 0.494 & 0.079 & 0.461 & 0.849 & 1.000 & 0.149
\end{tabular}

$\begin{array}{lllllll}\text { Fo } & 0.494 & 0.079 & 0.481 & 0.849 & 1.000 & 0.581\end{array}$

P1 $\quad 11.173$

Cation sum 0.00

$\because=<2$ Sigma
Elmt App. Conc. St. Sigme Fit index Int. Corm. Sid. Corm. Elmi $\%$ Sigma $\%$ Elmt Alom. \% Alom.mass Al\%"A.m. Conc. by m., $\%$

0.206

1.00016 .681

$0.081 \mathrm{Si}$

9.773

$0.073 \mathrm{~S}$

1.235

$\begin{array}{rr}28.090 & 274.520 \\ 32.060 & 39.564\end{array}$

$\begin{array}{lrrrr}0.048 & K & 0.047 & 39.100 & 1.850\end{array}$

$\begin{array}{llrrr}0.127 & \mathrm{Tl} & 0.122 & 47.880 & \mathbf{8 2 7 . 0 4 3} \\ 0.0952 & \mathrm{Fe} & 0.410 & 55.850 & \mathbf{2 2 . 9 0 2}\end{array}$

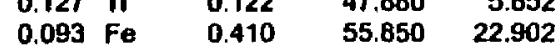

$\begin{array}{lllll}0.308 & P 1 & 3.368 & 195.100 & 657.121\end{array}$

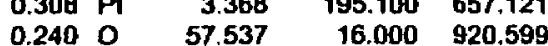

$16.000 \quad 920.599$
2936.516 Cation sum 0.00

2936.516

$\begin{array}{llll}0.439 & \mathrm{Na2O} & 0.441 & 0.305 \\ 2.301 & \mathrm{MgO} & 2.844 & 1.511\end{array}$

Compd \% Nos of lon Ca/s

$\begin{array}{lll} & 2.848 & 1.196\end{array}$

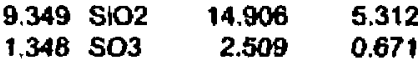

$\begin{array}{rrr}28.164 \mathrm{CaO} & 29.376 & 11.217\end{array}$

$\begin{array}{llll}0.199 \text { TiO } & 0.198 & 0.066\end{array}$

$\begin{array}{lll}0.780 \mathrm{FeO} & 0.748 & 0.223\end{array}$

22.378 PtO2 $19.416 \quad 1.031$

$\begin{array}{lrr}31.350 & 1.031 \\ 100.000 & 31.276\end{array}$

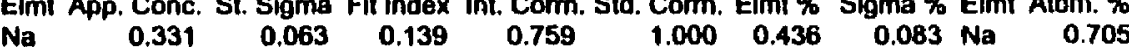

$\begin{array}{lllllllllll}\mathrm{Mg} & 0.889 & 0.038 & 0.000 & 0.491 & 1.000 & \mathbf{1 . 8 1 2} & 0.077 \mathrm{Mg} & 2.774 & \mathbf{2 4 . 3 1 0} & \mathbf{6 7 . 4 3 3}\end{array}$

$\begin{array}{llllllllllll}\text { Al } & 0.979 & 0.038 & 0.500 & 0.594 & 1.000 & 1.649 & 0.064 \text { Al } & 2.275 & 26.980 & 61.371\end{array}$

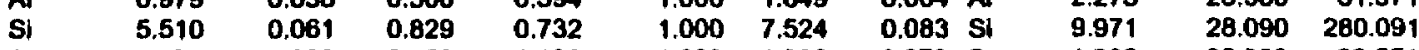

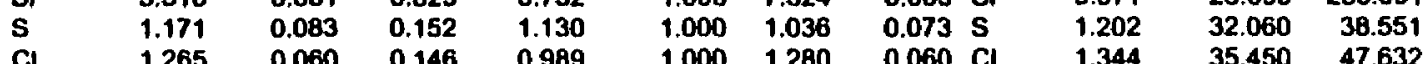

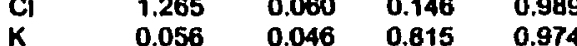

$\begin{array}{llllll}K & 0.056 & 0.046 & 0.815 & 0.974 \\ C a & 20.948 & 0.143 & 2.672 & 0.954\end{array}$

$\begin{array}{llll}\mathrm{Ca} & 20.948 & 0.143 & 2.672 \\ \mathrm{Ti} & 0.124 & 0.090 & 0.650\end{array}$

Ti $\quad 0.124$

$\begin{array}{lrllll} & \text { Fe } & 0.419 & 0.078 & 0.383 & 0.848\end{array}$

$1.000 \quad 1.280$

$0.060 \mathrm{Cl} \quad 1.344$

$1.000 \quad 21.950$

$0.048 \mathrm{~K} \quad 0.055$

1.0000 .0167

0.150 Ca 20.384

11.509

$0.207 \quad 0.423$

$0.667 \quad 1.000 \quad 0.493$

$\begin{array}{rrr}0.130 & 40.080 & 816.992\end{array}$

$\begin{array}{lllr}0.329 & 55.850 & 18.366\end{array}$

$\begin{array}{lllll}0.243 & 0 & 3.291 & 195.100 & 642.036\end{array}$

$\begin{array}{lrr}67.540 & 16.000 & 920.644 \\ \text { sum } 0.00 & 2917.705\end{array}$

Cation sum 0.00

" = <2 Sigma

$$
\text { Sum }
$$

24.733
70.386

Cation sum 0.00

Elmt App. Conc. St. Sigma Fit Index Int. Corm. Std. Corrn. Elmt \% Sigma \% Elmt Atom. \% Atom.mass At\%"A.m. Conc. by m.\%

$\begin{array}{llllllllllll}\mathrm{Na} & 0.306 & 0.062 & 0.306 & 0.747 & 1.000 & 0.410 & 0.083 \mathrm{Na} & 0.675 & 22.990 & 15.516\end{array}$

$\begin{array}{llllllllllll}\mathrm{Mg} & 0.544 & 0.035 & 0.079 & 0.485 & 1.000 & 1.123 & 0.073 & \mathrm{Mg} & 1.748 & 24.310 & 42.495\end{array}$

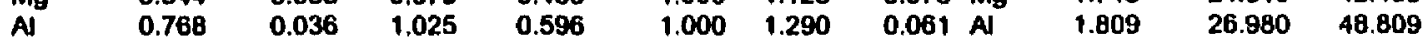

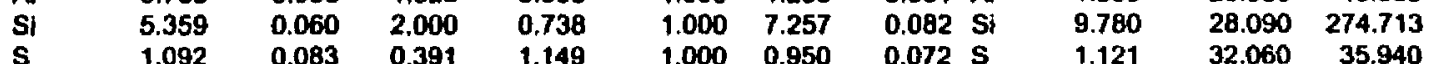

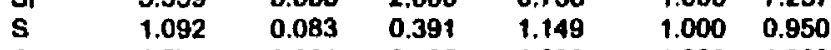

$\begin{array}{lllllll}\text { Cl } & 1.374 & 0.061 & 0.125 & 1.003 & 1.000 & 1.369\end{array}$

$\begin{array}{lllllll}K & 0.059 & 0.046 & 1.019 & 0.986 & 1.000 & 0.060\end{array}$

$\begin{array}{lrllllr}\mathrm{Ca} & 22.829 & 0.149 & 1.776 & 0.962 & 1.000 & 23.729 \\ \mathrm{Ti} & 0.156 & 0.094 & 0.234 & 0.739 & 1.000 & 0.211\end{array}$

$\mathrm{Fe} \quad 0.598$

PI 10.988

$0.082 \quad 0.074$

$1.000 \quad 0.211$

$0.072 \mathrm{~S}$

$0.061 \mathrm{Cl}$

1.121
1.462

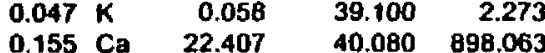

$0.205 \quad 1.016$

0.674

$1.000 \quad 16.310$

$0.128 \mathrm{Ti} \quad 0.166$

$40.080 \quad 898.063$

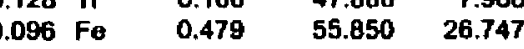

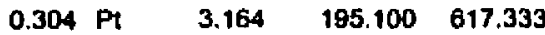

Cation sum 0.00

Sum

24.151
77.566

0.2410

57.131

$16.000 \quad 914.099$

Cation sum 0.00

2935.768

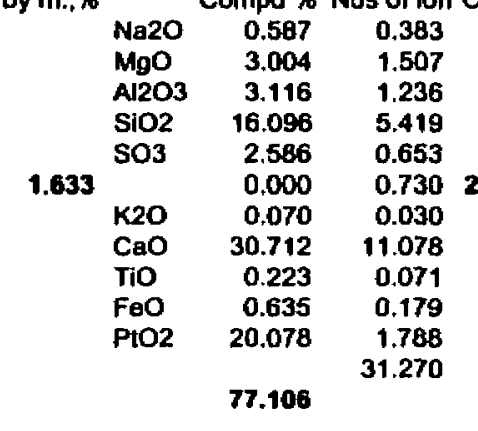

Compd \% Nos of ion Ca/S

$\begin{array}{lll}\mathrm{Na} 2 \mathrm{O} & 0.553 & 0.369\end{array}$

$\begin{array}{lll}\mathrm{MgO} & \mathbf{1 . 6 6 2} & 0.955\end{array}$

$\begin{array}{lll}\mathrm{A} 2 \mathrm{O} & 2.437 & 0.988\end{array}$

$\begin{array}{lrr}\mathrm{SIO}^{\mathrm{O}} & \mathbf{1 5 . 5 2 6} & \mathbf{5 , 3 4 1}\end{array}$

1.765

$\begin{array}{lll}\mathrm{SO} 3 & 2.371 & 0.612\end{array}$

$\begin{array}{lll}K 20 & 0.072 & 0.032\end{array}$

$\begin{array}{lrr}\mathrm{CaO} & 33.201 & 12.237 \\ \mathrm{~T} O \mathrm{O} & 0.281 & 0.091\end{array}$

$\begin{array}{lll}\text { F } & 0.009 & 0.909 \\ & & 0.262\end{array}$

$\begin{array}{lll}\mathrm{PIO2} & 18.986 & 1.728\end{array}$

76.197

31.202 


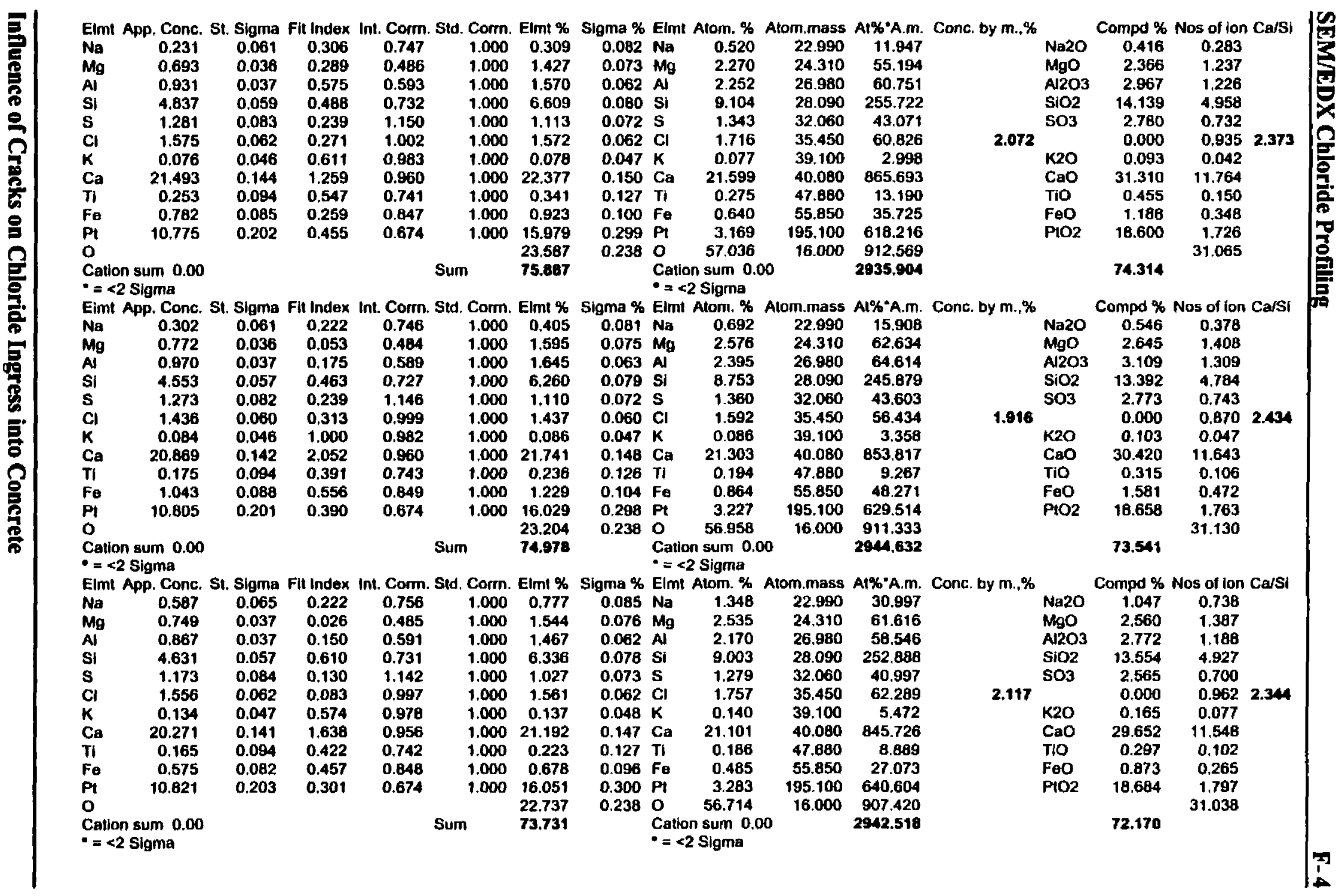




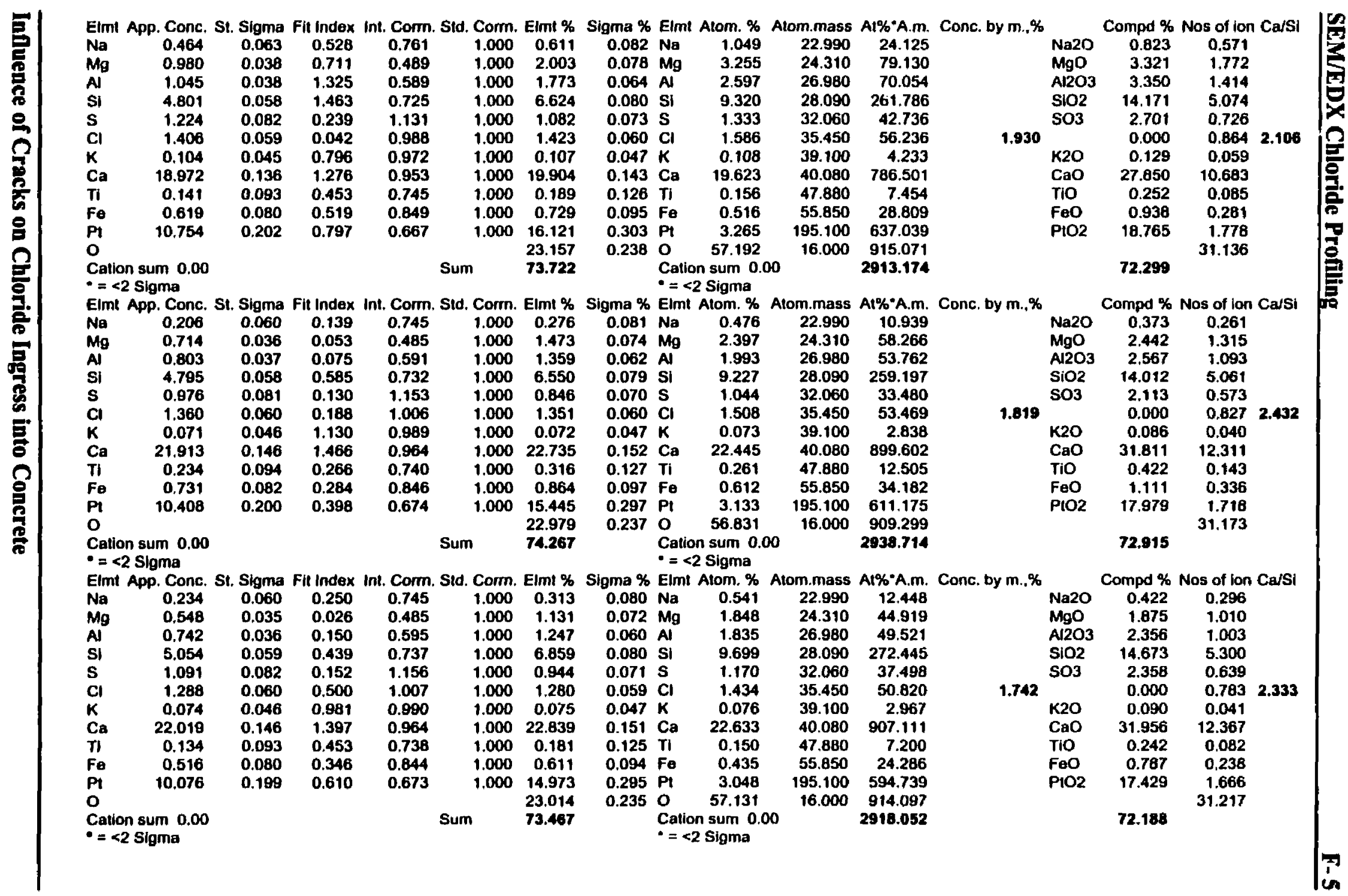




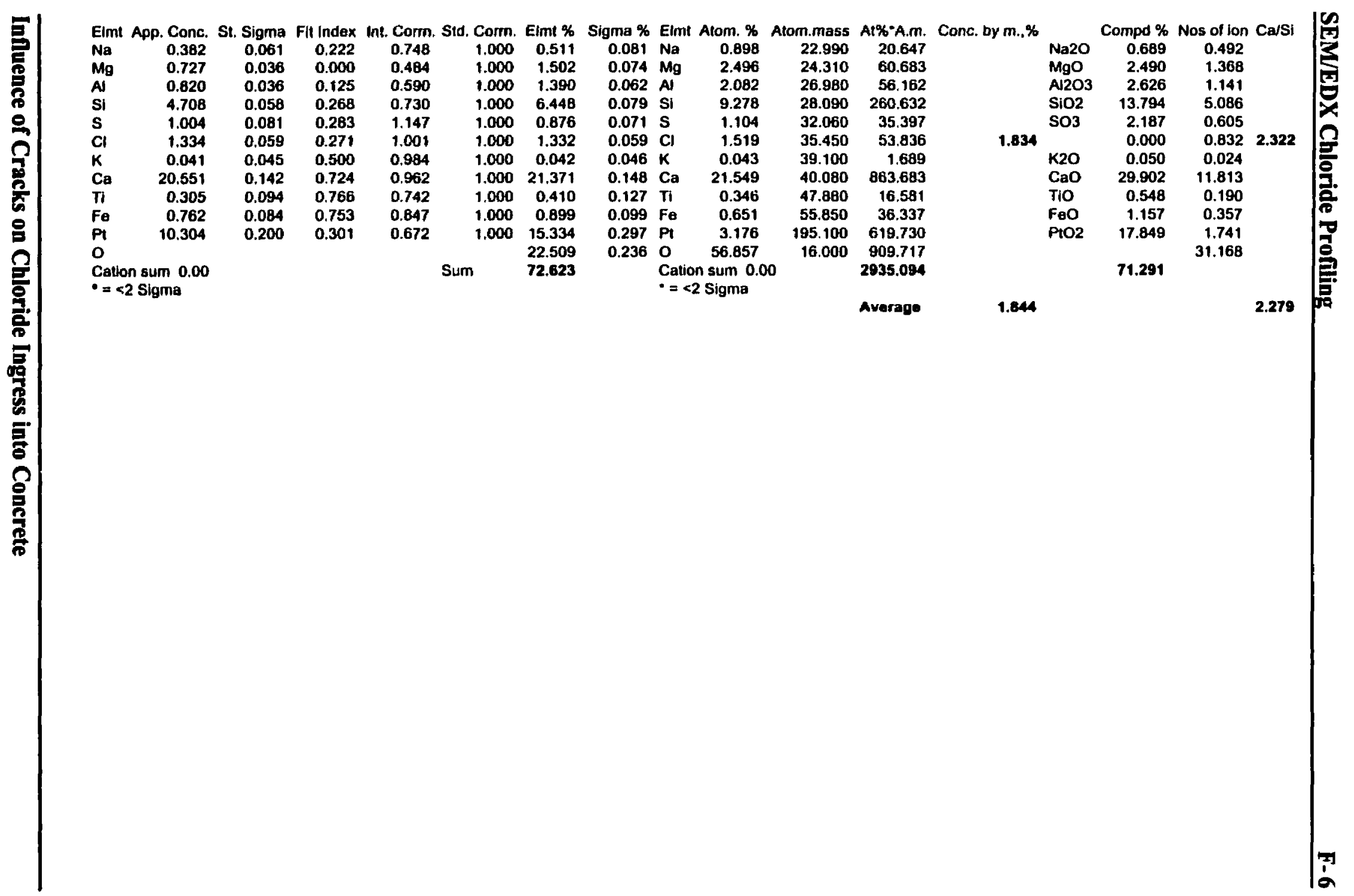




\section{APPENDIX G}

\section{Chloride Diffusion Cell}




\section{Calculation Example - Crack Width, Sample PS1D1}

Constant:

$$
\mathrm{D}_{\mathrm{Cl}^{-}}=2.03 \mathrm{E}-09 \mathrm{~m}^{2} / \mathrm{s}
$$

- chloride diffusion coefficient in water, (CRC Handbook, 1977)

Fixed Variable: $\quad C_{u}=500 \mathrm{~mole} / \mathrm{m}^{3}$ - concentration of the upstream solution Test Variables:

$$
\mathrm{D}=0.101 \mathrm{~m}
$$

- sample diameter

$$
x=0.038 m
$$

- sample thickness

$\mathrm{S}=8.81 \mathrm{E}-10 \mathrm{~mole} / \mathrm{s}$

- slope of steady state from regression

Calculations: $\mathrm{J}=\mathrm{S} / \mathrm{A}_{\mathrm{cr}}$ - steady state flux, mole $/ \mathrm{s}^{*} \mathrm{~m}^{2}$ substituting $\mathrm{J}$ in Fick's first law (Equation 2-3) -

$A_{c r}=S^{*} x / D_{\mathrm{Cl}^{-}}{ }^{*} C_{u} \quad$ - surface area of the crack, $m^{2}$

$$
\begin{aligned}
& A_{\mathrm{cr}}=3.33 \mathrm{E}-05 \mathrm{~m}^{2} \\
& \mathrm{CW}=\mathrm{A}_{\mathrm{cr}} / \mathrm{D} \quad \text { - crack width, } \mathrm{m} \\
& \mathrm{CW}=3.31 \mathrm{E}-04 \mathrm{~m}=0.331 \mathrm{~mm}
\end{aligned}
$$


Sample: PS1DI

Test: Diffusion Cell

$100 \%$ OPC, $0.115 \mathrm{~mm}$ Smooth Crack

Cell Volume:

$0.590 \mathrm{~L}$

Diameter:

$0.101 \mathrm{~m}$

Thickness:

$0.038 \mathrm{~m}$

Calculated Crack Width: $\quad 0.331 \mathrm{~mm}$

Data:

\begin{tabular}{|c|c|c|c|c|}
\hline $\begin{array}{l}\text { Day } \\
\text { Month } \\
\text { Year }\end{array}$ & Hour & $\begin{array}{l}\text { Elapsed } \\
\text { Time, } \\
\text { (Days) }\end{array}$ & $\begin{array}{l}\text { Downst. } \\
\text { Conc., } \\
\text { (mg/l) }\end{array}$ & $\begin{array}{l}\text { Mass } \\
\text { Passed, } \\
\text { (mg) }\end{array}$ \\
\hline 18-Feb-00 & $: 05$ PM & 0.00 & 0.00 & 0.00 \\
\hline & $M$ & 0.09 & 1.40 & 2.63 \\
\hline$b-00$ & 06:05 PM & 0.17 & 47.00 & 27.94 \\
\hline & $05: 4$ & 1.15 & 35.60 & 1.69 \\
\hline-00 & $05: 3$ & 3.15 & 41.20 & 25.35 \\
\hline & $12: 4$ & 3.94 & 5.10 & 2.16 \\
\hline $24-F$ & $01: 4$ & 5.99 & 58.60 & 36.38 \\
\hline & 11: & 39 & 6.50 & 1.62 \\
\hline $28-$ & 11:1 & 10.38 & 66.90 & 2.53 \\
\hline & 01: & 11.97 & 2.10 & 4.46 \\
\hline & 01:1 & 13.97 & 72.50 & 47.02 \\
\hline & $12: 0$ & 16.92 & 65.70 & 43.73 \\
\hline & $02: 0$ & 19.00 & 3.90 & 1.03 \\
\hline $10-1$ & $01: 5$ & 20.99 & 96.30 & 63.38 \\
\hline & $12: 2$ & 23.93 & 105.10 & 69.54 \\
\hline $17-1$ & $02: 3$ & 28.02 & 93.40 & 63.69 \\
\hline 22-Mar-00 & $12: 2 C$ & 32.93 & 128.80 & 85.51 \\
\hline 27 & $01: 3$ & 37.98 & 148.70 & 100.02 \\
\hline 03-Apr-00 & $02: 3$ & 45.02 & 60.10 & 106.75 \\
\hline 10-Apr-00 & $04: 4$ & 52.11 & 185.90 & 123.57 \\
\hline 17-Apr-00 & 08:21 PM & 59.26 & 215.10 & 142.66 \\
\hline & 12:53 PM & 66.95 & 242.50 & 160.97 \\
\hline$y-00$ & 12:23 PM & 72.93 & 255.80 & 171.25 \\
\hline 08-May-00 & 01:20 PM & 79.97 & 285.90 & 191.56 \\
\hline & $10: 15$ AM & 88.84 & 328.60 & 219.62 \\
\hline 23-Мay-00 & 01:10 PM & 94.96 & 352.00 & 236.71 \\
\hline 29-Мау-00 & 01:30 PM & 100.98 & 372.90 & 252.56 \\
\hline & 12:15 PM & 114.92 & 444.50 & 298.53 \\
\hline 26-Jun-00 & $11: 20 \mathrm{AM}$ & 128.89 & 505.50 & 338.97 \\
\hline 10-Jul-00 & 04:25 PM & 143.10 & 568.60 & 381.25 \\
\hline
\end{tabular}

Influence of Cracks on Chloride Ingress into Concrete 
PS1D1

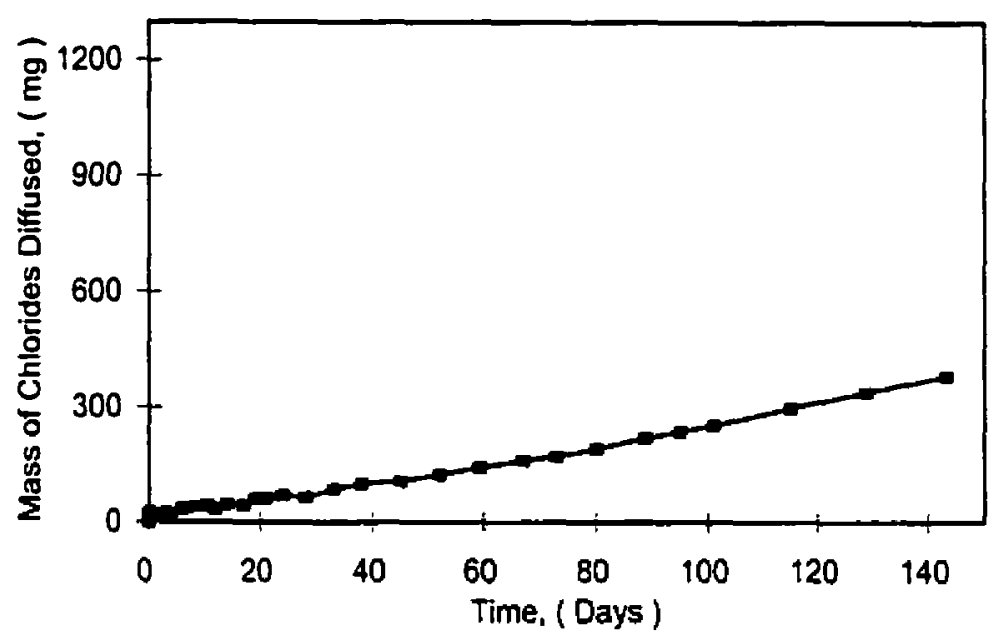


Sample: PSID2

Test: Diffusion Cell

$100 \%$ OPC, $0.064 \mathrm{~mm}$ Smooth Crack

Cell Volume:

$0.590 \mathrm{~L}$

Diameter:

$0.101 \mathrm{~m}$

Thickness:

$0.039 \mathrm{~m}$

Calculated Crack Width: $\quad 0.548 \mathrm{~mm}$

Data:

\begin{tabular}{|c|c|c|c|c|}
\hline $\begin{array}{l}\text { Day } \\
\text { Month } \\
\text { Year } \\
\end{array}$ & Hour & $\begin{array}{l}\text { Elapsed } \\
\text { Time, } \\
\text { (Days) }\end{array}$ & $\begin{array}{l}\text { Downst. } \\
\text { Conc., } \\
\text { (mg/l) }\end{array}$ & $\begin{array}{l}\text { Mass } \\
\text { Passed, } \\
(\mathrm{mg})\end{array}$ \\
\hline 18-Feb-00 & 02:12 PM & 0.00 & 0.00 & 0.00 \\
\hline 18-Feb-00 & 04:20 PM & 0.09 & 0.00 & 0.00 \\
\hline $18-F e b-00$ & 06:05 PM & 0.16 & 37.30 & 22.01 \\
\hline $19-\mathrm{Feb}-00$ & 05:45 PM & 1.15 & 30.80 & 18.55 \\
\hline 21-Feb-00 & 05:40 PM & 3.14 & 32.20 & 19.68 \\
\hline 22-Feb-00 & 12:44 PM & 3.94 & 40.20 & 24.72 \\
\hline 24-Feb-00 & 01:48 PM & 5.98 & 56.20 & 34.56 \\
\hline 26-Feb-00 & 11:30 PM & 8.39 & 76.30 & 46.98 \\
\hline 28-Feb-00 & 01:14 PM & 9.96 & 76.40 & 47.81 \\
\hline $01-$ Mar=00 & 01:22 PM & 11.97 & 70.80 & 45.27 \\
\hline 03-Mar-00 & 01:18 PM & 13.96 & 116.60 & 73.00 \\
\hline 06-Mar-00 & $12: 05 \mathrm{PM}$ & 16.91 & 151.00 & 94.46 \\
\hline 08-Mar-00 & 02:08 PM & 19.00 & 166.40 & 105.05 \\
\hline 10-Mar-00 & 01:56 PM & 20.99 & 208.80 & 131.73 \\
\hline 13-Mar-00 & $12: 23$ PM & 23.92 & 232.90 & 148.04 \\
\hline 17-Mar-00 & 02:33 PM & 28.01 & 239.90 & 154.50 \\
\hline 22-Mar-00 & 12:21 PM & 32.92 & 279.80 & 180.44 \\
\hline 27-Mar-00 & 12:53 PM & 37.95 & 409.40 & 259.70 \\
\hline 03-Apr-00 & 02:37 PM & 45.02 & 411.20 & 264.86 \\
\hline $10-A p r=00$ & 04:41 PM & 52.10 & 434.40 & 282.66 \\
\hline 17-Apr $=00$ & 08:22 PM & 59.26 & 481.80 & 314.97 \\
\hline 25-Apr-00 & 12:54 PM & 66.95 & 589.50 & 383.33 \\
\hline 01-Мау-00 & 12:24 PM & 72.93 & 632.20 & 414.42 \\
\hline 08-May-00 & $01: 20$ PM & 79.96 & 650.00 & 431.24 \\
\hline 17-May-00 & 10:15 AM & 88.84 & 685.10 & 458.45 \\
\hline 23-May-00 & 01:10 PM & 94.96 & 717.10 & 484.18 \\
\hline 29-May-00 & $01: 30$ PM & 100.97 & 751.50 & 511.65 \\
\hline $12-J u n-00$ & 12:15 PM & 114.92 & 820.40 & 559.81 \\
\hline 26-Jun-00 & $11: 20 \mathrm{AM}$ & 128.88 & 863.20 & 593.27 \\
\hline $10-J u l-00$ & 04:25 PM & 143.09 & 915.10 & 632.52 \\
\hline
\end{tabular}

Infuence of Cracks on Chloride Ingress into Concrete 


\section{PS1D2}

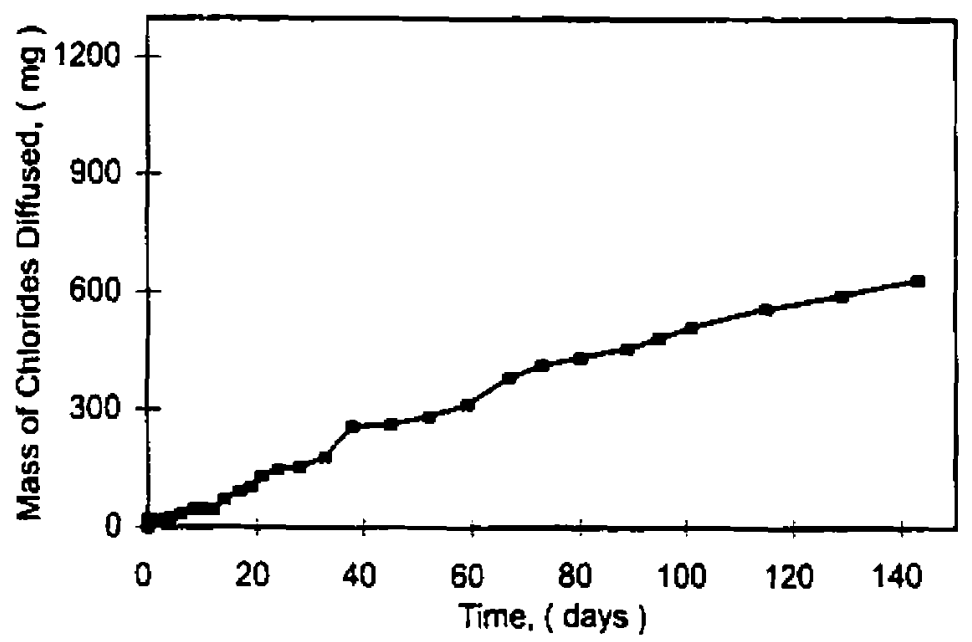


Sample: SSID1

Test: Diffusion Cell

$25 \%$ Slag, $0.102 \mathrm{~mm}$ Smooth Crack

Cell Volume:

$0.593 \mathrm{~L}$

Diameter:

$0.102 \mathrm{~m}$

Thickness:

$0.040 \mathrm{~m}$

Calculated Crack Width: $\quad 1.023 \mathrm{~mm}$

Data:

\begin{tabular}{|c|c|c|c|c|}
\hline $\begin{array}{l}\text { Day } \\
\text { Month } \\
\text { Year }\end{array}$ & Hour & $\begin{array}{l}\text { Elapsed } \\
\text { Time, } \\
\text { (Days) }\end{array}$ & $\begin{array}{l}\text { Downst. } \\
\text { Conc., } \\
\text { (mg/L) }\end{array}$ & $\begin{array}{l}\text { Mass } \\
\text { Passed, } \\
\text { (mg) }\end{array}$ \\
\hline 18-Feb-00 & 03:05 PM & 0.00 & 0.00 & 0.00 \\
\hline 18-Feb-00 & 04:20 PM & 0.05 & 0.00 & 0.00 \\
\hline 18-Feb-00 & 06:05 PM & 0.13 & 29.40 & 17.43 \\
\hline 19-Feb-00 & 05:45 PM & 1.11 & 31.10 & 18.74 \\
\hline 21-Feb-00 & $05: 42 \mathrm{PM}$ & 3.11 & 73.80 & 44.37 \\
\hline 22-Feb-00 & 12:46 PM & 3.90 & 84.10 & 51.21 \\
\hline 24-Feb-00 & $01: 50 \mathrm{PM}$ & 5.95 & 134.80 & 82.12 \\
\hline 26-Feb-00 & 11:32 PM & 8.35 & 165.20 & 101.50 \\
\hline 28-Feb-00 & 01:16 PM & 9.92 & 228.20 & 140.51 \\
\hline 03-Mar-00 & 01:19 PM & 13.93 & 235.60 & 149.46 \\
\hline 06-Mar-00 & 12:06 PM & 16.88 & 299.00 & 187.13 \\
\hline $08-$ Mar $=00$ & 02:09 PM & 18.96 & 327.60 & 207.08 \\
\hline 10-Mar-00 & 01:57 PM & 20.95 & 356.00 & 227.20 \\
\hline 13-Mar $=00$ & 12:24 PM & 23.89 & 365.90 & 236.63 \\
\hline 17-Mar-00 & 02:34 PM & 27.98 & 423.50 & 274.44 \\
\hline 22-Mar-00 & 12:22 PM & 32.89 & 471.80 & 307.32 \\
\hline 27-Mar-00 & 12:54 PM & 37.91 & 568.70 & 369.50 \\
\hline 03-Apr-00 & 02:38 PM & 44.98 & 626.30 & 409.34 \\
\hline 10-Apr-00 & $04: 42$ PM & 52.07 & 745.80 & 486.47 \\
\hline 17-Apr-00 & 08:23 PM & 59.22 & 900.00 & 585.37 \\
\hline 25-Apr-00 & 12:55 PM & 66.91 & 1017.70 & 664.16 \\
\hline $01-$ May-00 & 12:25 PM & 72.89 & 1066.90 & 703.52 \\
\hline 08-May-00 & 01:20 PM & 79.93 & 1096.40 & 731.68 \\
\hline $17-$ May -00 & 10:15 AM & 88.80 & 1154.20 & 776.92 \\
\hline 23-May-00 & 01:10 PM & 94.92 & 1208.20 & 820.48 \\
\hline 29-May-00 & 01:30 PM & 100.93 & 1263.50 & 865.36 \\
\hline 12-Jun-00 & 12:15 PM & 114.88 & 1435.50 & 979.99 \\
\hline 26-Jun-00 & $11: 20 \mathrm{AM}$ & 128.84 & 1640.20 & 1115.73 \\
\hline $10-J u l-00$ & $04: 25$ PM & 143.06 & 1754.80 & 1200.09 \\
\hline
\end{tabular}

Influence of Cracks on Chloride Ingress into Concrete 


\section{SS1D1}

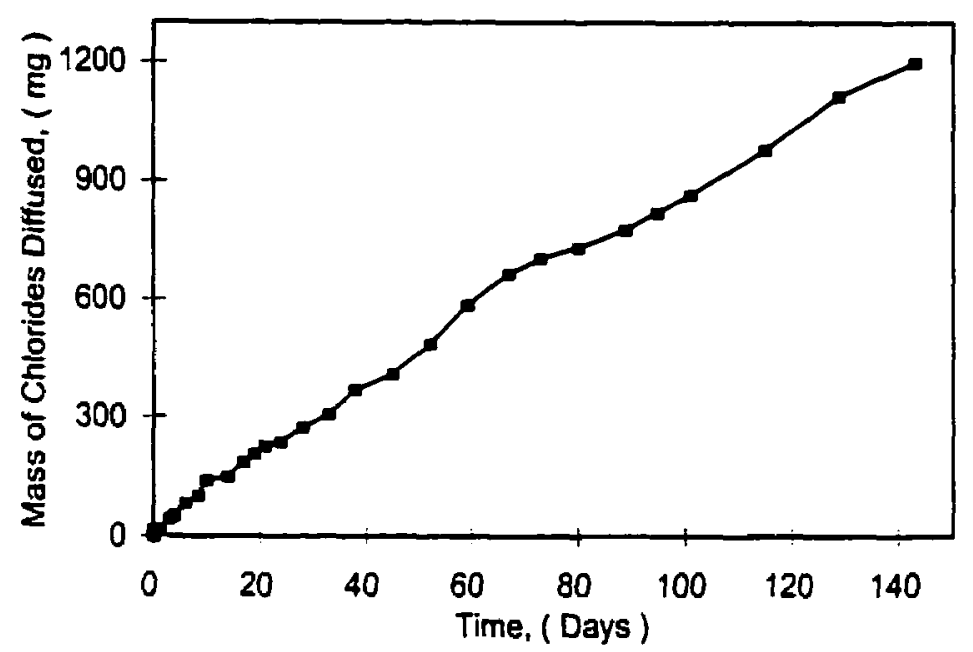


Sample: SSID2

Test: Diffusion Cell

$25 \%$ Slag, $0.078 \mathrm{~mm}$ Smooth Crack

Cell Volume:

$0.620 \mathrm{~L}$

Diameter:

$0.101 \mathrm{~m}$

Thickness:

$0.039 \mathrm{~m}$

Calculated Crack Width: $\quad 1.079 \mathrm{~mm}$

Data:

\begin{tabular}{|c|c|c|c|c|}
\hline $\begin{array}{l}\text { Day } \\
\text { Month } \\
\text { Year }\end{array}$ & Hour & $\begin{array}{l}\text { Elapsed } \\
\text { Time, } \\
\text { (Days) }\end{array}$ & $\begin{array}{l}\text { Oownst. } \\
\text { Conc., } \\
\text { (mg/L) }\end{array}$ & $\begin{array}{l}\text { Mass } \\
\text { Passed, } \\
\text { (mg) }\end{array}$ \\
\hline 18-Feb-00 & 03:25 PM & 0.00 & 0.00 & 0.00 \\
\hline 18-Feb-00 & 04:20 PM & 0.04 & 17.10 & 10.60 \\
\hline $18-F e b-00$ & 06:05 PM & 0.11 & 30.90 & 19.33 \\
\hline 19-Feb-00 & 05:47 PM & 1.10 & 32.70 & 20.75 \\
\hline 21-Feb-00 & 05:44 PM & 3.10 & 78.80 & 49.66 \\
\hline 22-Feb-00 & $12: 48 \mathrm{PM}$ & 3.89 & 86.90 & 55.47 \\
\hline 24-Feb-00 & 01:51 PM & 5.93 & 143.70 & 91.56 \\
\hline 26-Feb-00 & 11:33 PM & 8.34 & 176.10 & 113.08 \\
\hline 28-Feb-00 & 01:17 PM & 9.91 & 215.30 & 139.15 \\
\hline 01-Mar-00 & 01:25 PM & 11.92 & 226.90 & 148.49 \\
\hline 03-Mar-00 & $01: 20 \mathrm{PM}$ & 13.91 & 268.90 & 176.80 \\
\hline $06-$ Mar-00 & 12:07 PM & 16.86 & 339.20 & 223.08 \\
\hline $08-$ Mar $=00$ & 02:10 PM & $\{8.95$ & 370.80 & 246.06 \\
\hline 10-Mar-00 & 01:58 PM & 20.94 & 414.90 & 277.11 \\
\hline 13-Mar-00 & $12: 25 \mathrm{PM}$ & 23.88 & 459.60 & 308.97 \\
\hline $17-\operatorname{Mar}=00$ & 02:35 PM & 27.97 & 518.80 & 350.27 \\
\hline 22-Mar-00 & 12:23 PM & 32.87 & 593.30 & 401.65 \\
\hline 27-Mar-00 & 12:55 PM & 37.90 & 641.80 & 437.66 \\
\hline 03-Apr-00 & 02:39 PM & 44.97 & 706.10 & 483.94 \\
\hline 10-Apr-00 & 04:43 PM & 52.05 & 846.10 & 577.80 \\
\hline 17-Apr-00 & 08:24 PM & 59.21 & 899.90 & 619.62 \\
\hline 25-Apr-00 & $12: 56 \mathrm{PM}$ & 66.90 & 1035.30 & 712.56 \\
\hline 01-May-00 & 12:26 PM & 72.88 & 1090.70 & 757.27 \\
\hline $08-$ Мау-00 & 01:20 PM & 79.91 & 1150.60 & 805.31 \\
\hline 17-May-00 & $10: 15 \mathrm{AM}$ & 88.78 & 1238.60 & 871.38 \\
\hline 23-May-00 & 01:10 PM & 94.91 & 1288.40 & 914.64 \\
\hline 29-May-00 & $01: 30 \mathrm{PM}$ & 100.92 & 1332.00 & 954.55 \\
\hline 12-Jun-00 & $12: 15 \mathrm{PM}$ & 114.87 & 1483.50 & 1061.80 \\
\hline 26-Jun-00 & $11: 20 \mathrm{AM}$ & 128.83 & 1567.10 & 1128.47 \\
\hline $10-J u l-00$ & 04:25 PM & 143.04 & 1651.50 & 1196.47 \\
\hline
\end{tabular}

Inluence of Cracks on Chloride Ingress into Concrete 
SS1D2

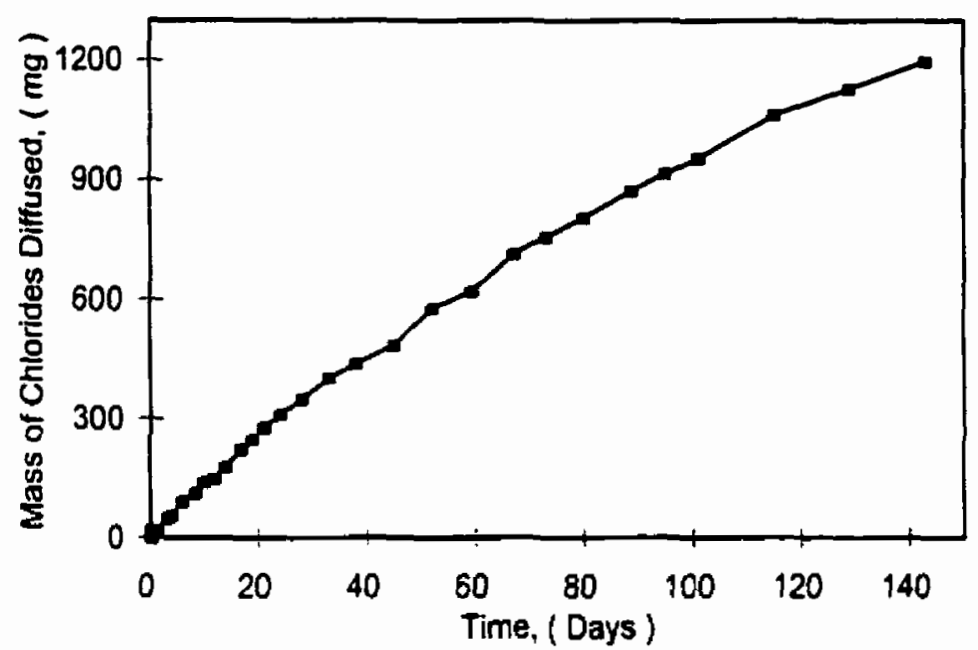




\title{
APPENDIX H
}

\section{Depth of Chloride Penetration}

\author{
VS TIME
}

INCLUDING AGGREGATE 


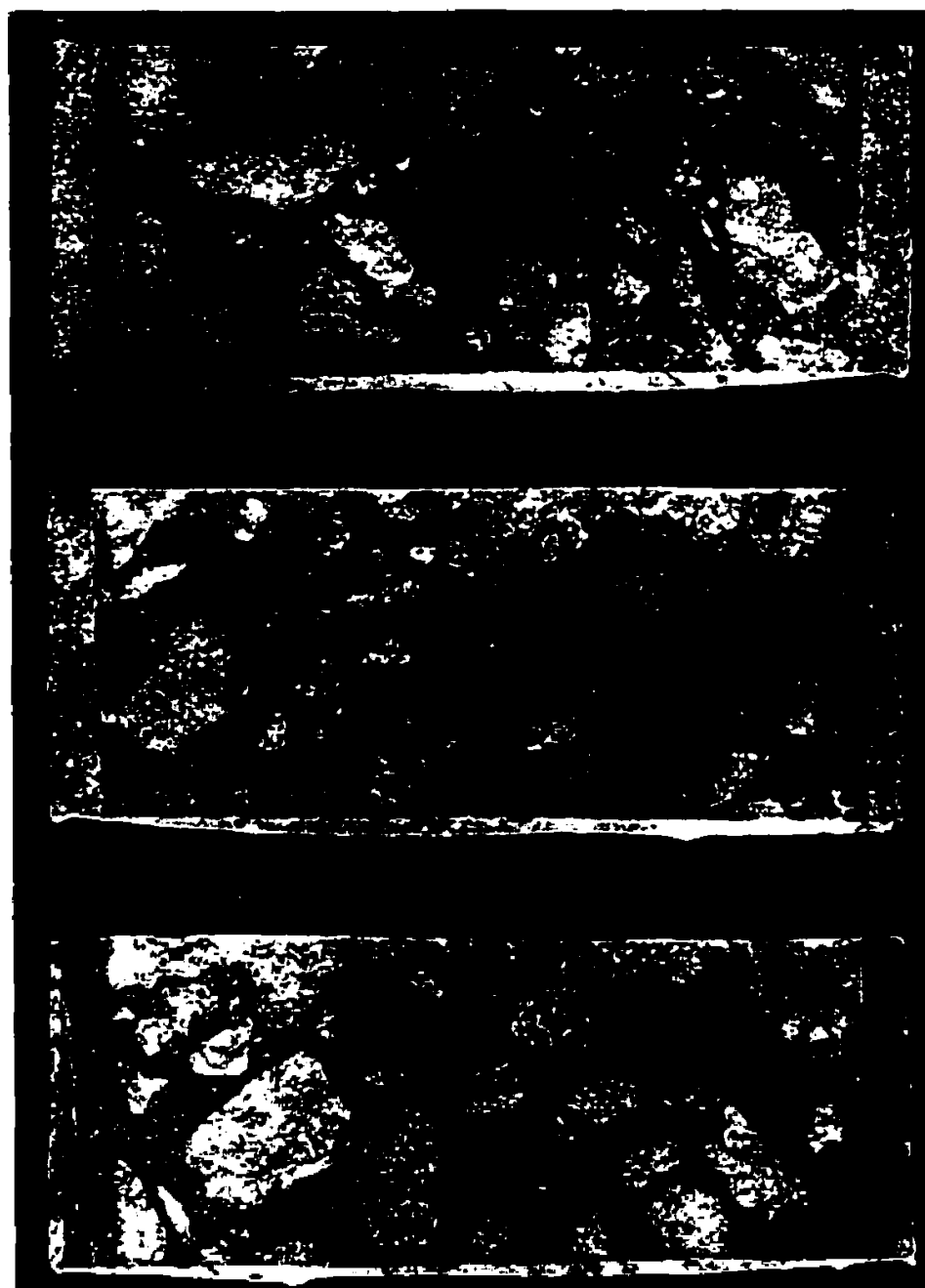

PNP5;

$\mathrm{V}=6.28 \mathrm{~mm}$.

PNP5;

$\mathrm{V}=6.33 \mathrm{~mm}$.

PNP6;

$\mathrm{V}=7.84 \mathrm{~mm}$.

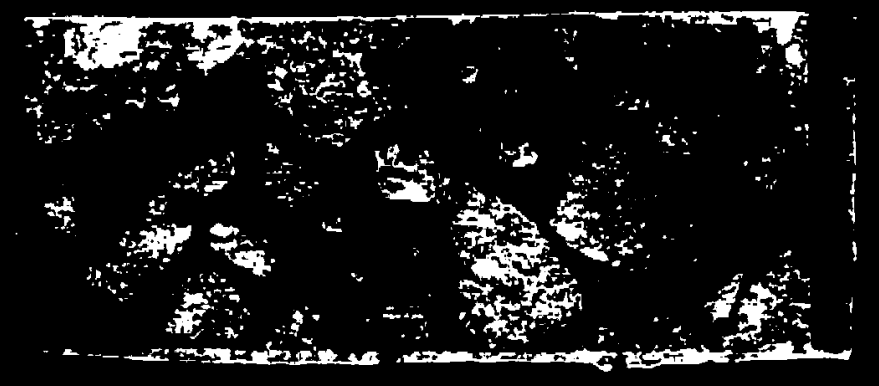

PNP6;

$\mathrm{V}=7.76 \mathrm{~mm}$.

$100 \%$ OPC, No Crack, 4 Days of Chloride Exposure 


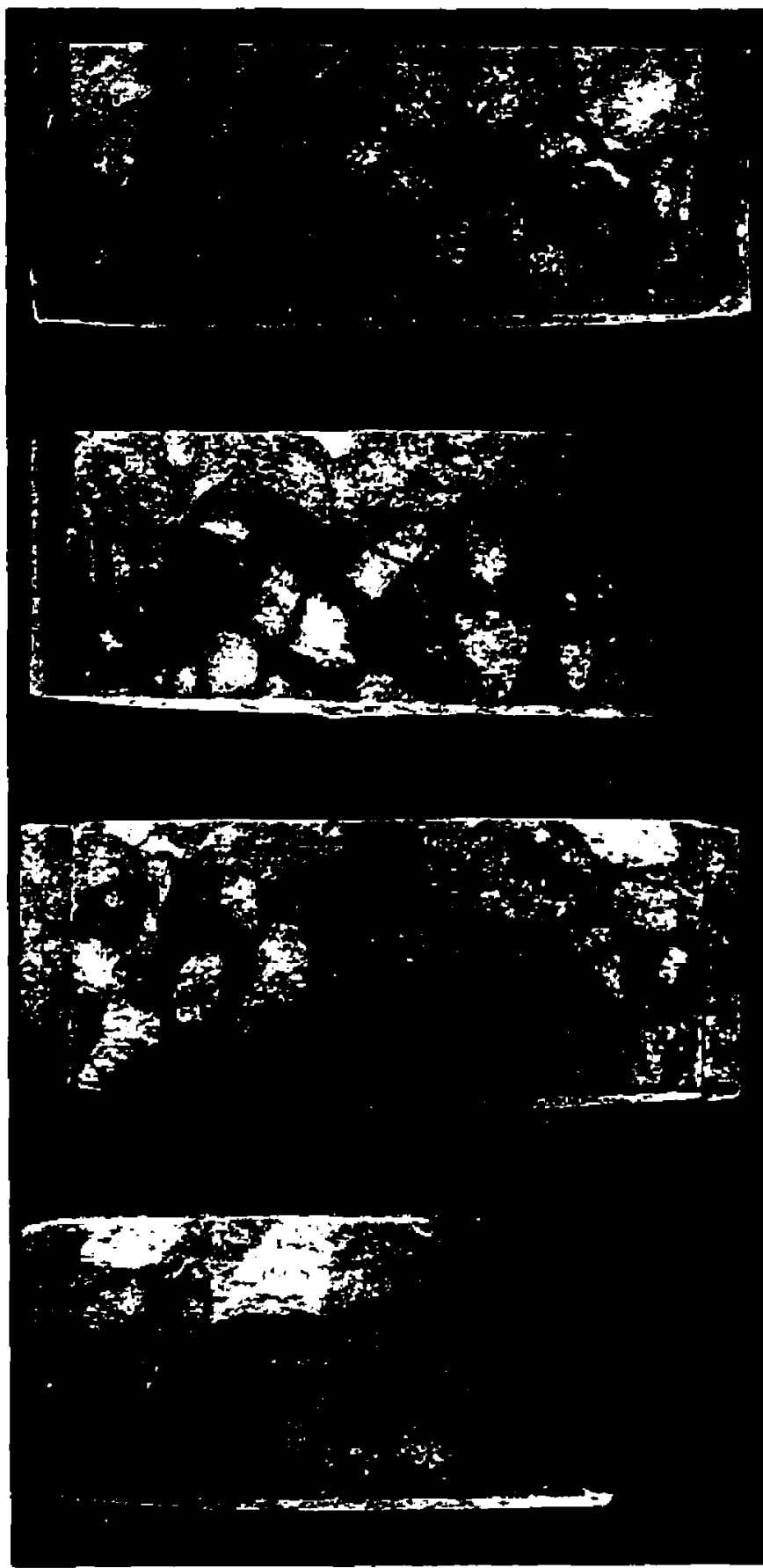

PNP7;

$\mathrm{V}=11.20 \mathrm{~mm}$.

PNP7;

$\mathrm{V}=11.53 \mathrm{~mm}$.

\section{PNP8;}

$\mathrm{V}=10.00 \mathrm{~mm}$.

PNP8;

$\mathrm{V}=9.53 \mathrm{~mm}$

$100 \%$ OPC, No Crack, 16 Days of Chloride Exposure 


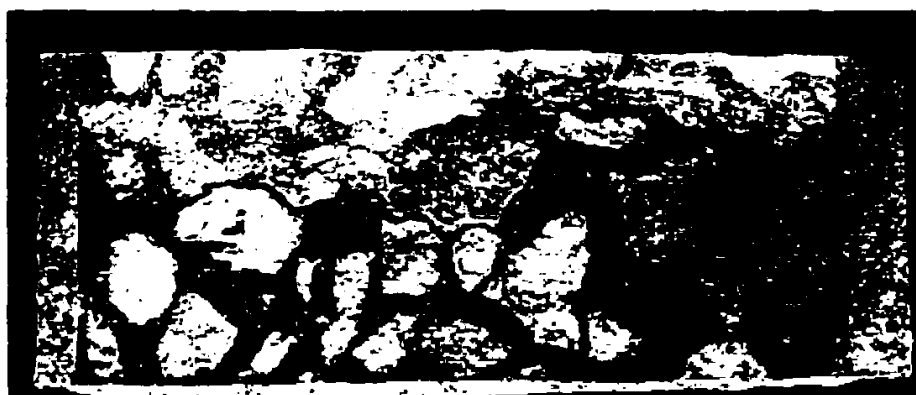

PNP3;

$\mathrm{V}=15.53 \mathrm{~mm}$

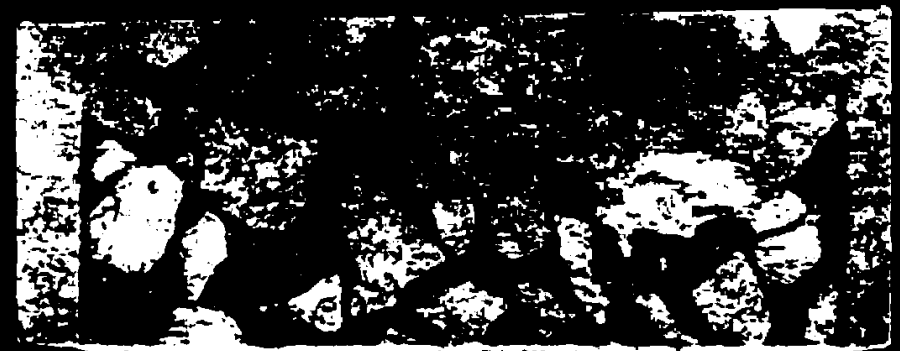

PNP3;

$V=18.17 \mathrm{~mm}$
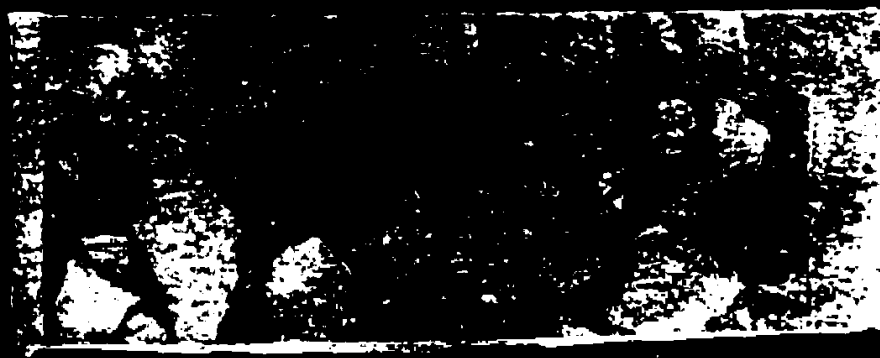

$\Leftrightarrow$ m

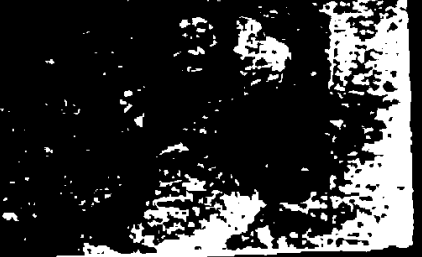

PNP4;

$\mathrm{V}=11.55 \mathrm{~mm}$

PNP4;

$\mathrm{V}=11.34 \mathrm{~mm}$

$100 \%$ OPC, No Crack, 36 Days of Chloride Exposure 


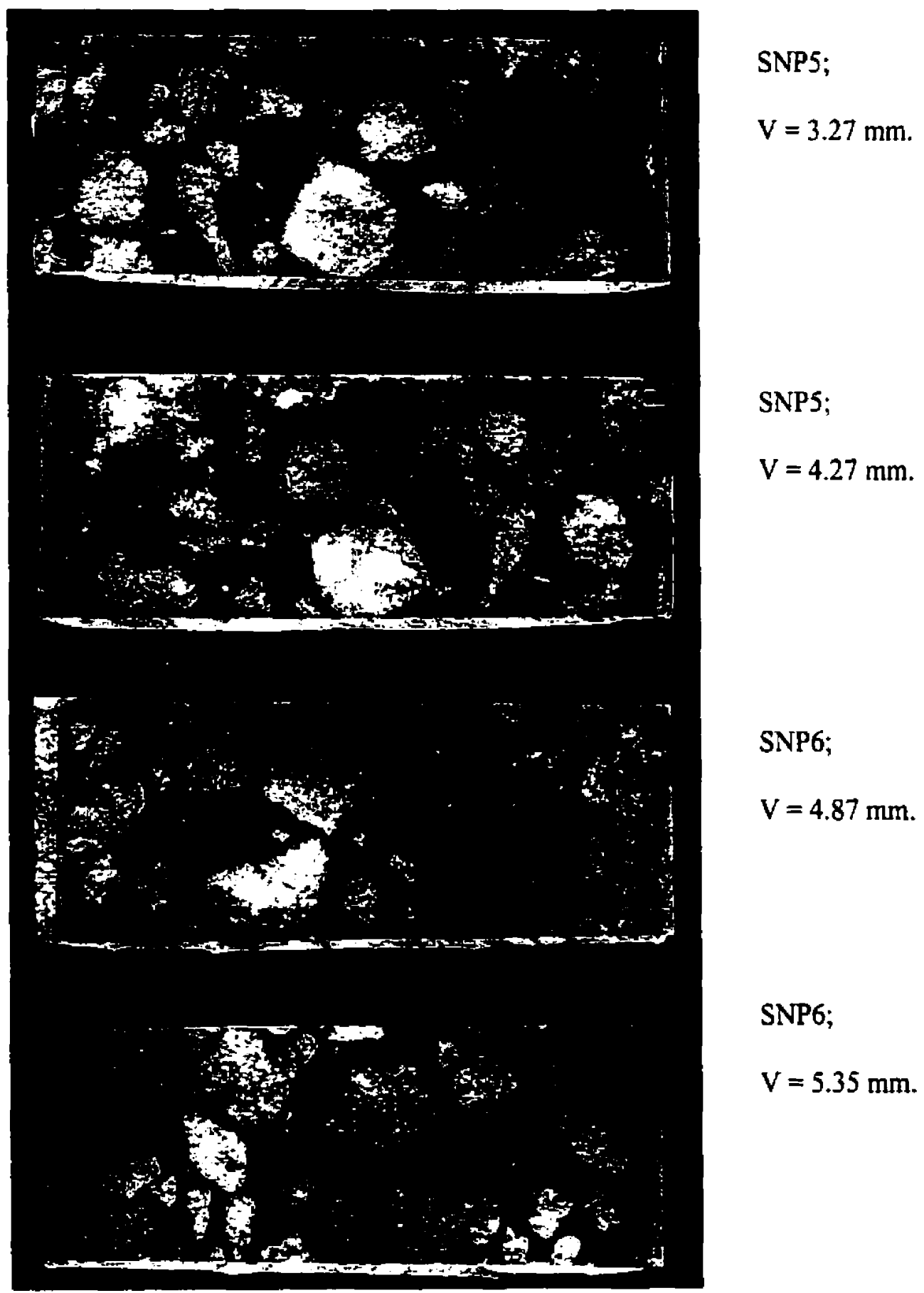

$25 \%$ Slag, No Crack, 4 Days of Chloride Exposure 


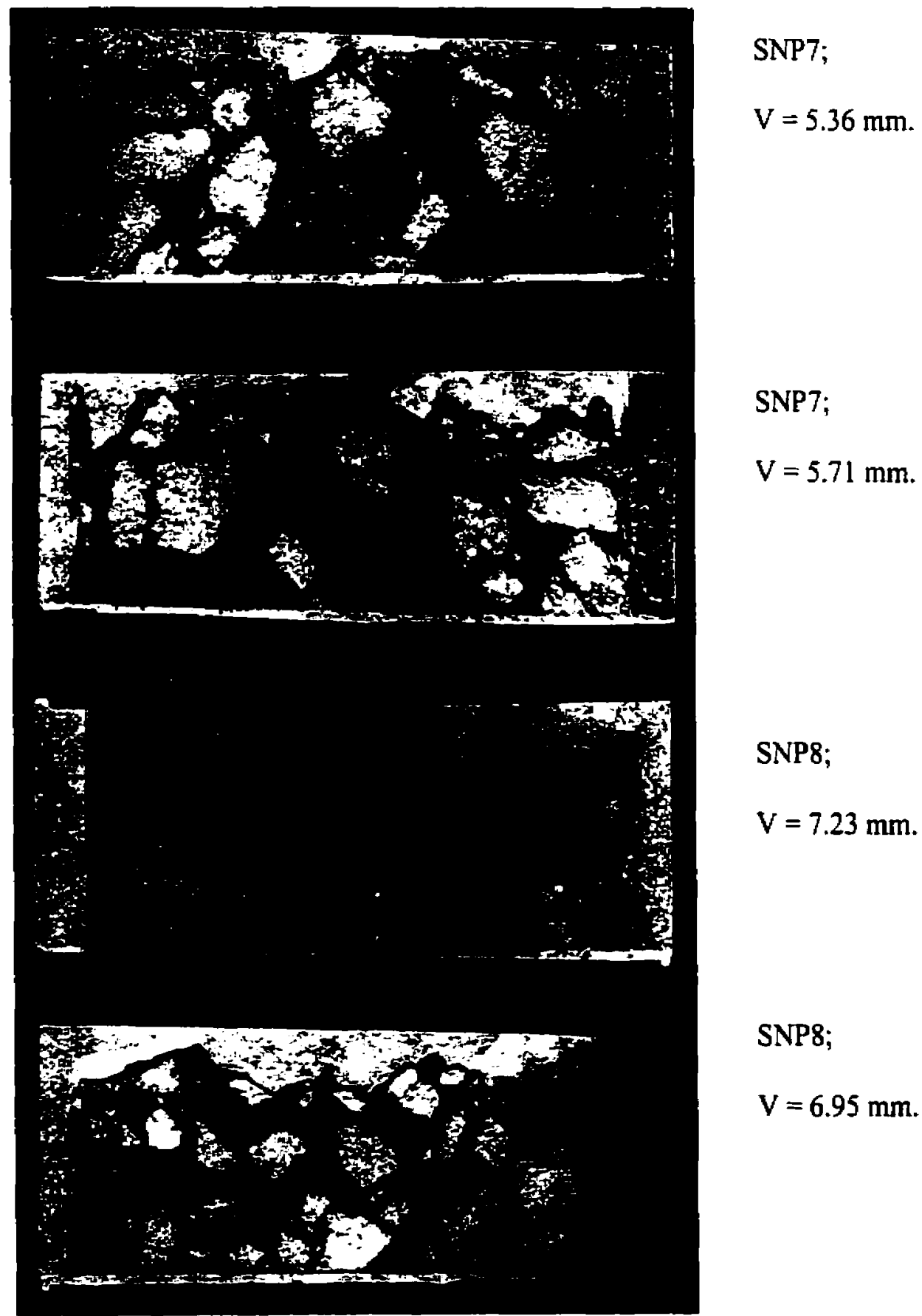

$25 \%$ Slag, No Crack, 16 Days of Chloride Exposure 


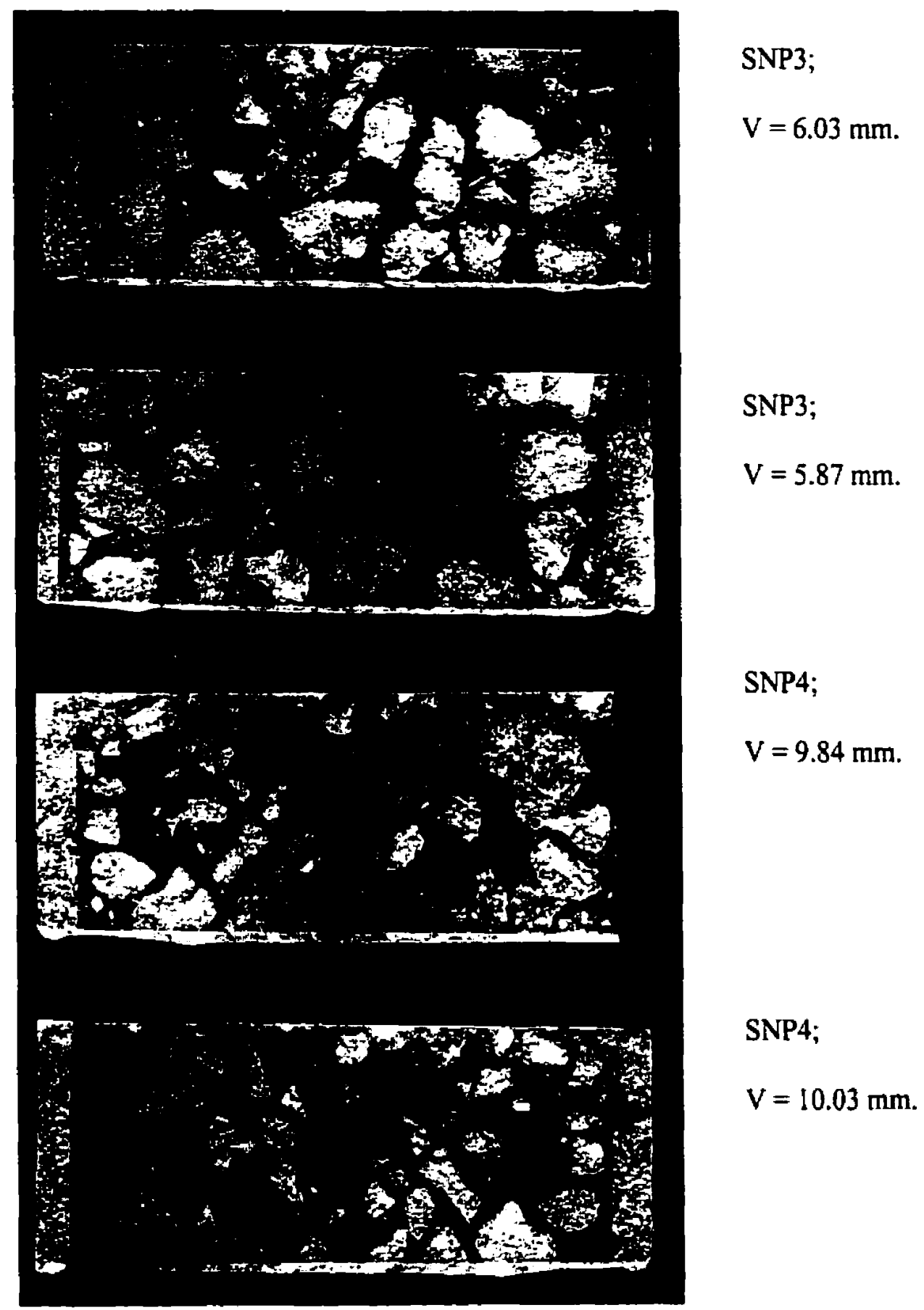

$25 \%$ Slag, No Crack, 36 Days of Chloride Exposure 


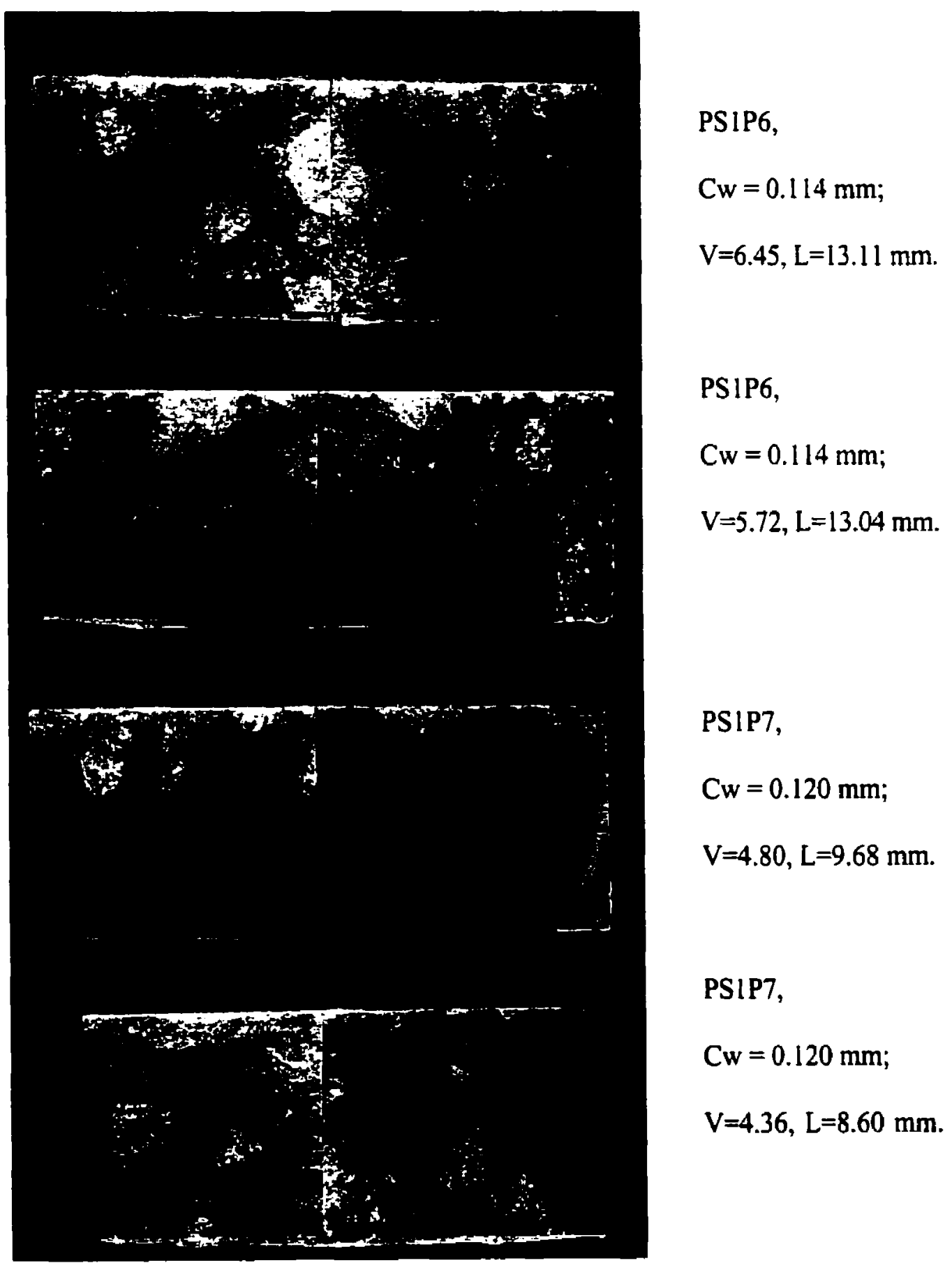

$100 \%$ OPC, Single Smooth Crack, 4 Days of Chloride Exposure 


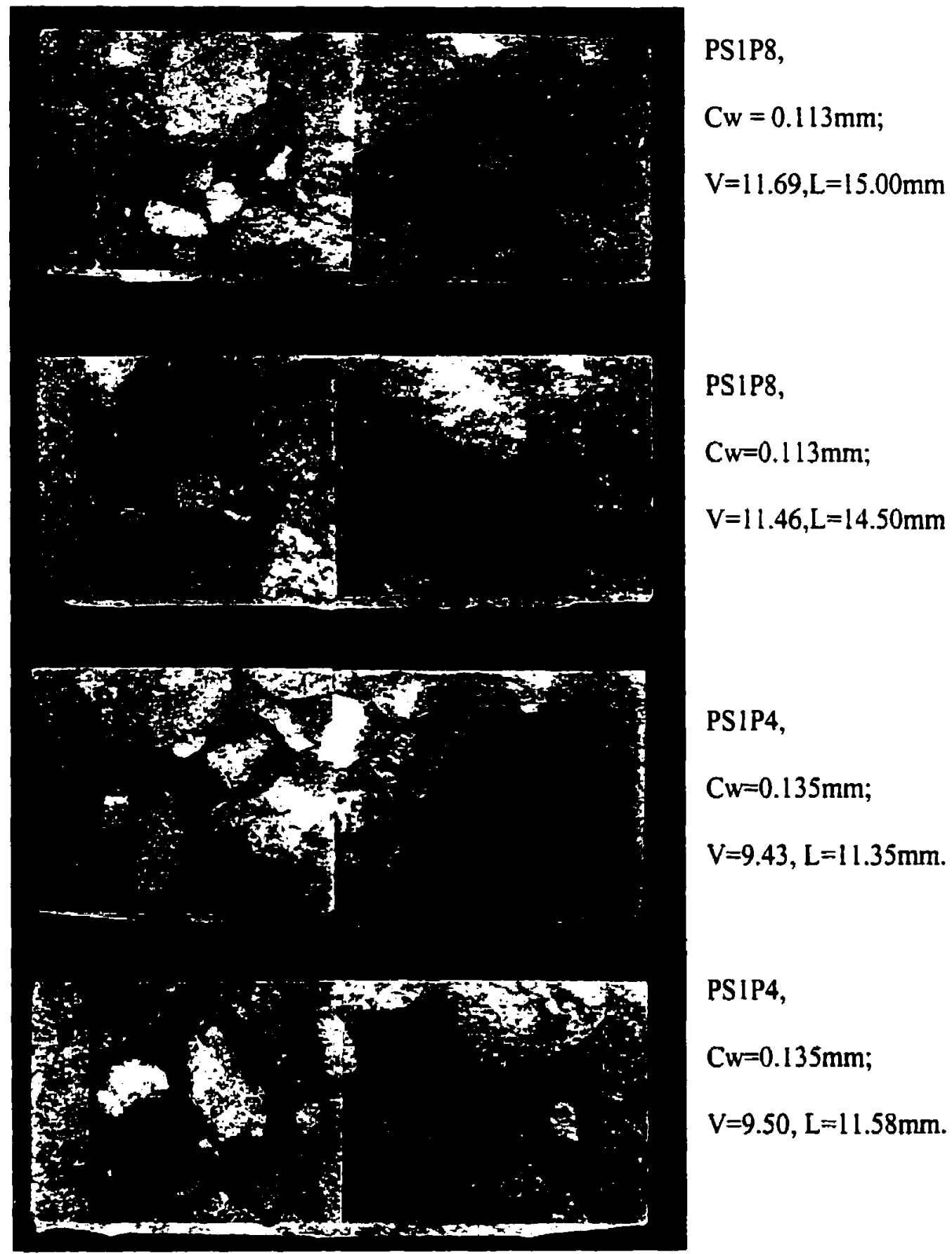

$100 \%$ OPC, Single Smooth Crack, 16 Days of Chloride Exposure 


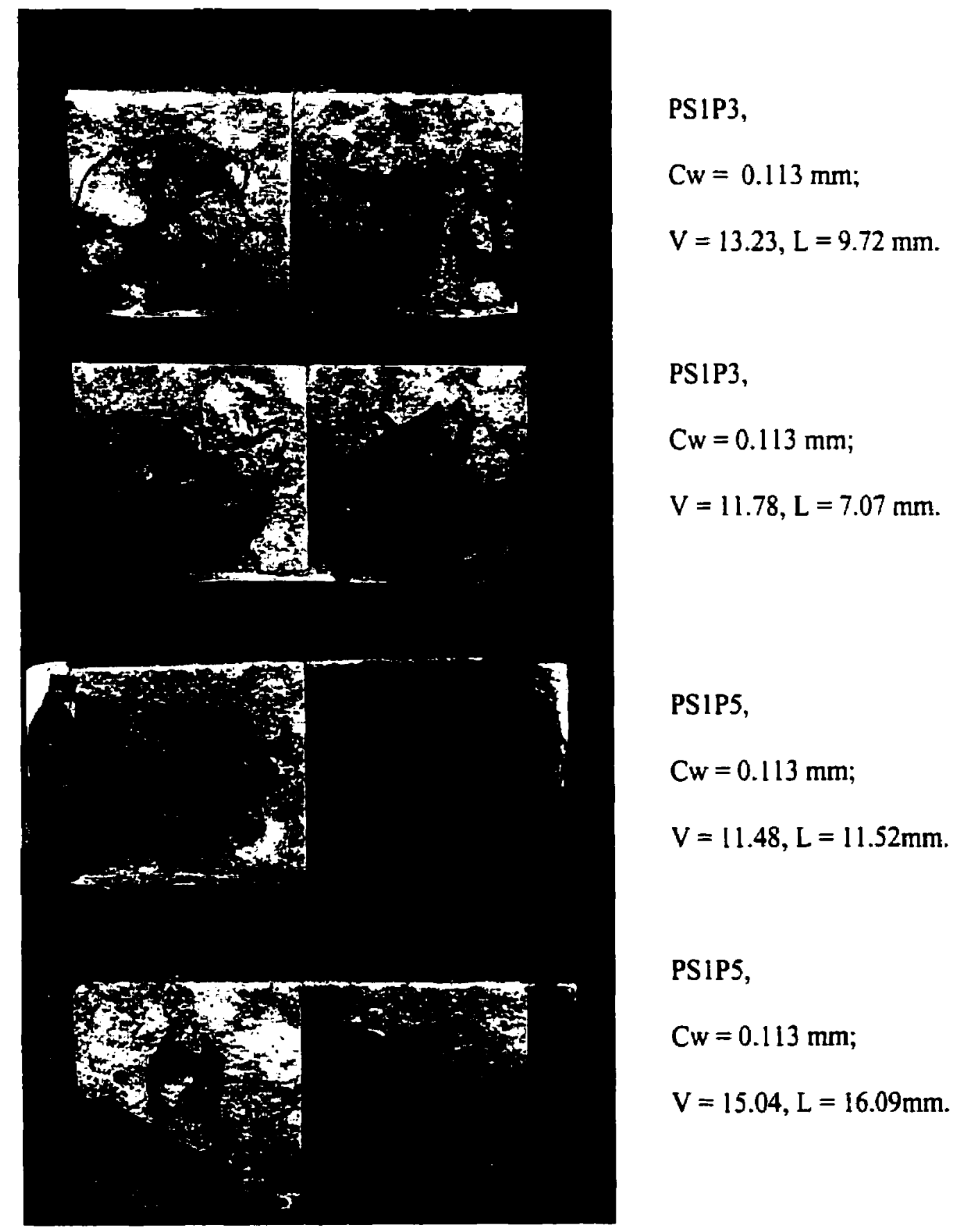

$100 \%$ OPC, Single Smooth Crack, 36 Days of Chloride Exposure 


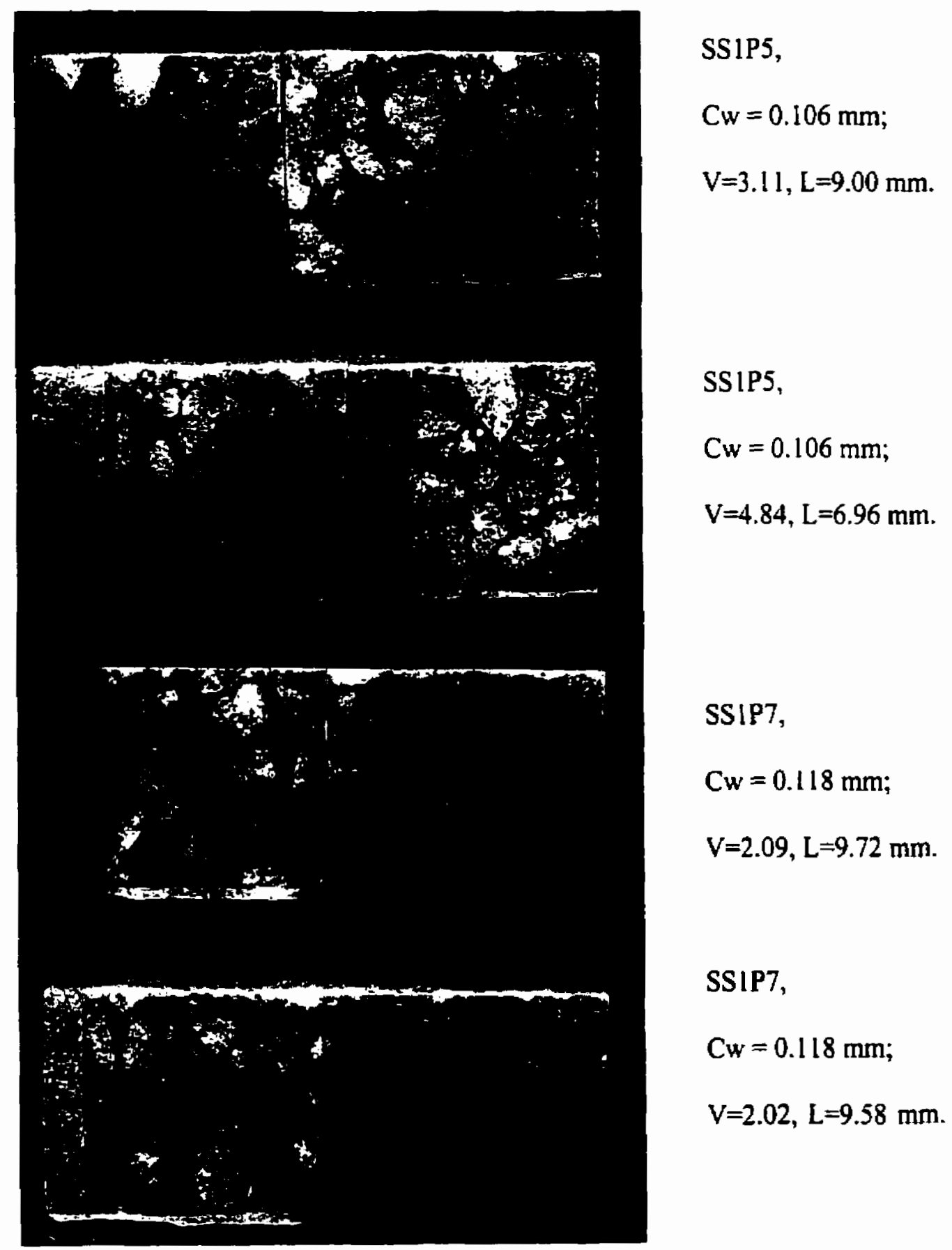

$25 \%$ Slag, Single Smooth Crack, 4 Days of Chloride Exposure 


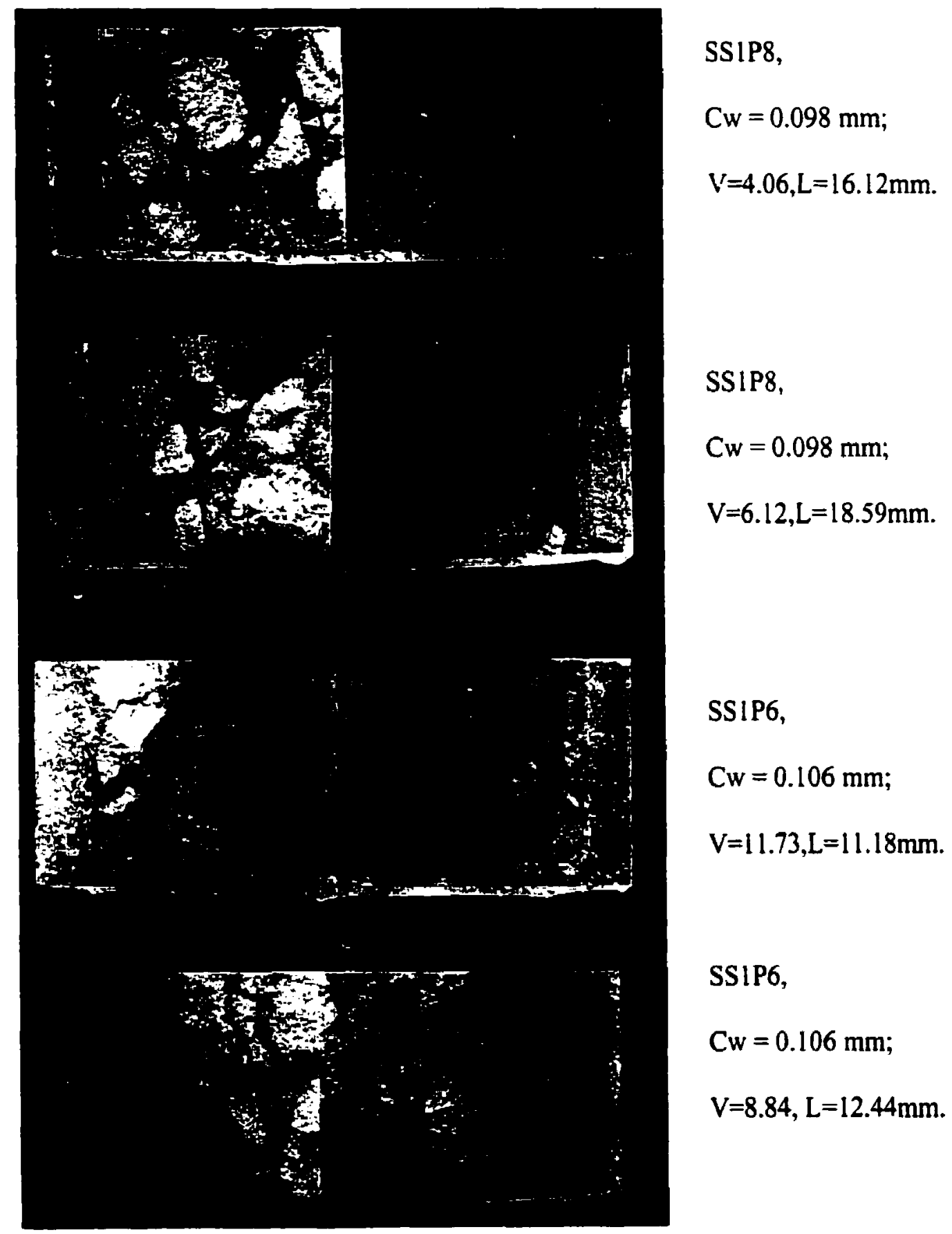

$25 \%$ Slag, Single Smooth Crack, 16 Days of Chloride Exposure 


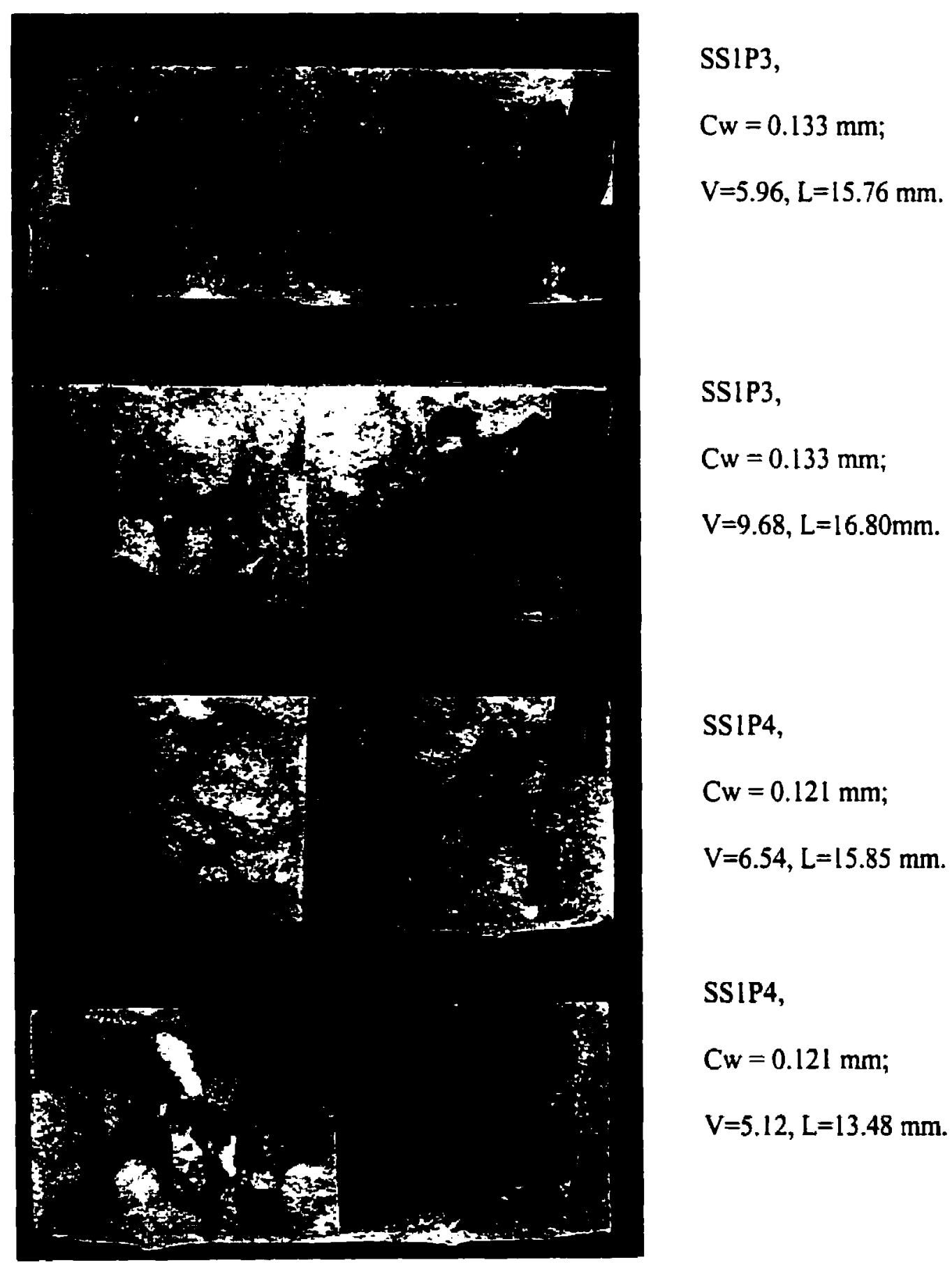

$25 \%$ Slag, Single Smooth Crack, 36 Days of Chloride Exposure 


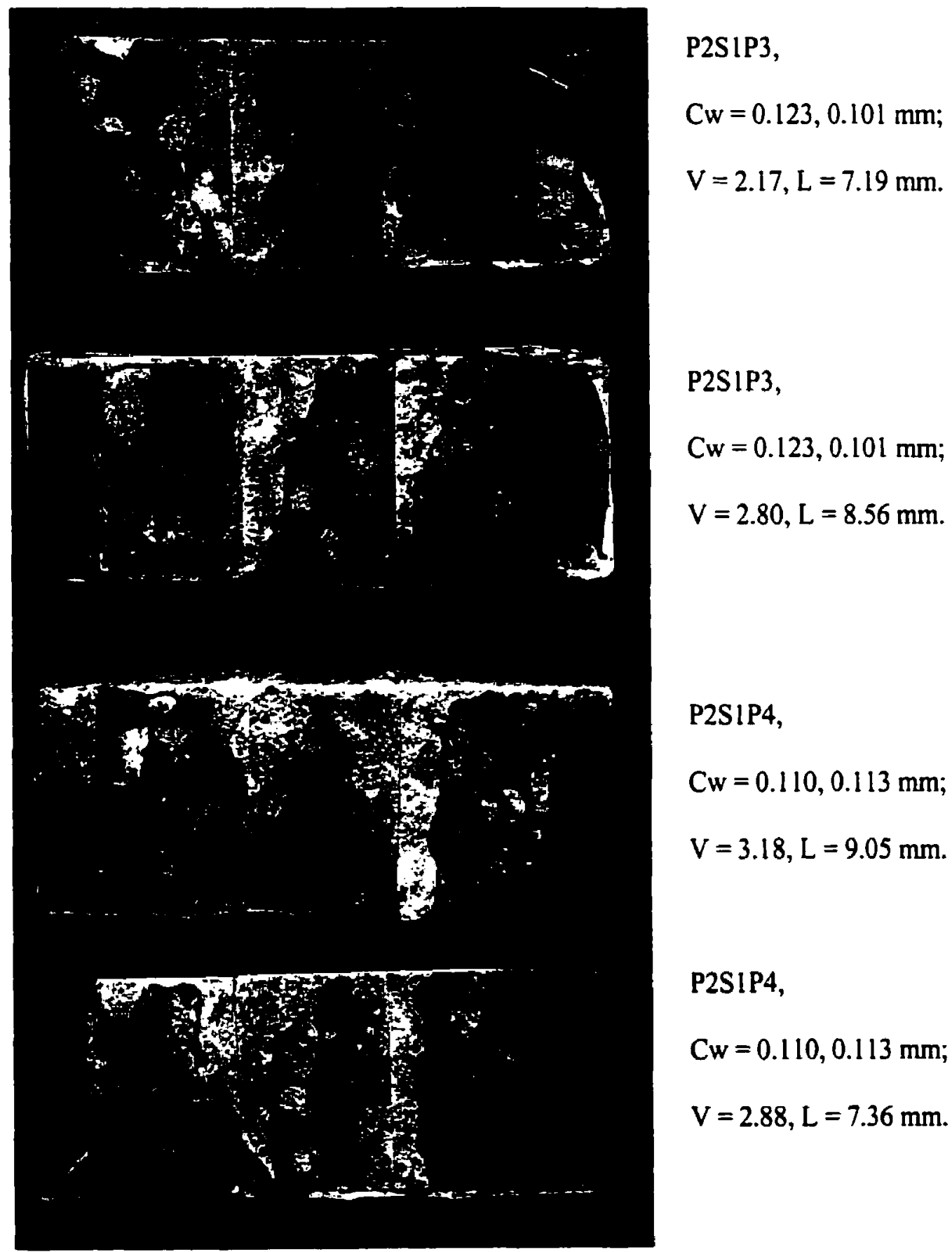

$100 \%$ OPC, Double Smooth Cracks, I Day of Chloride Exposure 


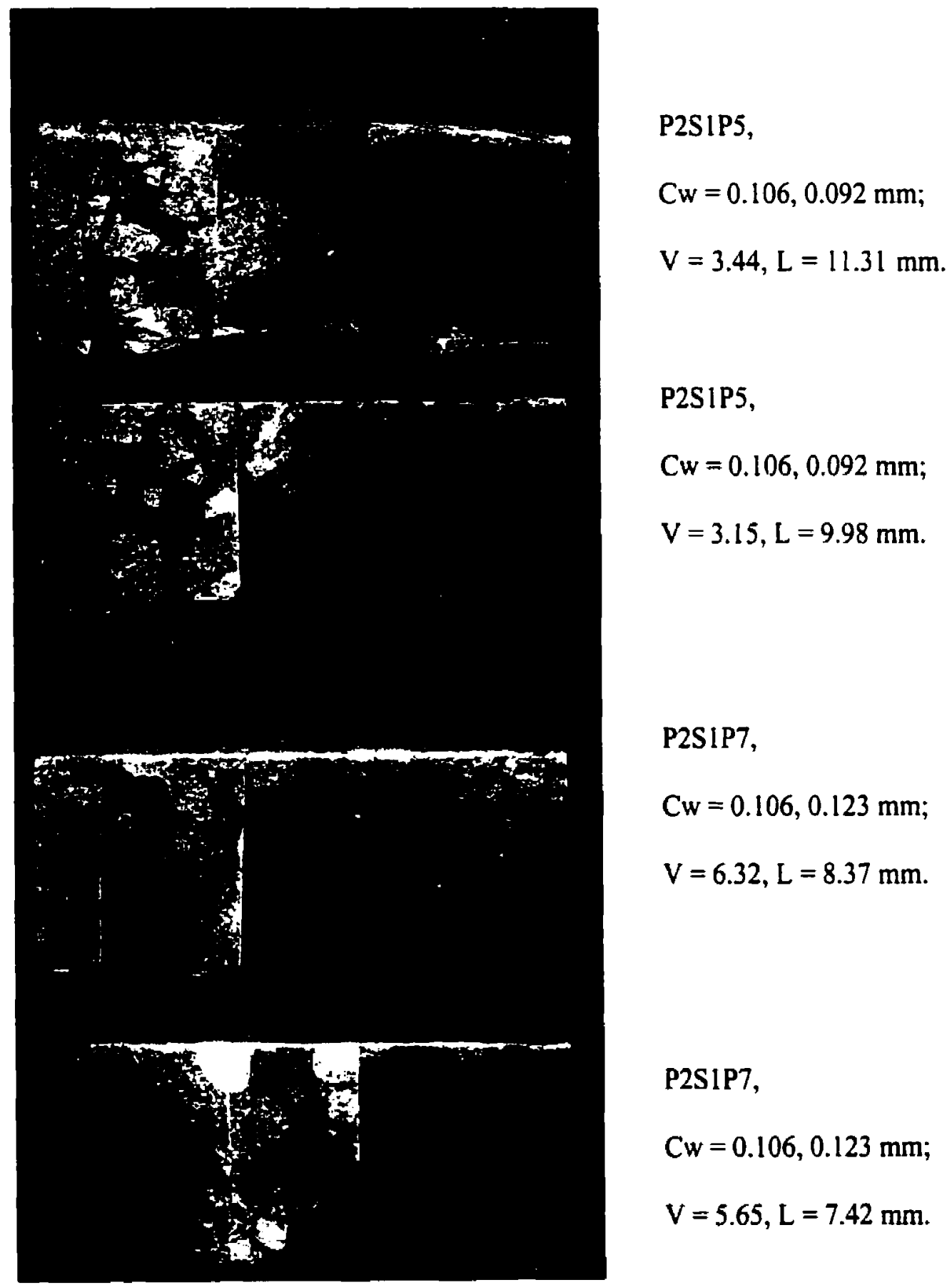

$100 \%$ OPC, Double Smooth Cracks, 4 Days of Chloride Exposure 


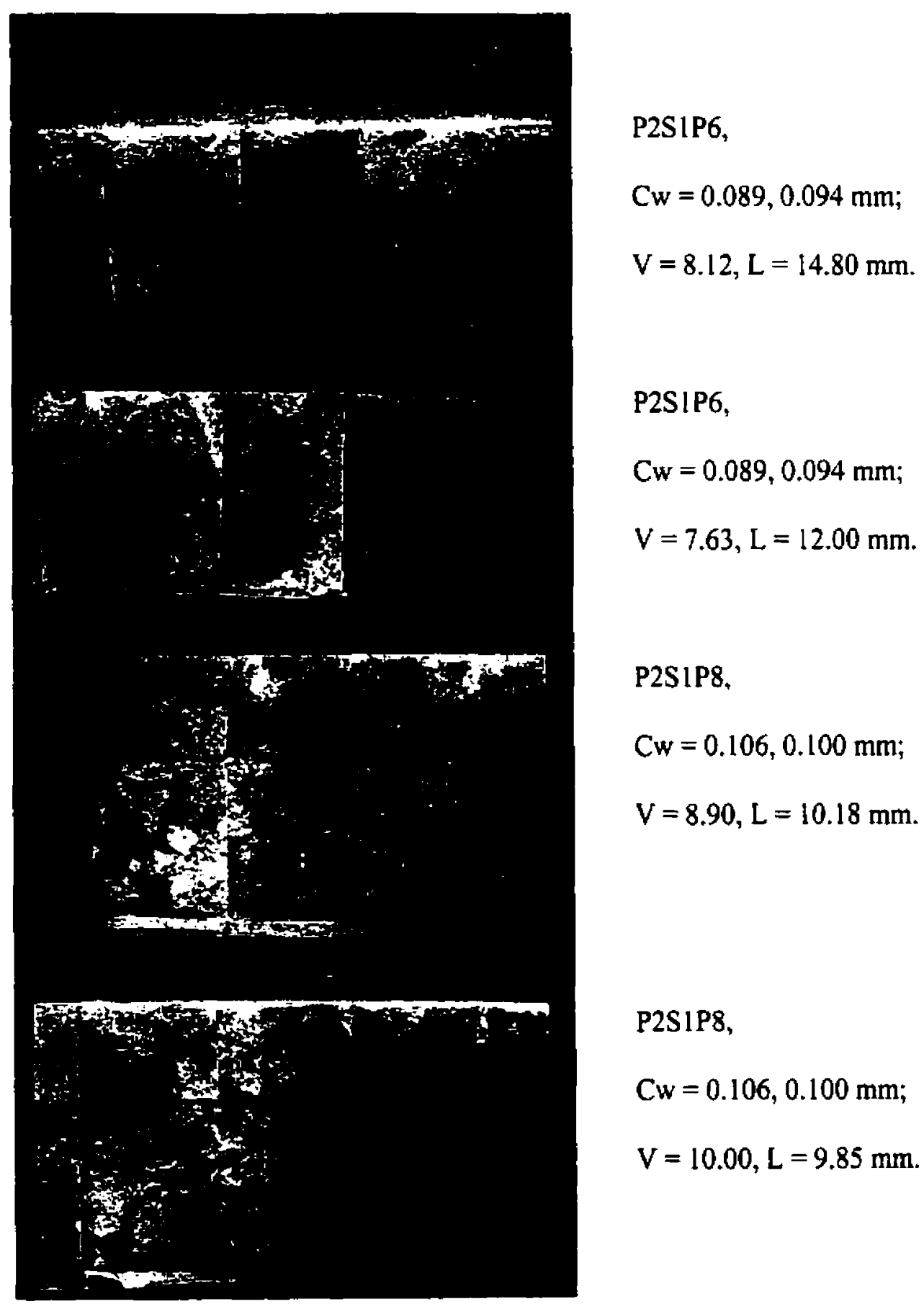

$100 \%$ OPC, Double Smooth Cracks, 7 Days of Chloride Exposure 


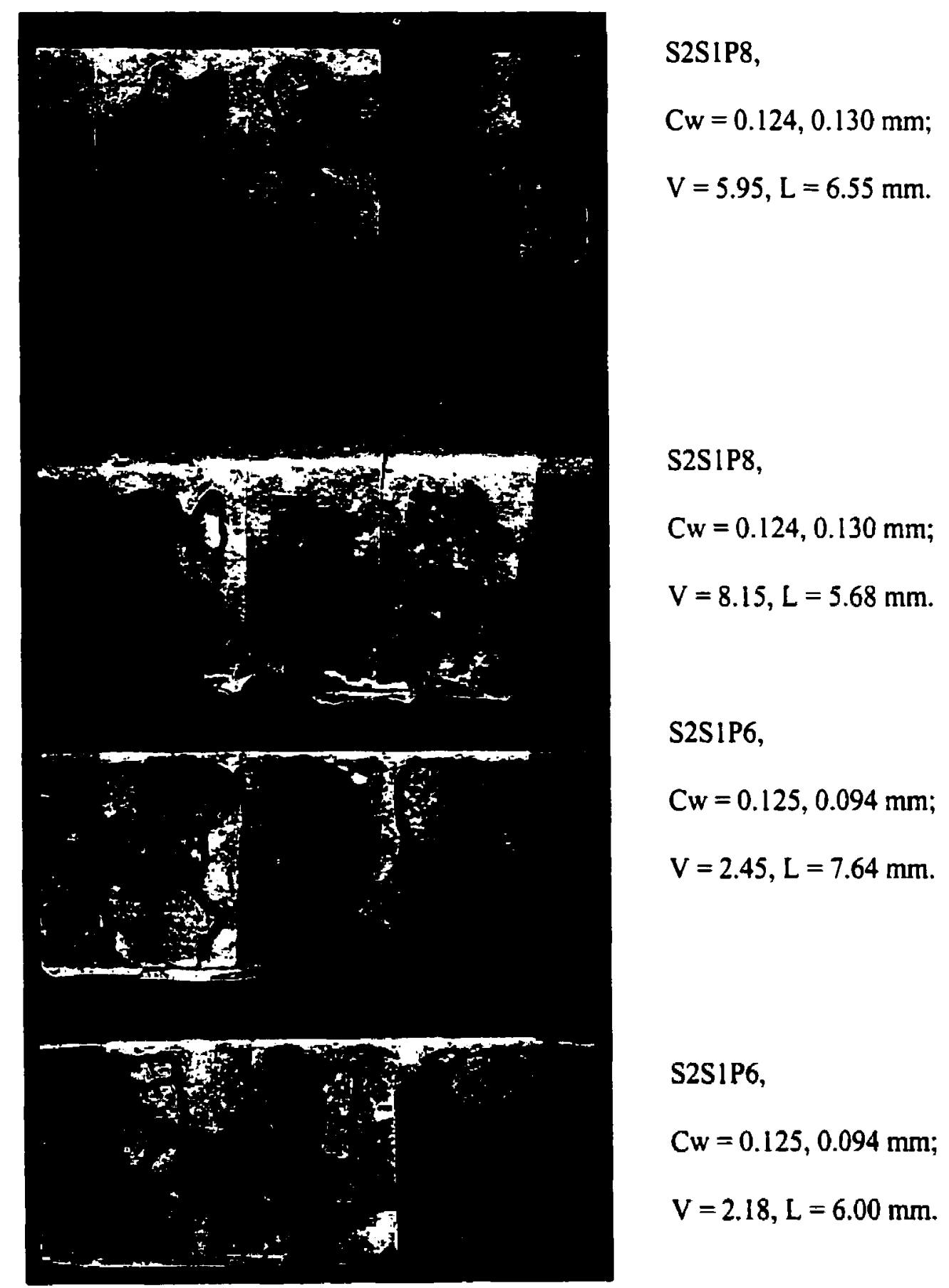

$25 \%$ Slag, Double Smooth Cracks, 4 Days of Chloride Exposure 


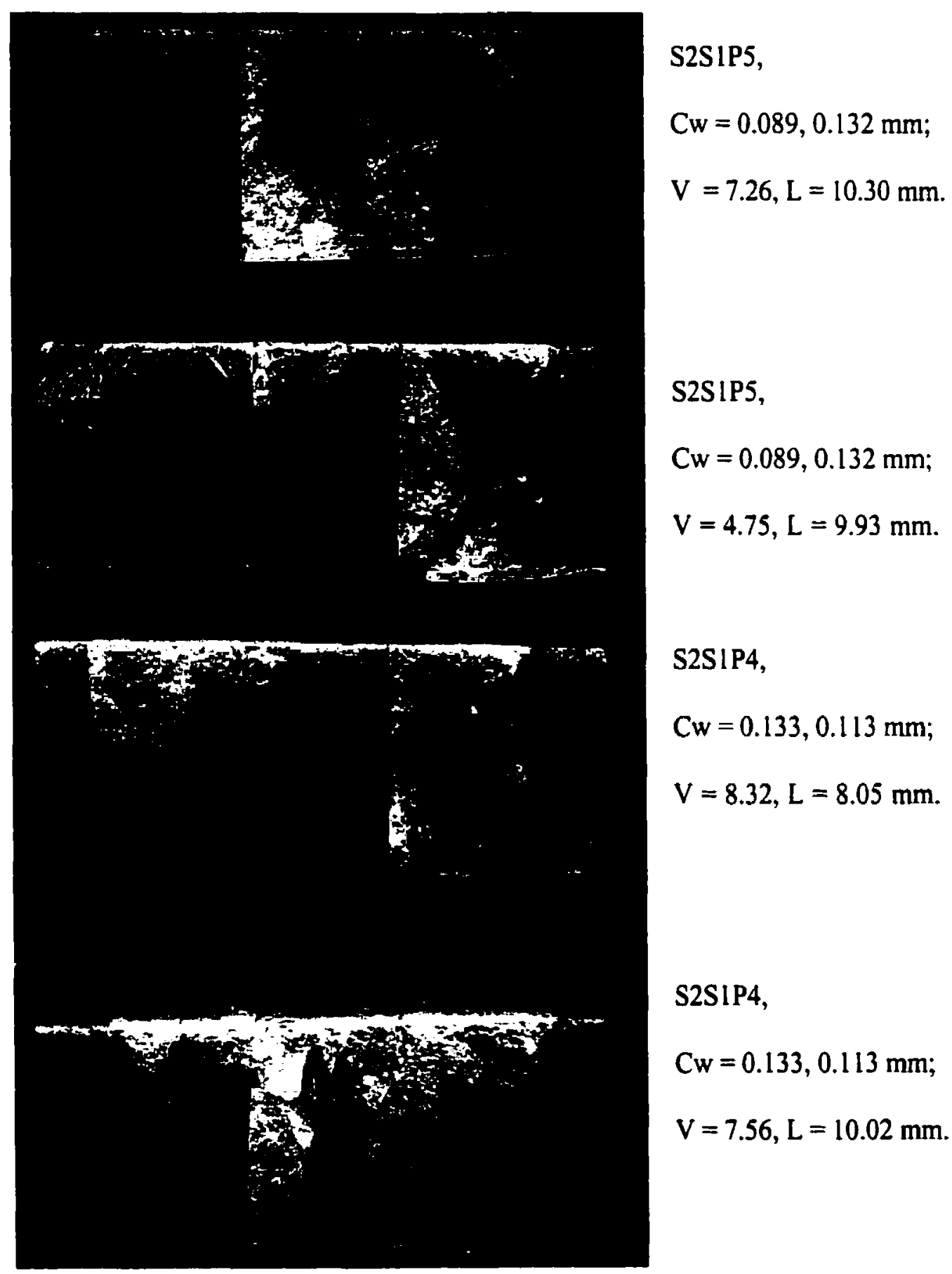

$25 \%$ Slag, Double Smooth Cracks, 7 Days of Chloride Exposure 


\title{
APPENDIX I
}

\section{Depth of Chloride Penetration}

\author{
VS TIME
}

EXCLUDING AGGREGATE 


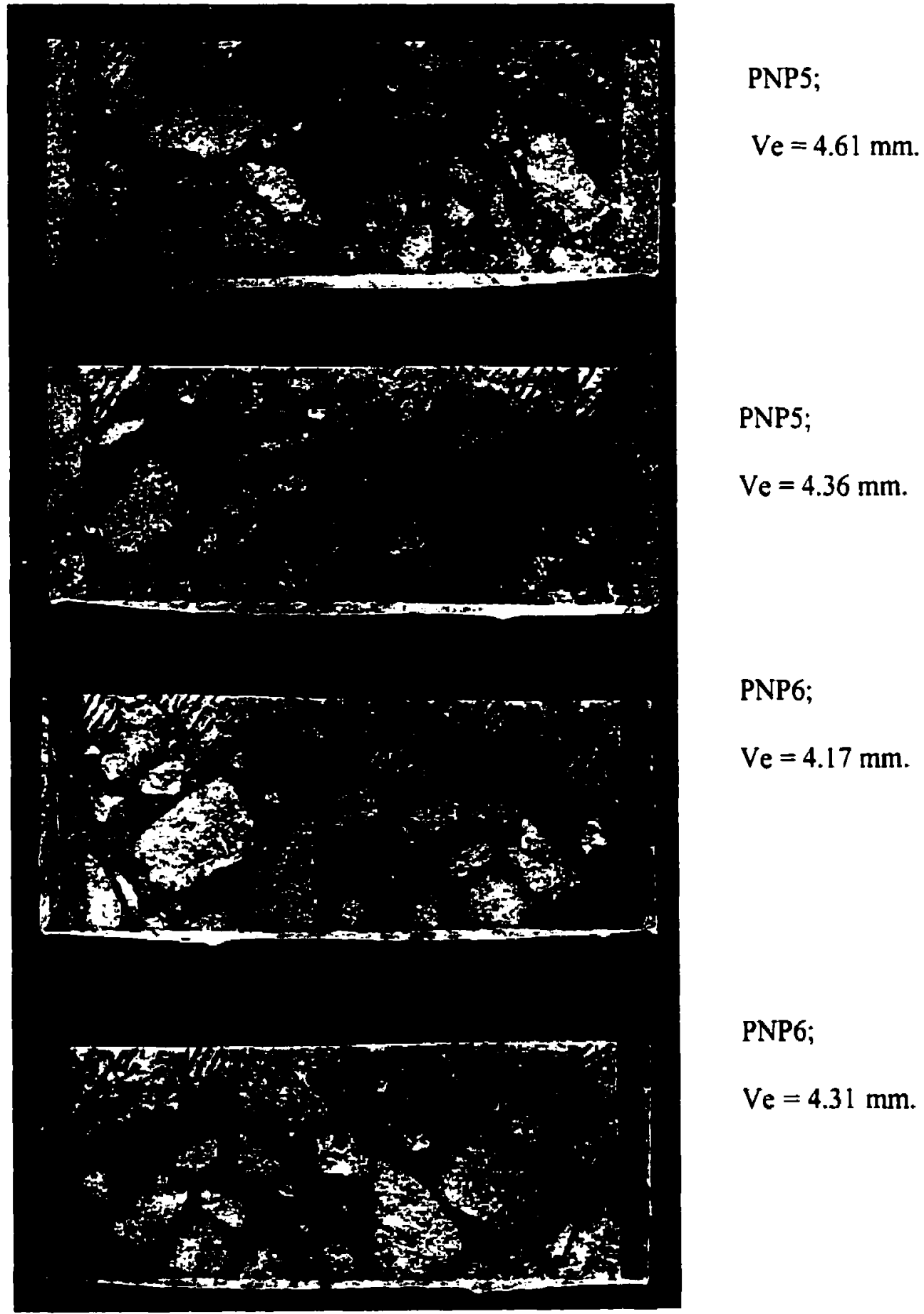

$100 \%$ OPC, No Crack, 4 Days of Chloride Exposure 


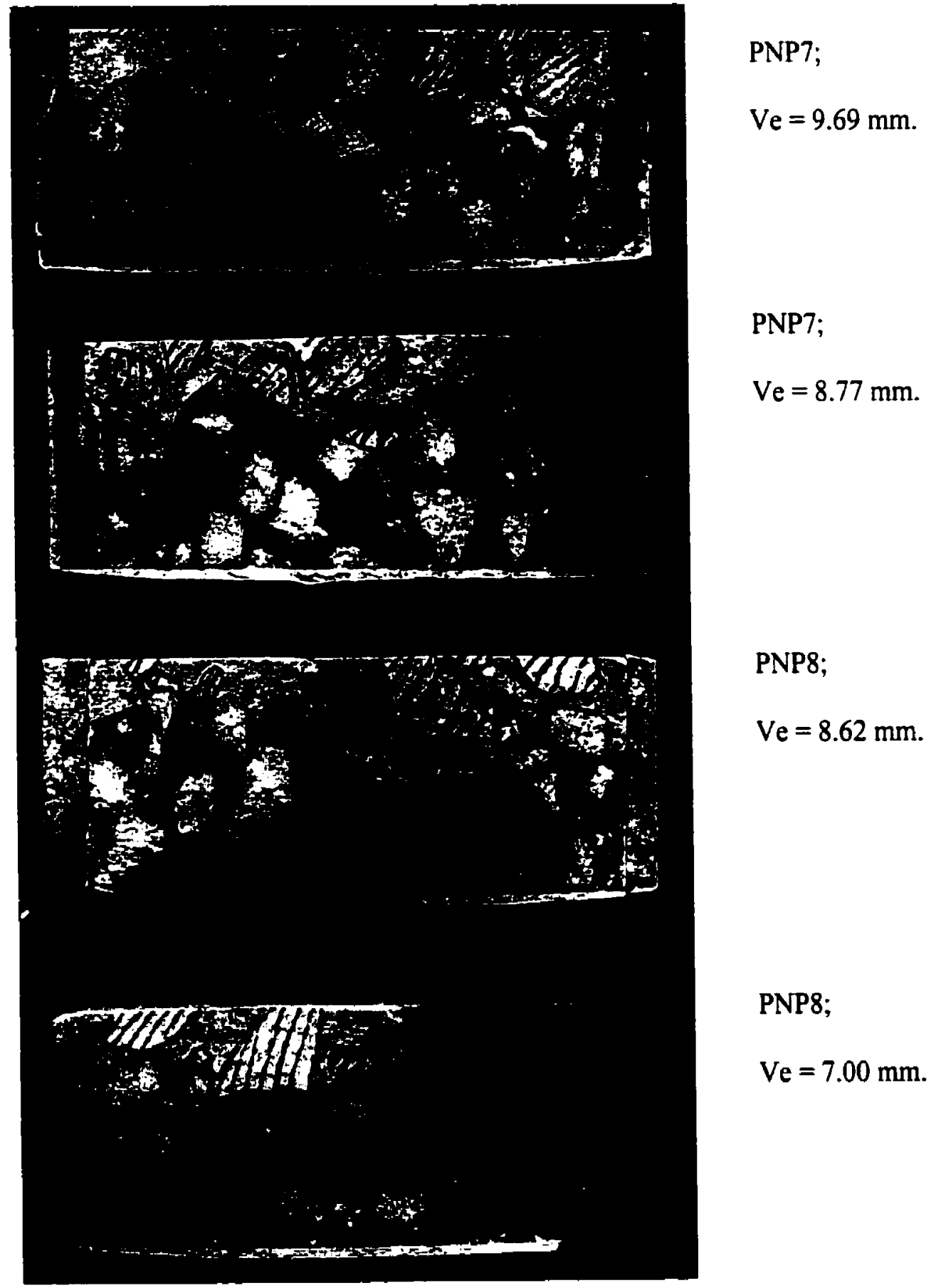

$100 \%$ OPC, No Crack, 16 Days of Chloride Exposure 


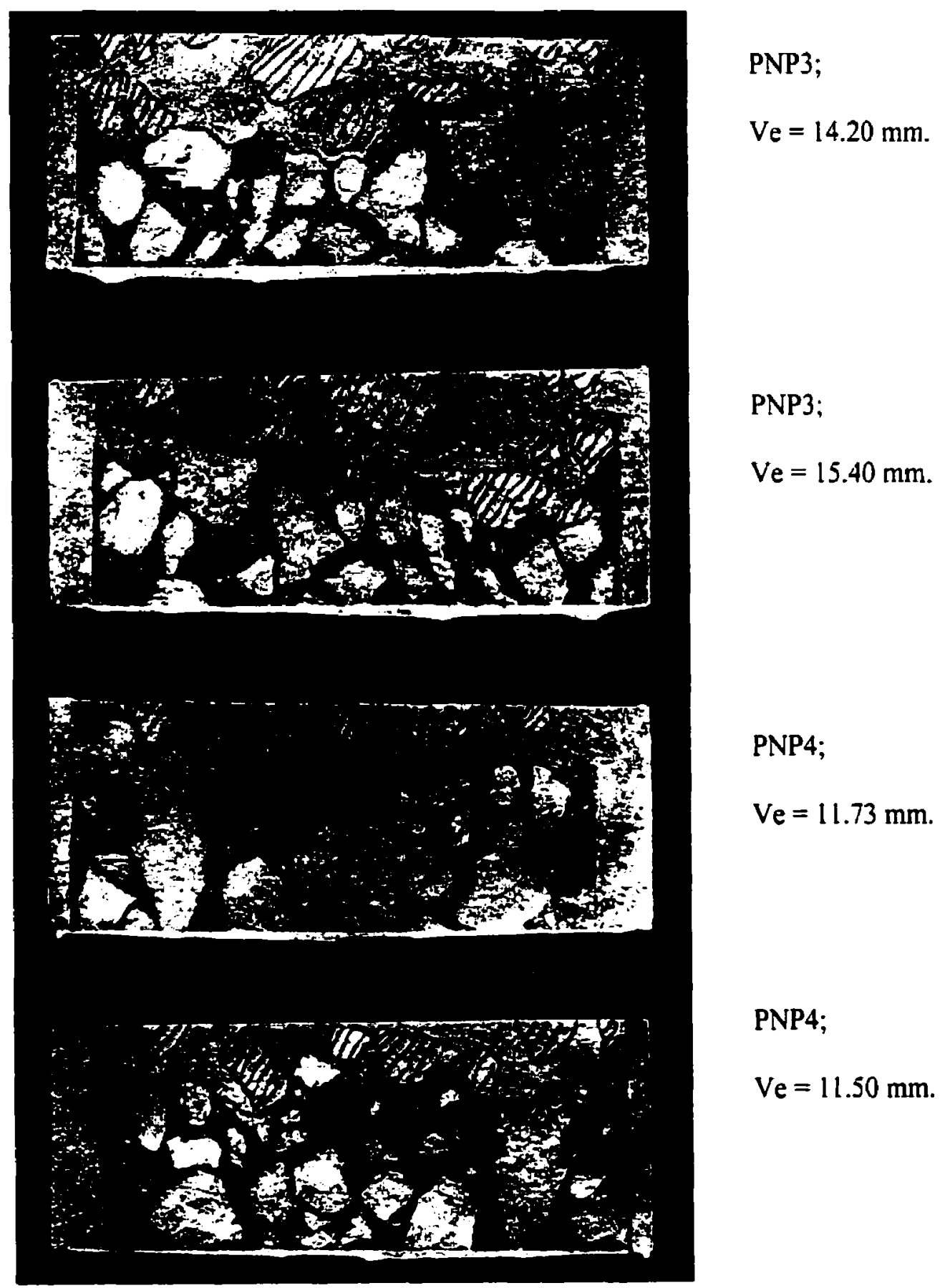

$100 \%$ OPC, No Crack, 36 Days of Chloride Exposure 


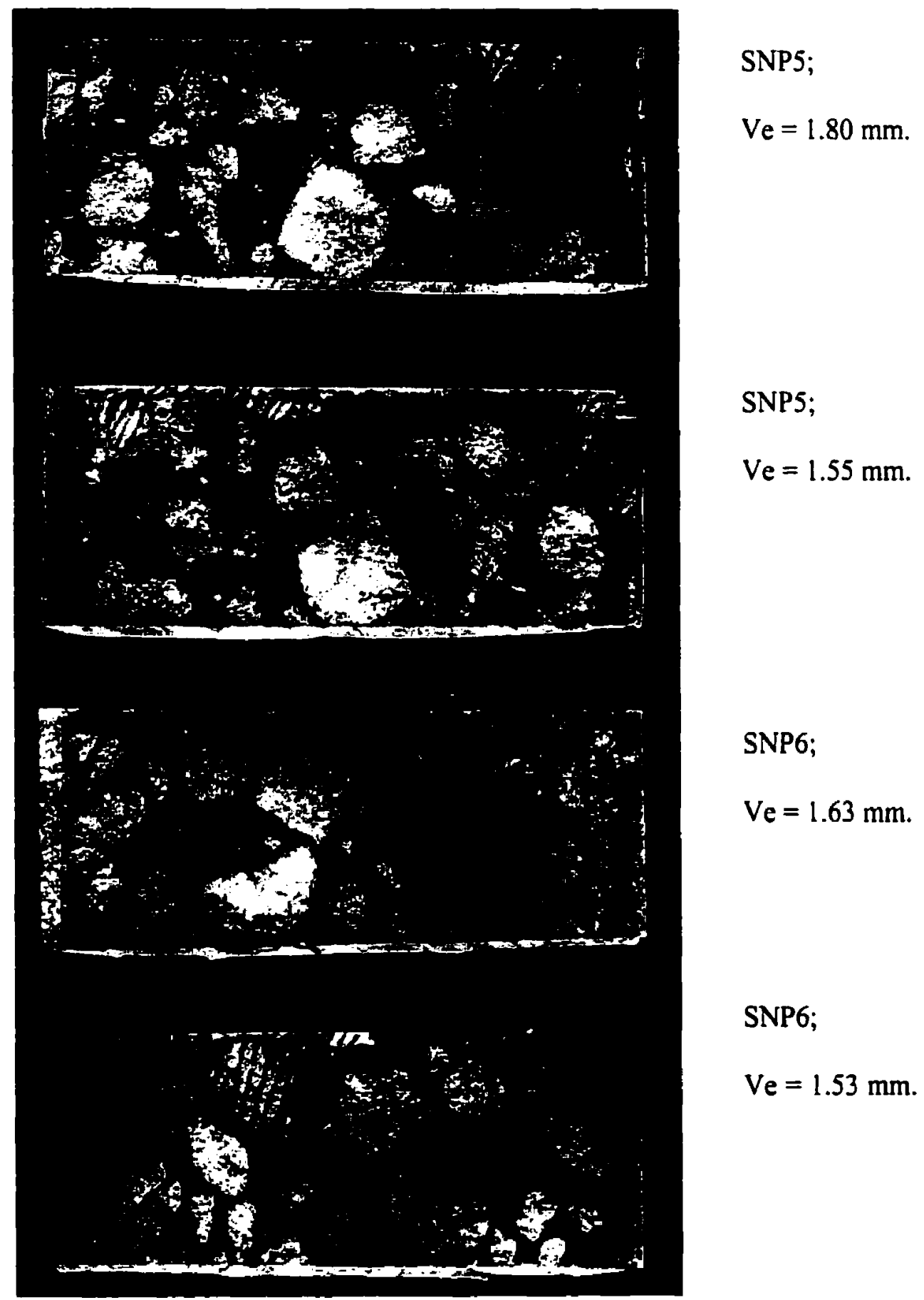

25 \% Slag, No Crack, 4 Days of Chloride Exposure 


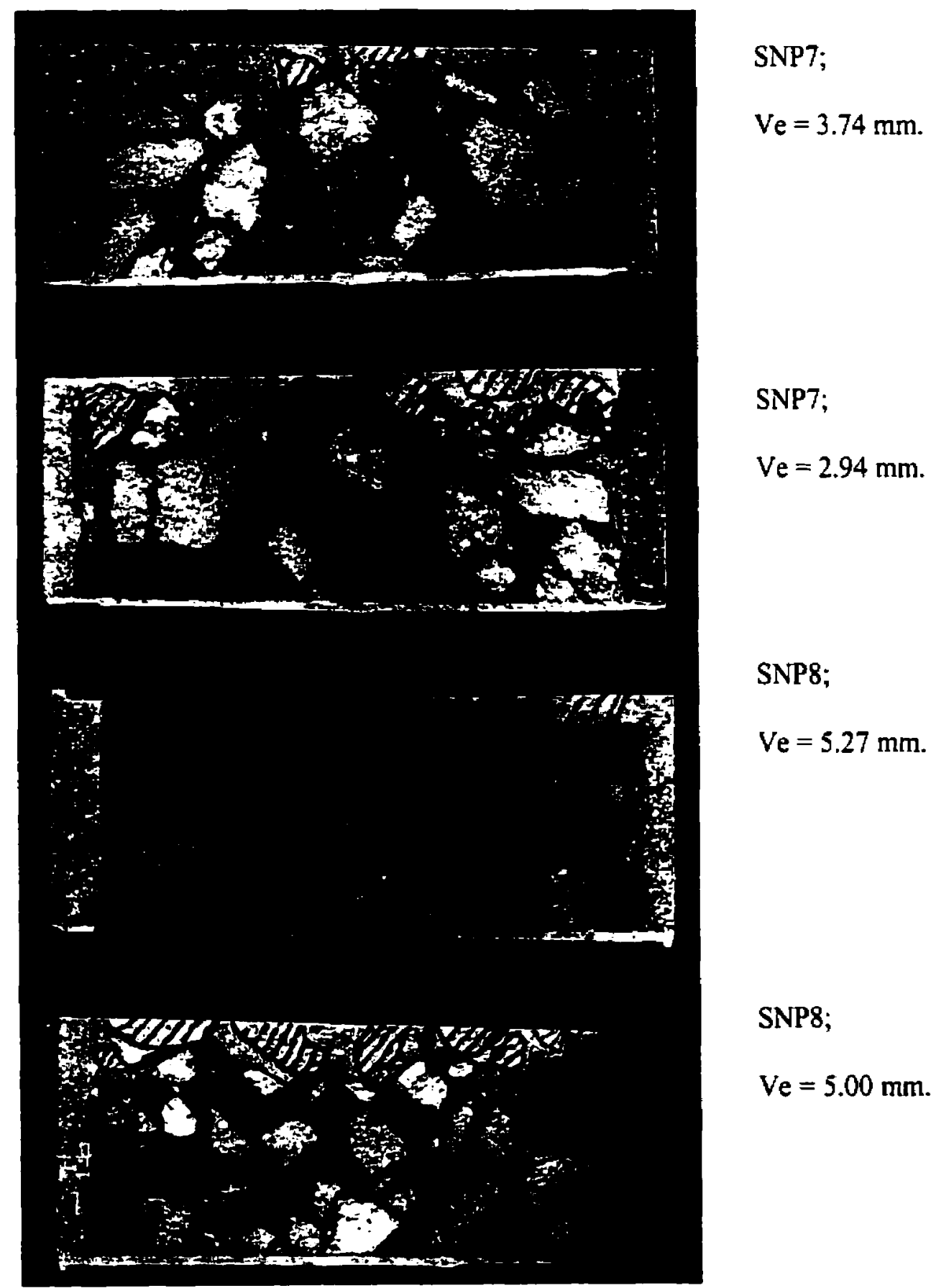

$25 \%$ Slag, No Crack, 16 Days of Chloride Exposure 


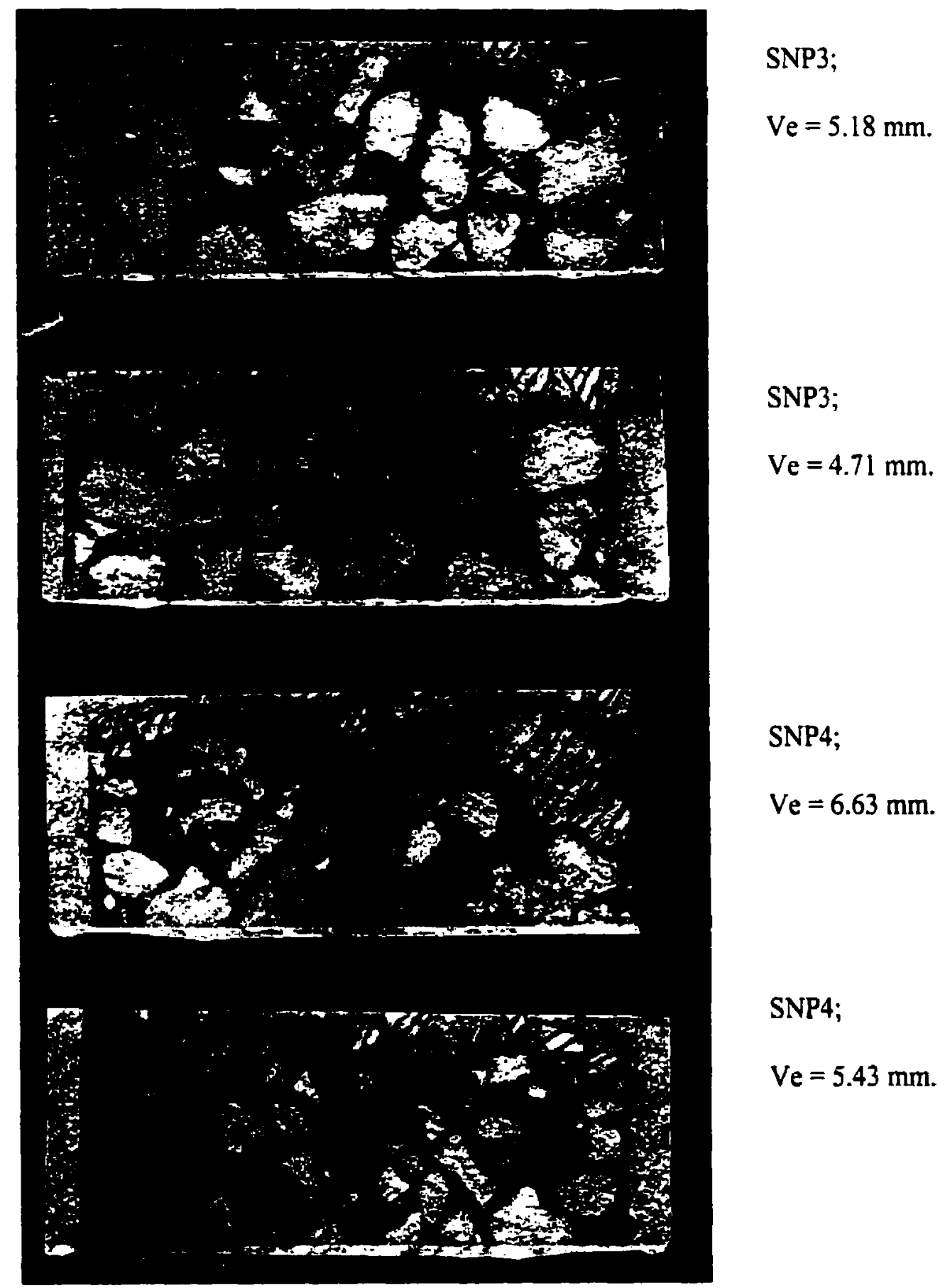

$25 \%$ Slag, No Crack, 36 Days of Chloride Exposure 


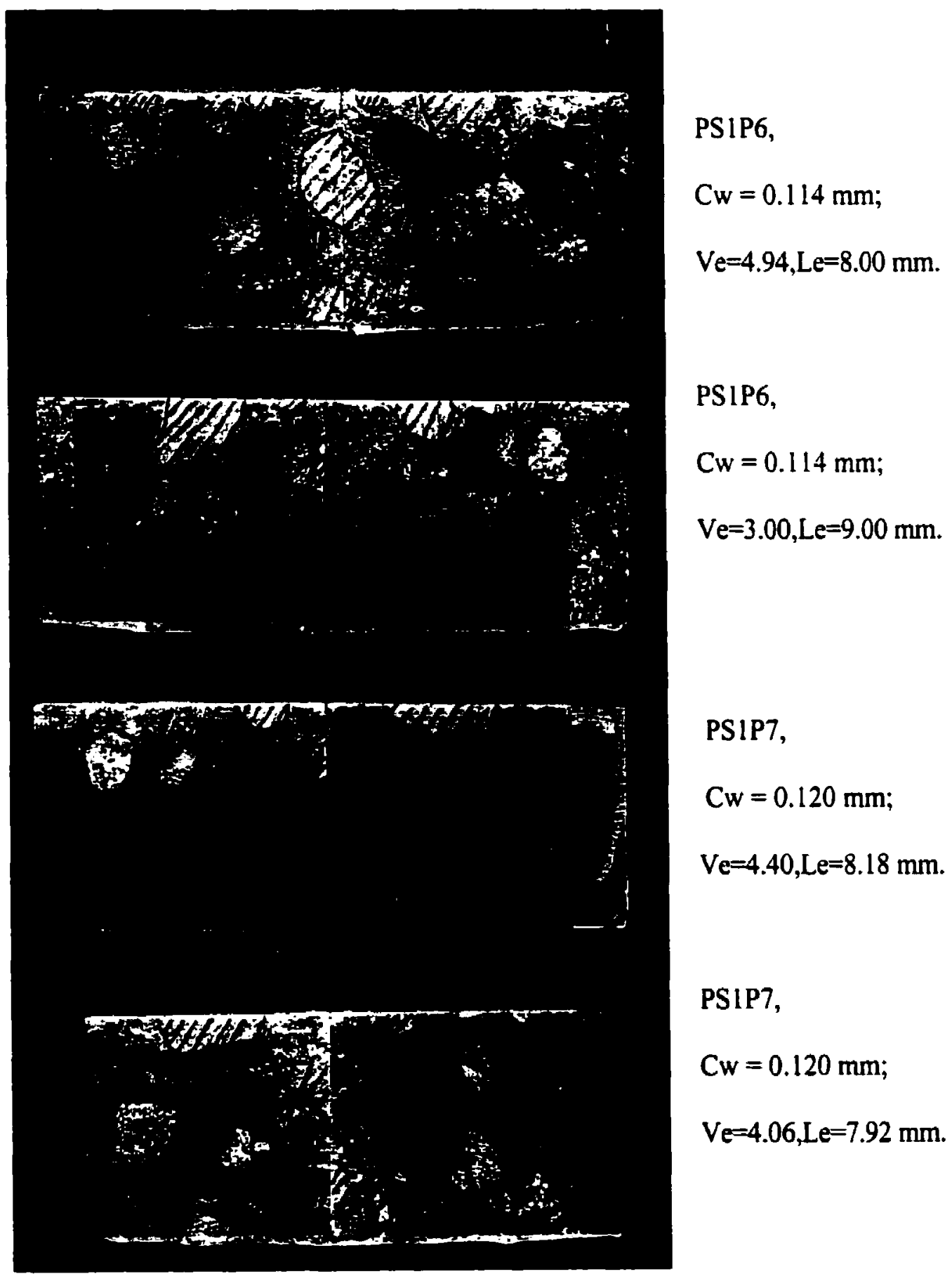

$100 \%$ OPC, Single Smooth Crack, 4 Days of Chloride Exposure 


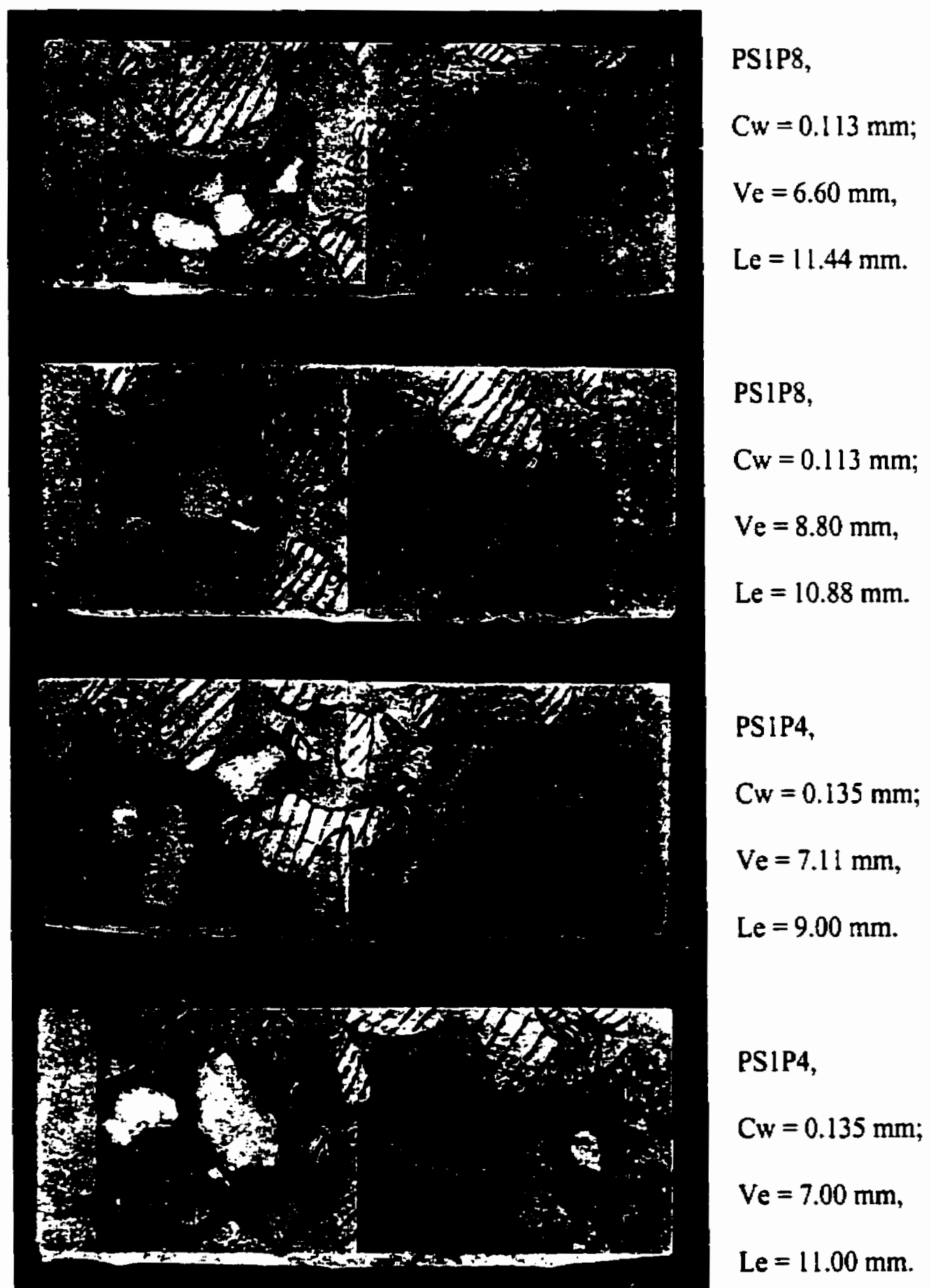

$100 \%$ OPC, Single Smooth Crack, 16 Days of Chloride Exposure 


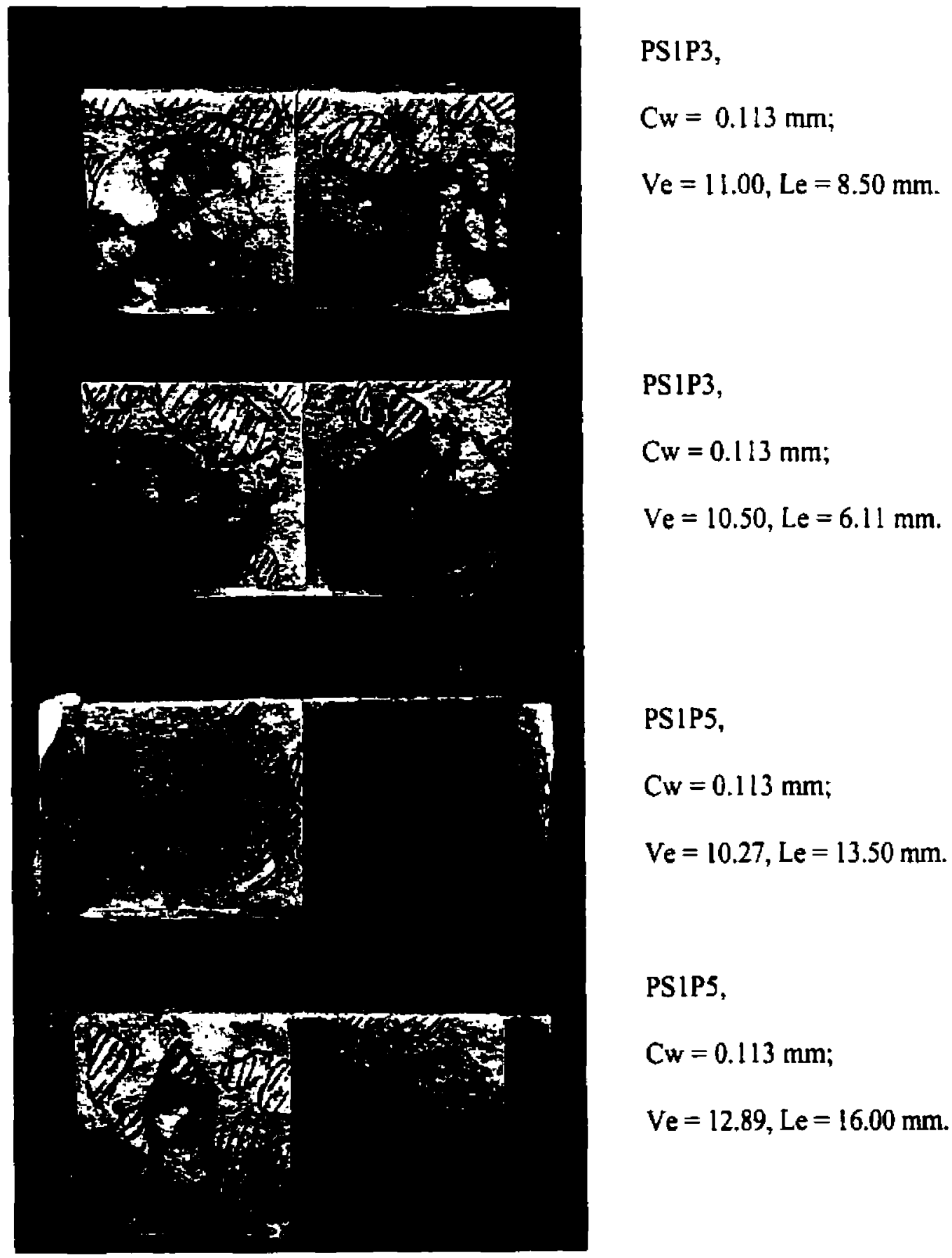

$100 \%$ OPC, Single Smooth Crack, 36 Days of Chloride Exposure 


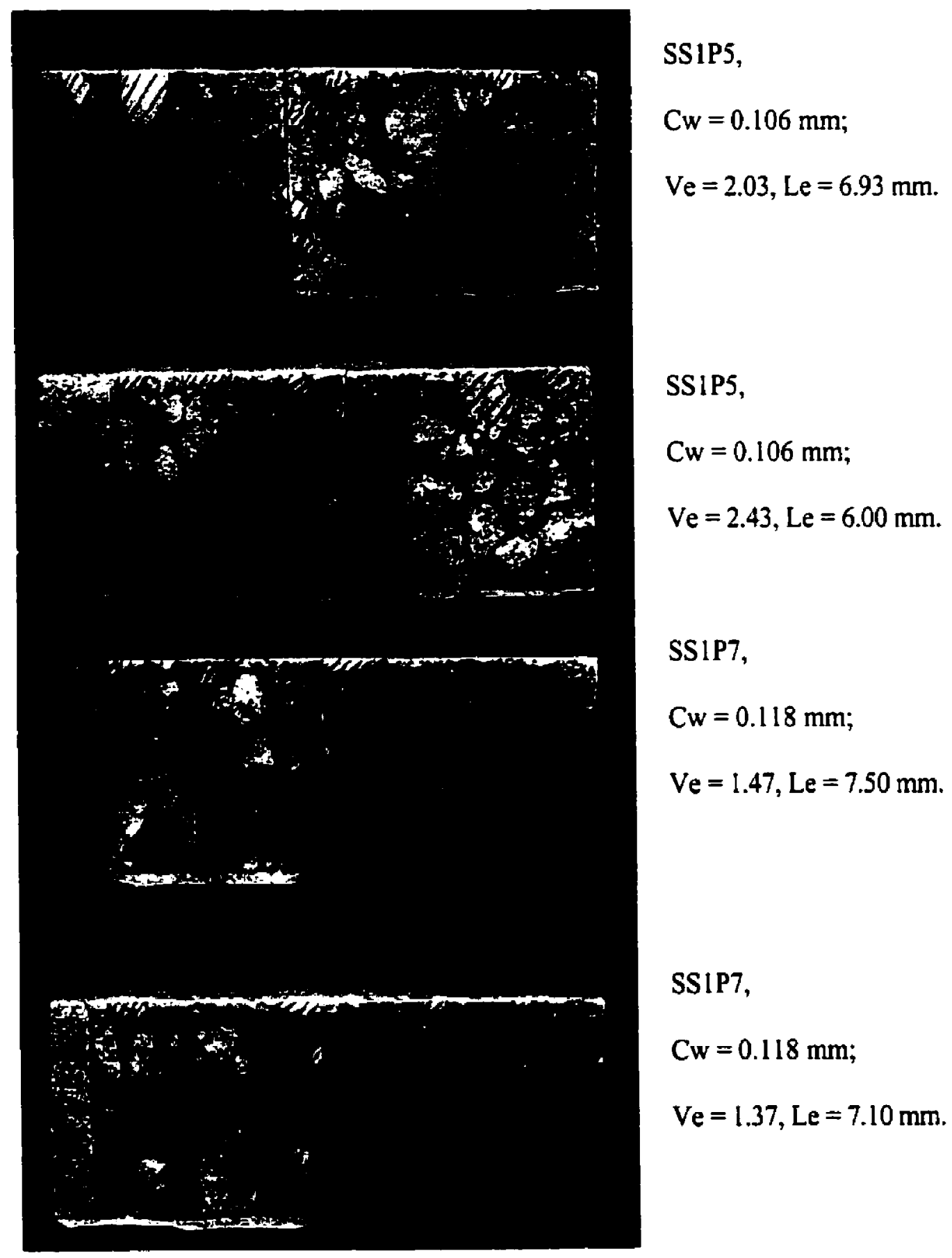

$25 \%$ Slag, Single Smooth Crack, 4 Days of Chloride Exposure 


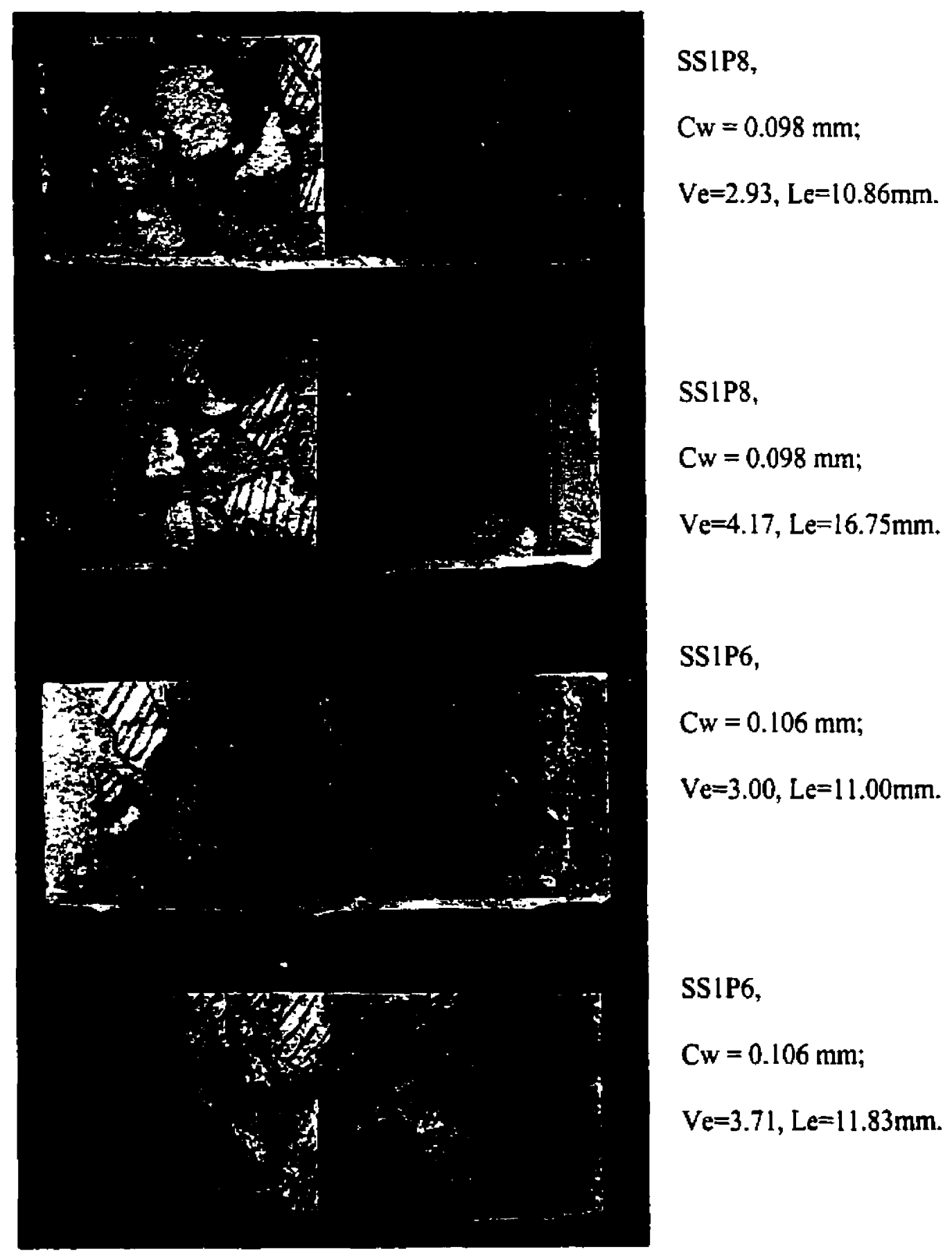

$25 \%$ Slag, Single Smooth Crack, 16 Days of Chloride Exposure 


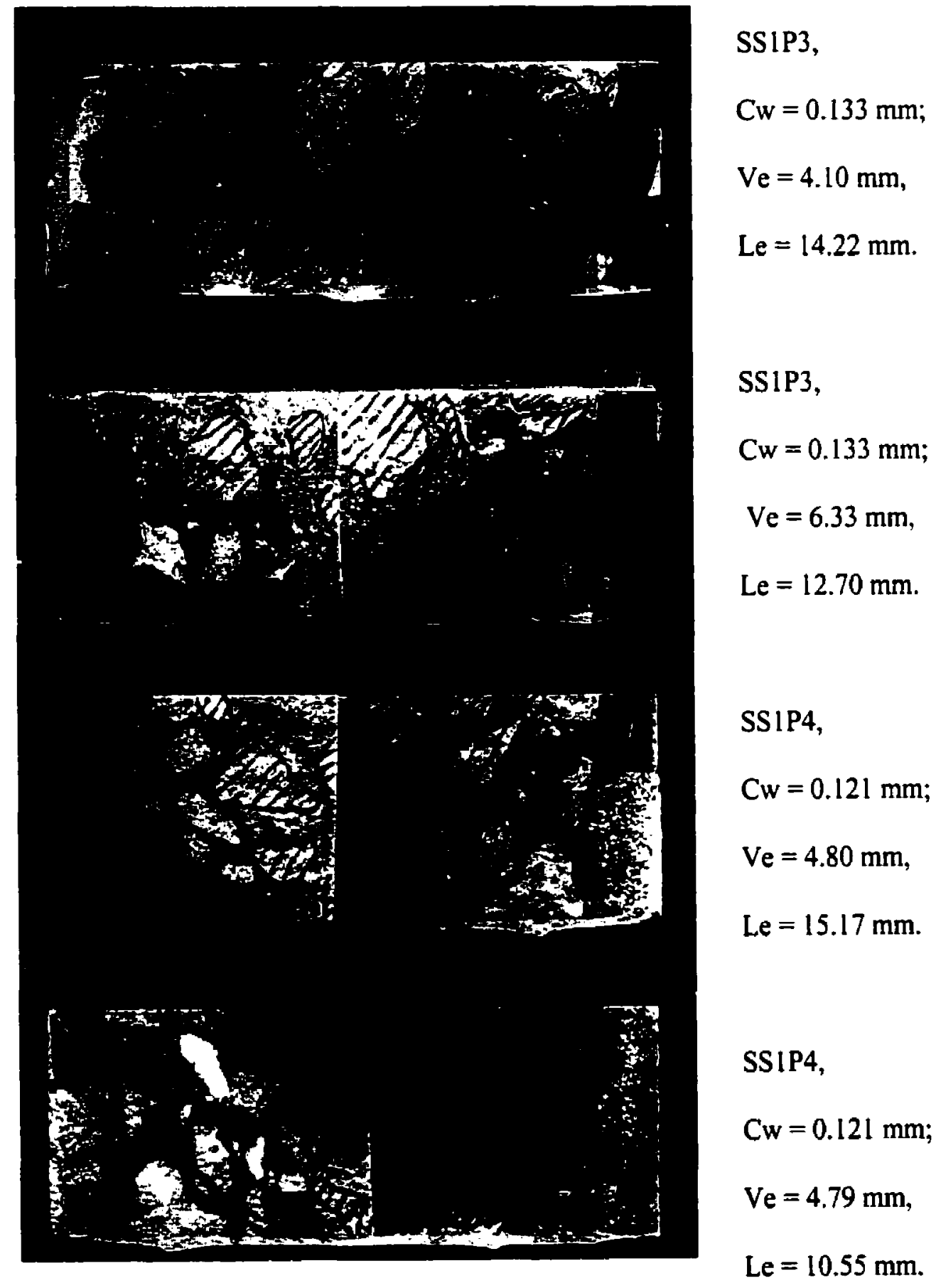

25 \% Slag, Single Smooth Crack, 36 Days of Chloride Exposure 


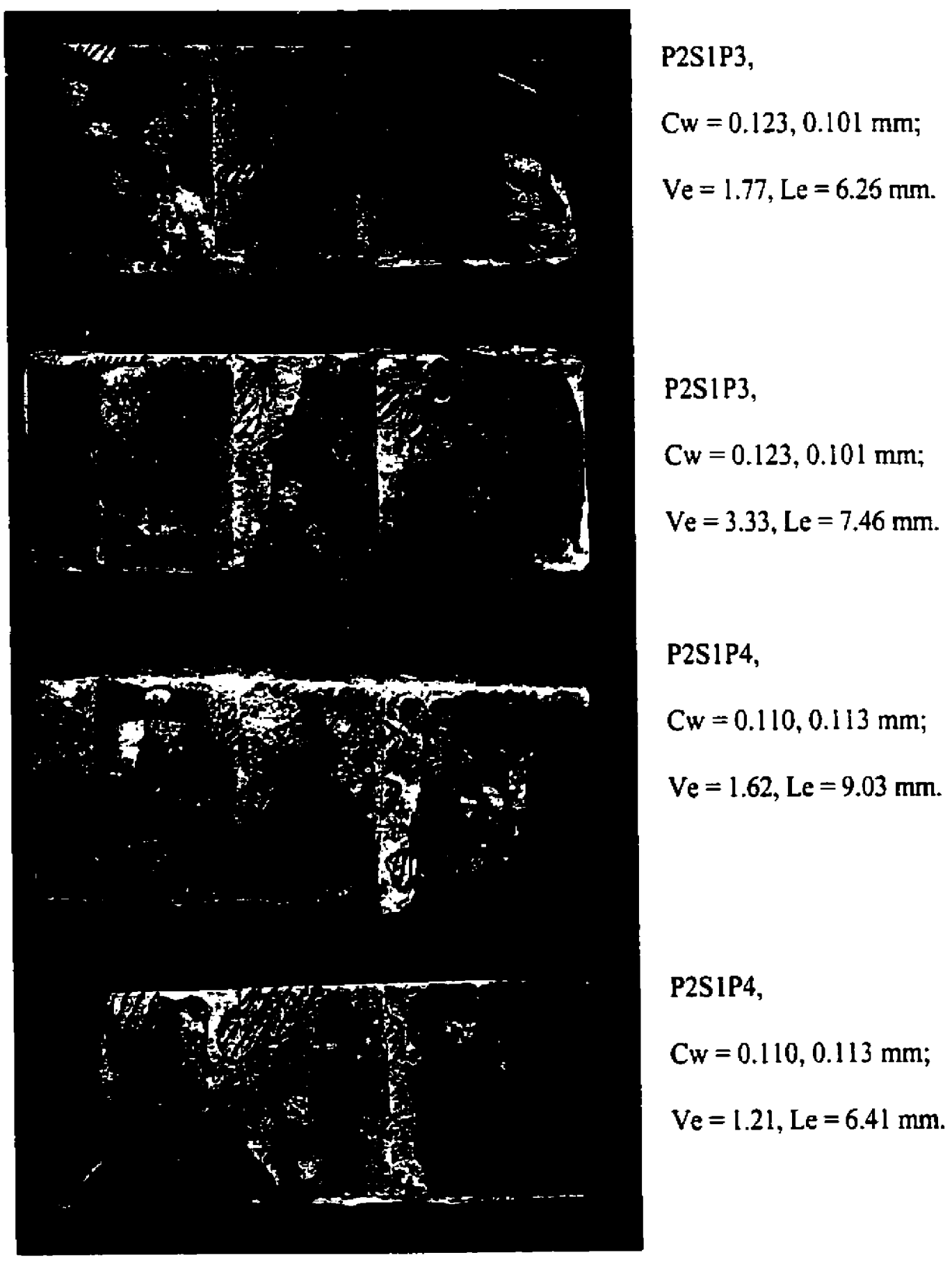

$100 \%$ OPC, Double Smooth Cracks, 1 Day of Chloride Exposure 


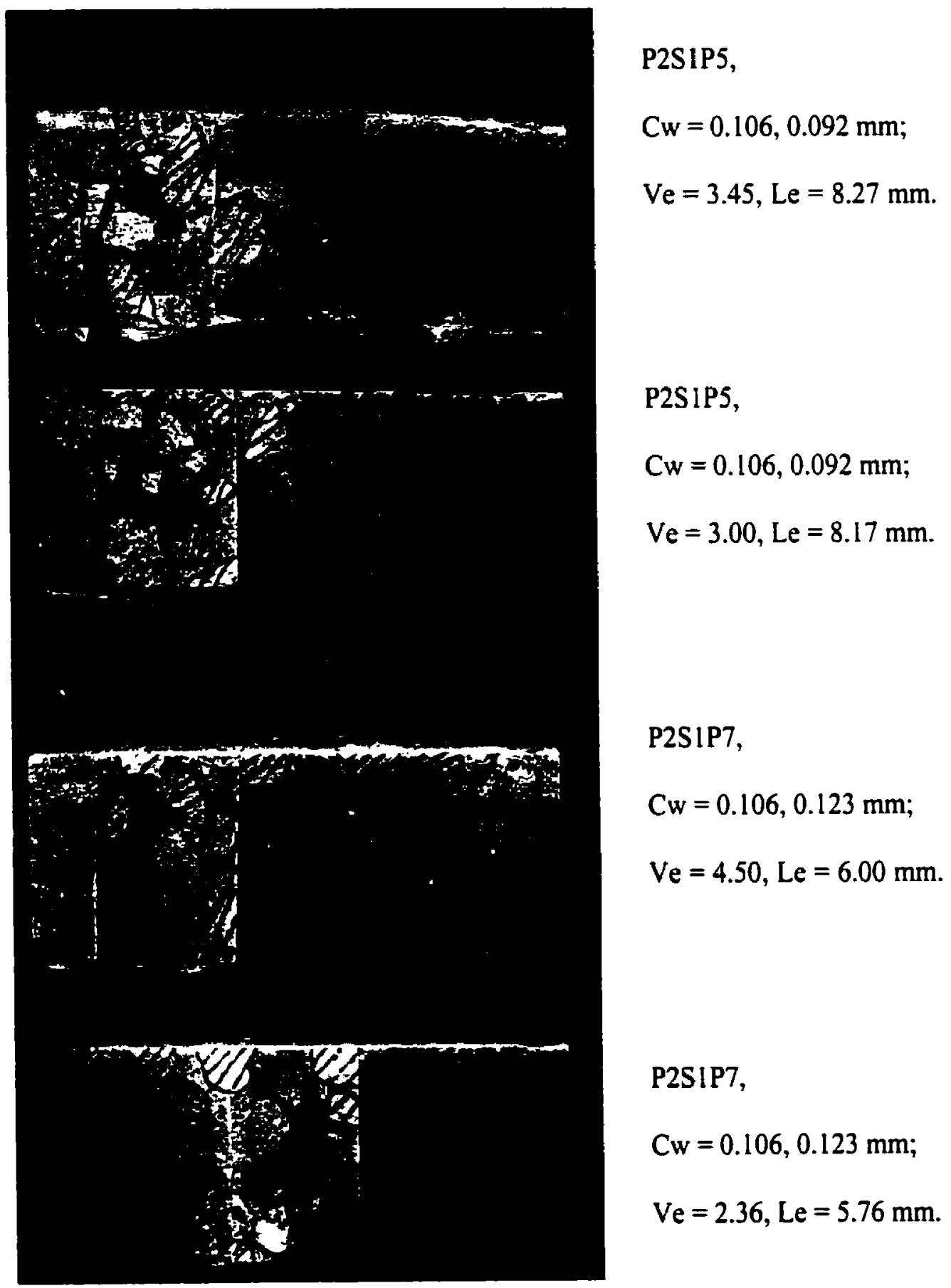

$100 \%$ OPC, Double Smooth Cracks, 4 Days of Chloride Exposure 


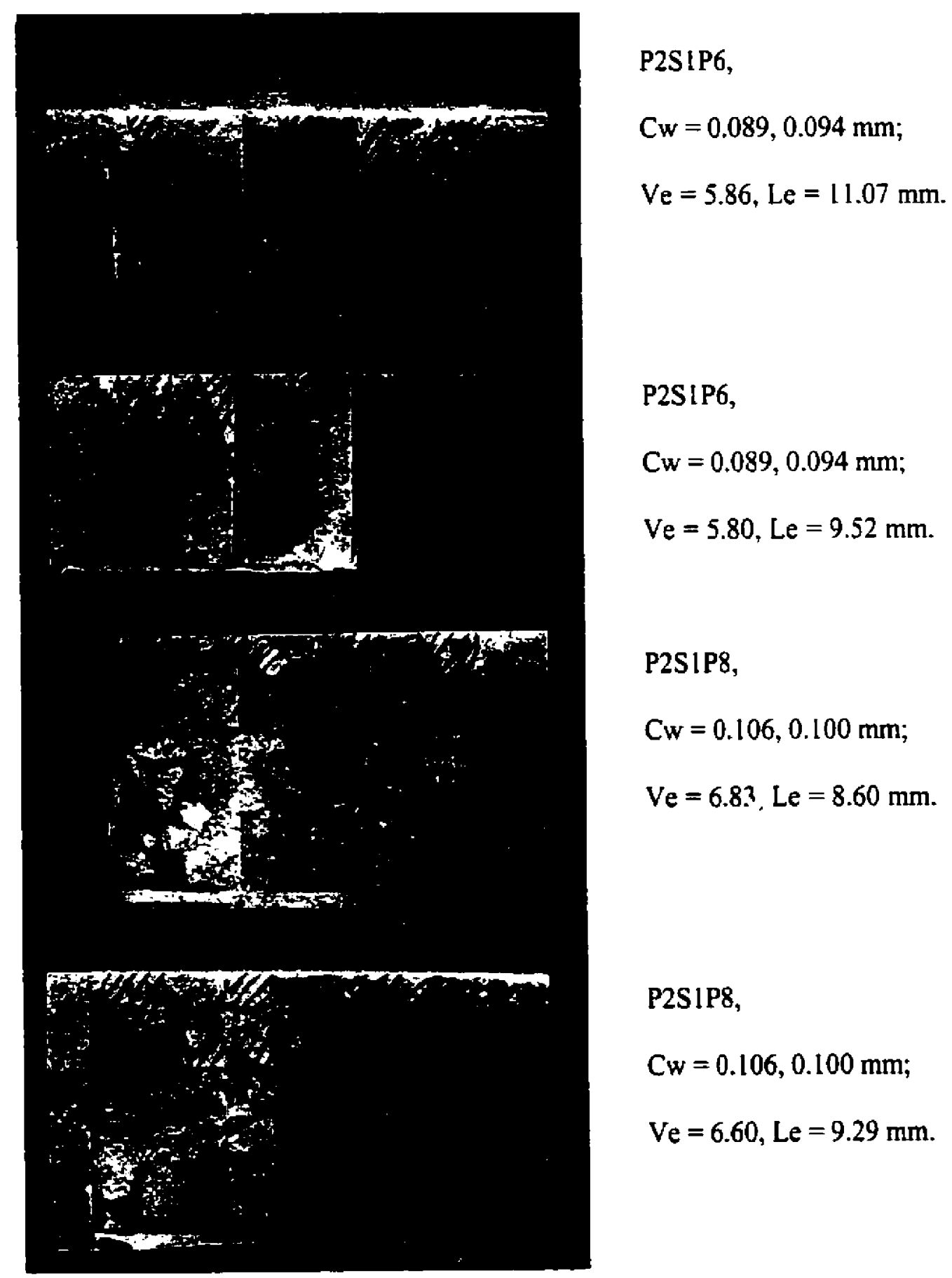

$100 \%$ OPC, Double Smooth Cracks, 7 Days of Chloride Exposure 


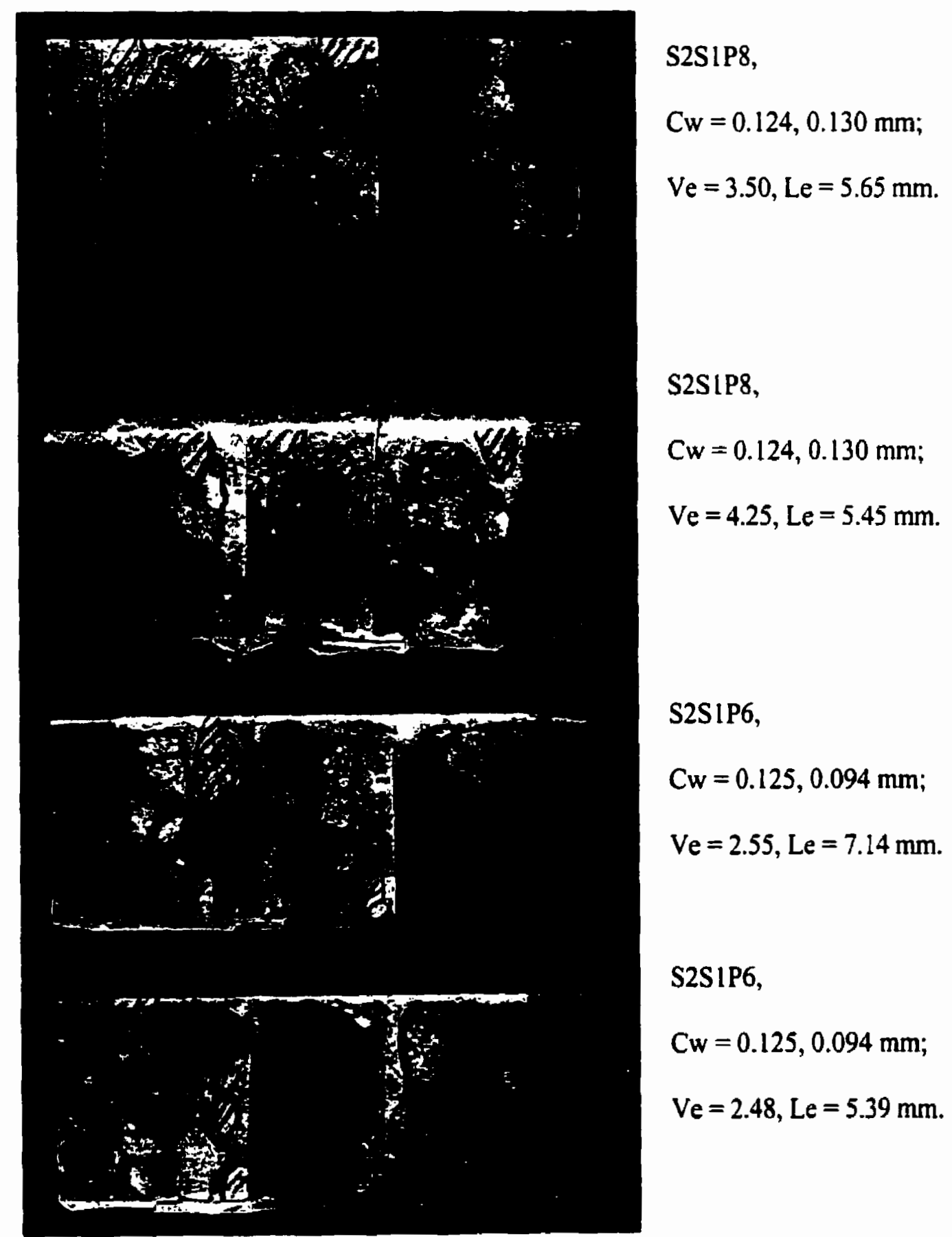

25 \% Slag, Double Smooth Cracks, 4 Days of Chloride Exposure 


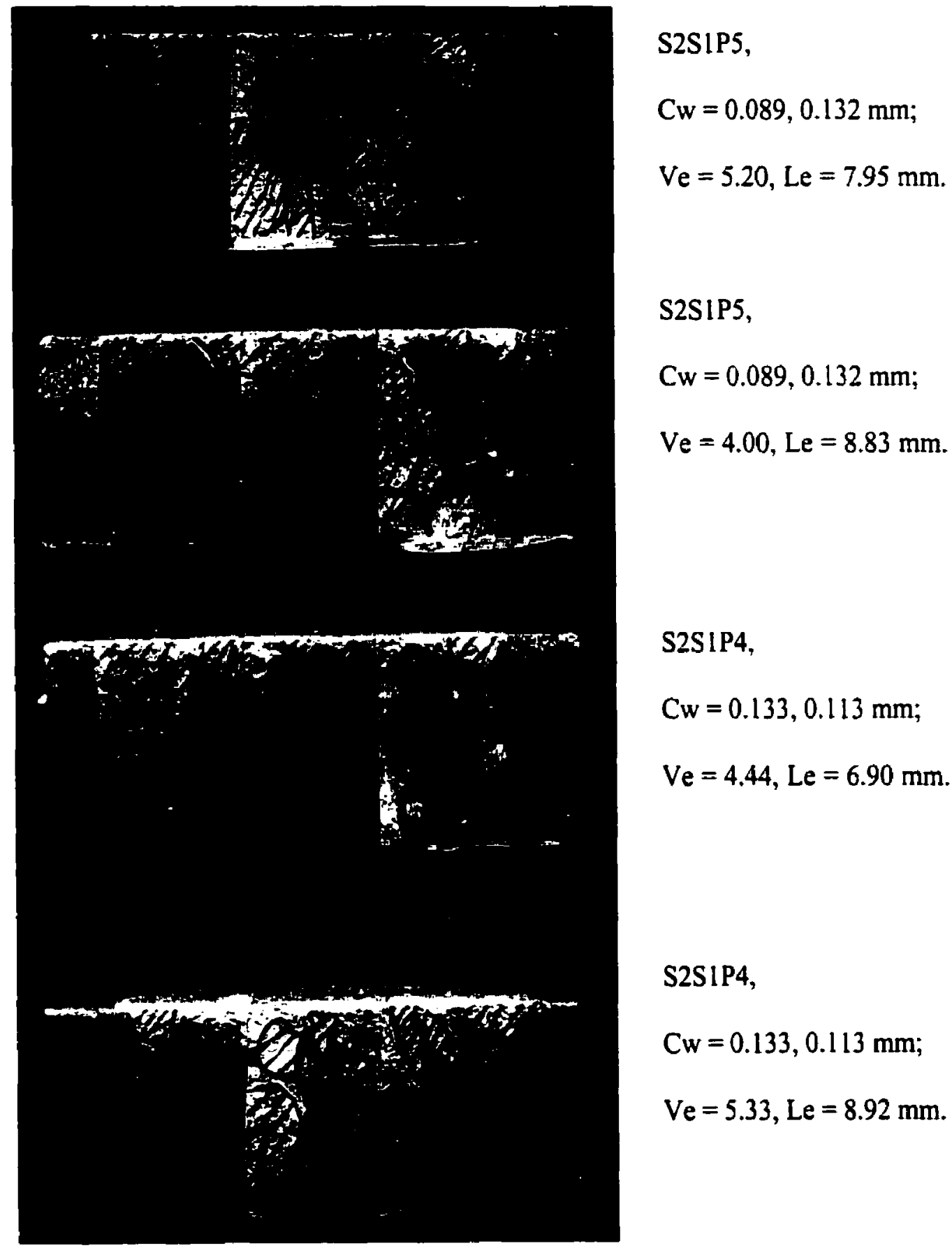

25 \% Slag, Double Smooth Cracks, 7 Days of Chloride Exposure 
APPENDIX J

\title{
DEPTH OF CHLORIDE PENETRATION
}

\author{
VS TIME
}

RESULTS

Influence of Cracks on Chloride Ingress into Concrete 
Depth of Chloride Penetration vs Square Root of Time.

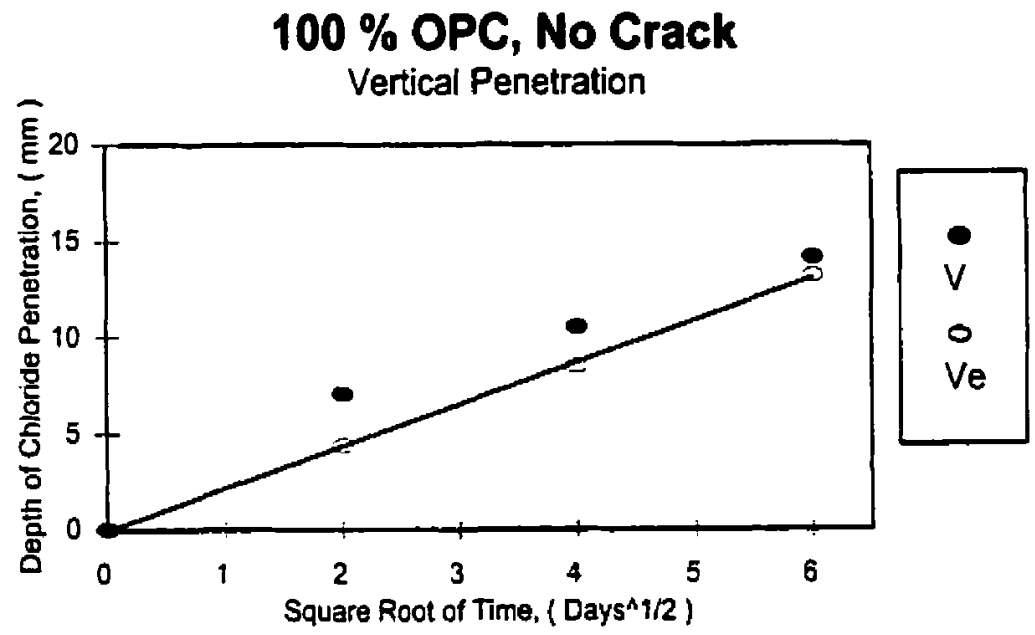

$\mathrm{V}$ - vertical depth of chloride penetration including aggregate;

Ve - vertical depth of chloride penetration excluding aggregate. 
Depth of Chloride Penetration vs Square Root of Time.

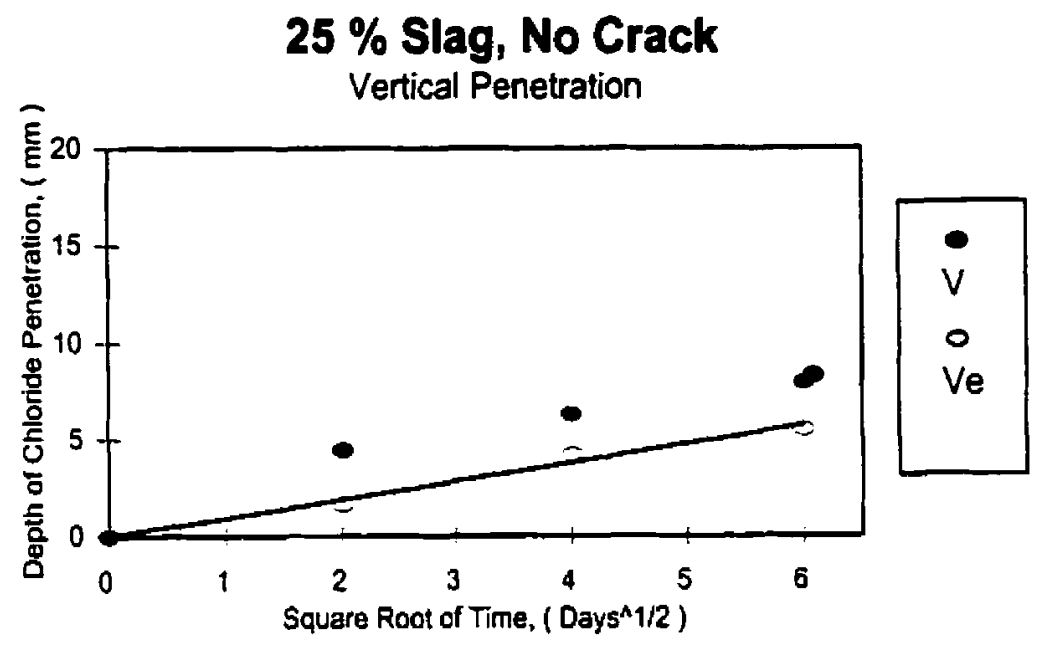

$\mathrm{V}$ - vertical depth of chloride penetration including aggregate;

Ve - vertical depth of chloride penetration excluding aggregate. 
Depth of Chloride Penetration vs Square Root of Time.
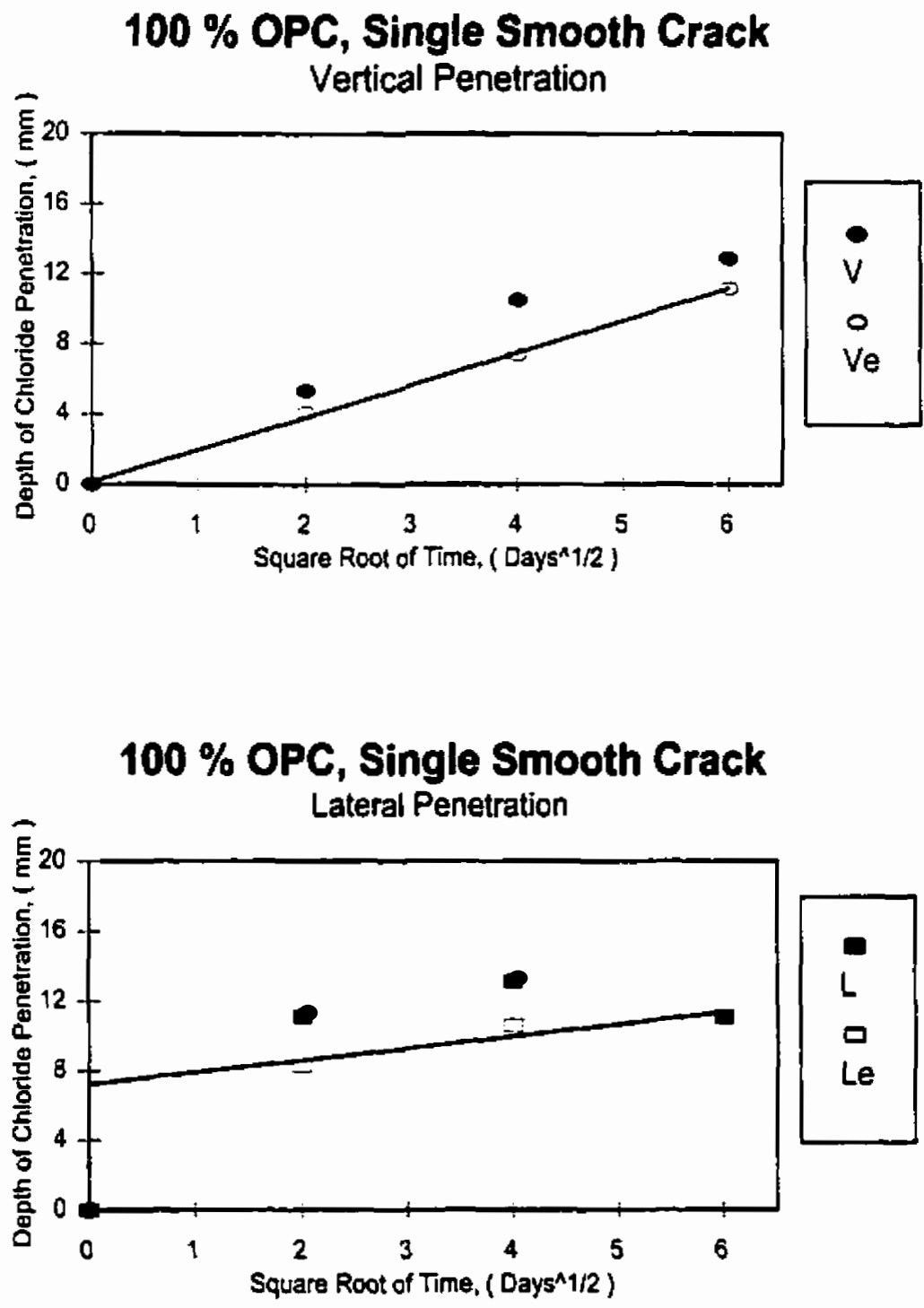

$\mathrm{V}$ and $\mathrm{Ve}$ - vertical depth of chloride penetration including and excluding aggregate;

$\mathrm{L}$ and Le - lateral depth of chloride penetration including and excluding aggregate. 
Depth of Chloride Penetration vs Square Root of Time.
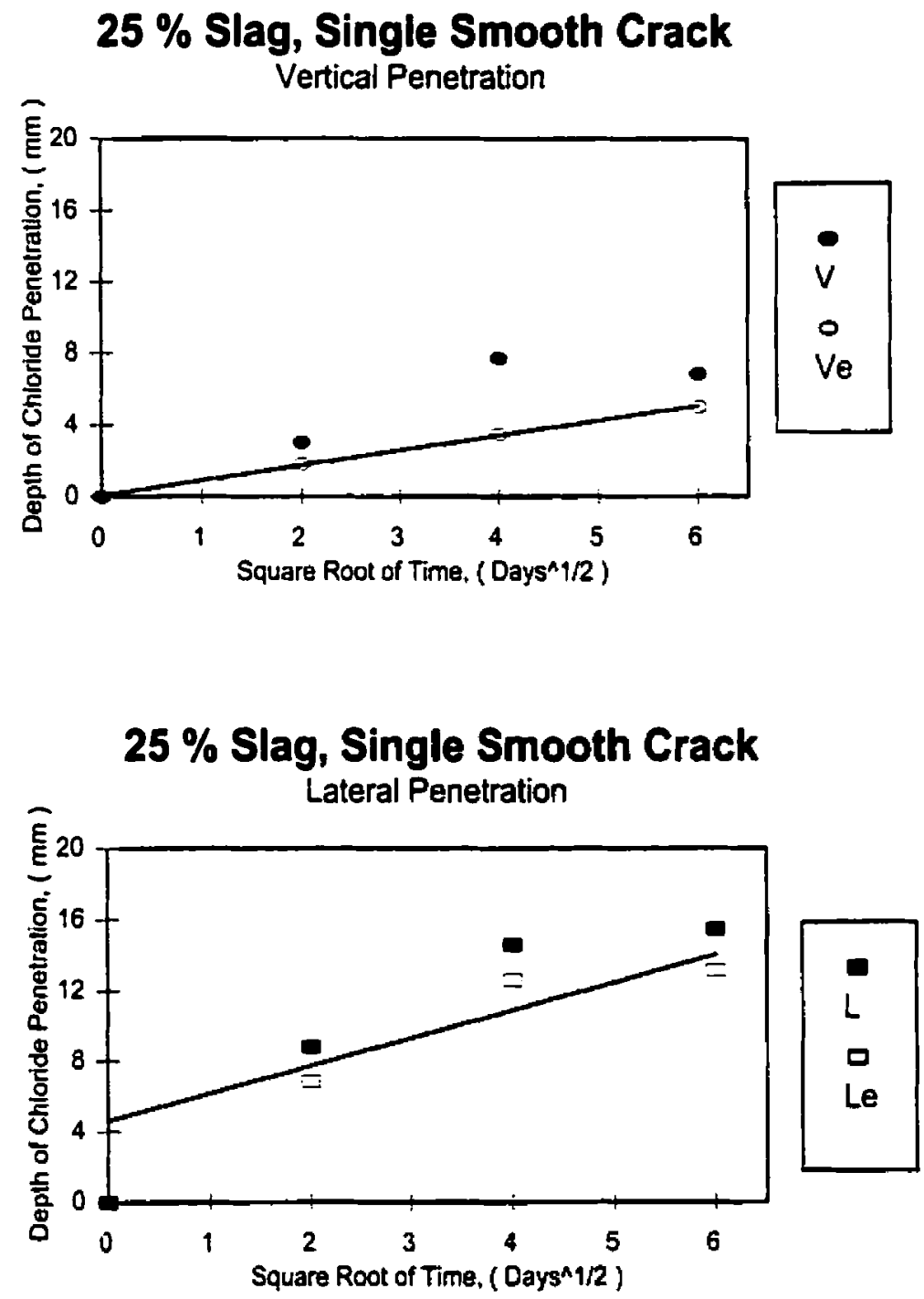

$\mathrm{V}$ and $\mathrm{Ve}$ - vertical depth of chloride penetration including and excluding aggregate;

$\mathrm{L}$ and Le - lateral depth of chloride penetration including and excluding aggregate. 
Depth of Chloride Penetration vs Square Root of Time.
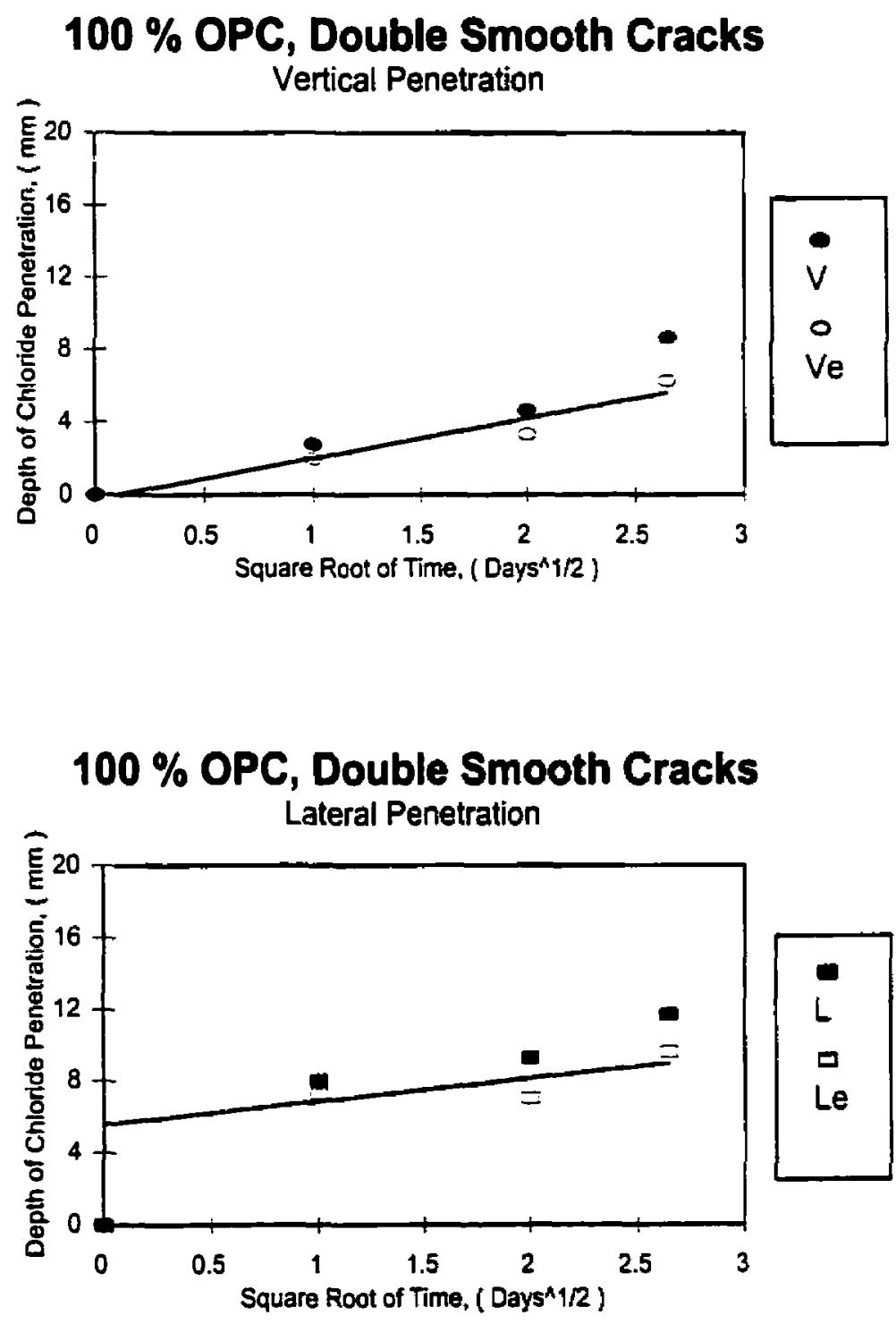

$\mathrm{V}$ and $\mathrm{Ve}$ - vertical depth of chloride penetration including and excluding aggregate;

L and Le - lateral depth of chloride penetration including and excluding aggregate. 
Depth of Chloride Penetration vs Square Root of Time.
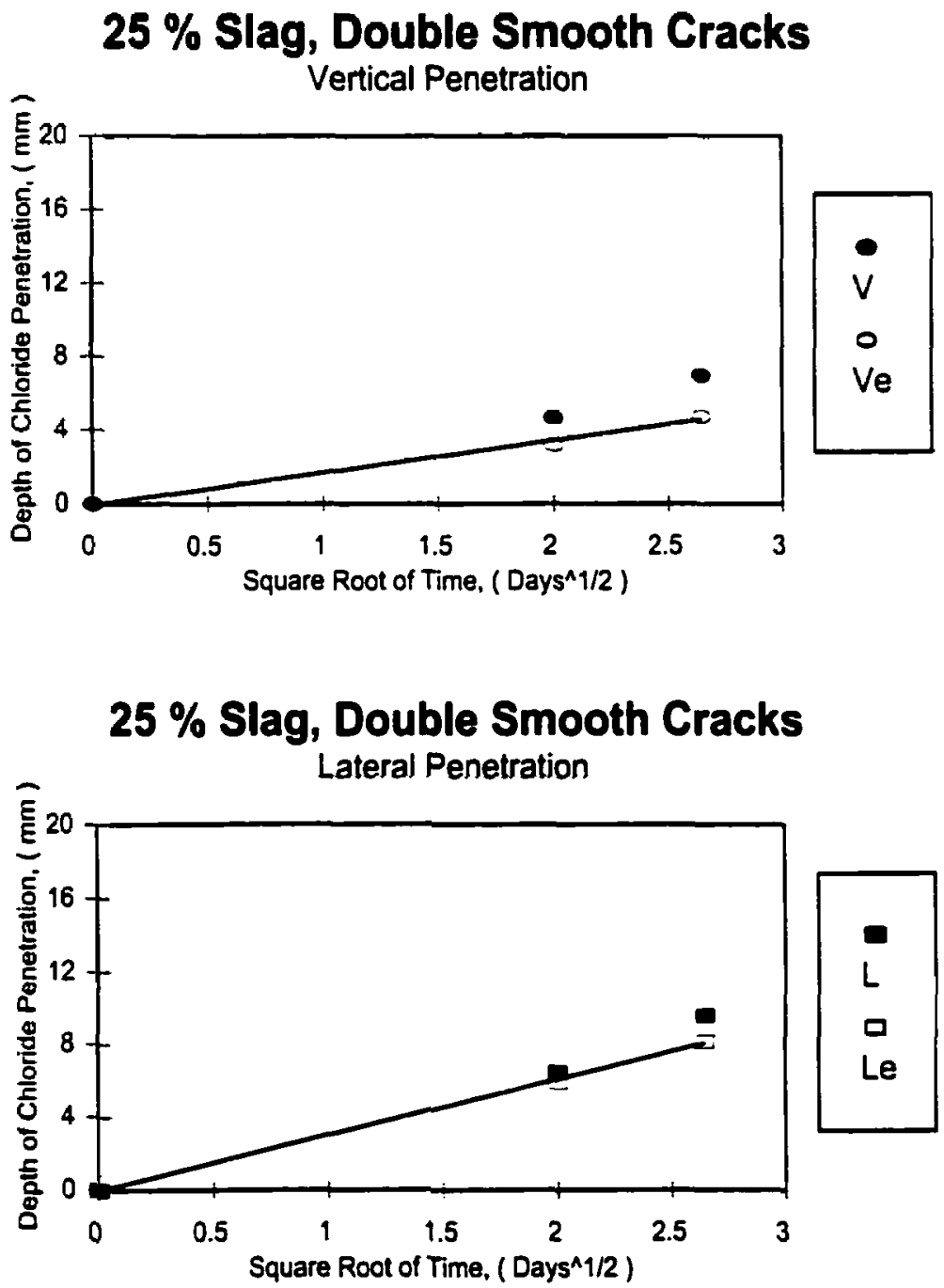

$\mathrm{V}$ and $\mathrm{Ve}$ - vertical depth of chloride penetration including and excluding aggregate;

$\mathrm{L}$ and Le - lateral depth of chloride penetration including and excluding aggregate. 
Lateral Depth of Chloride Penetration Excluding Absorption Effect vs Square Root of Time; Depth Due to Absorption $(A)=\mathrm{Le}_{4}-\mathrm{Ve}_{4}=4.18 \mathrm{~mm}$.

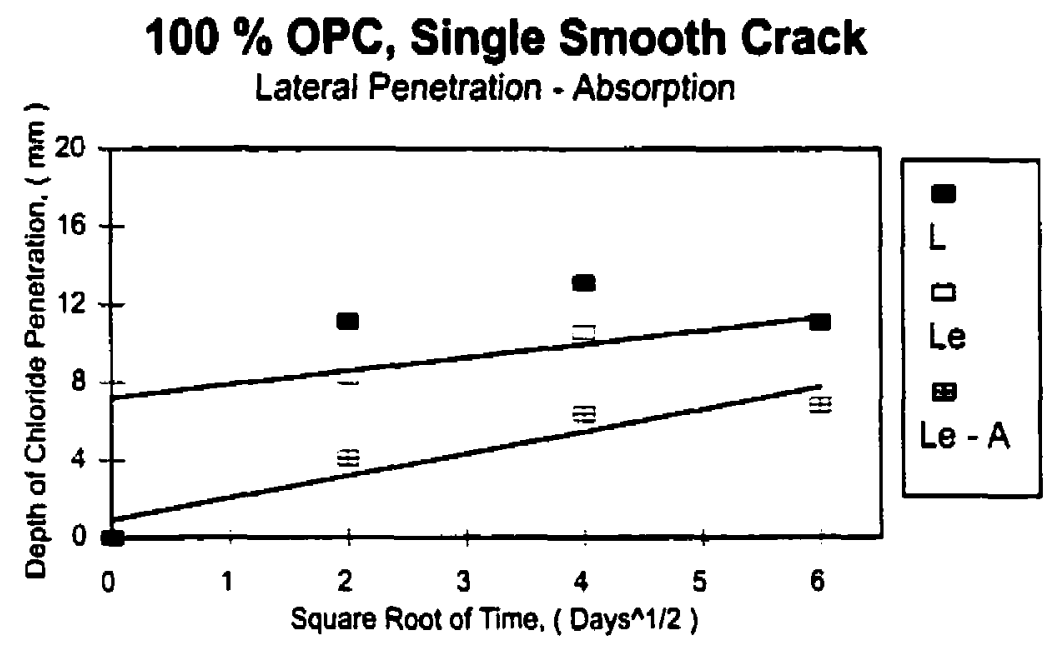

$\mathrm{Ve}_{4}$ and $\mathrm{Le}_{4}-4$ day vertical and lateral depths of chloride penetration excluding aggregate. 
Lateral Depth of Chloride Penetration Excluding Absorption Effect vs Square Root of Time; Depth Due to Absorption $(A)=\mathrm{Le}_{4}-\mathrm{Ve}_{4}=5.06 \mathrm{~mm}$.

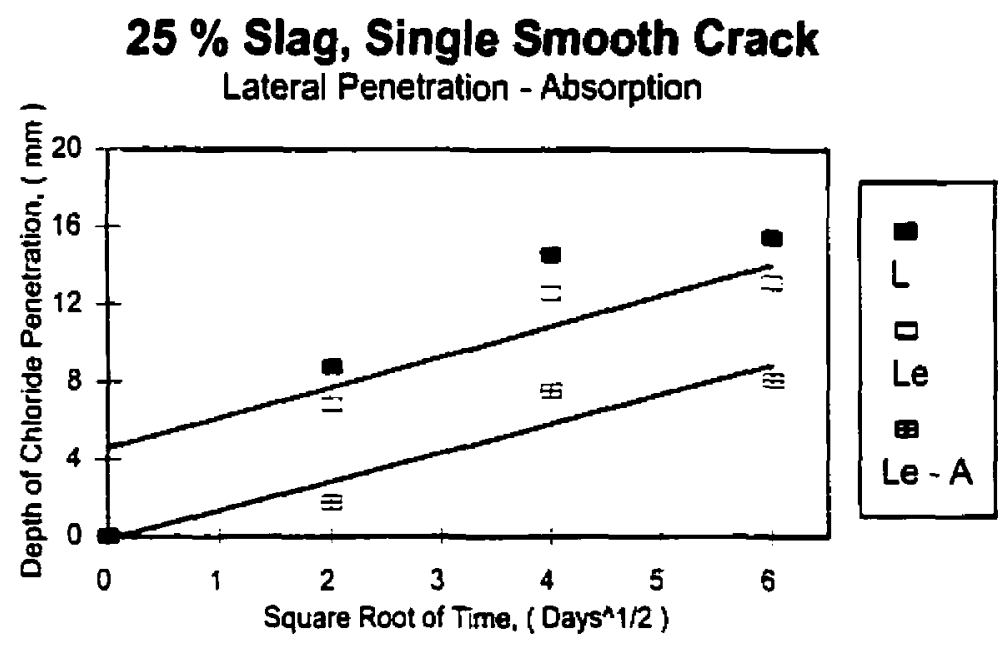

$\mathrm{Ve}_{4}$ and $\mathrm{Le}_{4}-4$ day vertical and lateral depths of chloride penetration excluding aggregate. 
Lateral Depth of Chloride Penetration Excluding Absorption Effect vs Square Root of Time; Depth Due to Absorption $(A)=\mathrm{Le}_{1}-\mathrm{Ve}_{1}=5.31 \mathrm{~mm}$.

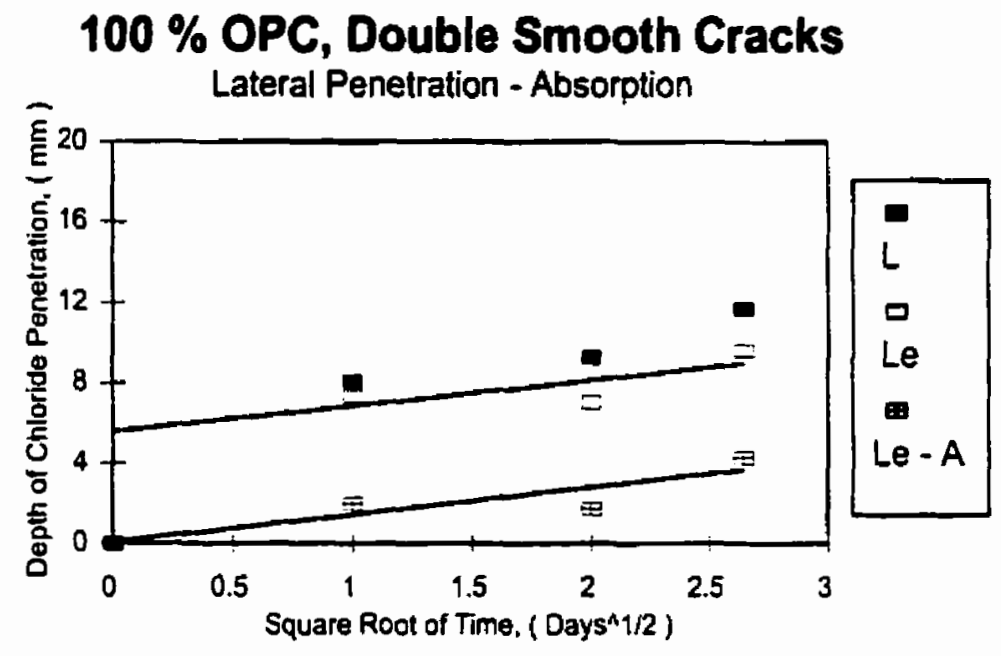

$V e_{1}$ and $L e_{1}-1$ day vertical and lateral depths of chloride penetration excluding aggregate. 
Saturation Monitoring:

Uncracked Samples

\begin{tabular}{|l|l|l|r|r|r|r|}
\hline Day & Hour & Elapsed & \multicolumn{4}{|c|}{ Mass, (g) } \\
\cline { 4 - 7 } $\begin{array}{l}\text { Month } \\
\text { Year }\end{array}$ & & $\begin{array}{l}\text { Time, } \\
\text { (Days) }\end{array}$ & PNP11 & PNP12 & SNP11 & SNP12 \\
\hline 18-Feb-01 & $09: 30$ AM & 0.00 & 820.12 & 815.49 & 808.31 & 824.90 \\
19-Feb-01 & $09: 30 \mathrm{AM}$ & 1.00 & 824.50 & 820.09 & 812.24 & 828.14 \\
20-Feb-01 & $10: 30 \mathrm{AM}$ & 2.04 & 826.21 & 821.16 & 813.01 & 828.93 \\
21-Feb-01 & $10: 45 \mathrm{AM}$ & 3.05 & 827.20 & 821.92 & 813.56 & 829.53 \\
22-Feb-01 & $11: 30 \mathrm{AM}$ & 4.08 & 827.79 & 822.39 & 813.87 & 829.62 \\
23-Feb-01 & $11: 40 \mathrm{AM}$ & $\mathbf{5 . 0 9}$ & 828.25 & 822.76 & 814.37 & 829.98 \\
\hline
\end{tabular}

Cracked Samples

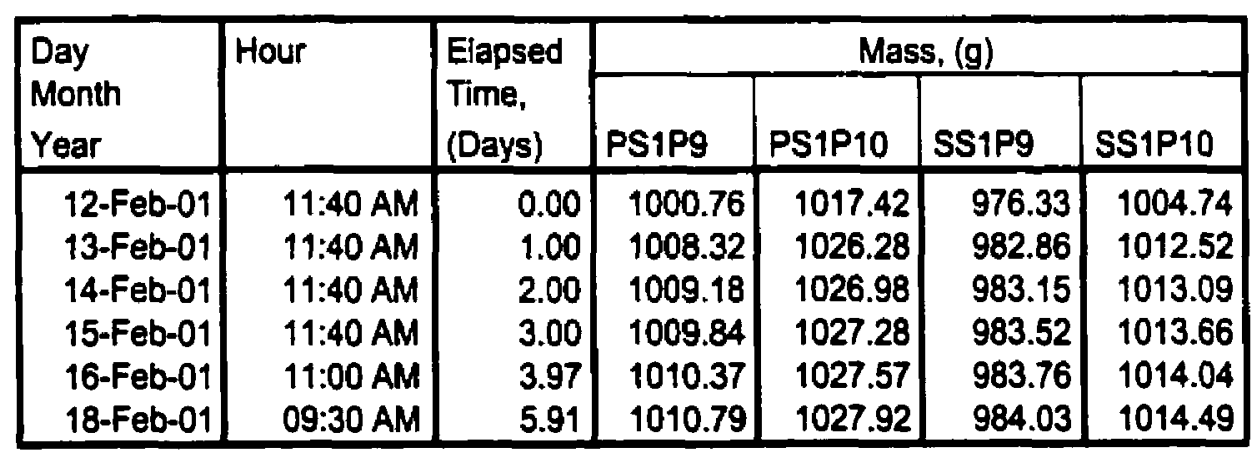

